\title{
Experimental characterization of heat transfer from an electrically heated thin filament
}

Amy J. Cragg

West Virginia University

Follow this and additional works at: https://researchrepository.wvu.edu/etd

\section{Recommended Citation}

Cragg, Amy J., "Experimental characterization of heat transfer from an electrically heated thin filament" (1999). Graduate Theses, Dissertations, and Problem Reports. 1888.

https://researchrepository.wvu.edu/etd/1888

This Thesis is protected by copyright and/or related rights. It has been brought to you by the The Research Repository @ WVU with permission from the rights-holder(s). You are free to use this Thesis in any way that is permitted by the copyright and related rights legislation that applies to your use. For other uses you must obtain permission from the rights-holder(s) directly, unless additional rights are indicated by a Creative Commons license in the record and/ or on the work itself. This Thesis has been accepted for inclusion in WVU Graduate Theses, Dissertations, and Problem Reports collection by an authorized administrator of The Research Repository @ WVU. For more information, please contact researchrepository@mail.wvu.edu. 


\title{
EXPERIMENTAL CHARACTERIZATION OF HEAT TRANSFER FROM AN ELECTRICALLY HEATED THIN FILAMENT
}

\author{
By
}

Amy J. Cragg

\section{A THESIS}

Submitted to

The College of Engineering and Mineral Resources

at

West Virginia University

in partial fulfillment of the requirements

for the degree of

Master of Science

in

Mechanical Engineering

Gary J. Morris, Ph.D., Chair

Robert E. Bond, Ph.D., Co-Chair

John L. Loth, Ph. D.

Department of Mechanical and Aerospace Engineering

Morgantown, West Virginia

1999 


\section{ABSTRACT \\ Experimental Characterization of Heat Transfer From an Electrically Heated Thin Filament}

By

\section{Amy J. Cragg}

Thin filaments for use in glass, polymer, or textile industries are formed by extruding molten material through an orifice to form a continuous filament. These filaments are cooled rapidly from the melting temperature of the material to near room temperature. If this cooling occurs too rapidly or too slowly imperfections can develop in the filaments. These imperfections can decrease the overall quality and strength of the fiber sometimes leading to temporary production shutdowns caused by filament breakage.

Driven by the need to understand and control the cooling of thin filaments, research has been conducted to attempt to experimentally characterize the heat transfer experienced by a thin filament. For this study, a platinum filament was placed axially in a vertical wind tunnel and electrically heated. Forced convective air flowing over the stationary heated filament was used to simulate the heat transfer associated with a forming filament moving through still air. A computerized data acquisition system was utilized to collect information on the heat dissipated by the filament. These data in addition to freestream data were used to evaluate the heat transfer coefficient. Data were collected for 5 different filament diameters, $25.4,38.5,51,63.5$ and 76 microns for 5 different dynamic pressure settings, 0.0, 0.466, 0.931, 1.397, and $1.863 \mathrm{~mm} \mathrm{Hg}$ over a temperature range of $400 \mathrm{~K}$ to $1100 \mathrm{~K}$ in increments of $100 \mathrm{~K}$. These data were taken at 
a zero crossflow setting. The angle of the test filament with the freestream was altered producing a crossflow effect and the same data were recorded for $2.5^{\circ}, 5^{\circ}$ and $7^{\circ}$ crossflow angles. From these data an empirical equation was developed for the heat transfer coefficient as a function of filament diameter, temperature difference between the filament and the freestream, freestream velocity and crossflow angle. When compared with the experimental data the empirical equation was accurate to approximately $11.5 \%$. 


\section{ACKNOWLEDGEMENTS}

I would like to thank my advisor, Dr. Morris, for his help and guidance throughout the duration of the project, and also for allowing me the opportunity to work on this project. Dr. Morris was always available to help when I needed it. I would like to thank my co-research advisor, Dr. Bond, for helping me in the lab anytime I needed it, which was frequently. He was always willing to abandon whatever he was doing to assist me. I wish to thank my committee member, Dr. Loth, for his expertise and new ideas. Thanks to the professors I have had who have increased my knowledge in the area of thermal sciences.

I would also like to thank my pseudo-officemates, Gearle Bailey and Brad Seanor, who always let me use their stuff when mine broke. Thanks as well to my friend Justin Kern who was, with infinite patience, always willing to listen to me complain if I got frustrated.

I would like to thank my mother who has an unending supply of support and love. Finally, I wish to thank my husband and best friend David for everything. 


\section{TABLE OF CONTENTS}

Page

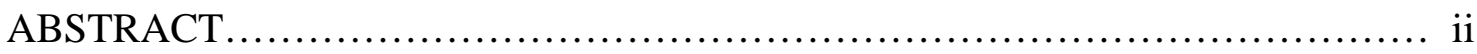

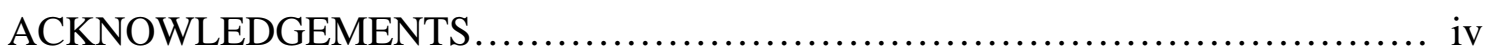

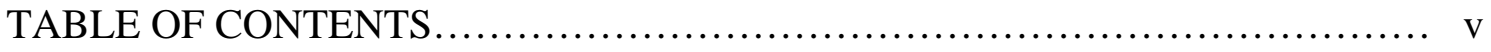

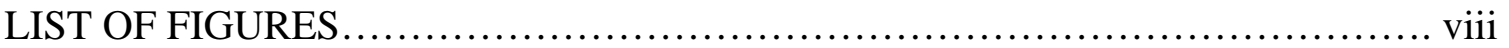

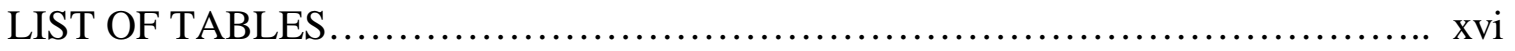

NOMENCLATURE.........................................................

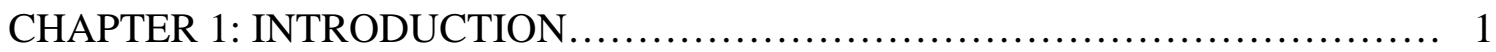

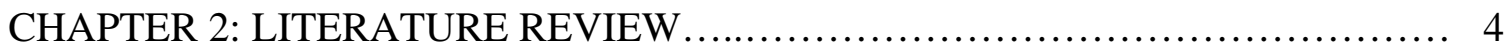

2.1: Studies on Melt Spinning...................................... 4

2.2: Boundary Layer Considerations............................... 6

2.3: Heat Transfer Through the Boundary Layer........................ 7

2.4: Convection and Conduction Heat Transfer during the Drawing Process...................................... 10

2.5: Other Research Concerning Heat Transfer............................ 11

2.6: Development of an Empirical Model for Heat Transfer from a Electrically Heated Thin Filament......................... 12

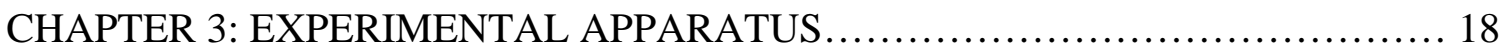

3.1: Vertical Wind Tunnel.............................................. 18

3.2: Filament Suspension.......................................... 23

3.3: Test Filament............................................. 26

3.4: Data Acquisition Setup.......................................... 27

3.5: LDA Setup................................................ 29 
CHAPTER 4: EXPERIMENTAL PROCEDURE.

4.1: Determination of Parameters................................... 35

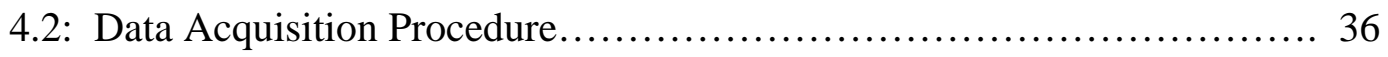

4.3: Data Reduction................................................... 38

4.4: Characterization of Vibration................................. 40

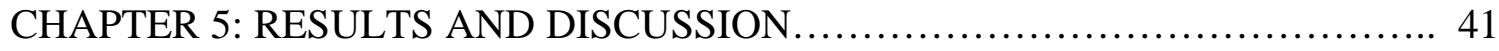

5.1: Heat Transfer Coefficient as a Function of Temperature............... 41

5.2: Heat Transfer Coefficient as a Function of Filament Diameter........... 43

5.3: Heat Transfer Coefficient as a Function of Crossflow Angle............ 44

5.4: Comparison of Phase I and Phase II Data......................... 44

5.5: Vibrational Heat Transfer Effects................................ 46

CHAPTER 6: EMPIRICAL EQUATION FOR HEAT TRANSFER COEFFICIENT... 91

6.1: Component A of Empirical Equation for Heat Transfer Coefficient..... 91

6.2: Component B of Empirical Equation for Heat Transfer Coefficient ..... 95

6.3: Error Analysis of Empirical Equation.......................... 97

6.4: Error Analysis of the Experimental Data........................... 98

CHAPTER 7: CONCLUSIONS........................................ 136

CHAPTER 8: RECOMMENDATIONS ................................. 138

REFERENCES ....................................................... 140

APPENDIX A: RESULTS OF HOT-FILM ANEMOMETERY .................. 142

APPENDIX B: DATA ACQUISITON BASIC PROGRAM.................... 150

APPENDIX C: BASIC PROGRAM TO PERFORM STATISTICAL ANALYSIS

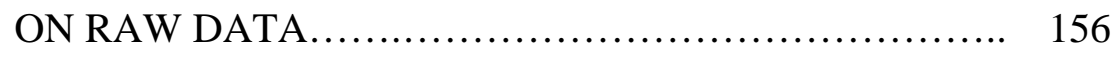


APPENDIX D: BASIC PROGRAM TO PRODUCE TIME RELATED DATA FROM A RAW DATA FILE ............................ 161

APPENDIX E: VERIFICATION OF FREQUENCY AND AMPLITUDE USING LDA SYSTEM................................... 164

APPENDIX F: SAMPLE HEAT TRANSFER DATA SPREADSHEET........... 171

APPENDIX G: ERROR ANALYSIS OF EXPERIMENTAL DATA............. 175

APPROVAL OF EXAMINING COMMITTEE............................... 178 


\section{TABLE OF FIGURES}

Figure $\quad$ Page

2.1 Calculated Temperature of Filament, T, vs. Distance Under Various

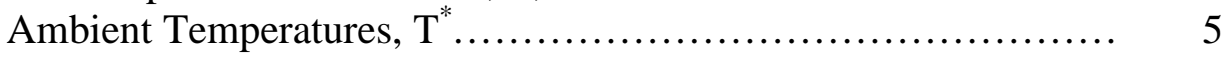

2.2 Calculated Cross Sectional Area of Filament at Various Ambient Air Temperatures........................................... 6

2.3 Comparison of Experimental and Theoretical Values of Average Local Nusselt Number vs. Varying Filament Diameter with Constant

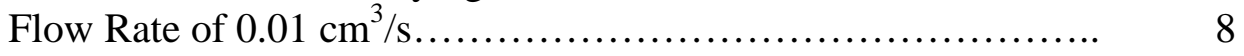

2.4 Comparison of Experiment and Theoretical Values of Average Local Nusselt Number vs. Fiber Speed U with Fixed Filament Radius

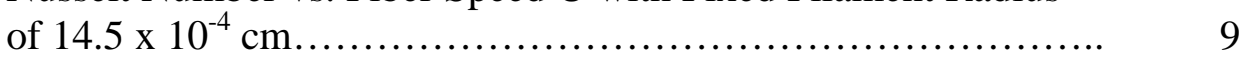

2.5 Surface Temperature vs. Axial Distance for a $0.09 \mathrm{~mm}$ Filament at $1 \mathrm{~m} / \mathrm{s}$.. $\quad 11$

2.6 Heat Transfer Coefficient and Temperature vs. Distance from Leading Edge for 76 Micron wire at $V=58.2 \mathrm{~m} / \mathrm{s} \ldots \ldots \ldots \ldots \ldots \ldots \ldots \ldots . . . \ldots \ldots$

2.7 Heat Transfer Coefficient Calculated from Empirical Equation for $\mathrm{T}=1100 \mathrm{~K}$

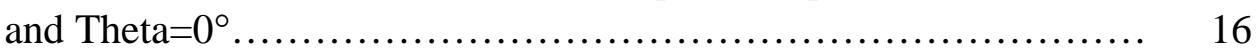

2.8 Heat Transfer Coefficient Calculated from Empirical Equation for $\mathrm{T}=1100 \mathrm{~K}$

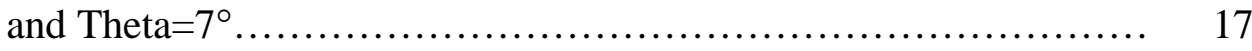

3.1 Vertical Wind Tunnel Setup....................................... 19

$3.2 \quad 3.73 \mathrm{~kW}$ Blower Used for Testing.................................. 20

3.3a Heights of Probe Positions for Measurement of Velocity and Turbulent Intensity Using a Hot-Film Anemometer in Wind Tunnel Test Section......................................................... 22

3.3b Cross-Sections of Test Section at Two Test Heights with Positions

Illustrated................................................... 22

$3.4 \quad$ Traversing Mechanism............................................. 24

3.5 Actual Voltage Divider and Current Lead Resistor...................... 28 
3.6 Schematic of Data Acquisition Circuit.................................. 29

3.7 Photo-Darlington Detector Circuit Diagram........................... 30

3.8 Interference Fringes Forming from the Intersection of Two Coherent and Monochromatic Laser Beams.............................. $\quad 32$

$3.9 \quad$ 2-Watt Argon-ion Laser Mounted to Optical Bench........................ 33

3.10 TSI Optics Mounted to Optical Bench.................................. 33

3.11 Laser and Optics on Optical Bench Mounted to Vertical Traversing System................................................ 34

5.1 Test Filament Voltage vs. Time for a 51 Micron Platinum Filament

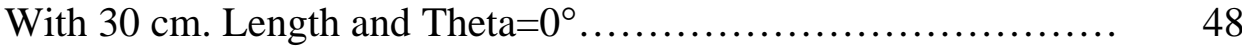

5.2 Heat Transfer Coefficient vs. Temperature for a 76 Micron Platinum Filament with $30 \mathrm{~cm}$. Length and Theta $=0^{\circ} \ldots \ldots \ldots \ldots \ldots \ldots \ldots \ldots \ldots . . \quad 49$

5.3 Heat Transfer Coefficient vs. Temperature for a 63.5 Micron Platinum

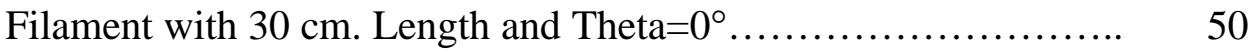

5.4 Heat Transfer Coefficient vs. Temperature for a 51 Micron Platinum Filament with $30 \mathrm{~cm}$. Length and Theta $=0^{\circ} \ldots \ldots \ldots \ldots \ldots \ldots \ldots \ldots \ldots$

5.5 Heat Transfer Coefficient vs. Temperature for a 38.5 Micron Platinum

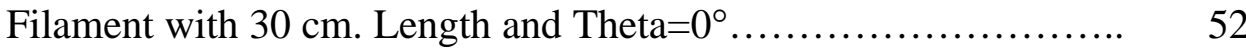

5.6 Heat Transfer Coefficient vs. Temperature for a 25.4 Micron Platinum Filament with $30 \mathrm{~cm}$. Length and Theta $=0^{\circ} \ldots \ldots \ldots \ldots \ldots \ldots \ldots \ldots \ldots \ldots \ldots \ldots \ldots \ldots$

5.7 Heat Transfer Coefficient vs. Temperature for a 76 Micron Platinum Filament with $30 \mathrm{~cm}$. Length and Theta $=2.5^{\circ} \ldots \ldots \ldots \ldots \ldots \ldots \ldots \ldots . . . \ldots$

5.8 Heat Transfer Coefficient vs. Temperature for a 63.5 Micron Platinum Filament with $30 \mathrm{~cm}$. Length and Theta $=2.5^{\circ} \ldots \ldots \ldots \ldots \ldots \ldots \ldots \ldots \ldots$

5.9 Heat Transfer Coefficient vs. Temperature for a 51 Micron Platinum Filament with $30 \mathrm{~cm}$. Length and Theta $=2.5^{\circ} \ldots \ldots \ldots \ldots \ldots \ldots \ldots \ldots . \quad 56$

5.10 Heat Transfer Coefficient vs. Temperature for a 38.5 Micron Platinum Filament with $30 \mathrm{~cm}$. Length and Theta $=2.5^{\circ}$

5.11 Heat Transfer Coefficient vs. Temperature for a 25.4 Micron Platinum Filament with $30 \mathrm{~cm}$. Length and Theta $=2.5^{\circ}$ 
5.12 Heat Transfer Coefficient vs. Temperature for a 76 Micron Platinum

Filament with $30 \mathrm{~cm}$. Length and Theta $=5^{\circ} \ldots \ldots \ldots \ldots \ldots \ldots \ldots \ldots \ldots \ldots$

5.13 Heat Transfer Coefficient vs. Temperature for a 63.5 Micron Platinum

Filament with $30 \mathrm{~cm}$. Length and Theta $=5^{\circ} \ldots \ldots \ldots \ldots \ldots \ldots \ldots \ldots \ldots \ldots \ldots \ldots$

5.14 Heat Transfer Coefficient vs. Temperature for a 51 Micron Platinum

Filament with $30 \mathrm{~cm}$. Length and Theta $=5^{\circ} \ldots \ldots \ldots \ldots \ldots \ldots \ldots \ldots \ldots \ldots \ldots \ldots \ldots$

5.15 Heat Transfer Coefficient vs. Temperature for a 38.5 Micron Platinum

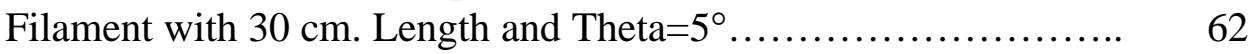

5.16 Heat Transfer Coefficient vs. Temperature for a 25.4 Micron Platinum

Filament with $30 \mathrm{~cm}$. Length and Theta $=5^{\circ} \ldots \ldots \ldots \ldots \ldots \ldots \ldots \ldots \ldots \ldots \ldots$

5.17 Heat Transfer Coefficient vs. Temperature for a 76 Micron Platinum

Filament with $30 \mathrm{~cm}$. Length and Theta $=7^{\circ} \ldots \ldots \ldots \ldots \ldots \ldots \ldots \ldots \ldots \ldots \ldots \ldots$

5.18 Heat Transfer Coefficient vs. Temperature for a 63.5 Micron Platinum

Filament with $30 \mathrm{~cm}$. Length and Theta $=7^{\circ} \ldots \ldots \ldots \ldots \ldots \ldots \ldots \ldots \ldots \ldots \ldots \ldots \ldots$

5.19 Heat Transfer Coefficient vs. Temperature for a 51 Micron Platinum

Filament with $30 \mathrm{~cm}$. Length and Theta $=7^{\circ} \ldots \ldots \ldots \ldots \ldots \ldots \ldots \ldots \ldots \ldots \ldots \ldots \ldots$

5.20 Heat Transfer Coefficient vs. Temperature for a 38.5 Micron Platinum

Filament with $30 \mathrm{~cm}$. Length and Theta $=7^{\circ} \ldots \ldots \ldots \ldots \ldots \ldots \ldots \ldots \ldots \ldots \ldots \ldots$

5.21 Heat Transfer Coefficient vs. Temperature for a 25.4 Micron Platinum

Filament with $30 \mathrm{~cm}$. Length and Theta $=7^{\circ} \ldots \ldots \ldots \ldots \ldots \ldots \ldots \ldots \ldots \ldots \ldots \ldots$

5.22 Heat Transfer Coefficient vs. Filament Diameter at Various Constant

Temperatures for a $30 \mathrm{~cm}$. Platinum Filament with Dynamic

Pressure $\mathrm{q}=0.0 \mathrm{~mm} \mathrm{Hg}$ and Theta $=0^{\circ}$

5.23 Heat Transfer Coefficient vs. Filament Diameter at Various Constant

Temperatures for a $30 \mathrm{~cm}$. Platinum Filament with Dynamic

Pressure q $=0.466 \mathrm{~mm} \mathrm{Hg}$ and Theta $=0^{\circ}$

5.24 Heat Transfer Coefficient vs. Filament Diameter at Various Constant

Temperatures for a $30 \mathrm{~cm}$. Platinum Filament with Dynamic

Pressure q $=0.931 \mathrm{~mm} \mathrm{Hg}$ and Theta $=0^{\circ}$

5.25 Heat Transfer Coefficient vs. Filament Diameter at Various Constant

Temperatures for a $30 \mathrm{~cm}$. Platinum Filament with Dynamic

Pressure $\mathrm{q}=1.397 \mathrm{~mm} \mathrm{Hg}$ and Theta $=0^{\circ}$ 
5.26 Heat Transfer Coefficient vs. Filament Diameter at Various Constant

Temperatures for a $30 \mathrm{~cm}$. Platinum Filament with Dynamic

Pressure $\mathrm{q}=1.863 \mathrm{~mm} \mathrm{Hg}$ and $\mathrm{Theta}=0^{\circ}$

5.27 Heat Transfer Coefficient vs. Crossflow Angle for a 76 Micron Platinum

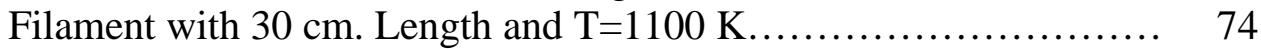

5.28 Heat Transfer Coefficient vs. Crossflow Angle for a 63.5 Micron Platinum

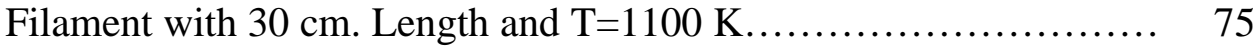

5.29 Heat Transfer Coefficient vs. Crossflow Angle for a 51 Micron Platinum

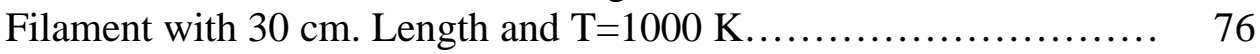

5.30 Heat Transfer Coefficient vs. Crossflow Angle for a 38.5 Micron Platinum

Filament with $30 \mathrm{~cm}$. Length and $\mathrm{T}=900 \mathrm{~K} \ldots \ldots \ldots \ldots \ldots \ldots \ldots \ldots \ldots \ldots \ldots$

5.31 Heat Transfer Coefficient vs. Crossflow Angle for a 25.4 Micron Platinum

Filament with $30 \mathrm{~cm}$. Length and $\mathrm{T}=900 \mathrm{~K} \ldots \ldots \ldots \ldots \ldots \ldots \ldots \ldots \ldots . \ldots \ldots$

5.32 Heat Transfer Coefficient vs. Dynamic Pressure for a 63.5 Micron Platinum

Filament with $30 \mathrm{~cm}$. Length and Theta $=2.5^{\circ}$

5.33 Comparison of Phase I and Phase II Heat Transfer Coefficients vs.

Temperature for a 76 Micron Platinum Filament with $30 \mathrm{~cm}$.

Length and Dynamic Pressure $\mathrm{q}=0.0 \mathrm{~mm} \mathrm{Hg}$ and Theta $=0^{\circ}$

5.34 Comparison of Phase I and Phase II Heat Transfer Coefficients vs.

Temperature for a 76 Micron Platinum Filament with $30 \mathrm{~cm}$.

Length and Dynamic Pressure $\mathrm{q}=0.931 \mathrm{~mm} \mathrm{Hg}$ and Theta $=0^{\circ}$

5.35 Comparison of Phase I and Phase II Heat Transfer Coefficients vs.

Temperature for a 51 Micron Platinum Filament with $30 \mathrm{~cm}$.

Length and Dynamic Pressure $\mathrm{q}=0.0 \mathrm{~mm} \mathrm{Hg}$ and Theta $=0^{\circ}$

5.36 Comparison of Phase I and Phase II Heat Transfer Coefficients vs.

Temperature for a 51 Micron Platinum Filament with $30 \mathrm{~cm}$.

Length and Dynamic Pressure $\mathrm{q}=0.931 \mathrm{~mm} \mathrm{Hg}$ and Theta $=0^{\circ}$

5.37 Comparison of Phase I and Phase II Heat Transfer Coefficients vs.

Temperature for a 76 Micron Platinum Filament with $30 \mathrm{~cm}$.

Length and Dynamic Pressure $\mathrm{q}=0.0 \mathrm{~mm} \mathrm{Hg}$ and Theta $=7^{\circ}$

5.38 Comparison of Phase I and Phase II Heat Transfer Coefficients vs.

Temperature for a 76 Micron Platinum Filament with $30 \mathrm{~cm}$.

Length and Dynamic Pressure $\mathrm{q}=0.931 \mathrm{~mm} \mathrm{Hg}$ and Theta $=0^{\circ}$ 
5.39 Comparison of Phase I and Phase II Heat Transfer Coefficients vs.

Temperature for a 51 Micron Platinum Filament with $30 \mathrm{~cm}$.

Length and Dynamic Pressure $\mathrm{q}=0.0 \mathrm{~mm} \mathrm{Hg}$ and Theta $=7^{\circ}$

5.40 Comparison of Phase I and Phase II Heat Transfer Coefficients vs.

Temperature for a 51 Micron Platinum Filament with $30 \mathrm{~cm}$.

Length and Dynamic Pressure $\mathrm{q}=0.931 \mathrm{~mm} \mathrm{Hg}$ and Theta $=7^{\circ}$

5.41 Heat Transfer Coefficient vs. Tensioning Weight with Frequency and Amplitude listed for Each Point for a 76 Micron Platinum Filament with Dynamic Pressure $\mathrm{q}=1.397 \mathrm{~mm} \mathrm{Hg}$ and Theta $=0^{\circ}$. ...

5.42 Heat Transfer Coefficient vs. Tensioning Weight with Frequency listed for Each Point for a 76 Micron Platinum Filament with Dynamic Pressure $\mathrm{q}=1.397 \mathrm{~mm} \mathrm{Hg}$ and Theta $=0^{\circ}$

5.43 Heat Transfer Coefficient vs. Tensioning Weight with Frequency listed for Each Point for a 76 Micron Platinum Filament with Dynamic Pressure $\mathrm{q}=0.466 \mathrm{~mm} \mathrm{Hg}$ and Theta $=0^{\circ}$

6.1 Effect of Velocity on Slope ${ }^{\text {ht }}$ of Heat Transfer Coefficient vs. Temperature Graphs for Theta $=0^{\circ}$ 100

6.2 Midpoint of Slope ${ }^{\text {ht }}$ vs. Filament Diameter at Theta $=0^{\circ}$.

6.3 Effect of Velocity on the Intercepts of Heat Transfer Coefficient vs.

Temperature Graphs at Theta $=0^{\circ}$.

6.4 Effect of Filament Diameter on $\mathrm{I}_{\mathrm{M}}$ of Heat Transfer Coefficient vs.

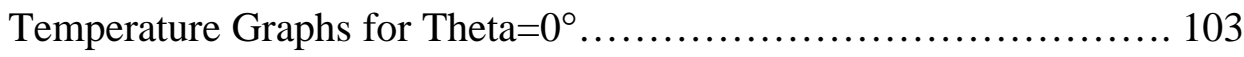

6.5 Comparison of Experimental and Model Heat Transfer Coefficients vs.

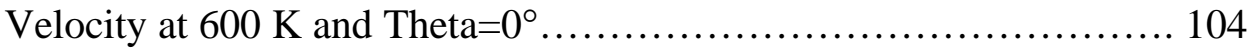

6.6 Experimental and Model Heat Transfer Coefficients vs. Temperature of a 25.4 Micron Platinum Filament with $30 \mathrm{~cm}$. Length and Theta $=0^{\circ}$

6.7 Experimental and Model Heat Transfer Coefficients vs. Temperature of a 51 Micron Platinum Filament with $30 \mathrm{~cm}$. Length and Theta $=0^{\circ}$ 106 
6.8 Experimental and Model Heat Transfer Coefficients vs. Temperature of a 76 Micron Platinum Filament with $30 \mathrm{~cm}$. Length and Theta $=0^{\circ}$

6.9 Increase in Heat Transfer coefficient Due to Velocity for a 25.4 Micron Platinum Filament with $30 \mathrm{~cm}$. Length and $\mathrm{T}=900 \mathrm{~K} \ldots \ldots \ldots \ldots \ldots \ldots . \ldots 108$

6.10 Increase in Heat Transfer coefficient due to Velocity for a 38.5 Micron Platinum Filament with $30 \mathrm{~cm}$. Length and T=1000 K................. 109

6.11 Increase in Heat Transfer coefficient due to Velocity for a 51 Micron Platinum Filament with $30 \mathrm{~cm}$. Length and $\mathrm{T}=1100 \mathrm{~K} \ldots \ldots \ldots \ldots \ldots \ldots . \ldots 110$

6.12 Increase in Heat Transfer coefficient due to Velocity for a 63.5 Micron Platinum Filament with $30 \mathrm{~cm}$. Length and $\mathrm{T}=1100 \mathrm{~K}$

6.13 Increase in Heat Transfer coefficient vs. Velocity for a 76 Micron Platinum Filament with $30 \mathrm{~cm}$. Length and $\mathrm{T}=1100 \mathrm{~K} \ldots \ldots \ldots \ldots \ldots \ldots . . \ldots 112$

6.14 Effect of Crossflow Angle on the Change of Slope of Delta $\mathrm{h}$ vs. Velocity Graphs ............................................... 113

6.15 Change in Slope of Delta h vs. Velocity Graphs vs. Crossflow Angle........... 114

6.16 Comparison of Sine-Squared and Quadratic Curve-Fitting Functions of Change in Slope of Delta h vs. Velocity Graphs vs. Crossflow Angle for a 76 Micron Platinum Filament with $30 \mathrm{~cm}$. Length and $\mathrm{T}=1100 \mathrm{~K}$

6.17 Comparison of Sine-Squared and Quadratic Curve-Fitting Functions of Change in Slope of Delta h vs. Velocity Graphs vs. Crossflow Angle for a 63.5 Micron Platinum Filament with $30 \mathrm{~cm}$. Length and $\mathrm{T}=1100 \mathrm{~K}$

6.18 Comparison of Sine-Squared and Quadratic Curve-Fitting Functions of Change in Slope of Delta h vs. Velocity Graphs vs. Crossflow Angle for a 51 Micron Platinum Filament with $30 \mathrm{~cm}$. Length and $\mathrm{T}=1100 \mathrm{~K}$

6.19 Comparison of Sine-Squared and Quadratic Curve-Fitting Functions of Change in Slope of Delta h vs. Velocity Graphs vs. Crossflow Angle for a 38.5 Micron Platinum Filament with $30 \mathrm{~cm}$. Length and $\mathrm{T}=1100 \mathrm{~K}$ 
6.20 Comparison of Sine-Squared and Quadratic Curve-Fitting Functions of Change in Slope of Delta h vs. Velocity Graphs vs. Crossflow Angle for a 25.4 Micron Platinum Filament with $30 \mathrm{~cm}$. Length and

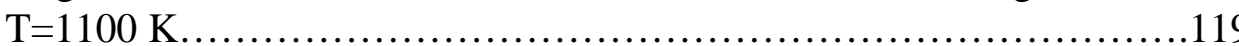

6.21 Slope Coefficient K(d) vs. Filament Diameter..............................120

6.22 Comparison of Experimental and Model Heat Transfer Coefficients for a Platinum Filament with $30 \mathrm{~cm}$. Length at $400 \mathrm{~K}$ and Theta $=2.5^{\circ} \ldots . .121$

6.23 Comparison of Experimental and Model Heat Transfer Coefficients for a Platinum Filament with $30 \mathrm{~cm}$. Length at $600 \mathrm{~K}$ and Theta $=2.5^{\circ} \ldots \ldots 122$

6.24 Comparison of Experimental and Model Heat Transfer Coefficients for a Platinum Filament with $30 \mathrm{~cm}$. Length at $1100 \mathrm{~K}$ and Theta $=2.5^{\circ} \ldots .123$

6.25 Comparison of Experimental and Model Heat Transfer Coefficients for a Platinum Filament with $30 \mathrm{~cm}$. Length at $400 \mathrm{~K}$ and Theta $=7^{\circ}$

6.26 Comparison of Experimental and Model Heat Transfer Coefficients for a Platinum Filament with $30 \mathrm{~cm}$. Length at $600 \mathrm{~K}$ and Theta $=7^{\circ} \ldots \ldots \ldots .125$

6.27 Comparison of Experimental and Model Heat Transfer Coefficients for a Platinum Filament with $30 \mathrm{~cm}$. Length at $1100 \mathrm{~K}$ and Theta $=7^{\circ} \ldots \ldots .126$

6.28 Experimental and Model Heat Transfer Coefficients vs. Temperature of 25.4 Micron Platinum Filament with $30 \mathrm{~cm}$. Length and Theta $=2.5^{\circ} \ldots .127$

6.29 Experimental and Model Heat Transfer Coefficients vs. Temperature of 25.4 Micron Platinum Filament with $30 \mathrm{~cm}$. Length and Theta $=5^{\circ} \ldots \ldots 128$

6.30 Experimental and Model Heat Transfer Coefficients vs. Temperature of 25.4 Micron Platinum Filament with $30 \mathrm{~cm}$. Length and Theta $=7^{\circ} \ldots \ldots 129$

6.31 Experimental and Model Heat Transfer Coefficients vs. Temperature of 51 Micron Platinum Filament with $30 \mathrm{~cm}$. Length and Theta $=2.5^{\circ} \ldots \ldots 130$

6.32 Experimental and Model Heat Transfer Coefficients vs. Temperature of 51 Micron Platinum Filament with $30 \mathrm{~cm}$. Length and Theta $=5^{\circ}$

6.33 Experimental and Model Heat Transfer Coefficients vs. Temperature of 51 Micron Platinum Filament with $30 \mathrm{~cm}$. Length and Theta $=7^{\circ}$

6.34 Experimental and Model Heat Transfer Coefficients vs. Temperature of 76 Micron Platinum Filament with $30 \mathrm{~cm}$. Length and Theta $=2.5^{\circ}$ 
6.35 Experimental and Model Heat Transfer Coefficients vs. Temperature of 76 Micron Platinum Filament with $30 \mathrm{~cm}$. Length and Theta $=5^{\circ}$

6.36 Experimental and Model Heat Transfer Coefficients vs. Temperature of 76 Micron Platinum Filament with $30 \mathrm{~cm}$. Length and Theta $=7^{\circ}$

A.1 Normalized Velocity Profiles at Low Dynamic Pressure $(\mathrm{q}=2.32 \mathrm{~mm} \mathrm{Hg})$ $(\mathrm{Umax}=22.39 \mathrm{~m} / \mathrm{s})$

A.2 Normalized Velocity Profiles at High Dynamic Pressure (q=9.31 mm Hg) $(\mathrm{Umax}=45.32 \mathrm{~m} / \mathrm{s})$

A.3 Percent Turbulence Intensity at Low Dynamic Pressure ( $\mathrm{q}=2.32 \mathrm{~mm} \mathrm{Hg}) \ldots \ldots . .146$

A.4 Percent Turbulence Intensity at High Dynamic Pressure $(\mathrm{q}=9.31 \mathrm{~mm} \mathrm{Hg}) \ldots \ldots .147$

A.5 Mean Values for Percent Turbulence Intensity at High Dynamic Pressure......148

A.6 Mean Values for Percent Turbulence Intensity at Low Dynamic Pressure.......149

E.1 Error in LDA Measured Frequency vs. Theoretical Frequency.................167

E.2 Error in LDA Measured Amplitude vs. Actual Amplitude.....................170 


\section{LIST OF TABLES}

Table Page

6.1 Summary of Error Analysis of Empirical Equation........................98

A.1 Hot-Film Anemometry Readings....................................143

E.1 Theoretical and LDA Measured Frequency for a 228 Micron Vibrating Steel Wire..........................................166

E.2 Actual and LDA Measured Amplitude of a 228 Micron

Vibrating Steel Wire.........................................169

F.1 Sample Heat Transfer Data Spreadsheet............................... 172

G.1 Uncertainty in Heat Transfer Coefficient.............................. 176

G.2 Percent Uncertainty............................................. 177 


\title{
NOMENCLATURE
}

\author{
A -Amplitude (Microns) or Empirical Equation Parallel Flow Component $\left(\mathrm{W} / \mathrm{m}^{2} \mathrm{~K}\right)$ \\ A(x) -Cross-Sectional Area of Filament $\left(\mathrm{cm}^{-2}\right)$ \\ B -Empirical Equation Crossflow Component $\left(\mathrm{W} / \mathrm{m}^{2} \mathrm{~K}\right)$ \\ d -Filament Diameter (Microns) \\ e -Emissivity \\ f $\quad$-Frequency $(\mathrm{Hz})$ \\ h -Convective Heat Transfer Coefficient of Local Film Coefficient (W/m $\left.\mathrm{m}^{2} \mathrm{~K}\right)$ \\ I or $i \quad$-Current (Amps) or Intercept $\left(\mathrm{Ws} / \mathrm{m}^{3} \mathrm{~K}\right)$ \\ $\mathrm{I}_{\mathrm{m}} \quad$-Intercept of Midpoint $\left(\mathrm{Ws} / \mathrm{m}^{3} \mathrm{~K}\right)$ \\ K -Thermal Conductivity of Air or Slope Coefficient $\left(\mathrm{Ws} / \mathrm{m}^{3} \mathrm{~K}\right)$ \\ LDA -Laser Doppler Anemometry \\ L -Length of Filament (cm) \\ $\mathrm{Nu} \quad$-Nusselt Number \\ P $\quad$-Power (Watts) \\ q -Dynamic Pressure $(\mathrm{mm} \mathrm{Hg})$ \\ $\mathrm{q}_{\mathrm{conv}} \quad$-Convective Heat Transfer \\ $\mathrm{q}_{\mathrm{rad}} \quad$-Radiation Heat Transfer \\ R1 -Resistor 1 (ohm) \\ R2 -Resistor 2 (ohm) \\ R3 -Resistor 3 (ohm)
}




\section{S $\quad$-Slope $\left(\mathrm{W} / \mathrm{m}^{2} \mathrm{~K}^{2}\right)$}

$\mathrm{S}_{\mathrm{I}} \quad$-Slope of the Intercept Trendlines $\left(\mathrm{Ws} / \mathrm{m}^{3} \mathrm{~K}\right)$

Slope $^{\text {ht }}$-Slope of Heat Transfer Coefficient vs. Temperature Graphs $\left(\mathrm{W} / \mathrm{m}^{2} \mathrm{~K}^{2}\right)$

T $\quad$-Temperature (Kelvin)

$\mathrm{T}^{*} \quad$-Ambient Temperature $\left({ }^{\circ} \mathrm{C}\right)$

$\mathrm{T}_{\mathrm{ref}} \quad$-Freestream Temperature (Kelvin)

$\mathrm{T}_{\mathrm{s}} \quad$-Surface Temperature $\left({ }^{\circ} \mathrm{C}\right)$

$\mathrm{T}_{\infty} \quad$-Freestream Temperature (Kelvin)

$\mathrm{T}_{\text {filament }}$-Filament Temperature (Kelvin)

$\mathrm{U} \quad$-Rate of Varying Filament Diameter $(\mathrm{cm} / \mathrm{s})$

$\mathrm{U}_{\max } \quad$-Maximum Velocity $(\mathrm{m} / \mathrm{s})$

V -Freestream Velocity $(\mathrm{m} / \mathrm{s})$ or Voltage (Volts)

$\mathrm{V}_{\mathrm{d}} \quad$-Voltage Read from Voltage Divider (Volts)

W -Uncertainty

X $\quad$-Distance $(\mathrm{cm})$

Z -Axial Distance (cm)

Greek

$\theta \quad$-Crossflow Angle (Degrees) 


\section{Chapter 1}

\subsection{Introduction}

Thin filaments, for use in industries such as fiberglass, polymers or textiles, are often formed by extruding molten material through a circular orifice to form a continuous fiber. This process is commonly referred to as melt spinning. These extruded filaments travel through the environment at high velocities to be wound onto spools below the orifice plate. Considerable heat transfer occurs as the fibers are pulled to the desired diameter. The filaments transform from molten material to solid filament within a small distance.

While the fibers cool, inclusions can occur in them, which result in loss of strength and increased probability of breakage. To reduce the imperfections in the filaments and thus increase their overall quality, it is necessary to understand the cooling process of the forming fibers. By developing a model to simulate the cooling rate of an extruded filament, thermal stresses can be reduced in the forming process to ensure a higher quality of fiber as an end result.

There are two obvious methods for attempting to characterize the heat transfer from a cooling filament. The first method is to work solely from theoretical equations. Basic heat transfer, thermodynamic and fluid dynamics equations can be applied to a system modeled to represent the actual filament forming process.

Attacking the problem from a theoretical standpoint is beneficial. To solve the theoretical equations requires making several basic assumptions, which can significantly alter their applicability. However, an experimental approach leads to an applicable 
empirical model for the heat transfer from a cooling fiber, while requiring fewer assumptions.

A viable experimental approach includes design and fabrication of an experimental setup that adequately simulates the conditions experienced by a forming filament. An electrically heated filament made of a conductive material with known physical properties was selected to simulate the forming filament. Analysis of power dissipated by the simulating filament provides an accurate model of the environment experienced by the forming filament.

Several factors appear to affect the heat transfer from the filament. In addition to the axial flow of air along the filament, there may be a crossflow velocity component, which affects the heat transfer. Forming filaments can often be observed to vibrate as they move through the air. It was, therefore, hypothesized that the vibrations occurring in the filament necessarily create relative crossflow, which plays a large role in the rate of heat transfer from the filament.

The object of this research project was to characterize the heat transfer from an electrically heated thin filament as a function of various operating parameters. This can be accomplished by improving an existing empirical model characterizing the heat transfer from a thin filament. This existing model was developed in 1997 by Morris, Loth and Bond [1] to characterize the heat transfer from a nonvibrating forming filament using an electrically heated platinum wire cooled by the parallel flow of air.

Utilizing a computerized data acquisition process allows collection of time dependent data and improves accuracy of time-averaged data, and expands the database to include a larger variety of wire diameters, more crossflow angles, and different axial 
flow velocities. Improvements were made to the existing model. However, filament vibration effects had not been included in this improved model. To study the effects of filament vibration, it was necessary to develop a method of measuring and recording data about the vibrational characteristics of a filament subjected to axial flow. A system capable of measuring the required data was developed based on existing Laser Doppler anemometry technology. This system made it possible to measure both filament vibrational frequency and amplitude optically without adverse effects on the filament. This new system was tested to verify its accuracy and then used in combination with the heat transfer measurement equipment to acquire data on the effect of filament vibrations on the overall heat transfer rates. 


\section{Chapter 2}

\subsection{Literature Review}

Significant research has been previously done in the area of characterizing heat transfer in forming filaments. While some of the research was experimental, a great deal of this material is theoretical in nature. An overview is presented in this chapter which describes the previous research conducted in this area, particularly research done developing the existing empirical model which formed the basis for this project.

\subsection{Studies on Melt Spinning}

Maebius [2] used several heat transfer models to try to determine the effects of convective and radiation heat transfer on melt spun fibers. Maebius used a onedimensional model for a Newtonian fluid to determine the radiation and convective heat transfer effects. Beginning from the governing continuity, momentum and energy conservation equations, Maebius used a fourth-order Runge-Kutta method to obtain a solution using several convective heat transfer models with and without radiation effects. These solutions led Maebius to believe that "Radiative cooling is a dominant form of heat transfer" and that assuming a constant convective film transfer coefficient can lead to misleading results.

Perhaps the most widely accepted correlation for a moving fiber in melt spinning was provided by Kase and Matsuo [3]. It is given in the form

$$
\mathrm{Nu}=\mathrm{hd} / \mathrm{K}=0.42(\mathrm{Re})^{0.344}
$$

where $\mathrm{Nu}$ is the local Nusselt number, Re is the local Reynolds number, $\mathrm{d}$ is local fiber diameter, $\mathrm{h}$ is local film coefficient, and $\mathrm{K}$ is the thermal conductivity of air. This 
relation was developed from the governing equations and relates Nusselt and Reynolds number for a cylinder in axial flow. Kase and Matsuo used this relation to obtain plots for a polyester filament of cross-sectional area and filament temperature as a function of distance from the issuing orifice (Figures 2.1 and 2.2). Kase and Matsuo were able to obtain fairly good agreement between the theoretical solution of the governing equations and the experimental plots versus distance from the orifice. Kase and Matsuo also included some vibrational assumptions, but did not involve them in an overall model for the heat transfer coefficient, which was not related to distance from the orifice.

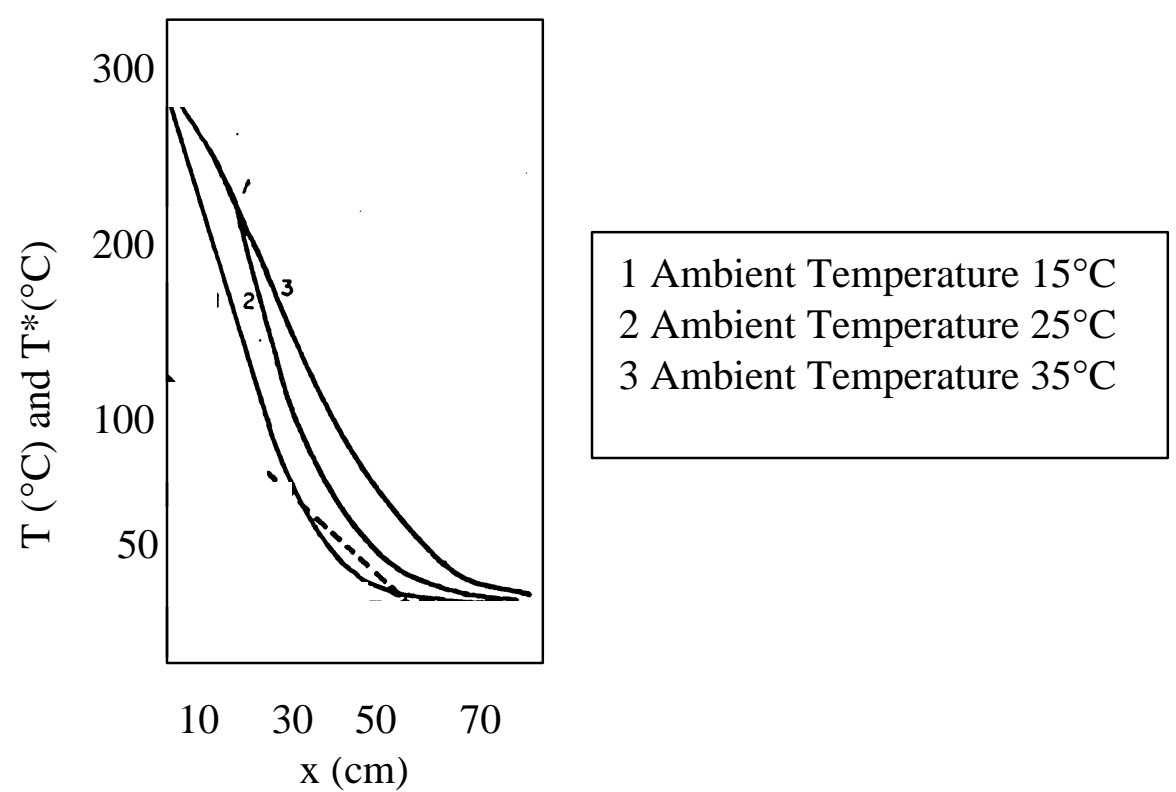

Figure 2.1: Calculated Temperature of Filament, T, vs. Distance Under Various Ambient Temperatures, $\mathrm{T}^{*} \cdot[3]$ 


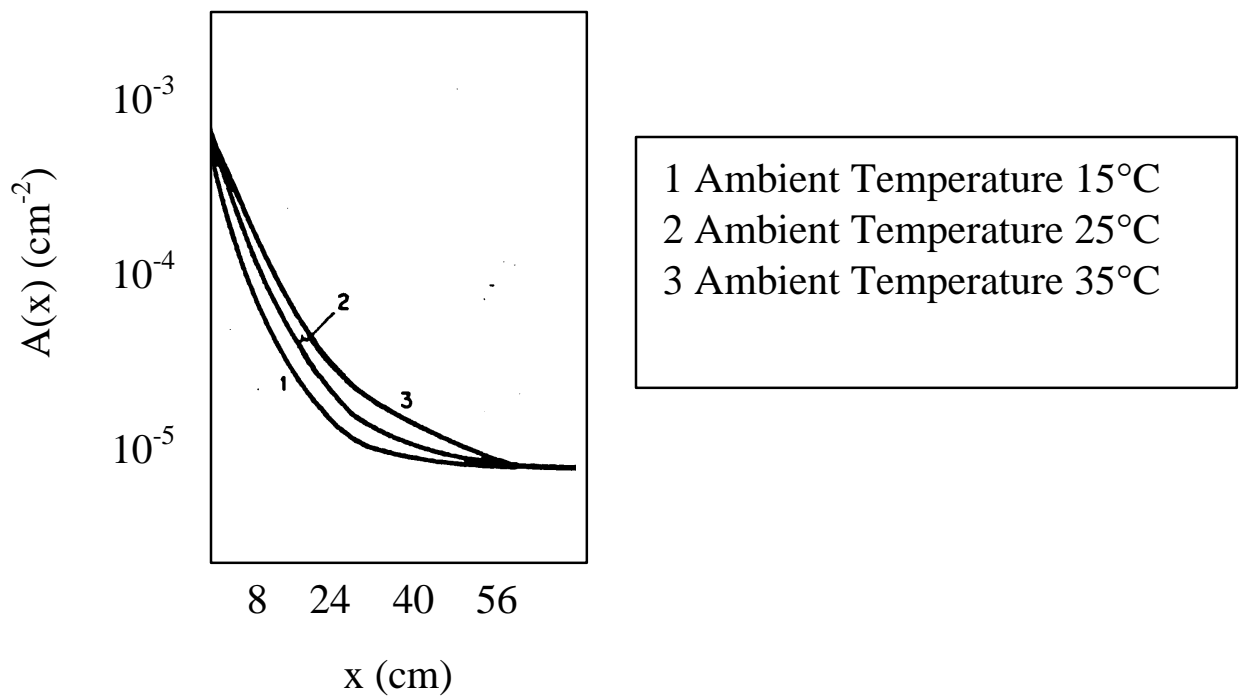

Figure 2.2: Calculated Cross Sectional Area of Filament at Various Ambient Air Temperatures [3]

\subsection{Boundary Layer Considerations}

Leuptow [4], Sakiadis [5] and Karnis and Pechoc [6] performed research regarding boundary layer behavior over a circular cylinder subjected to axial flow. Sakiadis provides detailed boundary layer equations for an infinite circular cylinder. Using experimental techniques, Lueptow determined that the cylindrical boundary layer is likely to become wake-like as the radius of the cylinder becomes small. The wake-like behavior that would be experienced by a thin filament could lead to increased cross flow and increased vibration. Karnis and Pechoc investigated the thermal boundary layer on a continuous circular cylinder. They developed an approximate solution to the boundary layer equations using the Karman-Pohlhausen technique and then developed a solution experimentally. A comparison of the two 
yielded the fact that the approximate solution tends to underestimate the experimental value of heat transfer by as much as ten percent.

\subsection{Heat Transfer through the Boundary Layer}

Research has been done in characterizing different methods of heat transfer through the boundary layer of a continuous circular cylinder. Bourne and Davies [7] developed a method for calculating the heat transfer of a heated long slender cylinder subjected to axial incompressible flow using a power law. This allowed a relationship between curvature and local Prandtl number on heat transfer to be obtained. The drawback to this method was that a new power calculation was required for every point. Bourne, Davies and Wardle [8] developed another method that determined heat transfer through the boundary layer of an infinite circular cylinder that lacked this problem utilizing a Karman-Pohlhausen method.

Eshghy and Hornbeck [9] analyzed heat transfer and boundary layer flows over a long thin cylinder. Using a finite difference approach to solving the governing equations, Eshghy and Hornbeck developed velocity and temperature profiles for different values of curvature. They were able to determine that temperature increased with increasing curvature.

Treating the forming fiber as an infinite cylinder at constant temperature allowed Bourne and Elliston [10] to develop a comparison between experimental and theoretical local Nusselt numbers (Figures 2.3 and 2.4). Theoretical local Nusselt numbers were generated from a Karman-Pohlhausen integral technique. A rough averaging method was then used to make the theoretical numbers comparable 
to experimental numbers. As evidenced in Figures 2.3 and 2.4, theoretical local Nusselt numbers fell about ten percent below experimental values. Building on the work done by Sakiadis, Bourne and Dixon, Bourne and Elliston and Karnis and Pechoc, Beese and Gersten [11] provide a solution to the second order governing equations to determine second-order effects of curvature and entrainment on heat transfer from a continuous circular cylinder. They determined that the entrainment effect does not influence heat transfer, but curvature and interaction between the cylinder and ambient air increase heat transfer.

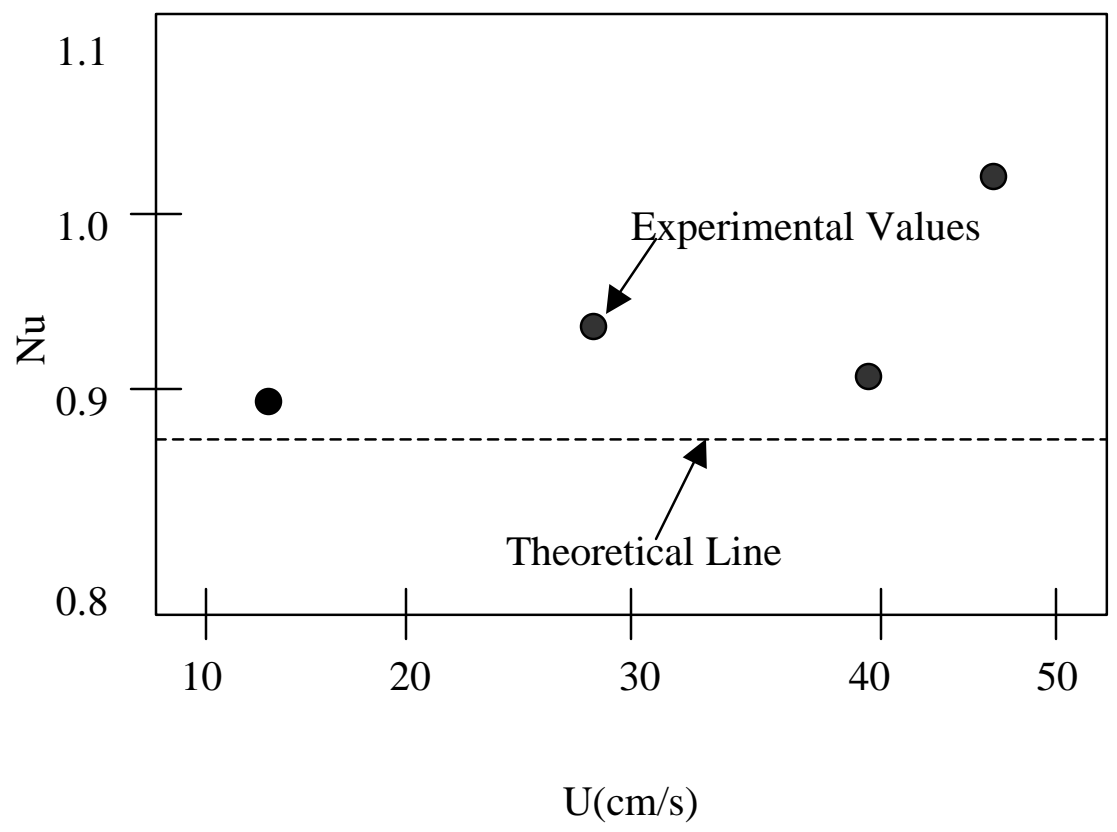

Figure 2.3: Comparison of Experimental and Theoretical Values of Average Local Nusselt Number vs. Varying Filament Diameter with Constant Flow Rate of $0.01 \mathrm{~cm}^{3} / \mathrm{s} \mathrm{[10]}$ 


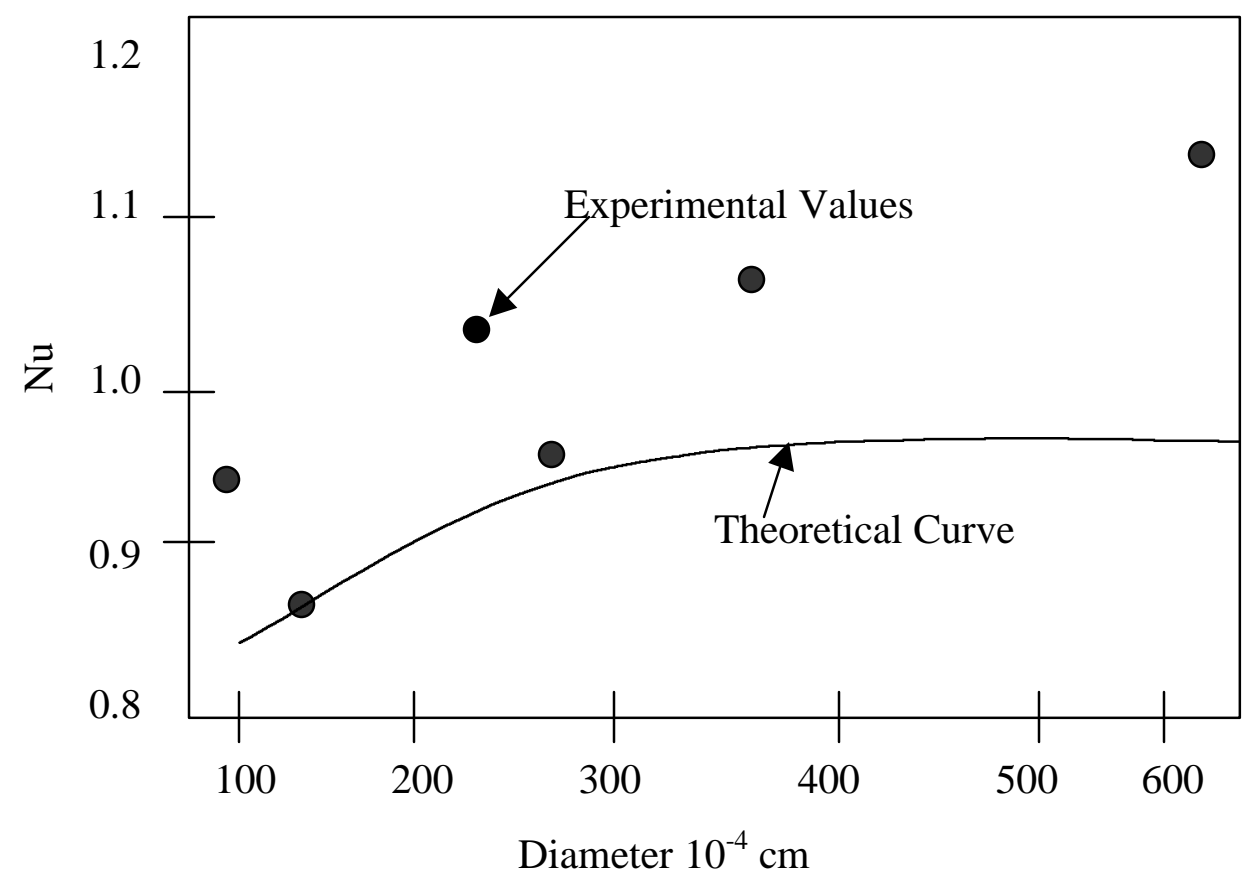

Figure 2.4: Comparison of Experimental and Theoretical Values of Average Local Nusselt Number vs. Fiber Speed U with fixed Filament Radius of $14.5 \times 10^{-4} \mathrm{~cm}$. [10]

Bourne and Dixon [12] used a Karman-Pohlhausen method to solve the boundary layer equations. To construct a simple model that would make the equations solvable, a forming fiber was considered to be an infinite circular cylinder issuing into an infinite fluid. The results were averaged to account for varying properties through the fluid and tended to be fairly close to previously obtained experimental values for a forming fiber. 


\subsection{Convection and Conduction Heat Transfer during the Drawing Process}

Papamichael and Miaoulis [13] performed a two-dimensional analysis on a forming glass fiber including forced and natural convection to develop axial and radial temperature profiles. Utilizing these profiles Papamichael and Miaoulis stated that a fiber manufacturer could determine cooling length and temperatures of the forming fibers. Figure 2.5 shows the surface temperature of a cooling fiber as a function as a function of axial distance resulting from Papamichael and Miaoulis's temperature profiles. Theoretical results seemed to show good agreement with experimental results previously obtained.

Papamichael and Miaoulis [14] also considered the effects of axial conduction during the cooling process. Analyzing thin filaments of $200-500 \mu \mathrm{m}$ in diameter Papamichael and Miaoulis were able to determine the local dimensionless heat transfer coefficient. Papamichael and Miaoulis use a Karman-Pohlhausen technique to solve the governing equations. It was determined that for filaments in these diameter ranges, axial conduction is important but neglected in most models for heat transfer from forming fibers.

For a cylinder moving against the free stream velocity, Eswara and Nath [15] used a quasilinearization technique combined with a finite difference technique to determine the effects of forced convection on the cylinder. Eswara and Nath determined that the free stream and cylinder velocities affect skin friction and heat transfer. Similarly to work done by Bourne and Davies and Beese and Gersten, Eswara and Nath determined that the skin friction and heat transfer tends to increase as transverse curvature increases. 


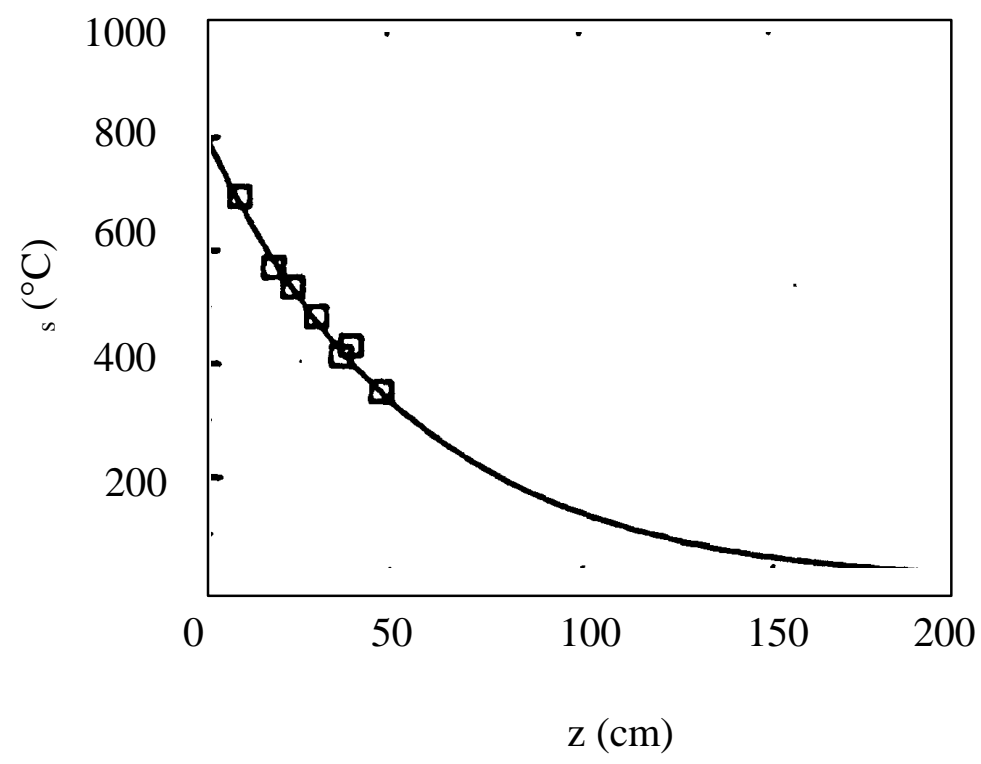

Figure 2.5: Surface Temperature vs. Axial Distance for a $0.09 \mathrm{~mm}$ Filament at $1 \mathrm{~m} / \mathrm{s}$ [13]

\subsection{Other Research Concerning Heat Transfer}

There are several other bodies of work pertaining to heat transfer from a cooling filament that do not fit easily into any of the previously mentioned categories. Ha, Jung and Kim [16] provide a numerical analysis of the convection associated with a heat generating body in an enclosure. They used dimensionless forms of the governing equations to develop models for Nusselt number as a function of dimensionless time. It was determined that increased flow in the enclosure increased heat transfer from the heat generating body. It was also determined that increasing the temperature difference between the ambient conditions inside the enclosure and the heat generating body changed the mode of heat transfer from natural convection to radiation. 
The cooling of a wire during formation can be likened in some respects to the application of a hot-wire anemometer. The hot-wire anemometer can be used at constant temperature mode. In constant temperature mode the current input into the probe must change to keep the probe at a certain temperature to account for convection heat transfer attempting to cool the wire. Ball, Ashforth-Frost, Jambunathan and Whitney [17] developed an experimental method for constructing temperature profiles utilizing the changing current input into the probe. The results compared well to direct temperature readings from the probe.

\subsection{Development of an Empirical Model for Heat Transfer from a Cooling Filament}

Although valuable in their theoretical content, many of these studies are not directly applicable to the fiber manufacturing process. To improve the quality of drawn filaments, a model that can be applied directly to the drawing process is needed. The most reliable empirical model would seem to be one that was taken from experimental data rather than only relying on theoretical equations. Characterizing the heat transfer from the filament as a function of variables such as filament diameter, drawing speed, cross flow velocity and temperature would allow manufacturers of thin filaments to see what effects changes in any of these variable would have on the end result.

Morris, Loth and Bond [1] developed an empirical model for the heat transfer of a cooling filament. The experimentally developed model accounted for filament diameter, filament velocity, velocity of cross flow and temperature. The empirical model developed by Morris, et al. identified both convective and radiation heat transfer effects and included them in the empirical model. 
To develop an empirical model that was comparable to the process actually experienced by cooling filament; several aspects of a forming filament had to be considered. A platinum filament was used to simulate the cooling filament. To simulate the effect of high velocities of the filaments, a platinum filament was placed in a wind tunnel and subjected to a similar axial velocity. Electric current was applied to the platinum filament to produce the thermal loss rate, representative of that of a cooling filament. Platinum was used because it is corrosion free, and its resistance provides an accurate measure of its temperature. This allows experimental data to be translated into data applicable to developing the empirical model. The current required to stabilize the wire at a specified temperature was measured. This value along with the voltage drop across the platinum filament were used to calculate the wire temperature and the power dissipated by convective and radiation heat transfer. The convective component was isolated and converted to heat transfer coefficients using the known properties of the platinum filament including length, diameter, emissivity and resistivity.

Platinum filament sizes of 51 microns and 76 microns were placed in the wind tunnel and heated. Calculated values of heat transfer coefficient could then be plotted for these two wire sizes at four different axial flow speeds, $0 \mathrm{~m} / \mathrm{s}, 4.3 \mathrm{~m} / \mathrm{s}, 9.9 \mathrm{~m} / \mathrm{s}$ and $17.5 \mathrm{~m} / \mathrm{s}$. Crossflow velocities were produced by altering the angle of the wire with the flow direction.

It was determined experimentally by Morris, et al. that the heat transfer coefficient varied little along the length of the test filament (Figure 2.6). This result suggested that the characterizing Reynolds number should be based on the diameter of the filament, not 
on the distance from the leading point. The investigators determined this characteristic Reynolds number to be on the order of 100 .

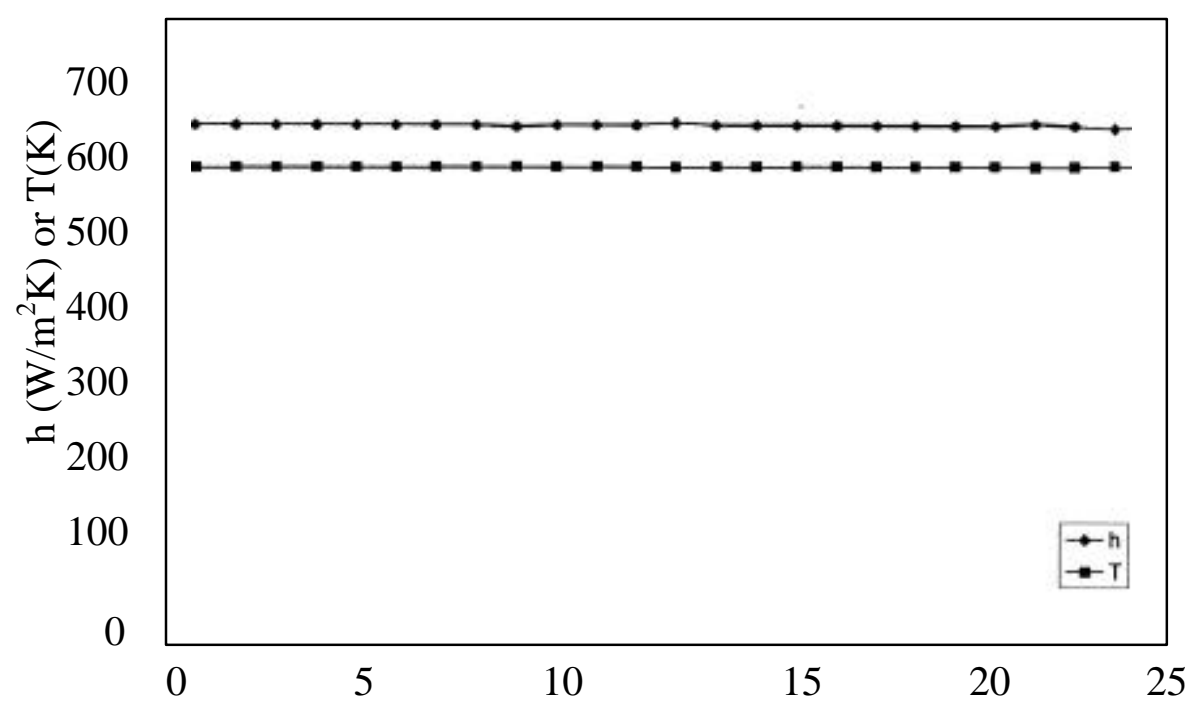

Distance from Leading Edge $(\mathrm{cm})$

Figure 2.6: Heat Transfer Coefficient and Temperature vs. Distance from Leading Edge for 76 micron wire at $\mathrm{V}=58.2 \mathrm{~m} / \mathrm{s}$

Due to the fact that the heat transfer appeared independent of axial distance, the remaining data were acquired with a fixed test length of $30 \mathrm{~cm}$. The heat transfer coefficient was plotted as a function of filament temperature at the four different wind tunnel velocities for a 76 micron wire at $0^{\circ}, 3.5^{\circ}$ and $7^{\circ}$ crossflow angle and then again at the different velocities and crossflow angles for a 51 micron wire. From the resulting graphs, Morris, et al. made several observations. It was noted that the heat transfer 
coefficient seemed to increase linearly with velocity and crossflow angle. A linear increase of heat transfer coefficient with velocity indicates an increase of Reynolds number based on filament diameter as a opposed to textbook behavior where the heat transfer coefficient increases with the square root of Reynolds number based on distance from the leading point.

Morris, et al. were able to develop an empirical model based on the experimental test data. The model that was developed determined the heat transfer coefficient as a function of filament diameter $\mathrm{d}$ (meters), temperature difference between the filament and the freestream $\mathrm{T}-\mathrm{T}_{\infty}($ Kelvin), the crossflow angle $\theta$ and wind tunnel velocity $\mathrm{V}(\mathrm{m} / \mathrm{s})$. The empirical model took the form:

$$
\mathrm{h}\left(\mathrm{W} / \mathrm{m}^{2} \mathrm{C}\right)=(1 / \mathrm{d})\left[0.0000116\left(\mathrm{~T}-\mathrm{T}_{\infty}\right)+0.012+0.0011 \mathrm{~V} /(12.69 \sin (\theta))\right]
$$

From this model Morris, et al. were able to develop graphs predicting the heat transfer as a function of velocity for many different filament diameters (Figures 2.7 and 2.8).

Morris, et al. note that this model is not complete. While this model fits their data to approximately plus or minus ten percent, they state that the amount of data collected in the study was "too few to provide a universal model." Another limitation with the model is the limited number of wire diameters tested. This low number necessitates linear interpolation or extrapolation to other wire diameters, which necessarily leads to increased inaccuracy in the model.

Furthermore, they noted that filaments when placed in the wind tunnel were prone to slight vibrations. While filament vibrations were not accounted for in the original empirical model, this phenomenon likely influences the overall heat transfer form the filament. Developing a way to determine the frequency and amplitude of these 
vibrations and then test with vibrating filaments was recommended to develop a better model.

Expansion of the original database that was taken by Morris, et al. could lead to a more accurate empirical model. Testing a larger variety of wire diameters at more wind tunnel velocities and more crossflow angles would allow more confidence in the final model. Automating the data acquisition procedure would lessen the likelihood of experimenter error and reduce the overall error.

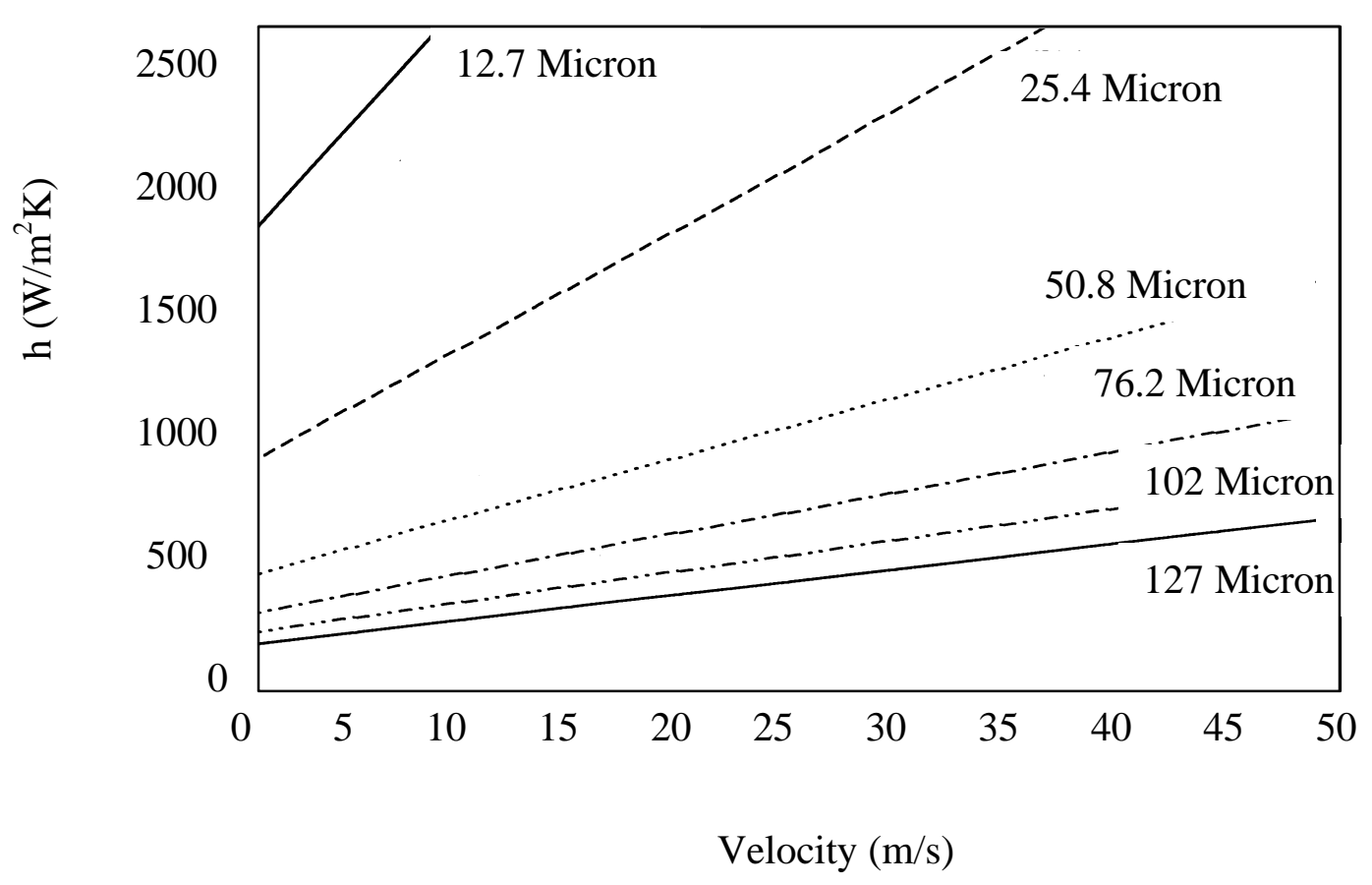

Figure 2.7: Heat Transfer Coefficient Calculated from Empirical Equation for $\mathrm{T}=1100 \mathrm{~K}$ and Theta $=0[1]$ 


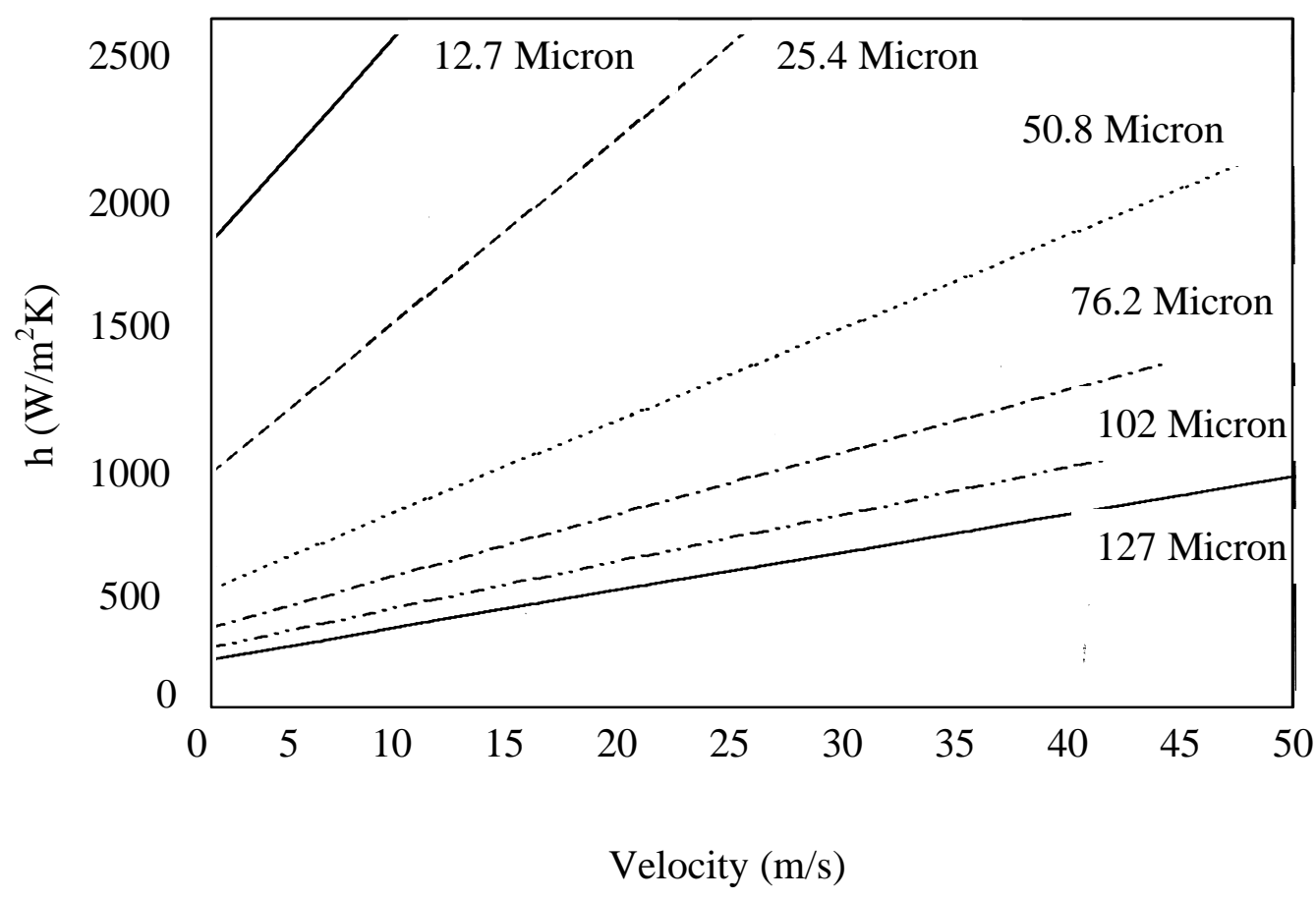

Figure 2.8: Heat Transfer Coefficient Calculated from Empirical Equation for $\mathrm{T}=1100 \mathrm{~K}$ and Theta $=7^{\circ}[1]$ 


\section{Chapter 3}

\subsection{Experimental Apparatus}

In order to develop a reliable empirical model for the heat transfer from a forming drawn filament, the experimental setup must closely resemble the actual process that is experienced by the filament. The setup must also allow for measurements of such quantities as power dissipated by and temperature of the filament, in order to facilitate the development of an accurate empirical model to characterize the heat transfer from the forming filament.

\subsection{Vertical Wind Tunnel}

In an earlier research study performed by Morris, Loth and Bond [1], an electrically heated platinum filament was placed in a horizontal 45"x32" subsonic wind tunnel test section. Unexpectedly, the cooling of the filament due to natural crossflow occurring in the wind tunnel appeared to be of the same order as the forced convection that occurred in the axial direction from forced convection. From these tests it became apparent to the investigators that a horizontal wind tunnel was inappropriate for the project. They then determined that subjecting the heated filament to axial flow in a vertical wind tunnel would most accurately simulate the forced convection heat transfer from the vertically moving filament. A vertical wind tunnel was constructed to most accurately simulate the moving filament. For use in the present study, this facility was modified with a new blower allowing higher test velocities to be obtained. 
The vertical wind tunnel consisted of four parts: a test section, plenum, a contraction section and a blower as shown in Figures 3.1 and 3.2. Section 1 is the plenum, section 2 is the contraction section with two contracting nozzles, and section 3 is the cylindrical acrylic test section. The test section has a $14.61 \mathrm{~cm} ., 5$ 3/4 in., inner diameter and length of $60.96 \mathrm{~cm} ., 24$ in. Screens were installed between the plenum and the first nozzle and in between the two nozzles to reduce the freestream turbulence.

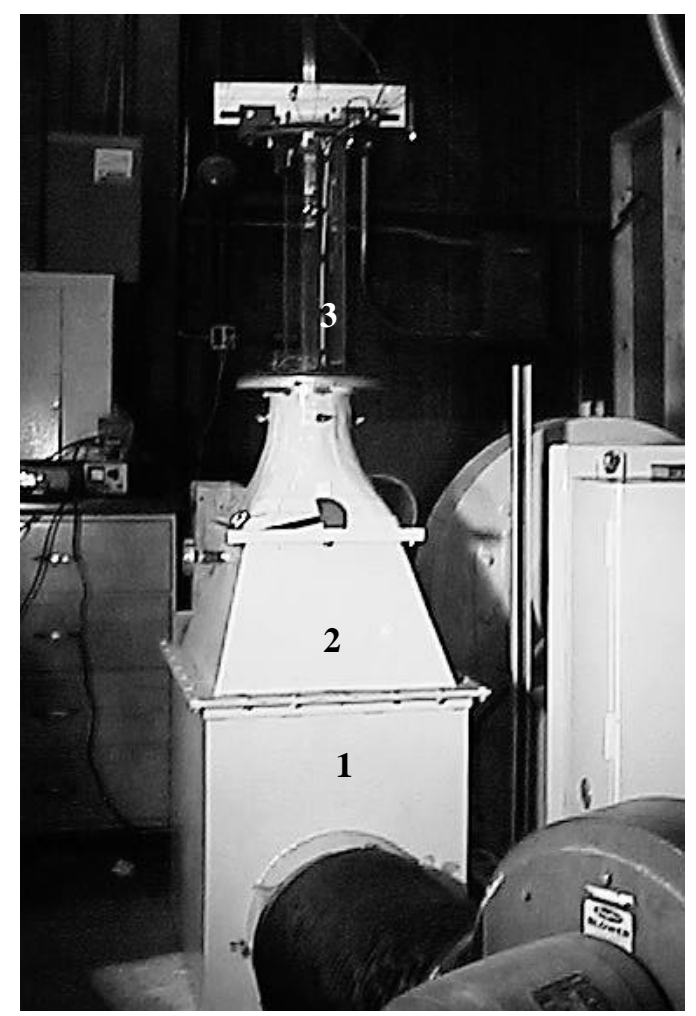

Figure 3.1: Vertical Wind Tunnel Setup

In the study conducted by Morris, Loth and Bond [1], both a 37.3-W, 50-hp, motor and a $0.373-\mathrm{W}, 1 / 2-\mathrm{hp}$, motor were used to provide flow for the vertical wind tunnel. The 50-hp blower was found to be too powerful and it was difficult to control the tunnel 
velocity. The $0.373-\mathrm{W}$ blower provided accurate and easy tunnel velocity control, however; it lacked the power to provide the high velocity desired. Because of this, a 3.73-W, 5-hp, blower (Figure 3.2) was acquired and connected to the previously existing tunnel setup. To vary the air speed in the test section, a throttle gate was added to the intake of the blower. The gate simply consisted of a plate that could slide in and out of the opening covering anywhere from 0 to $100 \%$ of the intake area. A screen was also added to the intake for safety and to prevent debris ingestion. In addition to changing the blower and speed control a modification was desired to facilitate the stringing of filaments. This was accomplished by adding a door in the acrylic tube, which provided access to the test section.

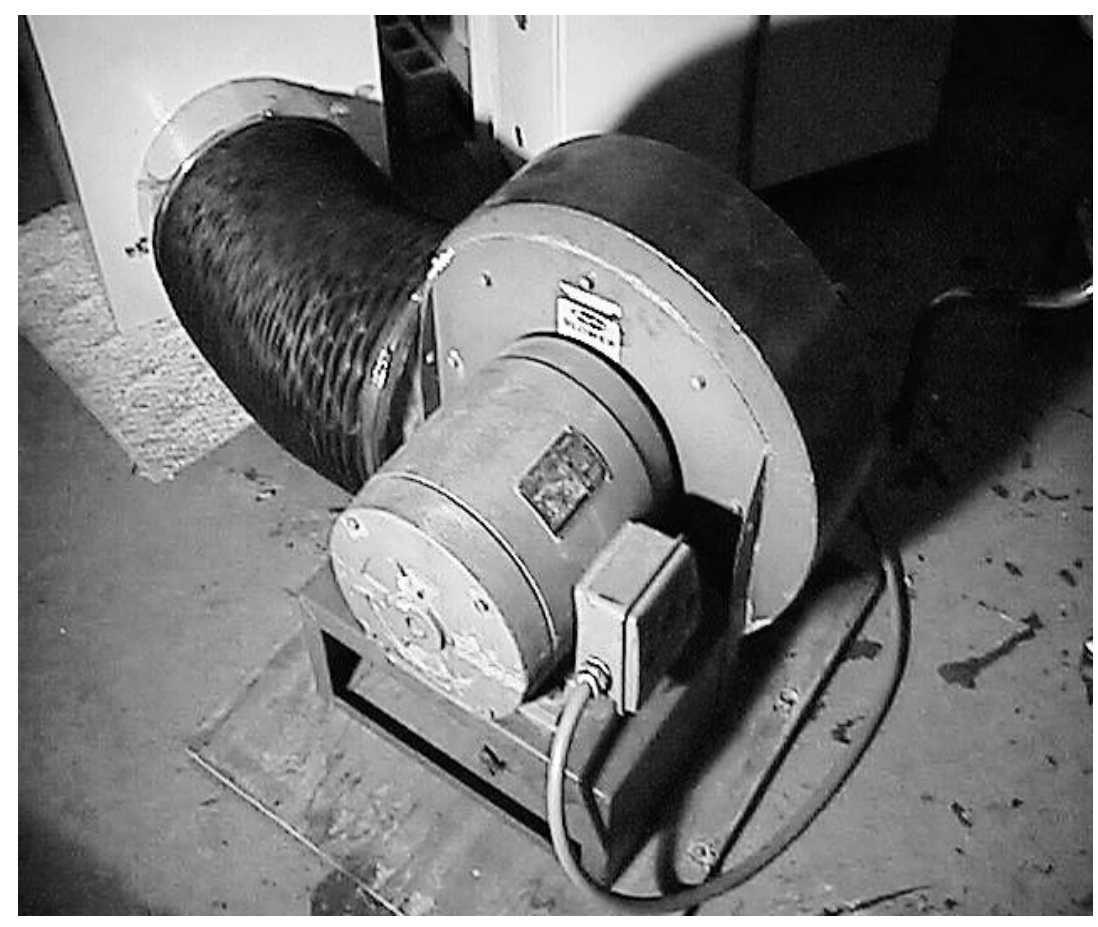

Figure 3.2: 3.73-W Blower Used for Testing 
Periodic filament vibrations were observed in the wind tunnel while operating with a heated filament or with an unheated filament. During the periods of filament vibration, the heat transfer rate increased, which was apparent by the varying visible glow, associated with periodic longitudinal temperature fluctuations. It is believed that periodic filament contractions caused by turbulence induced periodic cooling provides the required energy to drive the vibrations. However, with an unheated filament, vibrations still occurred, although less violently. For the unheated filament, the filament contractions were absent and the vibration energy came from turbulence in the surrounding airflow and vibrations from the tunnel walls. For this reason, measuring and minimizing the freestream turbulence was considered a primary objective.

A hot-film anemometer was used to measure the freestream velocity and the percent turbulence intensity at various locations throughout the flow at different wind tunnel speeds. The hot-film probe was inserted into the flow, and velocity profiles were obtained for the flow at one-centimeter increments in the radial direction of the test section. These velocity profiles were obtained along two different lines, which differed from each other by 90 degrees around the test sections and at two different circular crosssectional heights along the test section. The different positions were then named $1 \mathrm{~A}, 2 \mathrm{~A}$, 1B, and 2B (Figures 3.3a and 3.3b).

Readings were taken at each of these points for two tunnel speeds: a low dynamic pressure setting producing approximately $22 \mathrm{~m} / \mathrm{s}$, which is referred to as low pressure and at a high dynamic pressure setting producing about $44 \mathrm{~m} / \mathrm{s}$, which is referred to as high pressure. When the velocity profiles were plotted against position, the resulting graphs 
were relatively flat indicating uniform velocity distributions. Percent turbulence intensity averaged about 1.25 for low pressure and 0.8 for high pressure (Appendix A).

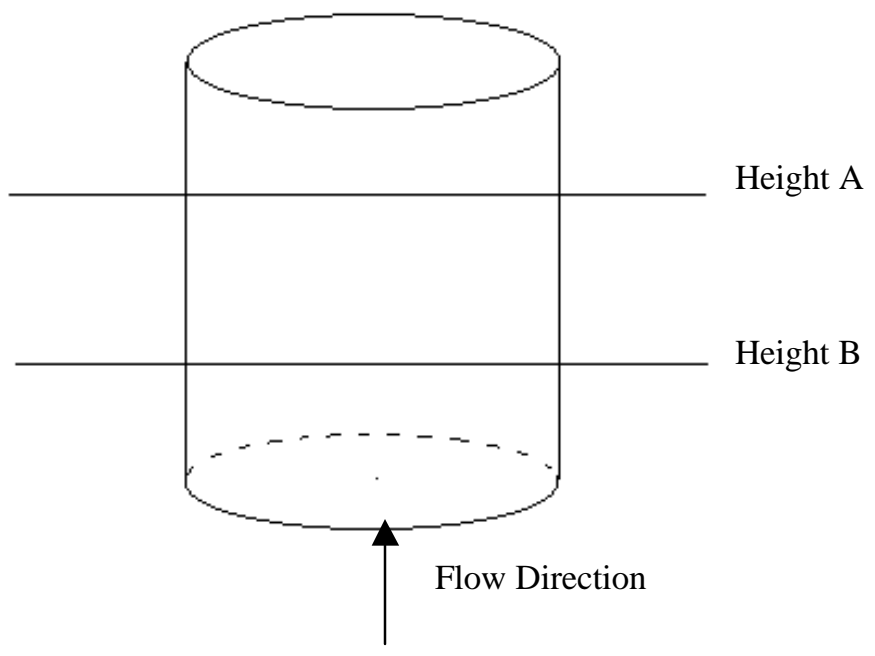

Figure 3.3a: Heights of Probe Positions for Measurement of Velocity and Turbulent Intensity Using Hot-Film Anemometer in Wind Tunnel Test Section

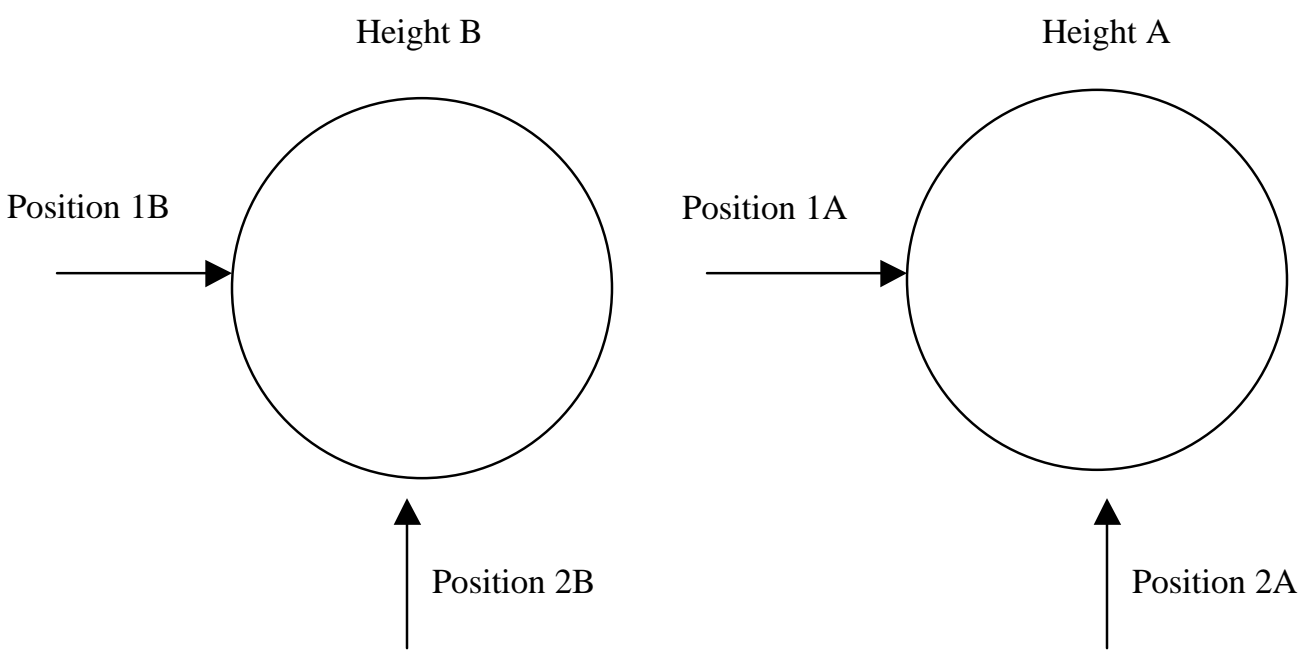

Figure 3.3b: Cross-Sections of Test Section at Two Test Heights with Positions Illustrated.

Although the turbulence numbers were relatively low, some efforts were made to further reduce these values. Several configurations were proposed and tried, but none 
had a significant positive impact on the turbulence levels in the flow. It was anticipated that an indraft tunnel would produce less turbulence than the current positive pressure tunnel. Based on this hypothesis the tunnel was reconfigured to use the intake side of the 3.73-W blower and a section of aluminum flue pipe. Measured turbulence values in the indraft case were never significantly lower that those obtained using the baseline positive pressure configuration, and in most cases the turbulence in the indraft configuration was slightly higher than that of the positive pressure configuration. Therefore, the output side of the blower was reconnected to the tunnel via medium duty corrugated vinyl tubing and was used in the positive pressure configuration for further testing.

Dynamic pressure was determined by a pitot static tube at the top of the test section. The pitot static tube was attached to a micromanometer from which dynamic pressure in inches of water could be determined. Ambient air temperature readings were taken by means of a K-type thermocouple placed at the exit of the test section in a position that would not be affected by the high temperature filament wake. The thermocouple was connected to a reader where temperature settings and fluctuations were observed.

\subsection{Filament Suspension}

The mounting system for the filament had to be one that would not disrupt the developing boundary layer, due to the dependence of the convective heat transfer coefficient on the viscous and thermal boundary layers. A method of suspension was developed in which the test filament ran from a thin cross-wire, to minimize boundary layer disruption, to a traversing mechanism and then to a tensioning device. A 76-micron Ni-Chrome wire spanned the entrance to the test section and was used as the cross-wire. 
The tension in this cross-wire was provided by connecting one end of the cross-wire to a small spring and the other end to a solid pin across the width of the cylindrical test section.

The test filament was attached to a voltage terminal at the base of the test section and was then wrapped once around the spanning cross-wire and then ran vertically upward to the traversing mechanism. The voltage at the leading point of the test filament was read from the spanning cross-wire, which had no current running through it. The traversing mechanism (Figure 3.4) consisted of a gold-plated pin and an aluminum pulley combination mounted on the end of a digital caliper. The test filament ran over the gold pin where the downstream voltage was measured. The aluminum pulley was used to insure the test filament remained in contact with the pin. The traversing mechanism allowed for exact determination of the working length of the test filament. The length as well as the angle with the vertical could be adjusted using the traversing mechanism.

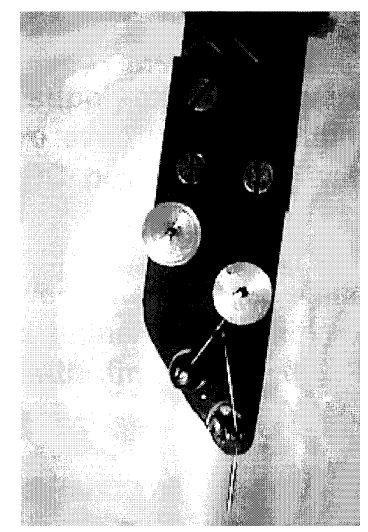

Figure 3.4: Traversing Mechanism 
The test filament continued from the traversing mechanism to a tensioning device at the top of the cylindrical test section. In the original design, the test filament was anchored to an electric lead at the top of the test section. A string connected to this lead and then ran around a pulley and along the top (exit) of the test section. The string then wrapped around a small pulley and the tensioning weight was applied. During data acquisition it became evident that the tensioning system could be improved. The string, which supported the tensioning weight, was in the cross flow, and at high velocities the tensioning weight was observed to oscillate slightly up and down. This movement of the weight added unnecessary stress to the fragile test filament and was a likely source of filament vibration.

The proposed solution was to attach the wire to a rigid object instead of a string to alleviate the vibration that occurred in the string. To accomplish this, a wire attachment cleat was soldered to a light spring attached to the end of a $12.7 \mathrm{~cm}$., five-inch, long piece of $0.159 \mathrm{~cm} ., 1 / 16 \mathrm{in}$. , outer diameter copper tubing and the tensioning weight was placed on the other end of the tube. In the middle of this tube another similar tube was attached perpendicularly to the first tube. The second tube was then attached to the test section via axle pins, which allowed the configuration to pivot. The pivoting accounted for the changing length of the test wire with changing temperature allowing proper tension to remain on the test filament regardless of filament length. Small lead weights were used to apply tension to the test filaments. The number of weights used could be varied to achieve appropriate tensions for all filament diameters. The appropriate tension was determined by the finding the tension that was high enough to discourage filament vibration, while not being high enough to encourage filament failure. 


\subsection{Test Filament}

The test filaments were platinum wires of varying diameters. Platinum was chosen due to its large temperature coefficient of resistance and resistance to oxidation. As the electrical resistance of platinum wire is known as a function of temperature, the temperature of the wire can be accurately determined from this measurement. The resistance of the wire can be easily determined if the electrical current through the filament and the voltage drop across the filament are known. The resistance can be determined from Ohm's law:

$$
\mathrm{V}=\mathrm{IR} \quad \text { or } \mathrm{R}=\mathrm{V} / \mathrm{I}
$$

where $\mathrm{V}$ is voltage across the wire in Volts, I is current running through the wire in amperes, and $\mathrm{R}$ is the resistance of the test wire in ohms.

The platinum filaments used were $99.99 \%$ pure platinum. This high grade platinum wire was used because the accuracy of parameters determined using published properties decreased greatly as the quality of the platinum used decreased. The platinum wires used as test filament varied in diameter. The diameters used were 76 microns, 63.5 micron, 51 microns, 38 microns and 25.4 microns. The working length for all test filaments was 30 $\mathrm{cm}$. This constant test length was used based on work done by Morris, Loth and Bond [1] indicating that changing length had little to do with heat transfer coefficient (Figure 2.6).

From the published properties of platinum, the geometry of the test filament, voltage across the wire and current running through the wire several parameters were determined. First, the power dissipated by the wire was calculated. The heat transfer coefficient of the heated filament may be calculated by performing an energy balance 
including joule heating, radiant heat transfer and convective heat transfer. Radiation heat transfer was shown to be a second order effect by Morris, Loth and Bond [1]. The wire temperature was maintained by controlling the wire voltage, which determines the current through the wire. Although the applied voltage is maintained at a constant some fluctuations were observed in the temperature readings.

\subsection{Data Acquisition Setup}

A data acquisition board was used to monitor current flowing through the wire and voltage drop across the wire. The data acquisition board was an Analog Devices RTI815, which contained eight channels although not all were used. The maximum RTI815 board input voltage range is $0-10 \mathrm{~V}$, and since the maximum voltage drop across the wire was found to be as high as 50 volts DC, a method was needed to reduce the voltage level read by the board.

To solve this problem an external voltage divider was constructed to reduce the actual voltage to a voltage within the $0-10$ volt range (Figures 3.5 and 3.6). The voltage divider was developed using a $22 \mathrm{~K}$ resistor and a $4.1 \mathrm{~K}$ resistor in series. The actual voltage was applied across both resistors and the measured voltage was read across the

4.1 $\mathrm{K}$ resistor (Figure 3.6). The voltage divider system allowed for a reduction in measured voltage by a factor of six.

To measure the current flow in the wire, a 250-Watt rated 5-ohm, large wire wound resistor (Figures 3.5 and 3.6) was connected in series with the test lead, and the current was found by reading the voltage drop across this resistor. Analog to digital board channels one and two were connected to the circuit. Power from a voltage limiting direct 
current power supply was wired into the circuit. (Alternating current supply was observed to cause vibration in the wire in the earlier study by Morris, Loth, and Bond [1]. Due to the fact that the vibration was present even in a vacuum chamber, Morris, et al. attributed the vibrations as the platinum wire responding to the "periodic polarity reversal of the alternating current.")

A BASIC program was written which read the voltage data from channel one (wire voltage) and channel two (wire current) at a frequency of $1000 \mathrm{~Hz}$ (Appendix B). The data acquisition board was set to record 5000 data points over a five-second period. Once this system was tested and debugged, the data acquisition system was completed.

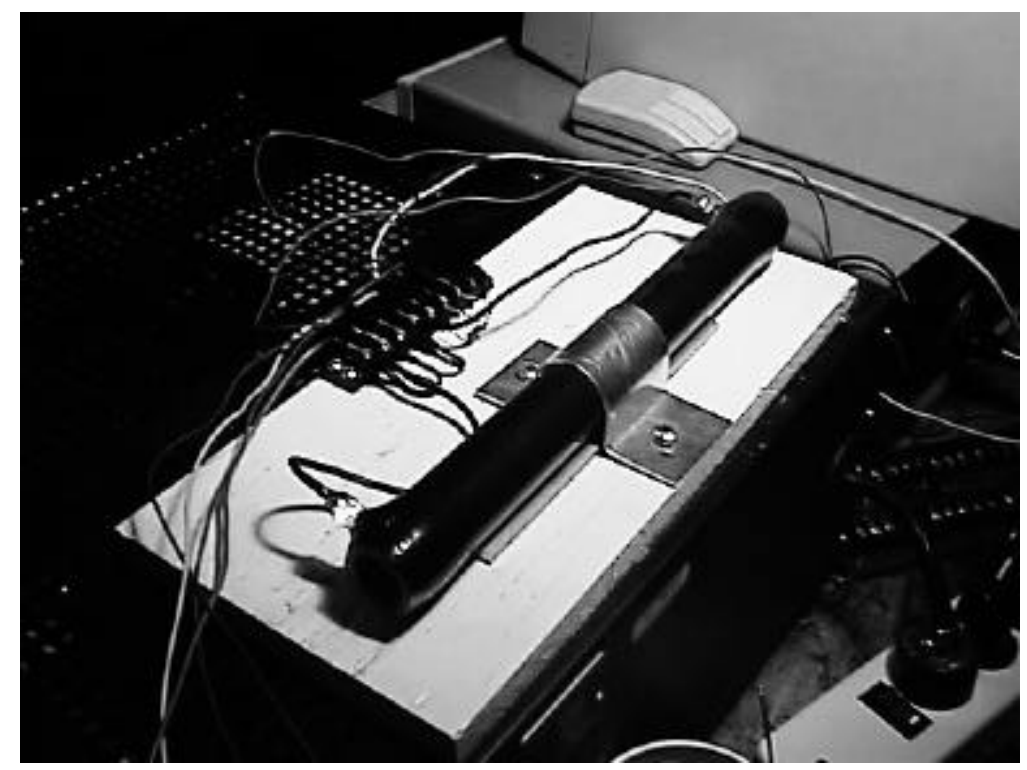

Figure 3.5 Actual Voltage Divider and Current Lead Resistor 


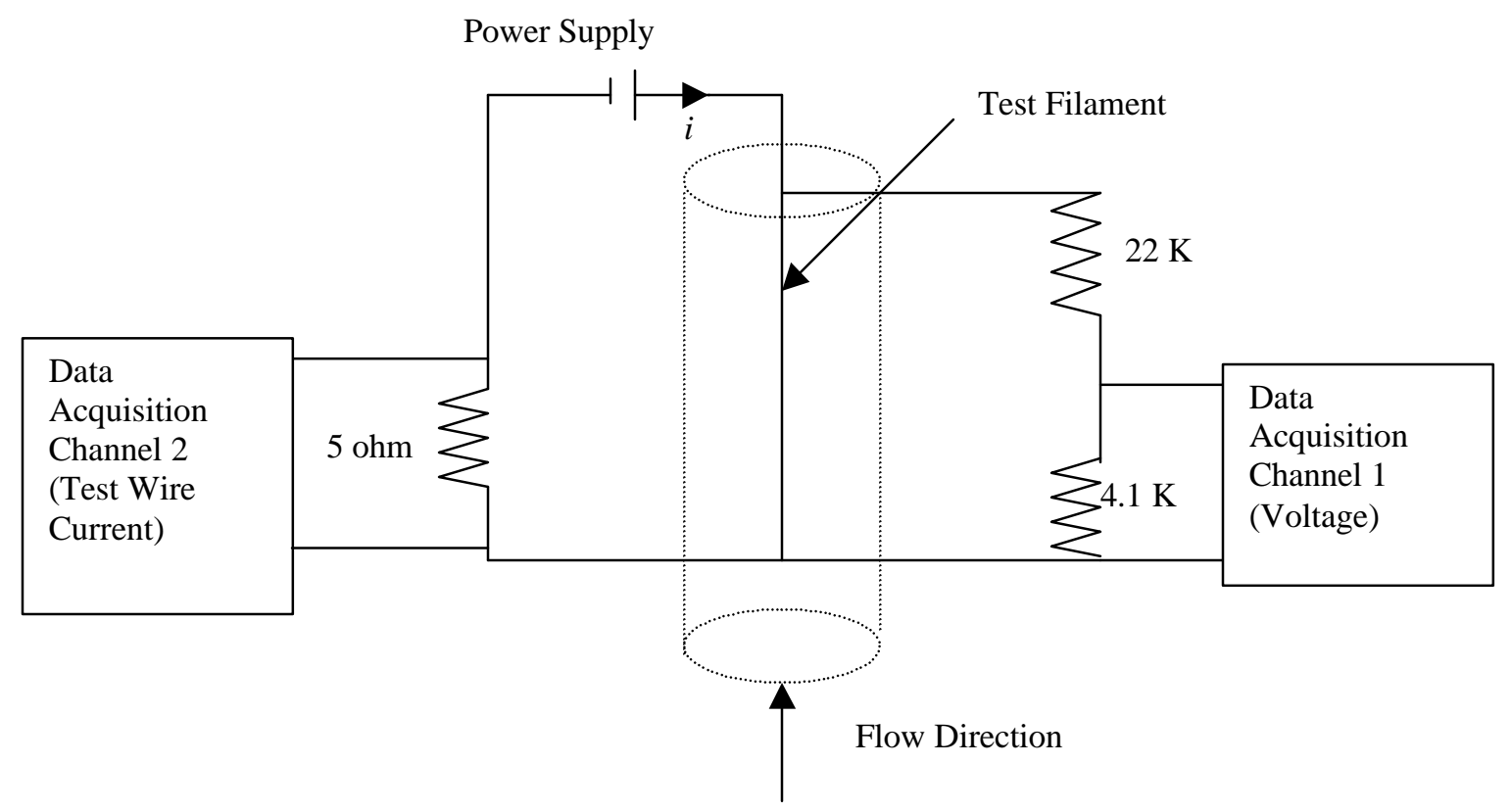

Figure 3.6: Schematic of Data Acquisition circuit

\subsection{LDA Setup}

Developing a way of measuring and characterizing the vibrational motion observed in the wire appeared to be vital to characterizing its effect on the heat transfer from the wire. The first step was to determine the best way to detect this motion and therefore, determine the natural frequency and amplitude of the filament.

A setup was developed where a nickel filament was mounted between two supports affixed to a positioning table, which utilized threaded lead screws for ease of movement in the two orthogonal directions. This allowed for accurate placement of the filament with respect to the fixed frequency measuring equipment. 
An 18-mW He-Ne laser was used to illuminate the vibrating filament. A photodarlington detector, which is actually a highly sensitive phototransistor arrangement, was focused on the light reflected from the filament. This detector consists of two transistors in series (Figure 3.7). The detected light is focussed on the base, which governs the bias of the transistor pair. By monitoring the output signal from this device the vibration frequency is easily observed. This system is very simple and low cost; however, it yields no filament speed or amplitude information, which could prove important to characterize the overall vibrational effect on total heat transfer from the electrically heated test filament.

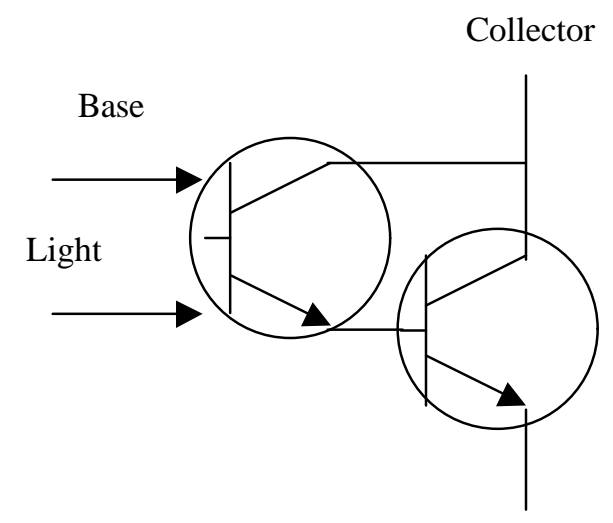

Emitter

Figure 3.7: Photo-Darlington Detector Circuit Diagram

Laser anemometry offers several distinct advantages to other methods of optical measurement. Not only does laser Doppler anemometry offer the ability to measure the 
desired quantity unobtrusively; laser Doppler anemometry offers high resolution. There are, however, advantages to using simpler optics such as the photo-darlington detector system. Laser Doppler anemometry requires the use of a beam splitter, a converging lens and a photomultiplier tube that the photo-darlington detector does not require. However, the photo-darlington detector system is effective for measuring the natural frequency but not the amplitude or velocity which are ultimately necessary for to quantify the filament vibrational characteristics.

In this application, the laser Doppler anemometry is used in the backscatter mode. A beam from the laser is split producing two equal intensity beams. The beams intersect forming a measuring volume where the filament vibration quantities are measured. The backscatter system measures the vibration of a filament perpendicular to the incident beam axis. The intersection of the two beams forms a fringe pattern and defines a measuring volume. When the measuring volume is incident on the filament, the converging lens gathers the "backscattered" light (Figure 3.8). This backscattered light is focussed onto a photomultiplier tube. The photomultiplier can be connected to a computer, a signal processor or, as used for this research, a digital storage oscilloscope. The resulting data can be graphed by the oscilloscope, and data trends can be observed on the screen by the experimenter. The fringe spacing is known and from the time information gathered from the vibrating wire as it crosses the fringes, the velocity and amplitude of the vibrating wire can be determined from observing the traces that appear on the screen of the digital storage oscilloscope. 


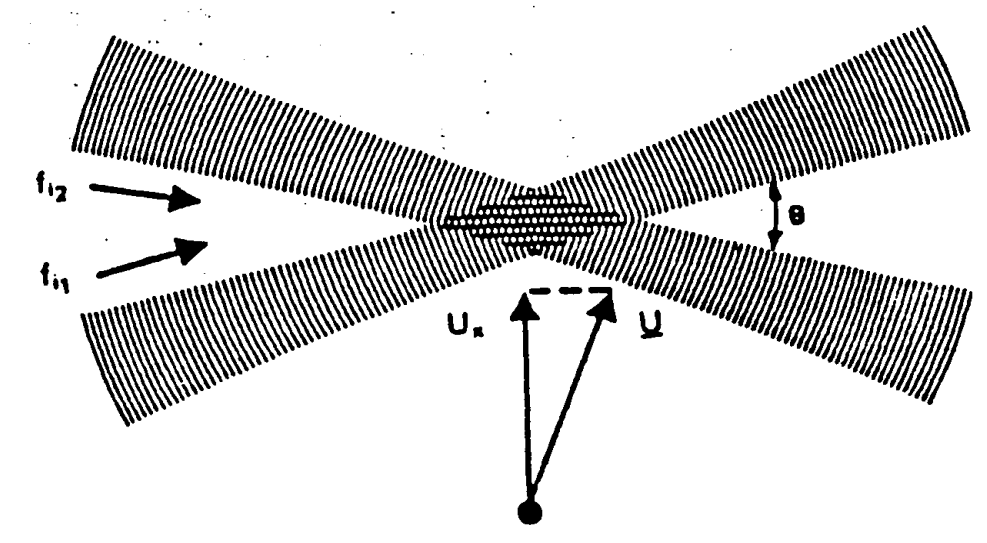

Figure 3.8: Interference Fringes Forming From the Intersection of Two Coherent and Monochromatic Laser Beams

While this system is more complex than one using a photo-darlington detector, the laser Doppler anemometry system yields information on both vibrational frequency as well as maximum velocity, from which amplitude can be determined. Because of this, laser Doppler anemometry was determined to be the most efficient method of characterizing the vibration of the filament.

Once it was decided that Laser Doppler anemometry would be a significant tool for characterizing wire vibration, an optical system and a laser appropriate for the needs of the project had to be selected. Early tests were conducted with an 18-mw He-NE laser, but these tests indicated a more powerful laser would be beneficial. Therefore, a $2.0-\mathrm{W}$ argon-ion laser was acquired and mounted onto an optical bench (Figure 3.9). Several different optical systems were then fitted and evaluated and it was found that the best results were observed using TSI optics in backscatter mode (Figure 3.10). When a storage oscilloscope was connected to the photomultiplier tube, a signal caused by the vibration of a filament could be stored and observed. 


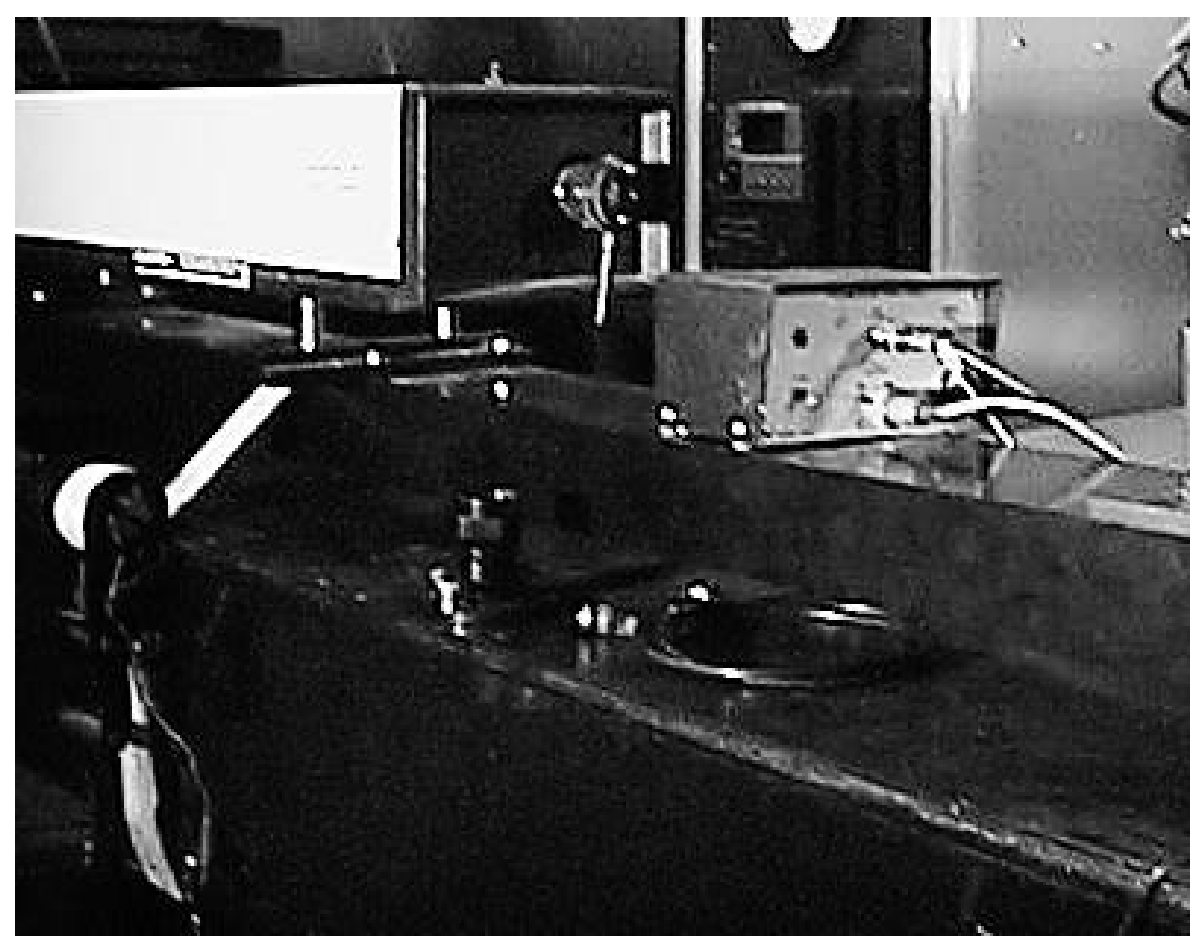

Figure 3.9: 2.0-Watt Argon-ion Laser Mounted to Optical Bench

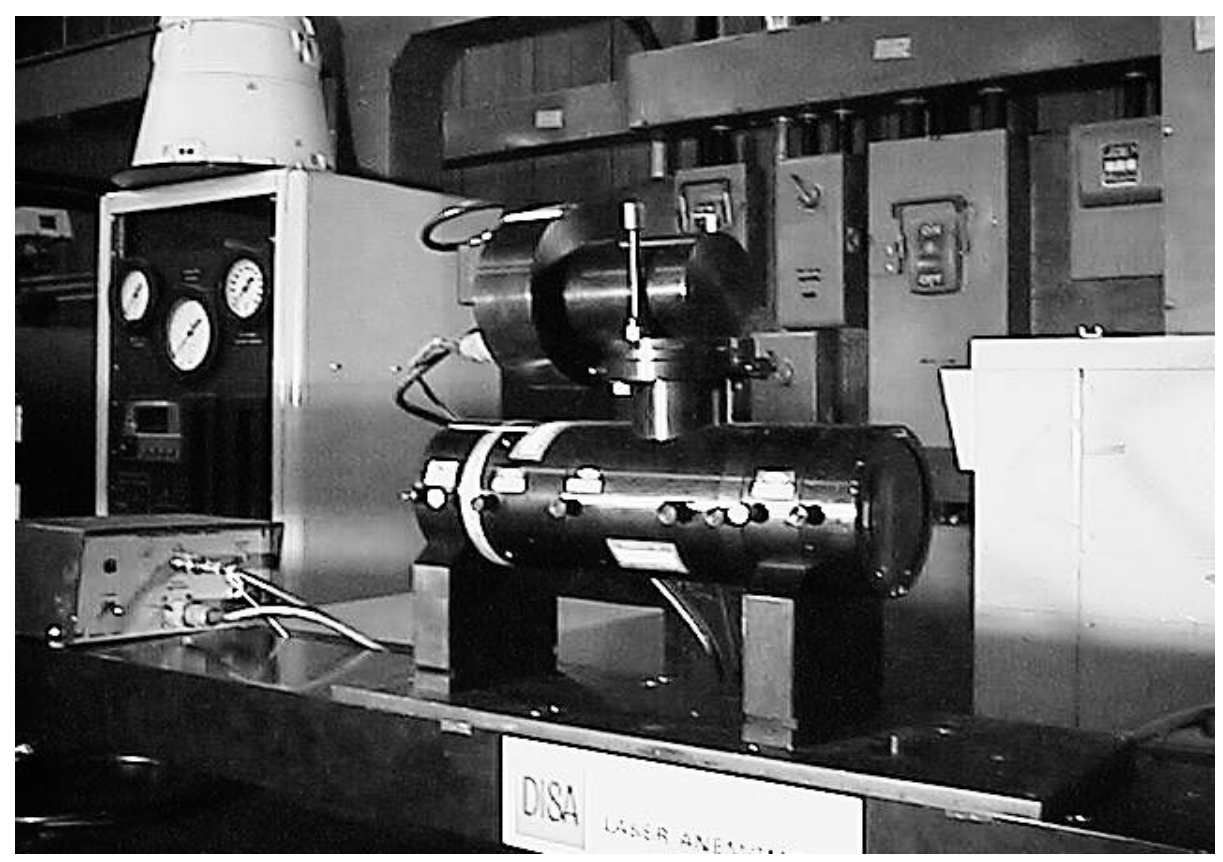

Figure 3.10: TSI Optics Mounted to Optical Bench 
After the optics were selected, they were mounted to the optical bench and the bench was then mounted to a traversing system that facilitates vertical positioning of the laser (Figure 3.11). This permitted frequency measurement to be recorded at as many different axial positions along the test wire as desired.

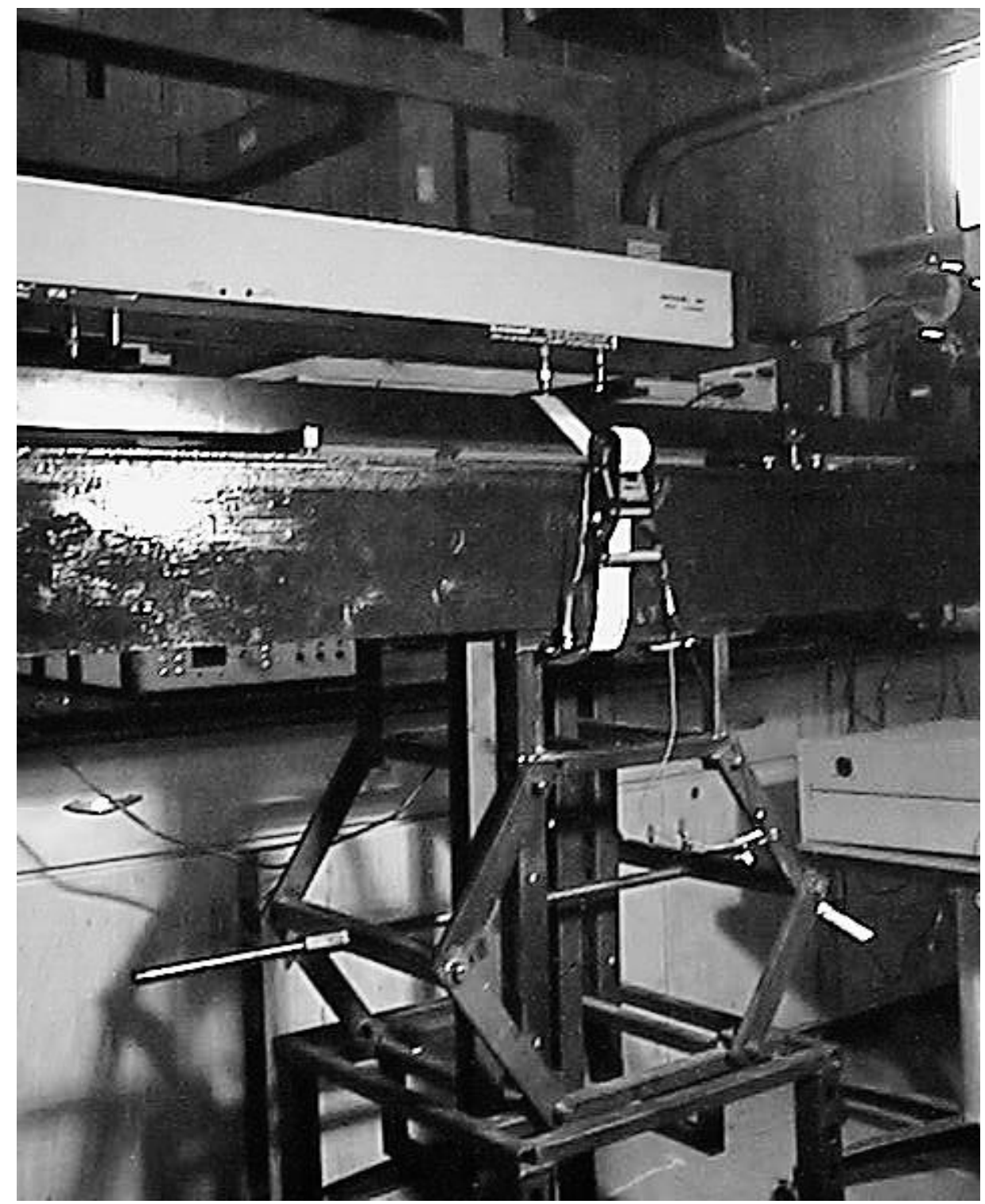

Figure 3.11: Laser and Optics on Optical Bench Mounted to Vertical Traversing System 


\section{Chapter 4}

\subsection{Experimental Procedure}

\subsection{Determinations of Parameters}

A filament was suspended from the tensioning device in the cylindrical test section at zero degree crossflow angle and the voltage leads were attached (See Figures 3.1 and 3.6). The dynamic pressure as read from a pitot-static tube attached to a micromanometer was increased incrementally until wire vibration was visually observed. Visible vibrations began after the dynamic pressure reading exceeded $1.863 \mathrm{~mm} \mathrm{Hg}$ (one inch of water). Because it was desired to obtain data without wire vibrations, this was set as the maximum for test velocities.

The lowest dynamic pressure at which testing was to be preformed was the "noflow" case, where the blower was not turned on. It was decided that testing at a dynamic pressure of $\mathrm{q}=0,0.466,0.931,1.397$, and $1.863 \mathrm{~mm} \mathrm{Hg}(0,0.25,0.5,0.75$ and 1 inch of water) would give an accurate representation of the range of drawn filament velocities, while minimally exciting filament vibrations.

Once dynamic pressure ranges were selected, temperature ranges for the filament had to be determined. Full data sets were difficult to obtain at temperatures nearing the melting point of platinum due to the high incidence of filament breakage at these high temperatures. Because of the reduced strength of the thin filaments, temperature ranges also had to vary with filament diameter. An appropriate starting temperature was determined to be 400 Kelvin; and was used as the starting temperature for all wire sizes. The larger wire sizes, 76 micron and 63.5 microns, were capable of reliably attaining 
temperatures of 1100 Kelvin. The 51 micron and 38.5 micron wires consistently failed at temperatures over 1000 Kelvin, so the maximum temperature was determined for these filaments to be 1000 Kelvin. Similarly, the maximum operational temperature for the 25.4-micron filament was only 900 Kelvin.

\subsection{Data Acquisition Procedure}

Perhaps the most important step of the research project was the careful collection of the experimental data. The data acquisition software allowed data to be taken with relatively low occasion of experimenter error. Care had to be taken to record the correct environmental conditions, such as atmospheric pressure and ambient air temperature.

The data acquisition software then read voltages across the voltage divider and the wire-wound resistor and then converted these data into an actual voltage drop occurring in the filament and an actual current flowing through the filament (Equations 4.1 and 4.2).

$$
\mathrm{V}=\mathrm{V}_{\mathrm{d}} *(\mathrm{R} 1+\mathrm{R} 2) / \mathrm{R} 2
$$

where $\mathrm{V}$ is the actual voltage in volts, $\mathrm{V}_{\mathrm{d}}$ is the voltage read from the voltage divider, $\mathrm{R} 1$ is the $22 \mathrm{~K}$ resistor, and $\mathrm{R} 2$ is the $4.1 \mathrm{~K}$ resistor,

$$
i=\mathrm{V}_{\mathrm{r}} / \mathrm{R} 3
$$

where $i$ is the current through the wire in amps, $\mathrm{V}_{\mathrm{r}}$ is the voltage recorded from channel two and R3 is the large 250-watt rated 5-ohm wire-wound resister. Using Ohm's law, the resistance of the filament was calculated. A curve-fit for resistivity of platinum from the Electrical Resistivity Handbook [18] was used to develop an equation for temperature (Equation 4.3) of the test filament. 


$$
\begin{aligned}
& \mathrm{T}=40.25+22.1161 * \mathrm{~A} *(\mathrm{~V} /(\mathrm{L} * i))^{*} 100 * 100000000 \\
& +.14058 *\left(\mathrm{~A} *(\mathrm{~V} /(\mathrm{L} * i))^{*} 100 * 100000000\right)^{\wedge} 2
\end{aligned}
$$

where $\mathrm{T}$ is temperature in Kelvin, $\mathrm{A}$ is filament cross-sectional area, $\mathrm{V}$ is voltage across filament, $\mathrm{L}$ is length of wire and $i$ is current through filament.

The regulated power supply controlled the temperature of the test filament. By increasing the voltage across the filament, its temperature was adjusted to a desired temperature. Test filament temperature increments were chosen at 100 Kelvin, beginning at 400 Kelvin.

Each data set resulted in a raw data file containing 5000 data points acquired over a 5-second period, at a frequency of $1000 \mathrm{~Hz}$. The first data set involved a 76-micron filament. The first velocity setting was $0.0 \mathrm{~mm} \mathrm{Hg}(0.0$-in. water). At this dynamic pressure, eight raw data files were produced, one at each temperature setting from $400 \mathrm{~K}$ to $1100 \mathrm{~K}$ at $100 \mathrm{~K}$ increments. Then the dynamic pressure was set to $0.466 \mathrm{~mm} \mathrm{Hg}$ (0.25-in. water). Another eight files were produced from the eight temperature settings. Eight files were then produced from the temperature settings at $0.931 \mathrm{~mm} \mathrm{Hg}(0.5$-in. water), $1.397 \mathrm{~mm} \mathrm{Hg}$ (0.75-in. water) and $1.863 \mathrm{~mm} \mathrm{Hg}$ (1.0-in. water). The same procedure was then repeated for $63.5,51,38.5$ and 25.4 micron filaments for all five dynamic pressure settings over the appropriate temperature ranges.

All of these data considered only axial flow. The test filament was at a zero degree angle with respect to the vertical flow direction. The next aspect of characterizing the heat transfer from the thin filament was the consideration of crossflow angles. Data files were produced for each diameter wire at each of the five dynamic pressure settings across 
the temperature range, which differed for each wire diameter, for three cross flow angles, $2.5^{\circ}, 5^{\circ}$ and $7^{\circ}$ with respect to the vertical.

\subsection{Data Reduction}

Two BASIC data reduction programs were written to facilitate analysis of the data (Appendices $\mathrm{C}$ and $\mathrm{D}$ ). The first program performed a statistical analysis on the raw data file. The raw data file was read and then the program calculated the average voltage drop across the wire, average current through the wire and, using these values, average temperature of the wire. This program also calculated standard deviations for each of these quantities.

The second BASIC program was used to produce time-dependent data from the raw data files. This program related the 5-second period to the raw data. These data could be used to observe fluctuations in the current in the filament, the voltage across the filament and the temperature of the filament as a function of time over the data acquisition period.

After the data were reduced they could be imported into a spreadsheet program. The spreadsheet formed from importing the statistical data was used to calculate many quantities vital to characterizing the heat transfer from the wire. Power dissipated by the filament was calculated using Equation 4.4.

$$
\mathrm{P}=\mathrm{V} i
$$

where $\mathrm{P}$ is the power dissipated by the wire, $\mathrm{V}$ is the voltage across the wire and $i$ is the current through the wire.

The emissivity of the platinum wire as a function of temperature is given in Equation 4.5 from the Handbook of Chemistry and Physics [19]. 


$$
\mathrm{e}=-0.235(\mathrm{~T} / 1000) \wedge 2+0.1538(\mathrm{~T} / 1000)-0.0072
$$

where $\mathrm{e}$ is the emissivity and $\mathrm{T}$ is the absolute temperature in Kelvin. From the emissivity, the radiation heat transfer can be determined (Equation 4.6)

$$
\mathrm{qrad}=\mathrm{e}^{*} 5.669^{*} \mathrm{~A} *\left((\mathrm{~T} / 100)^{4}-\left(\mathrm{T}_{\mathrm{ret}}+0.222 * \mathrm{~L} / 100\right)^{4}\right)
$$

where qrad is the radiation heat transfer, e is the emissivity, A is the surface area of the filament, $T$ is the temperature of the filament, $T_{\text {ref }}$ is the temperature of the ambient air and $\mathrm{L}$ is the length of the filament. The radiation heat transfer can be used to determine the convective heat transfer (Equation 4.7).

$$
\text { qconv=P-qrad }
$$

where qconv is the convective heat transfer, $\mathrm{P}$ is the power of active length of test filament and qrad is the radiation heat transfer. The convective heat transfer can be used to compute the experimental heat transfer coefficient (Equation 4.8).

$$
\mathrm{h}=\mathrm{q} \operatorname{conv} /\left(\mathrm{A} *\left(\mathrm{~T}-\left(\mathrm{T}_{\text {ref }}+0.222 * \mathrm{~L}\right)\right)\right)
$$

where $\mathrm{h}$ is the experimental heat transfer coefficient, $\mathrm{A}$ is the surface area of the test filament, $\mathrm{T}$ is the temperature of the test filament, $\mathrm{T}_{\text {ref }}$ is the temperature of the ambient air and $\mathrm{L}$ is the active length of the test filament.

Once all these quantities had been determined, plots were generated that allowed trends to be easily ascertained. These plots were constructed to compare heat transfer as a function of temperature, time, filament diameter or crossflow angle. These plots were a significant tool in ascertaining the most important quantities affecting the heat transfer from the electrically heated filament. Once the data were plotted the new empirical model could be developed. These data were also compared to data taken in an earlier study by Morris, Loth and Bond [1]. 


\subsection{Characterization of Vibration}

Before any data were taken including the effects of filament vibration, verifications were made to determine the accuracy of the frequency and amplitudes of a vibrating wire determined by means of Laser Doppler anemometry compared to theoretical frequency and amplitude of a vibrating wire (Appendix E). Following the determination of the accuracy of the LDA measurements, data were recorded.

A test filament was mounted in the cylindrical test chamber. Data were collected for each wire exactly as done previously, but while data were taken the wire was in the measuring volume of the laser Doppler anemometry system. Backscattered light from any vibration occurring during data acquisition was scattered from the vibrating filament and was recorded in the storage mode of the oscilloscope. Tension in the filament was varied by changing the tensioning weight applied. The frequency and amplitude of any vibration were determined by the waveform on the oscilloscope, recorded and plotted. 


\section{Chapter 5}

\subsection{Results and Discussion}

To characterize the heat transfer from an electrically heated thin filament, many data were acquired, analyzed and plotted. From these plots, relationships between different operating parameters could be determined. For the convenience of the reader, all the plots referred to in this chapter and following chapters appear at the end of the appropriate chapter.

As discussed in Chapter 3, the following results are an average of 500 data points for each of the 800 test conditions. Some fluctuation occurs in the 5000 data points. Figure 5.1 illustrates the actual fluctuation occurring in voltage as it is being recorded.

\subsection{Heat Transfer Coefficient as a Function of Temperature}

The primary objective of this research was to characterize the heat transfer from an electrically heated thin filament. This data could then be used to model a forming filament as it is cooled from solidification temperature to near room temperature. This can be accomplished by determining the heat transfer coefficient as a function of various operating parameters and using these data to model the cooling rate of the filament. To determine the effect of various operating parameters on the heat transfer coefficient, many experimental data were acquired using a thin electrically heated filament. Data acquired included the freestream flow conditions, as well as the voltage drop across and current through the filament. By entering the data into a spreadsheet (Appendix F), the heat transfer coefficient could easily be obtained and relationships between parameters, 
such as filament temperature, filament diameter, crossflow angle and freestream velocity could be examined.

Figures 5.1 through 5.20 represent the heat transfer coefficient obtained by a statistical average of the 5000 data points recorded for each filament temperature, filament diameter, flow velocity and crossflow angle. Figures 5.2 through 5.6 show the heat transfer coefficient vs. temperature difference between the test filament and the freestream for five filament diameters, $76,63.5,51,38.5$ and 25.4 microns respectively. Each Figure illustrates one filament diameter at five different dynamic pressure readings at zero crossflow angle. As can be observed on the graphs, the heat transfer coefficient increases with increasing temperature and increasing flow velocity.

Figures 5.7 through 5.11 illustrate the relationship between the heat transfer coefficient and temperature for the five different filament diameters at a crossflow angle of $2.5^{\circ}$. Figures 5.12 through 5.16 show heat transfer coefficient versus temperature at a $5^{\circ}$ crossflow angle and Figures 5.17 through 5.21 illustrate heat transfer coefficient vs. temperature for a crossflow angle of $7^{\circ}$.

Trends are constant throughout Figures 5.2 through 5.21. The heat transfer coefficient tends to increase with increasing temperature and flow velocity. Heat transfer coefficients also tend to increase with decreasing filament diameter and, therefore, reach their highest values at the smallest diameters, highest velocities, and the largest angles. Independent of filament diameter, heat transfer coefficients remain fairly constant for no flow data as expected. The change in heat transfer coefficient between no flow data and data taken when the electrically heated filament is subjected to axial flow increases with decreasing filament diameter. 
Further examination of the relationship between heat transfer coefficient and filament temperature reveals an apparent linear behavior for all filament diameters, angles, and flow velocities. To substantiate this hypothesis, a linear least squares fit was performed on the data and trendlines were plotted through the experimental points. In each case the trendlines appear to fit the experimental data.

\subsection{Heat Transfer Coefficient as a Function of Filament Diameter}

In an attempt to better understand the importance of filament diameter on the heat transfer coefficient, data were plotted as a function of this parameter. Figures 5.22 through 5.26 show the heat transfer coefficients plotted versus filament diameters for constant temperature families. The heat transfer coefficient can be seen to decrease considerably with increasing filament diameter.

Plotting heat transfer coefficient versus filament diameter (Figures 5.22 through 5.26) gives an indication of the relationship between heat transfer coefficient and filament diameter. Based on data taken for two filament diameters in a previous study by Morris, Loth and Bond [1] it was speculated that the heat transfer coefficient was inversely proportional to the filament diameter; however, Figures 5.22 through 5.26 indicate a more complex relationship. These data show that the relationship between heat transfer and filament diameter is not simply an inversely proportional relationship but tends to be of a higher order. With the exception of the 51 micron data, the heat transfer coefficients appear to decrease following a second order relationship with increasing filament diameter. 


\subsection{Heat Transfer Coefficient as a Function of Crossflow Angle}

Figures 5.27 through 5.31 illustrate the relationship between heat transfer coefficient and crossflow angle. The heat transfer coefficients at the maximum filament temperature tested are plotted versus crossflow angle in families of five dynamic pressures, 0.0, 0.466, 0.931, 1.397, and $1.863 \mathrm{~mm} \mathrm{Hg}$ (velocities ranging from 0.0 to $20.1 \mathrm{~m} / \mathrm{s}$ ). Observation of these graphs indicates a nonlinear relationship between heat transfer coefficient and crossflow angle. The heat transfer coefficient tends to increase with increasing crossflow angle, with the exception of zero flow velocity case. As expected, with zero flow velocity or no forced convection, there is little effect of filament angle. The effect of crossflow angle increases with decreasing filament diameter. This is illustrated by observing the amount of change in the heat transfer coefficients as a function of filament

diameter. In several instances the amount of increase in heat transfer coefficient is greatest between the angle of $2.5^{\circ}$ and $5^{\circ}$. The heat transfer coefficient can also be observed in Figures 5.27 through 5.31 to increase with increasing freestream velocity, as seen in previous figures.

\subsection{Comparison of Phase I and Phase II Data}

A previous study by Morris, Loth and Bond [1] conducted many of the same tests on platinum filaments of 76 microns and 51 microns. This project was used as the basis for the current research; as such it will be referred to a Phase I. The current research is referred to a Phase II.

In Phase I data were collected over a smaller range of angles, filament diameters and dynamic pressures. Data were collected for both phases for 76 micron and 51 micron 
filaments, at dynamic pressures of $0 \mathrm{~mm} \mathrm{Hg}$ and $0.931 \mathrm{~mm} \mathrm{Hg}$, and at angles of $0^{\circ}$ and $7^{\circ}$. Repeatability of data can be determined by comparing Phase I and Phase II experimental data under the same operating parameters. Although the same operating parameters were observed in Phase I and Phase II, some difference in data in the two Phases is to be expected. Significant improvements were made in the filament tensioning system and the data acquisition system from Phase I to Phase II. Another Consideration is general data repeatability. Operating conditions varied greatly from day to day. Small atmospheric changes may have significant effects on the data. Uncertainties in variables involved in data acquisition make data difficult to repeat exactly. Data taken under the same operating conditions on two different days exhibited up to a $15 \%$ difference due to errors in achieving the same operating parameters, errors from limited accuracy of measuring devices and variable atmospheric conditions. Figure 5.32 illustrates the difference in data taken on different says. Figures 5.33 and 5.34 illustrate Phase I and Phase II data for a 76 micron filament at theta $=0^{\circ}$, zero crossflow. The trends between Phase I and Phase II, Figures 5.33 through 5.35, data are similar for both filaments at both dynamic pressures and both crossflow angles. Most of the figures illustrate less than a 10 percent difference in data from the two phases. The greatest difference in heat transfer coefficients from one phase to another occurs at 76 microns, $\mathrm{q}=0.0 \mathrm{~mm} \mathrm{Hg}$ and theta $=0^{\circ}$ (Figure 5.33). The greatest difference is only approximately a 25 percent difference.

It is interesting to note that the sudden spike in heat transfer coefficient for a 51 micron platinum filament at $7^{\circ}$ (Figures 5.39 and 5.40). This may indicate inaccuracies in Phase I data at low temperatures for high angles at some of the filament diameters. 
This sudden spike is not present in phase II data. Advances in data acquisition systems from Phase I to Phase II may be responsible for eliminating the spikes that can be seen in Phase I data.

\subsection{Vibrational Heat Transfer Effects}

Laser Doppler anemometry measurements taken for an electrically heated platinum filament can help characterize the effects of filament vibration on heat transfer coefficient. A 76 micron filament was chosen to perform vibrational testing because it is sturdier than the smaller filaments and less likely to fail.

Once the filament was heated and subjected to axial flow, the frequency of the vibrating filament was easily determined by observing the wave produced by the backscattering of laser light gathered by the photomultiplier tube. The amplitude was not possible to accurately observe on the oscilloscope primarily due to the presence of many modes and frequencies of vibrations in the filament. Additional difficulties were presented in part by the very small nature of the amplitude and the limitations of the oscilloscope; therefore, it was determined that the most accurate amplitude measurements could be determined by projecting the vibrating filament onto a screen and directly recording the amplitude.

Figure 5.41 shows the heat transfer coefficient versus the tensioning weight for two different temperatures at a dynamic pressure of $1.397 \mathrm{~mm} \mathrm{Hg}$. The frequency and amplitude of the vibrating filament are also recorded on this figure. From these data it can be seen that the amplitude increases and frequency decreases with decreasing tensioning weights. At $1000 \mathrm{~K}$, the amplitude decreased from approximately 18 filament 
diameters to approximately 3 filament diameters over the tested range. The heat transfer coefficient values asymptotically approach the steady state values taken using a $4.77 \mathrm{~g}$ tensioning weight (not shown on this plot). Figures 5.42 and 5.43 illustrate heat transfer coefficient as a function of tensioning weight for the same 76 micron platinum filament with dynamic pressures of 1.397 and $0.466 \mathrm{~mm} \mathrm{Hg}$ respectively. On each figure frequency can be seen to increase with increasing tensioning weight. The heat transfer coefficient also appears to decrease with increasing tensioning weight. As the tensioning weight decreases amplitude increases and frequency decreases. The increasing amplitude causes the wire to experience some crossflow as well as the axial flow. The crossflow component increases the heat transfer coefficient. 


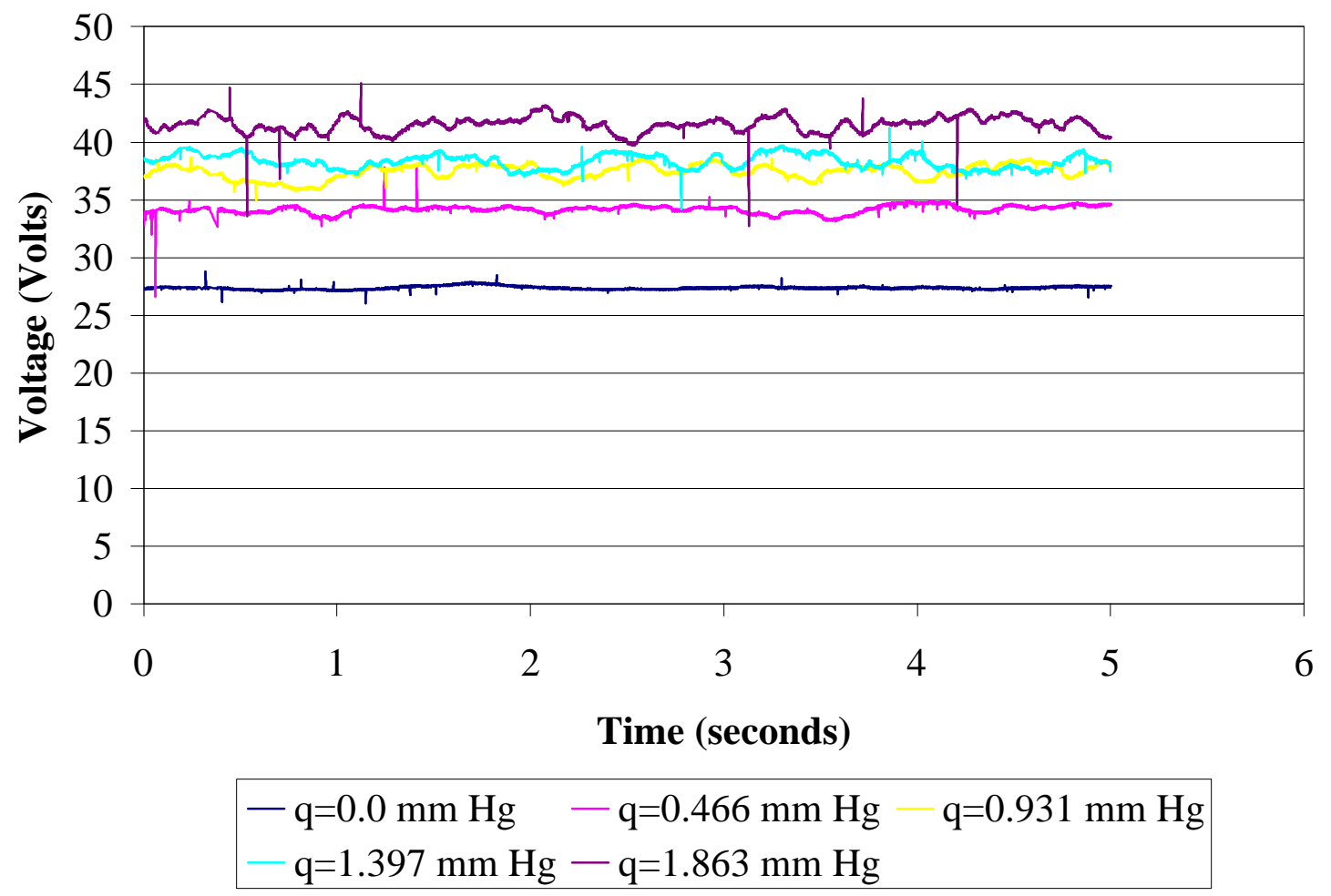

Figure 5.1: Test Filament Voltage vs. Time for a 51 Micron Platinum Filament with 30 $\mathrm{cm}$. Length and Theta $=0^{\circ}$ 


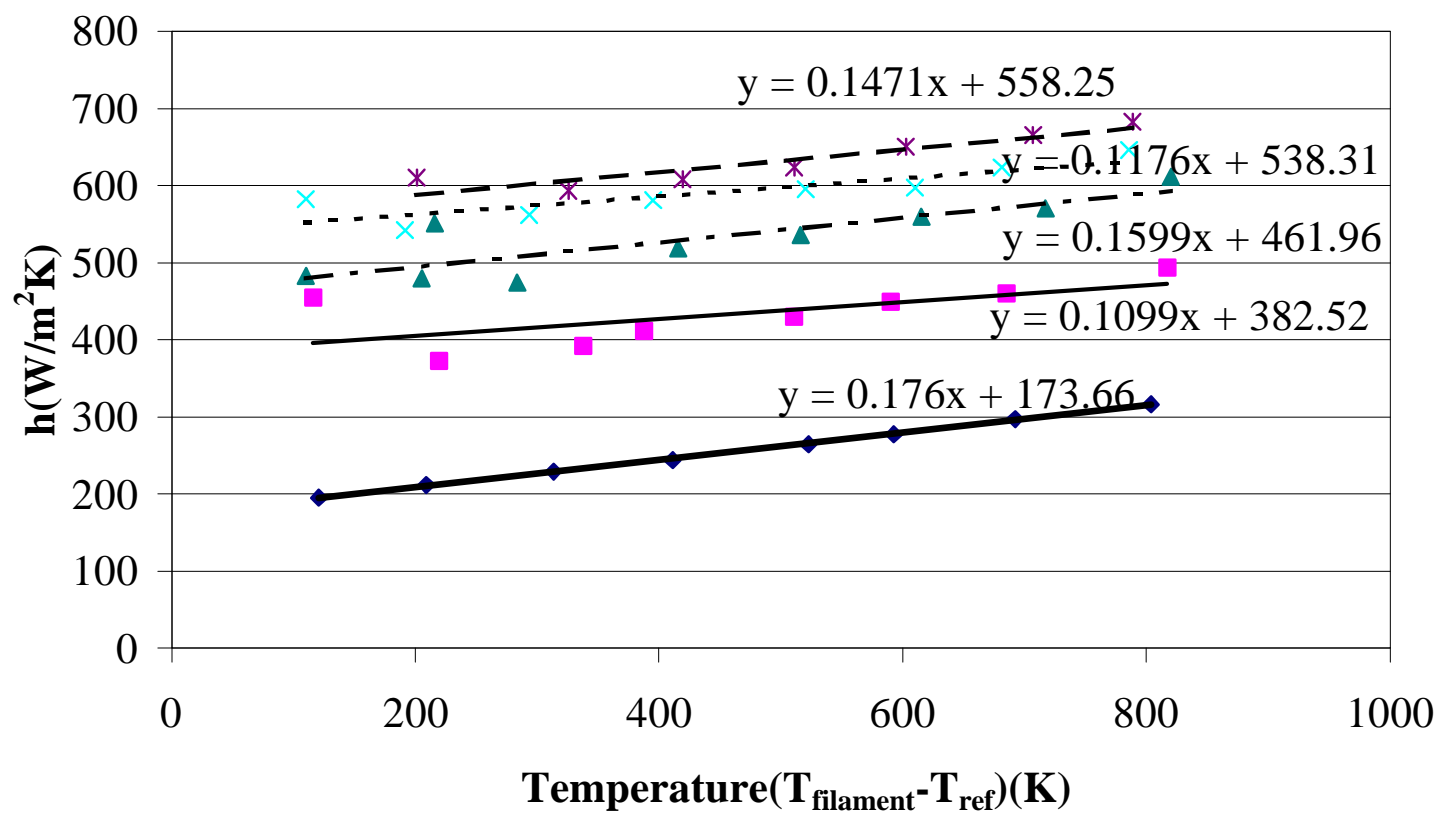

\begin{tabular}{|c|c|c|}
\hline - $\mathrm{q}=0.0 \mathrm{~mm} \mathrm{Hg}$ & $\mathrm{q}=0.466 \mathrm{~mm} \mathrm{Hg}$ & $\Delta \mathrm{q}=0.931 \mathrm{~mm} \mathrm{Hg}$ \\
\hline$\times \quad \mathrm{q}=1.397 \mathrm{~mm} \mathrm{Hg}$ & * $\mathrm{q}=1.863 \mathrm{~mm} \mathrm{Hg}$ & - - Linear $(\mathrm{q}=1.863 \mathrm{~mm} \mathrm{Hg})$ \\
\hline - - - Linear $(\mathrm{q}=1.397 \mathrm{~mm} \mathrm{Hg})$ & - - Linear $(\mathrm{q}=0.931 \mathrm{~mm} \mathrm{Hg})$ & Linear $(\mathrm{q}=0.466 \mathrm{~mm} \mathrm{Hg})$ \\
\hline
\end{tabular}

Figure 5.2: Heat Transfer Coefficient vs. Temperature Difference of a 63.5 Micron Platinum Filament with $30 \mathrm{~cm}$. Length and Theta $=0^{\circ}$ 


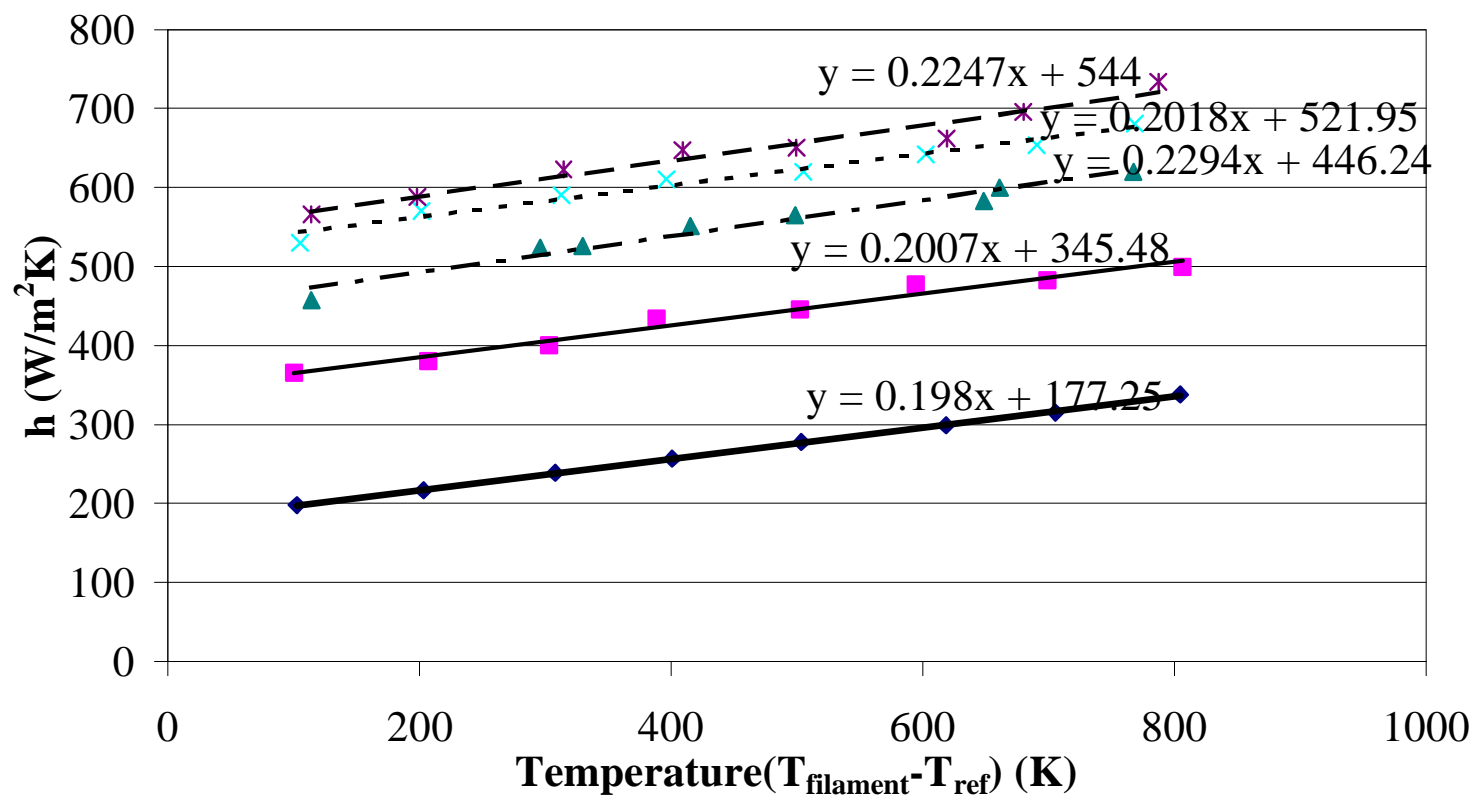

- $\mathrm{q}=0.0 \mathrm{~mm} \mathrm{Hg}$

- $\mathrm{q}=.466 \mathrm{~mm} \mathrm{Hg}$

$\triangle \mathrm{q}=.931 \mathrm{~mm} \mathrm{Hg}$

$\mathrm{q}=1.397 \mathrm{~mm} \mathrm{Hg}$

* $\mathrm{q}=1.863 \mathrm{~mm} \mathrm{Hg}$

- - Linear $(\mathrm{q}=1.863 \mathrm{~mm} \mathrm{Hg})$

- - Linear (q=1.397 mm Hg)

- - Linear (q=.931 $\mathrm{mm} \mathrm{Hg})$

- Linear $(\mathrm{q}=.466 \mathrm{~mm} \mathrm{Hg})$

Linear $(\mathrm{q}=0.0 \mathrm{~mm} \mathrm{Hg})$

Figure 5.3: Heat Transfer Coefficient vs. Temperature Difference of a 63.5 Micron Platinum Filament with $30 \mathrm{~cm}$. Length and Theta $=0^{\circ}$ 


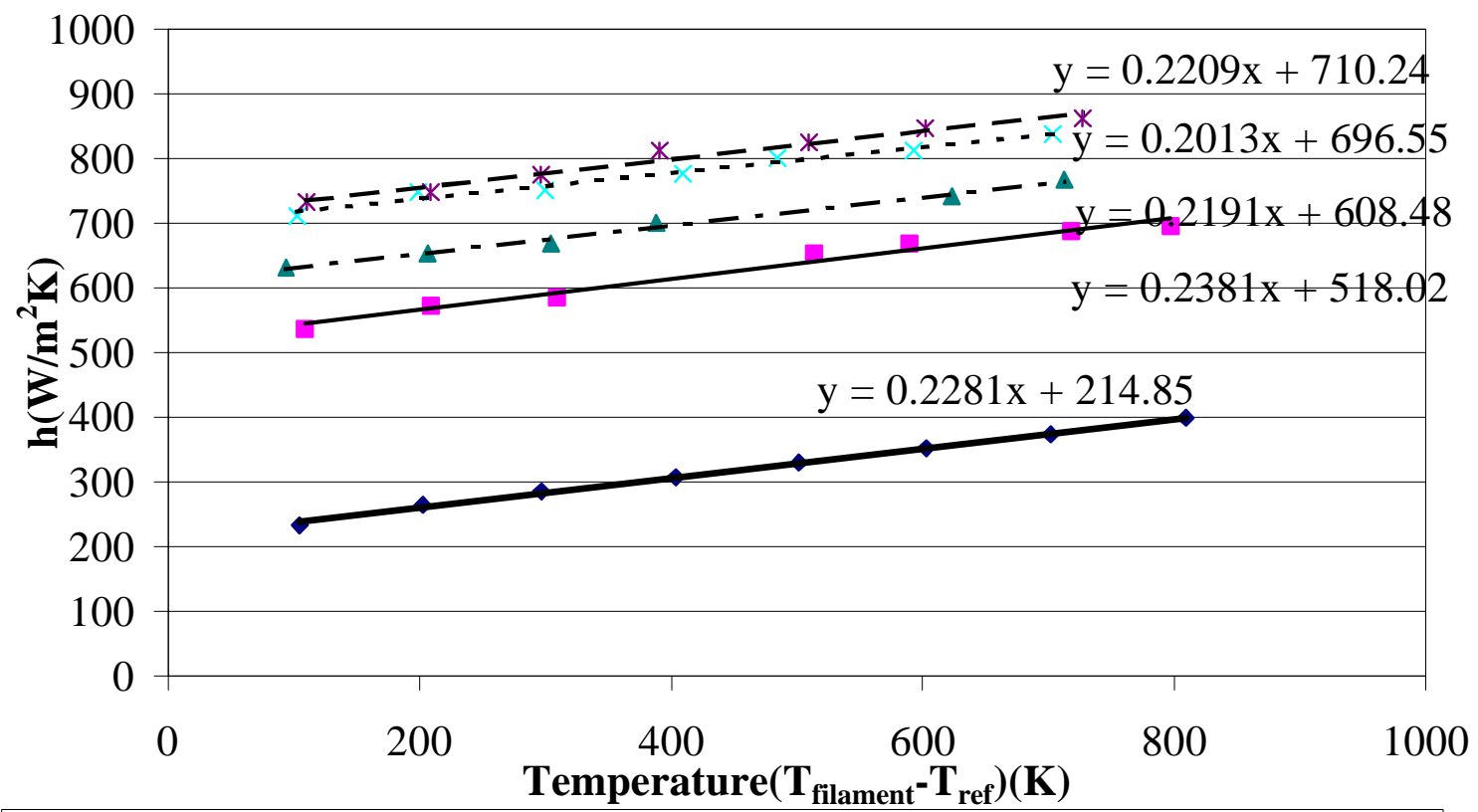

- $\mathrm{q}=0.0 \mathrm{~mm} \mathrm{Hg}$

- $\mathrm{q}=0.466 \mathrm{~mm} \mathrm{Hg} \quad \Delta \mathrm{q}=0.931 \mathrm{~mm} \mathrm{Hg}$

$\mathrm{q}=1.397 \mathrm{~mm} \mathrm{Hg}$

* $\mathrm{q}=1.863 \mathrm{~mm} \mathrm{Hg}$

- - Linear (q=1.863 $\mathrm{mm} \mathrm{Hg})$

- - Linear $(\mathrm{q}=1.397 \mathrm{~mm} \mathrm{Hg})$

- - Linear $(\mathrm{q}=0.931 \mathrm{~mm} \mathrm{Hg})$

- Linear $(\mathrm{q}=0.466 \mathrm{~mm} \mathrm{Hg})$

Linear $(\mathrm{q}=0.0 \mathrm{~mm} \mathrm{Hg})$

Figure 5.4: Heat Transfer Coefficient vs. Temperature Difference of a 51 Micron Platinum Filament with $30 \mathrm{~cm}$. Length and Theta $=0^{\circ}$ 


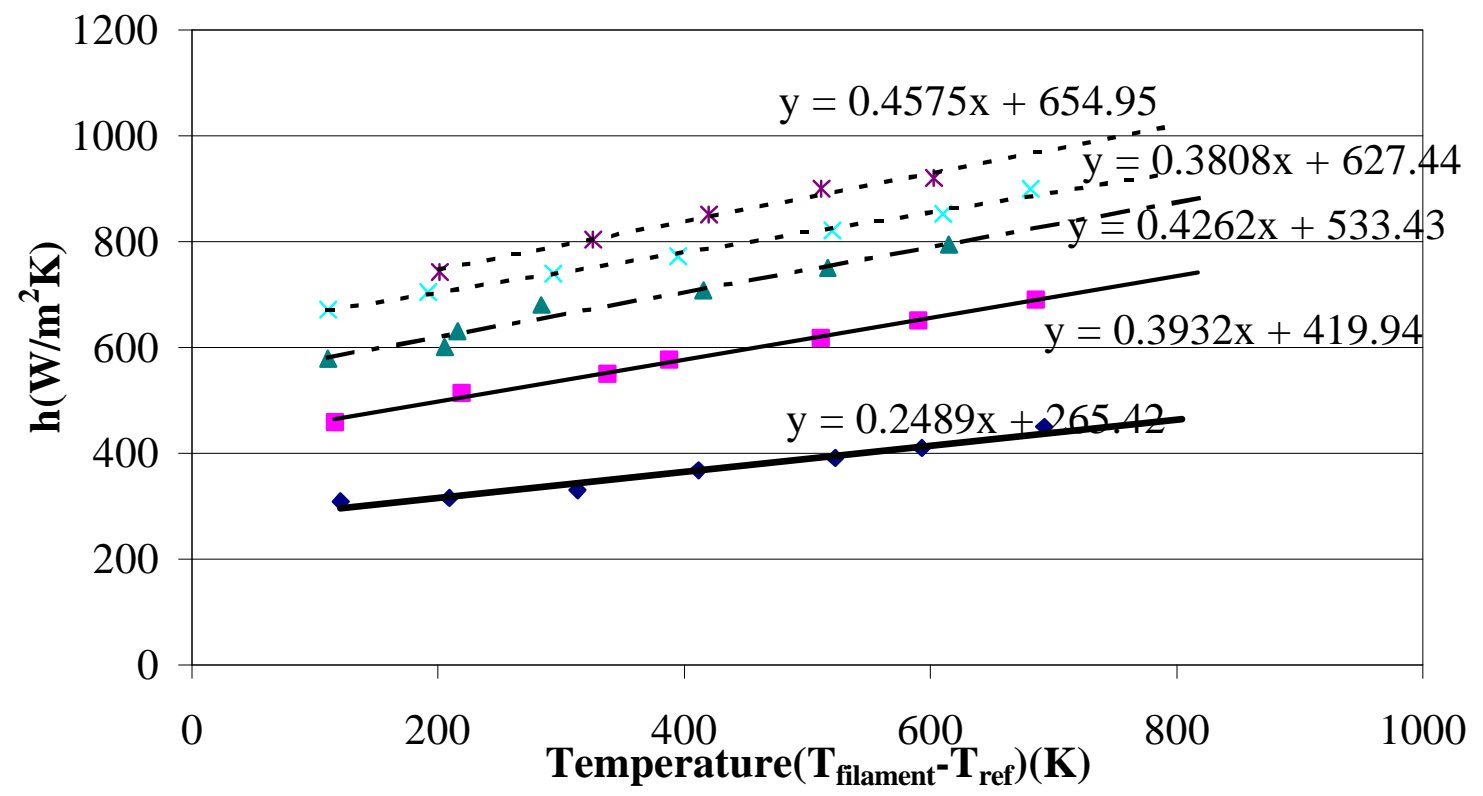

- $\mathrm{q}=0.0 \mathrm{~mm} \mathrm{Hg}$

$\times \mathrm{q}=1.397 \mathrm{~mm} \mathrm{Hg}$

- $\mathrm{q}=0.466 \mathrm{~mm} \mathrm{Hg}$

* $\mathrm{q}=1.863 \mathrm{~mm} \mathrm{Hg}$

$\triangle \mathrm{q}=0.931 \mathrm{~mm} \mathrm{Hg}$

- - Linear (q=1.397 $\mathrm{mm} \mathrm{Hg}) \quad$ - Linear $(\mathrm{q}=0.931 \mathrm{~mm} \mathrm{Hg})$

- Linear $(\mathrm{q}=0.0 \mathrm{~mm} \mathrm{Hg})$

Figure 5.5: Heat Transfer Coefficient vs. Temperature difference of a 38.5 Micron Platinum Filament with $30 \mathrm{~cm}$. Length and Theta $=0^{\circ}$ 


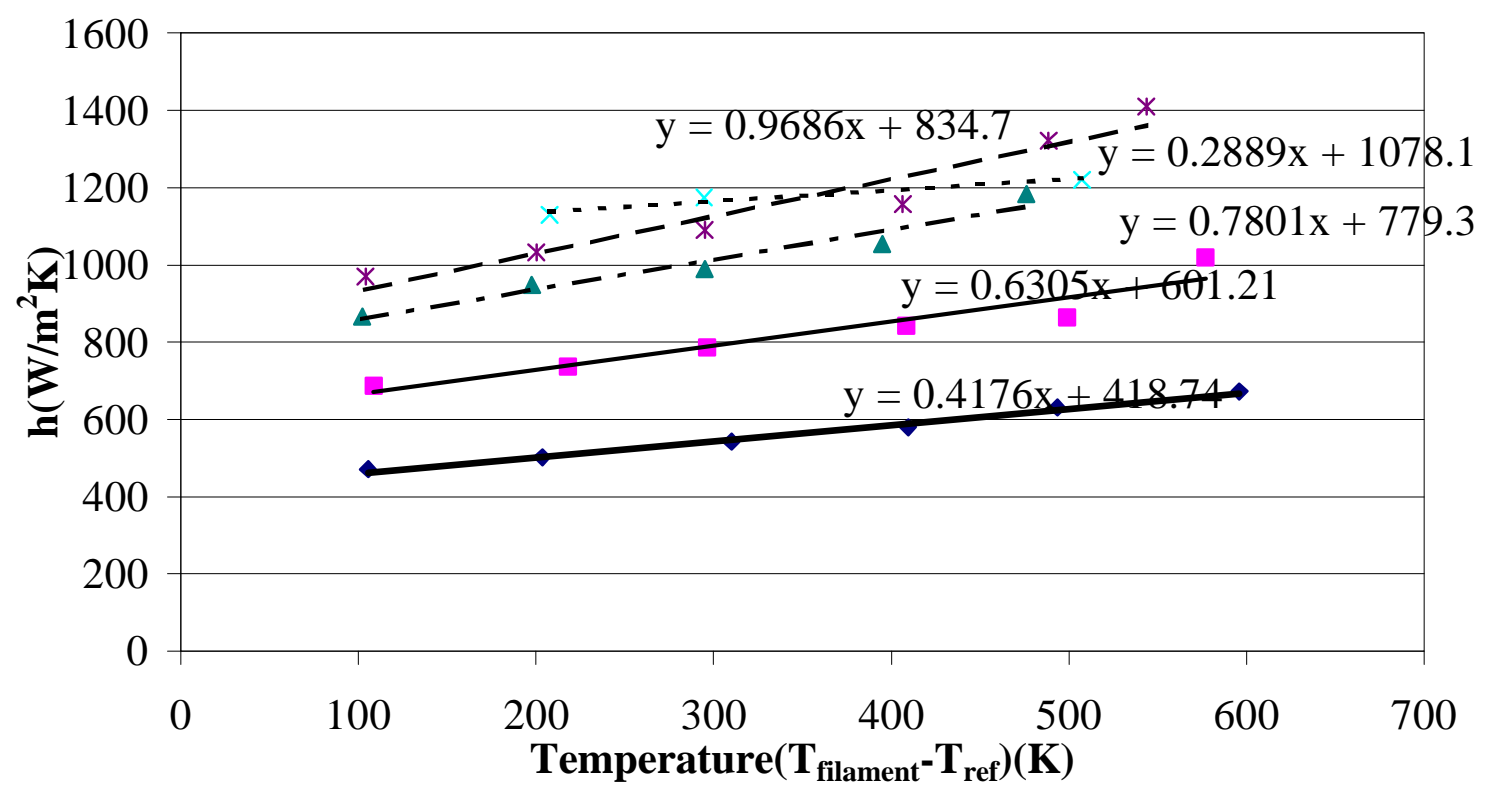

- $\mathrm{q}=0.0 \mathrm{~mm} \mathrm{Hg}$ - $\mathrm{q}=0.466 \mathrm{~mm} \mathrm{Hg}$ $\Delta \mathrm{q}=0.931 \mathrm{~mm} \mathrm{Hg}$

$\times \quad \mathrm{q}=1.397 \mathrm{~mm} \mathrm{Hg}$

* $\mathrm{q}=1.863 \mathrm{~mm} \mathrm{Hg}$ - - Linear ( $\mathrm{q}=1.863 \mathrm{~mm} \mathrm{Hg}$ )

- - Linear (q=1.397 mm Hg)

- - Linear (q=0.931 $\mathrm{mm} \mathrm{Hg}$ )

Linear $(\mathrm{q}=0.0 \mathrm{~mm} \mathrm{Hg})$

Figure 5.6: Heat Transfer Coefficient vs. Temperature Difference of a 25.4 Micron Platinum Filament with $30 \mathrm{~cm}$. Length and Theat $=0^{\circ}$ 


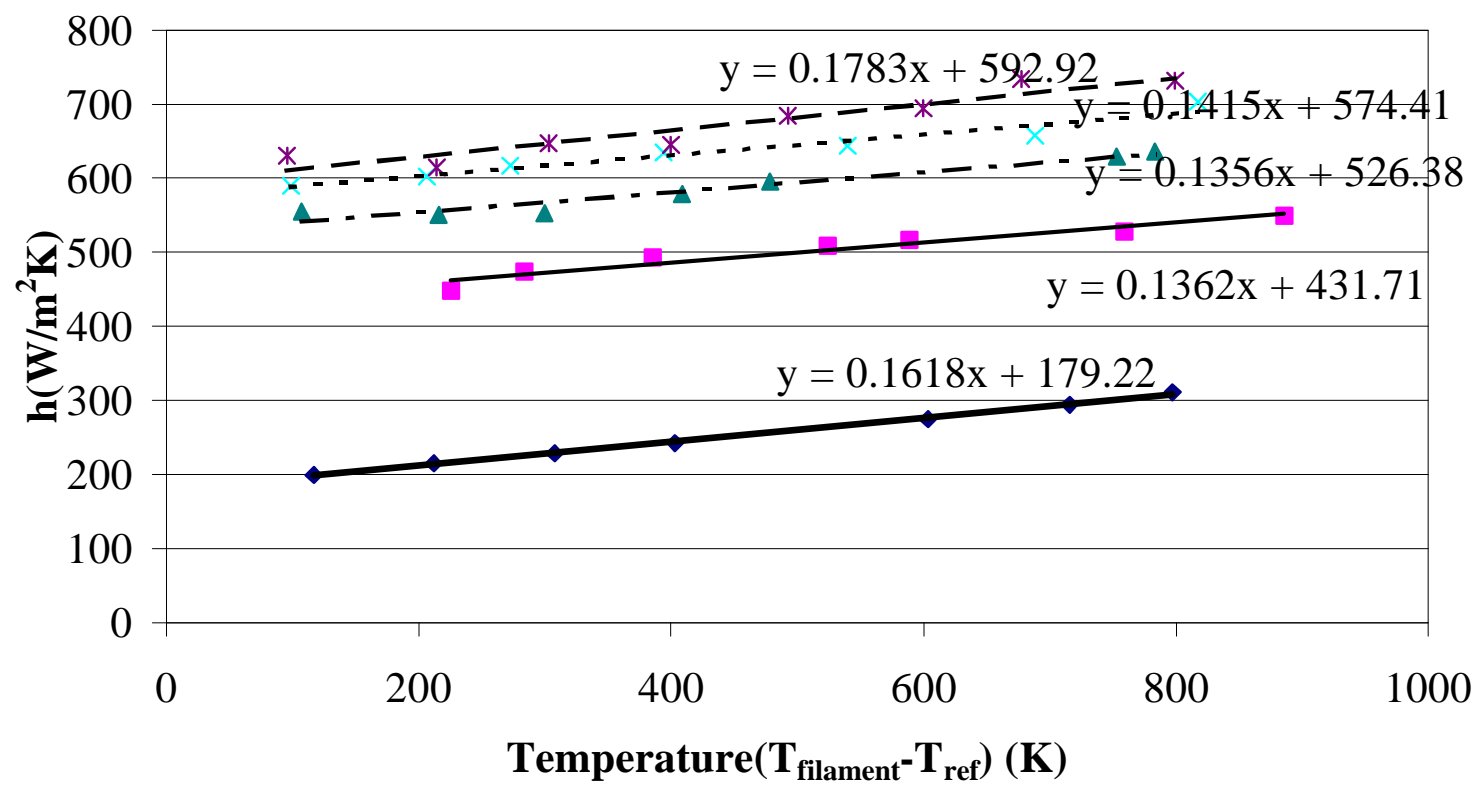

- $\mathrm{q}=0.0 \mathrm{~mm} \mathrm{Hg}$

$\times \mathrm{q}=1.397 \mathrm{~mm} \mathrm{Hg}$

- - Linear $(\mathrm{q}=1.397 \mathrm{~mm} \mathrm{Hg})$

- Linear $(\mathrm{q}=0.0 \mathrm{~mm} \mathrm{Hg})$
- $\mathrm{q}=0.466 \mathrm{~mm} \mathrm{Hg}$

* $\mathrm{q}=1.863 \mathrm{~mm} \mathrm{Hg}$

- - Linear (q=0.931 $\mathrm{mm} \mathrm{Hg})$

$\Delta \mathrm{q}=0.931 \mathrm{~mm} \mathrm{Hg}$

- - Linear (q=1.863 $\mathrm{mm} \mathrm{Hg})$

- Linear (q=0.466 mm Hg)

Figure 5.7: Heat Transfer Coefficient vs. Temperature Difference of a 76 Micron Platinum Filament with $30 \mathrm{~cm}$. Length and Theta $=2.5^{\circ}$ 


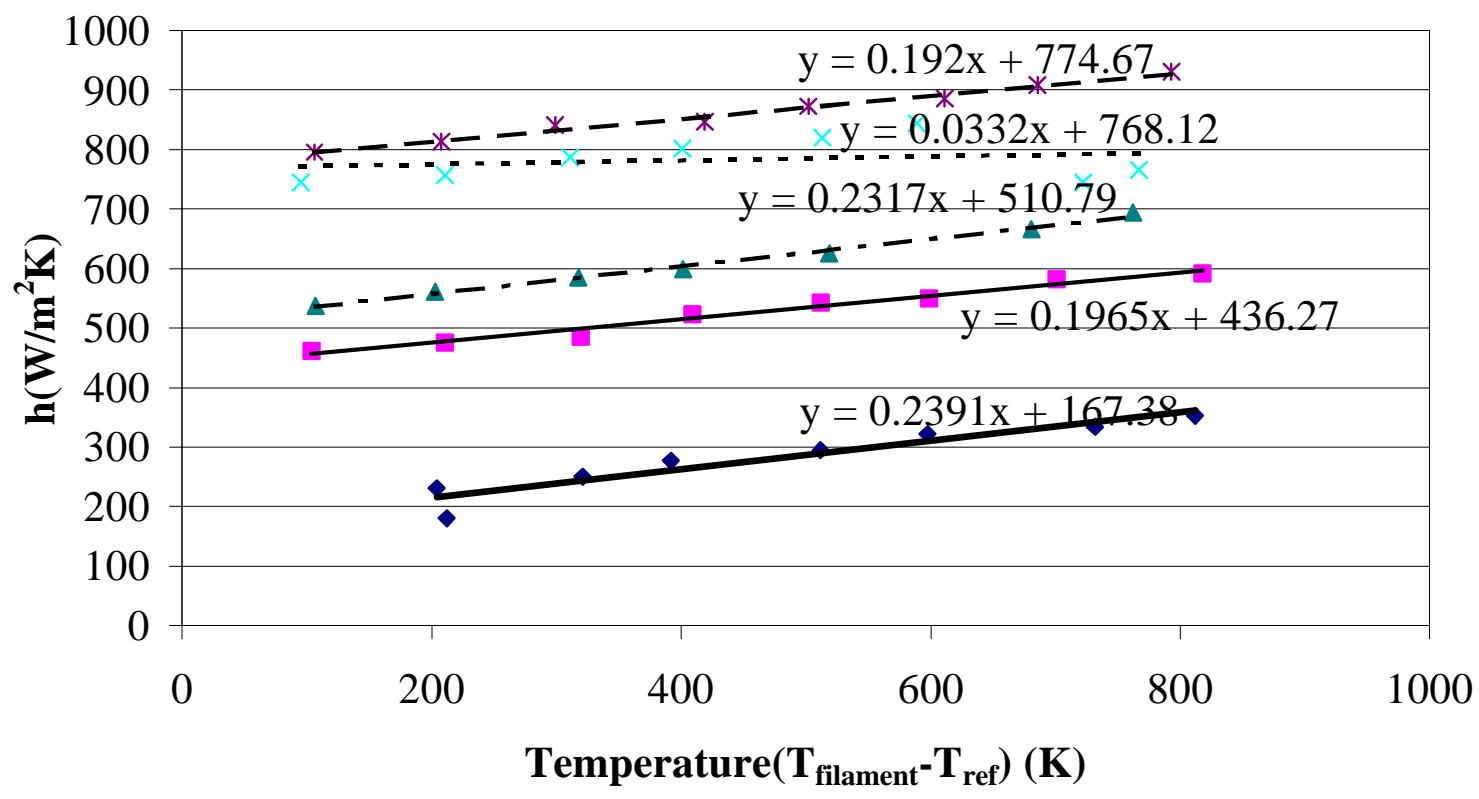

- $\mathrm{q}=0.0 \mathrm{~mm} \mathrm{Hg}$

$\times \mathrm{q}=1.397 \mathrm{~mm} \mathrm{Hg}$

- - - Linear (q=1.397 $\mathrm{mm} \mathrm{Hg})$

Linear $(\mathrm{q}=0.0 \mathrm{~mm} \mathrm{Hg})$

\section{- $\mathrm{q}=0.466 \mathrm{~mm} \mathrm{Hg}$}

* $\mathrm{q}=1.863 \mathrm{~mm} \mathrm{Hg}$

- - Linear (q=0.931 mm Hg)

$\Delta \mathrm{q}=0.931 \mathrm{~mm} \mathrm{Hg}$

- - Linear (q=1.863 $\mathrm{mm} \mathrm{Hg})$

- Linear (q=0.466 mm Hg)

Figure 5.8: Heat Transfer Coefficient vs. Temperature Difference of a 63.5 Micron Platinum Filament with $30 \mathrm{~cm}$. Length and Theta $=2.5^{\circ}$ 


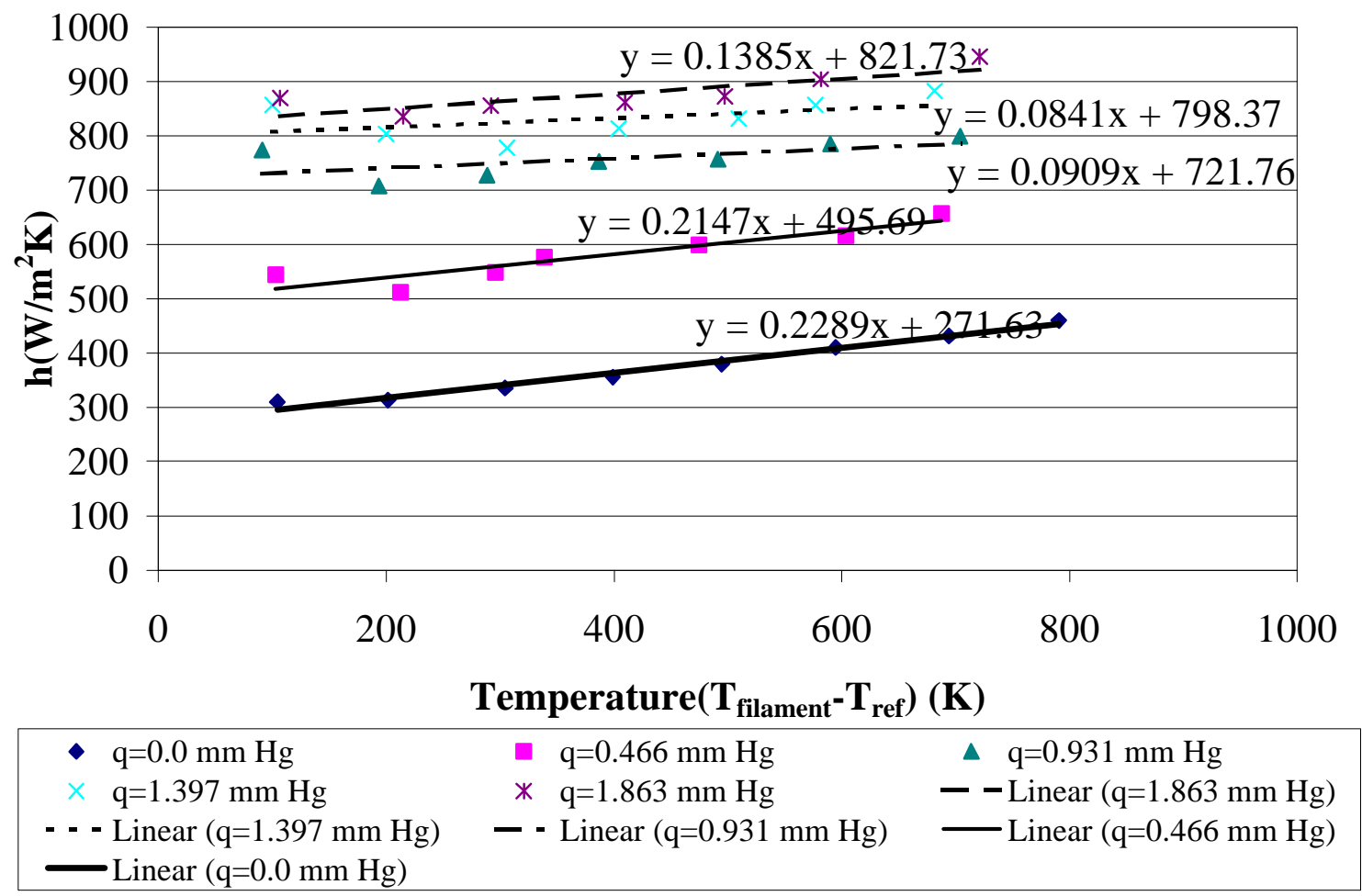

Figure 5.9: Heat Transfer Coefficient vs. Temperature Difference of a 51 Micron Platinum Filament with $30 \mathrm{~cm}$. Length and Theta $=2.5^{\circ}$ 


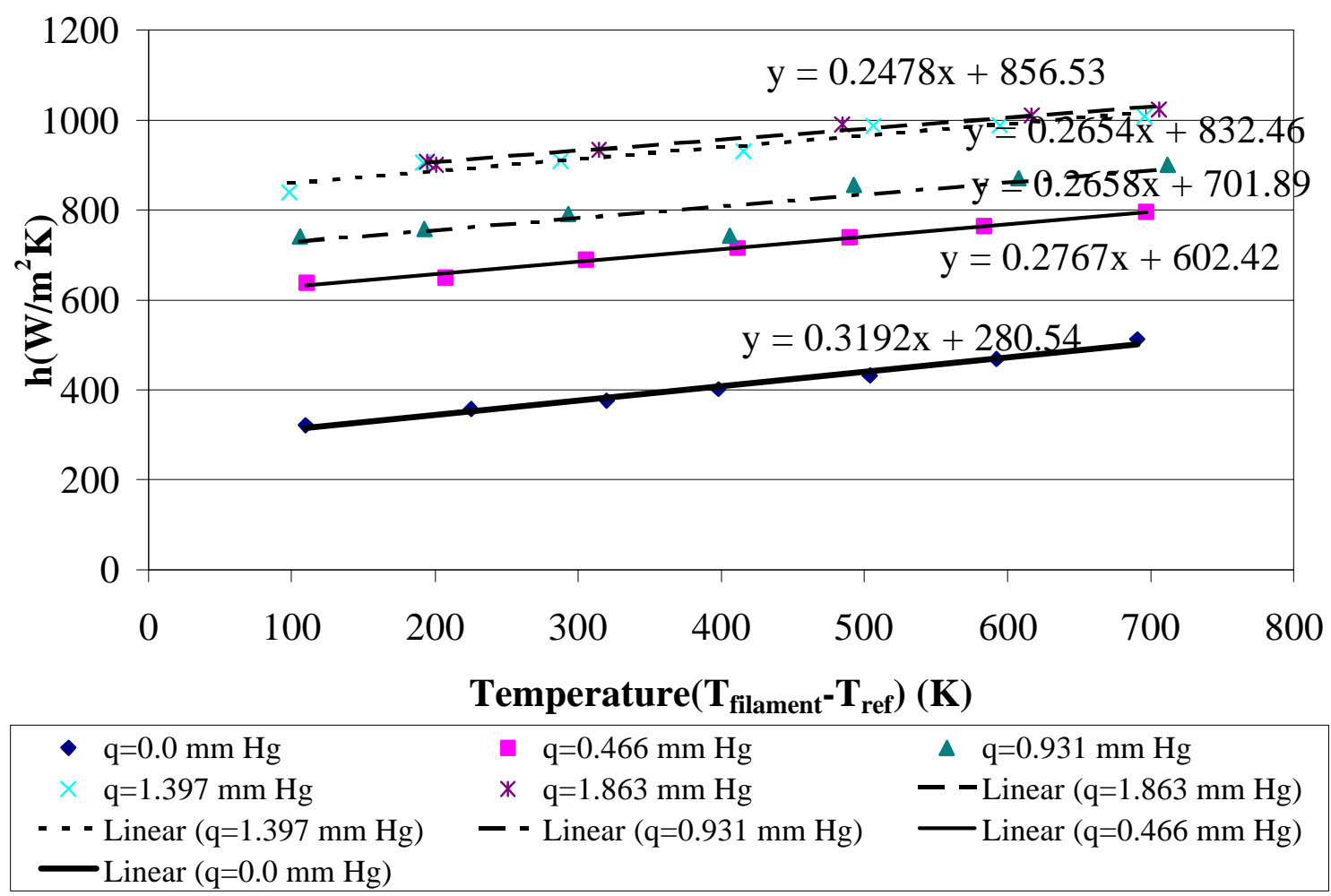

Figure 5.10: Heat Transfer Coefficient vs. Temperature Difference of a 38.5 Micron Platinum Filament with $30 \mathrm{~cm}$. Length and Theta $=2.5^{\circ}$ 


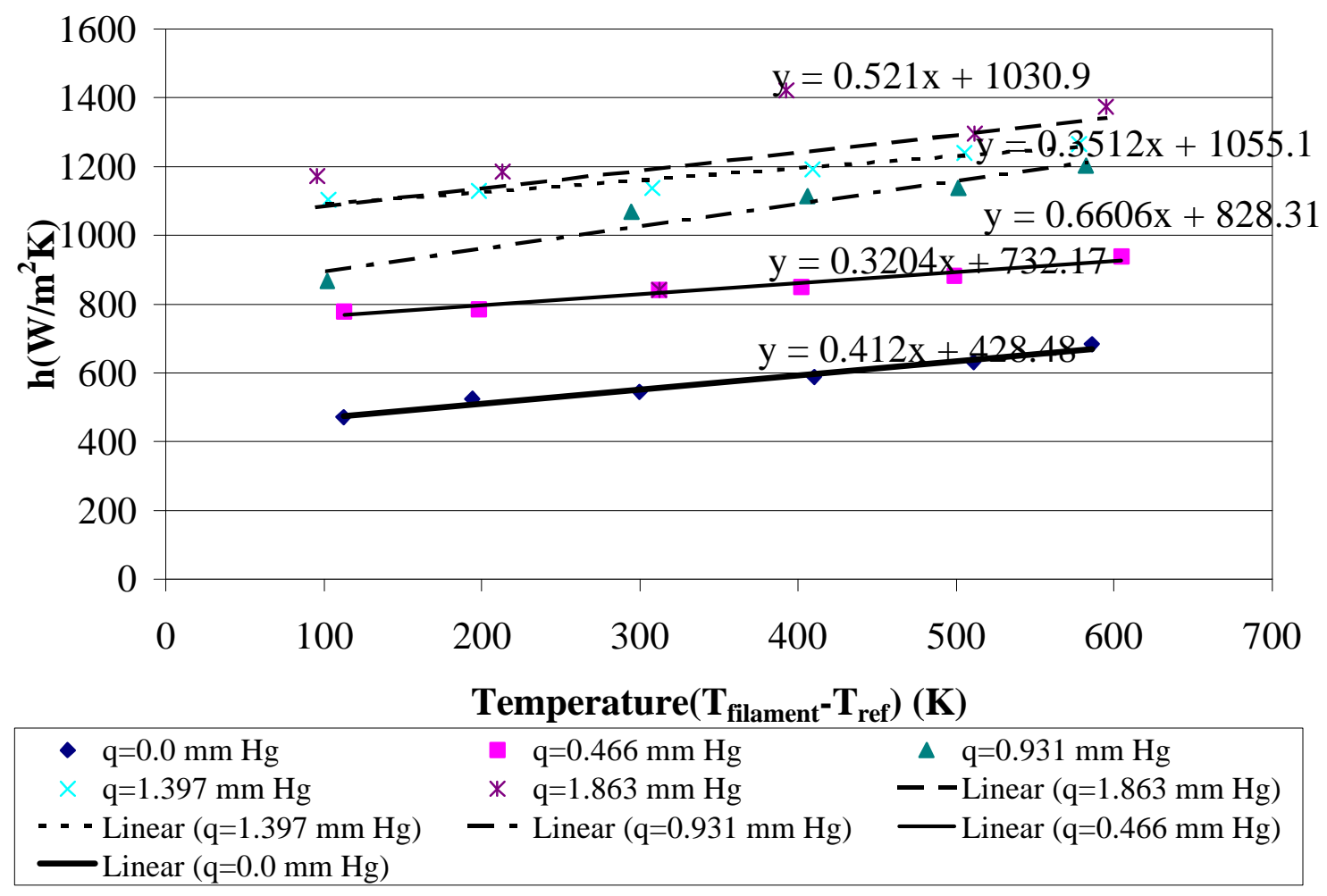

Figure 5.11: Heat Transfer Coefficient vs. Temperature Difference of a 25.4 Micron Platinum Filament with $30 \mathrm{~cm}$. Length and Theta $=2.5^{\circ}$ 


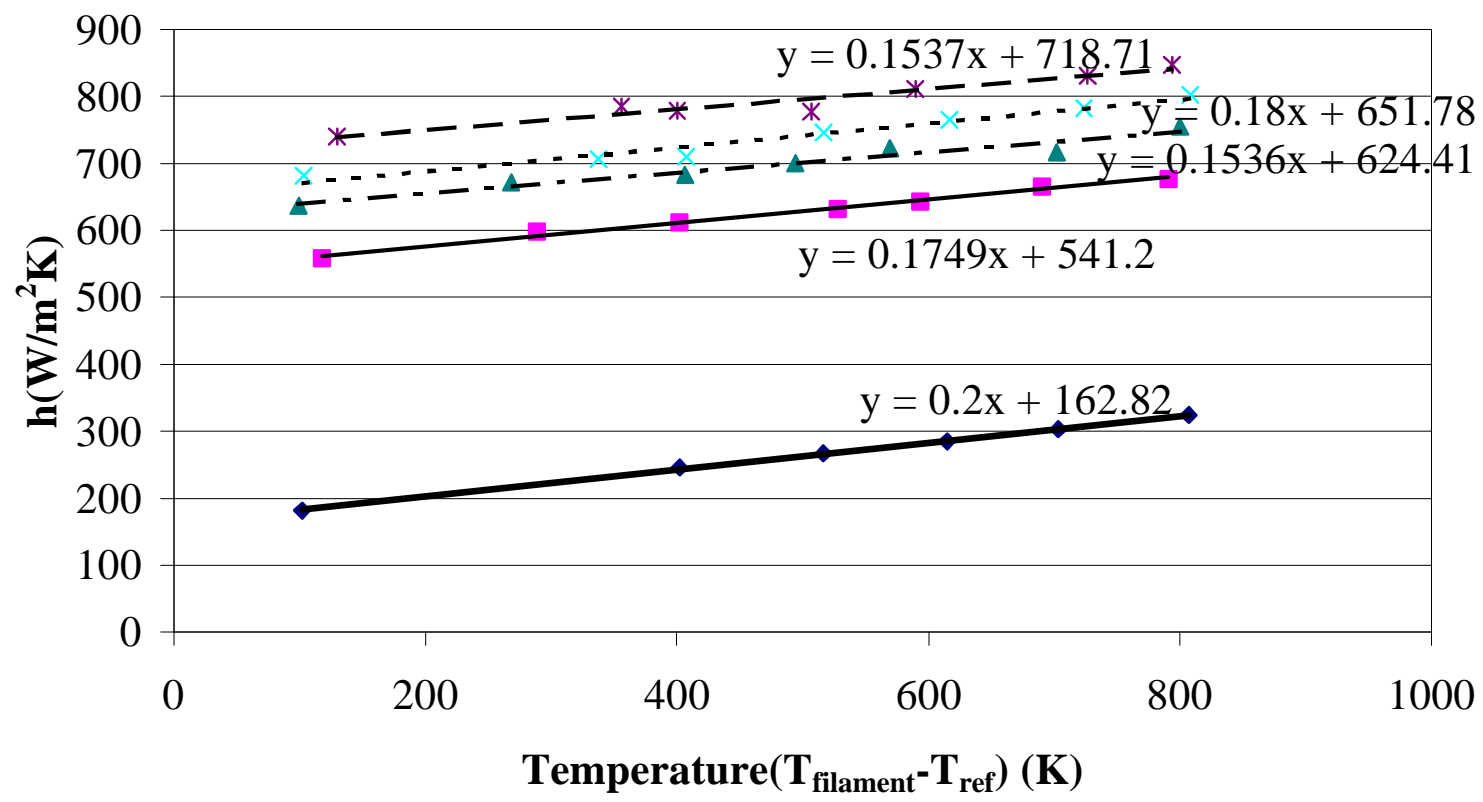

- $\mathrm{q}=0.0 \mathrm{~mm} \mathrm{Hg}$

$\times \mathrm{q}=1.397 \mathrm{~mm} \mathrm{Hg}$

- - - Linear $(\mathrm{q}=1.397 \mathrm{~mm} \mathrm{Hg})$

- Linear $(\mathrm{q}=0.0 \mathrm{~mm} \mathrm{Hg})$
- $\mathrm{q}=0.466 \mathrm{~mm} \mathrm{Hg}$

* $\mathrm{q}=1.863 \mathrm{~mm} \mathrm{Hg}$

- - Linear (q=0.931 $\mathrm{mm} \mathrm{Hg})$

$\Delta \mathrm{q}=0.931 \mathrm{~mm} \mathrm{Hg}$

- - Linear $(\mathrm{q}=1.863 \mathrm{~mm} \mathrm{Hg})$

- Linear $(\mathrm{q}=0.466 \mathrm{~mm} \mathrm{Hg})$

Figure 5.12: Heat Transfer Coefficient vs. Temperature Difference of a 76 Micron Platinum Filament with $30 \mathrm{~cm}$. Length and Theta $=5^{\circ}$ 


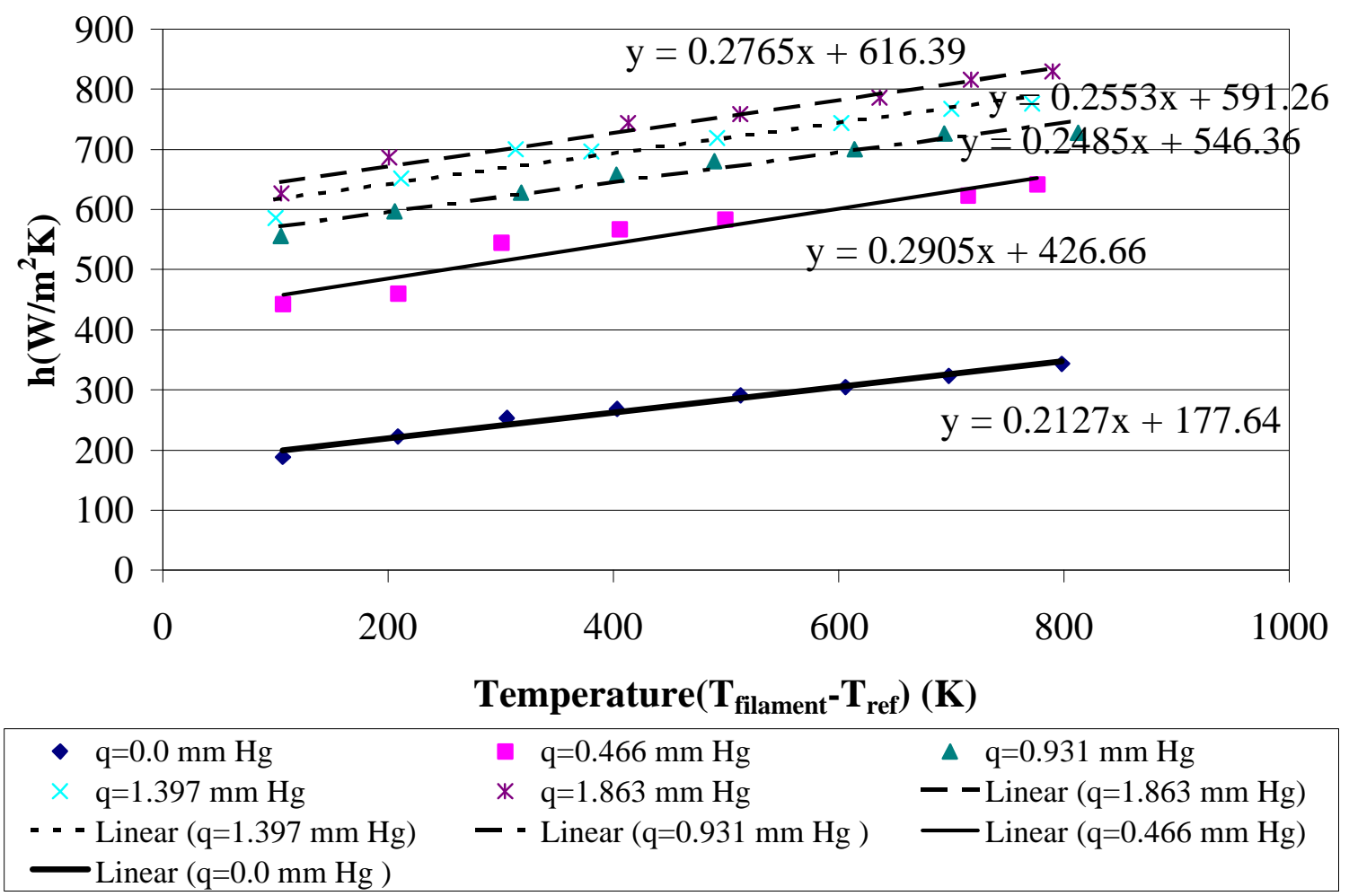

Figure 5.13: Heat Transfer Coefficient vs. Temperature Difference of a 63.5 Micron Platinum Filament with $30 \mathrm{~cm}$. Length and Theta $=5^{\circ}$ 


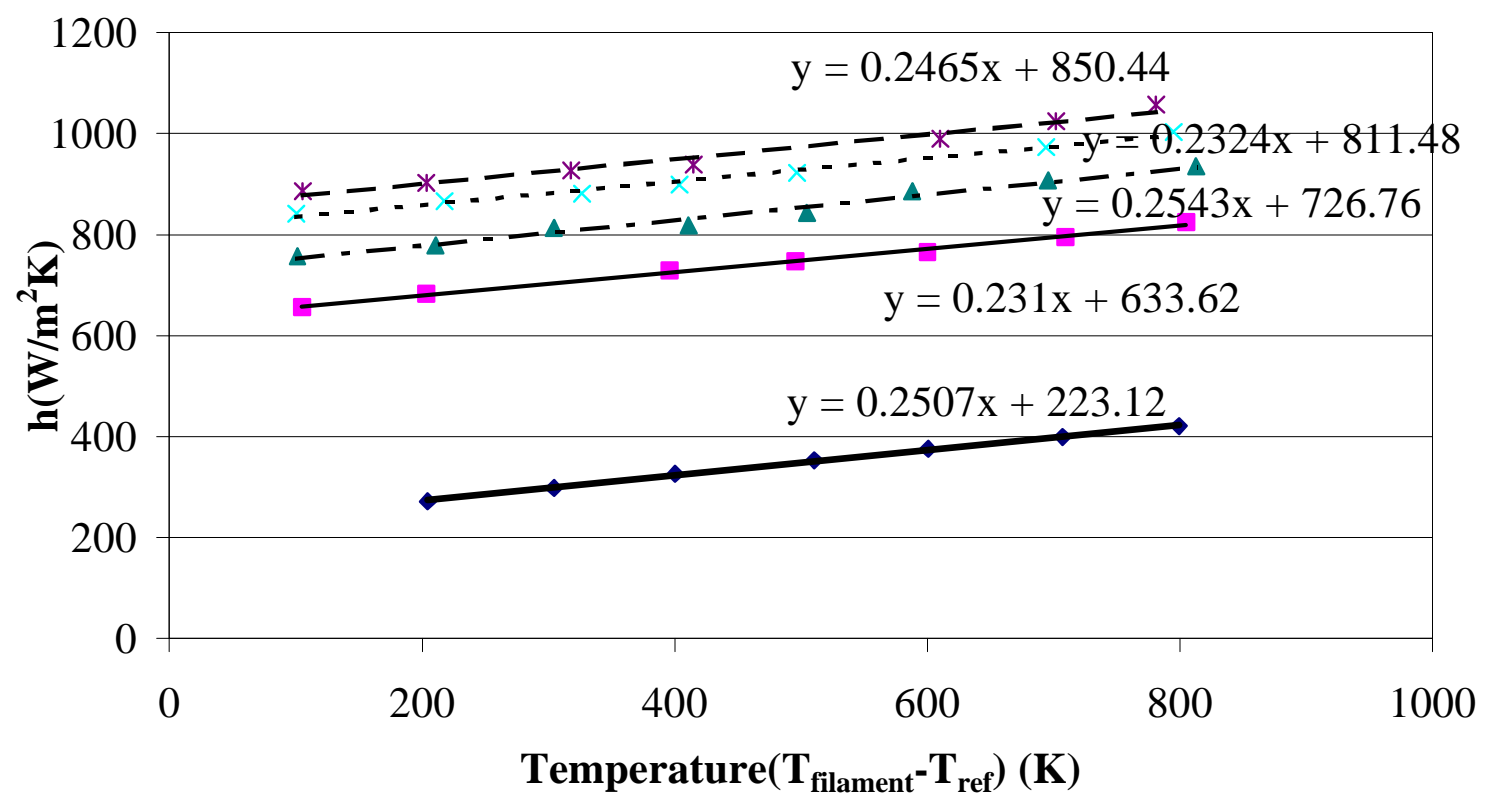

\begin{tabular}{|c|c|c|}
\hline - $\mathrm{q}=0.0 \mathrm{~mm} \mathrm{Hg}$ & $\mathrm{q}=0.466 \mathrm{~mm} \mathrm{Hg}$ & $\Delta \mathrm{q}=0.931 \mathrm{~mm} \mathrm{Hg}$ \\
\hline$\times \quad \mathrm{q}=1.397 \mathrm{~mm} \mathrm{Hg}$ & $* \mathrm{q}=1.863 \mathrm{~mm} \mathrm{Hg}$ & - - Linear $(\mathrm{q}=1.863 \mathrm{~mm} \mathrm{Hg})$ \\
\hline $\begin{array}{l}\cdots \text { Linear }(\mathrm{q}=1.397 \mathrm{~mm} \mathrm{Hg}) \\
\text { Linear }(\mathrm{q}=0.0 \mathrm{~mm} \mathrm{Hg})\end{array}$ & - - Linear $(\mathrm{q}=0.931 \mathrm{~mm} \mathrm{Hg})$ & —Linear $(\mathrm{q}=0.466 \mathrm{~mm} \mathrm{Hg})$ \\
\hline
\end{tabular}

Figure 5.14: Heat Transfer Coefficient vs. Temperature Difference of a 51 Micron Platinum Filament with $30 \mathrm{~cm}$. Length and Theta $=5^{\circ}$ 


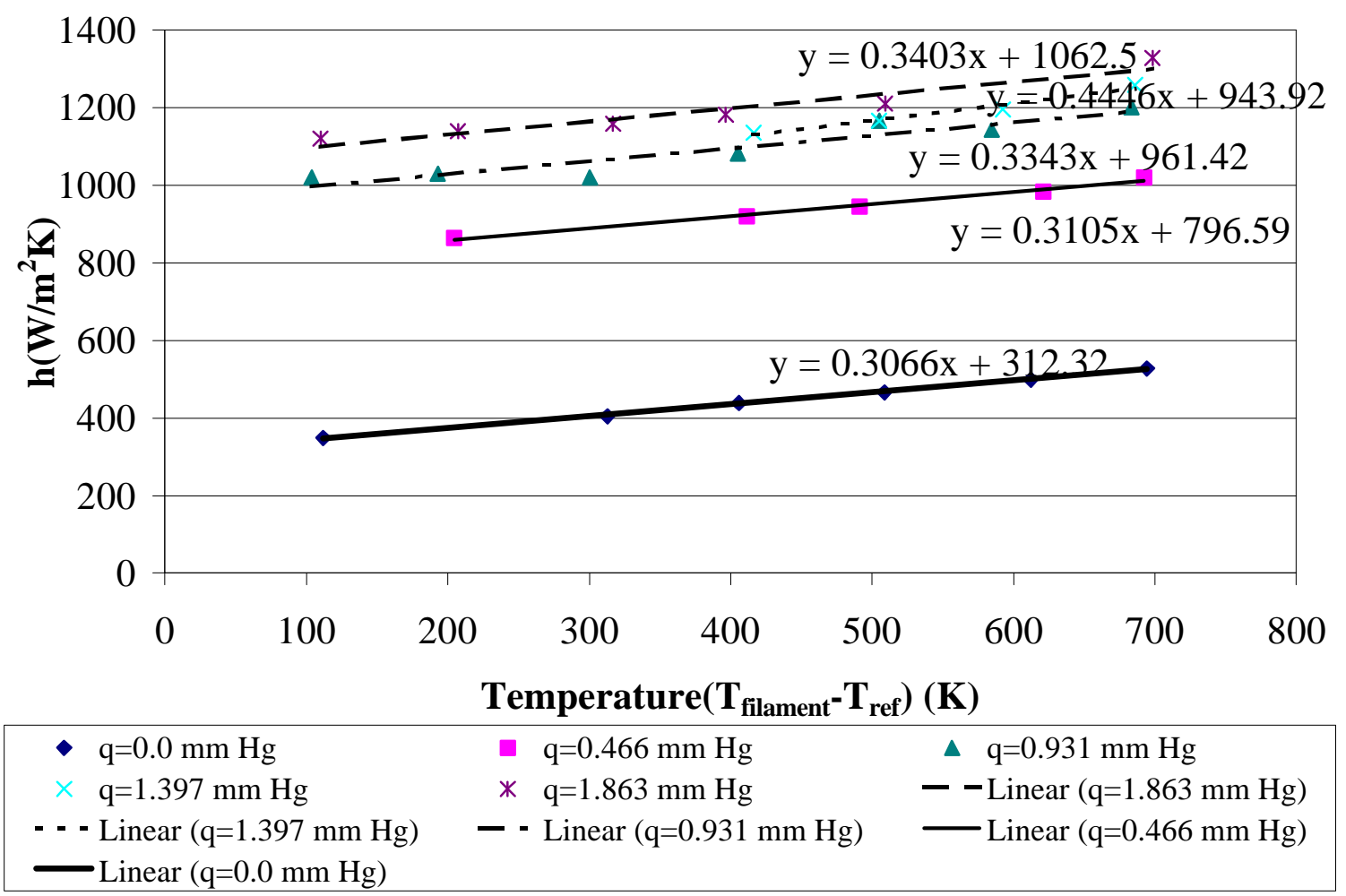

Figure 5.15: Heat Transfer Coefficient vs. Temperature Difference of a 38.5 Micron Platinum Filament with $30 \mathrm{~cm}$. Length and Theta $=5^{\circ}$ 


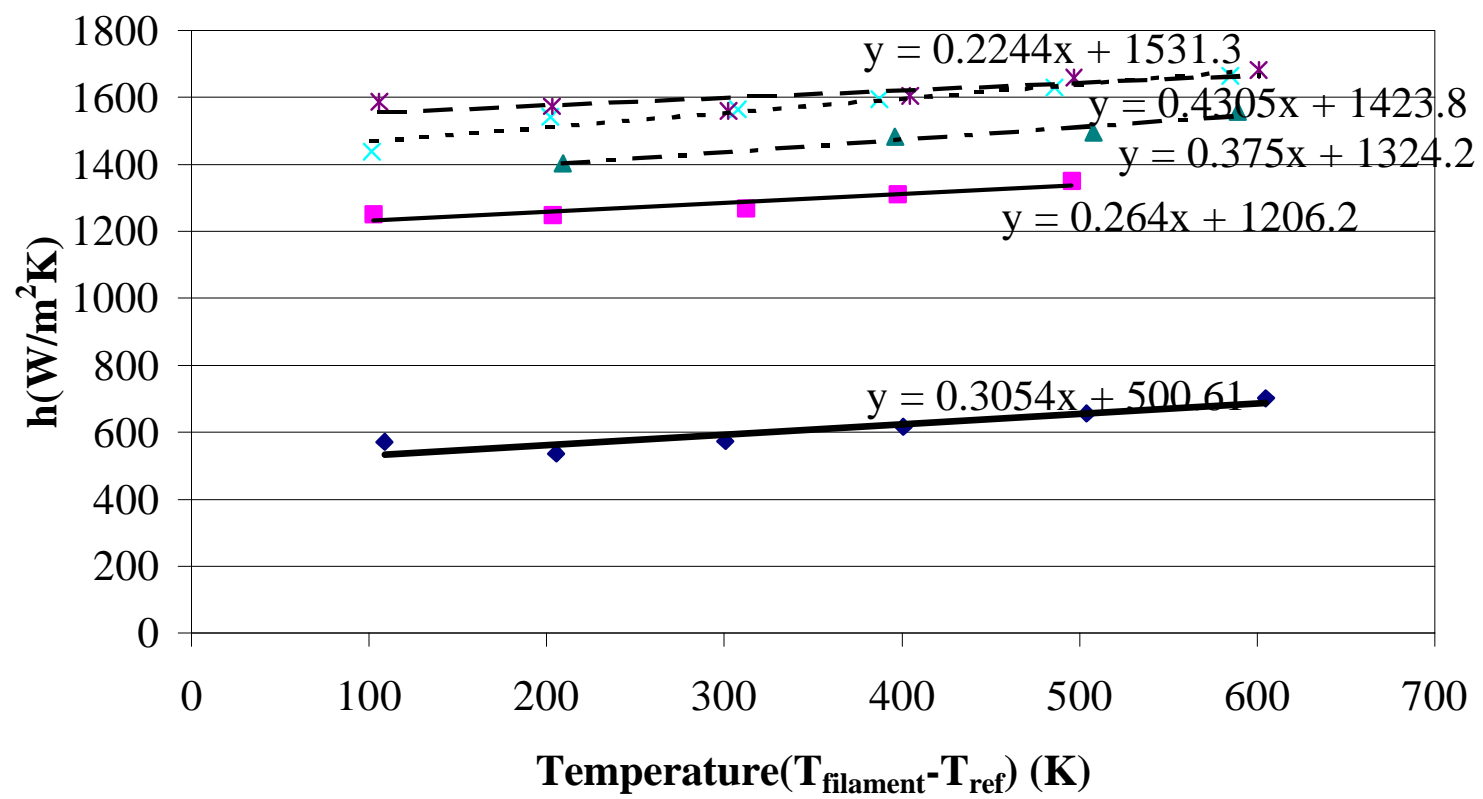

\begin{tabular}{|c|c|c|}
\hline - $\mathrm{q}=0.0 \mathrm{~mm} \mathrm{Hg}$ & $\mathrm{q}=0.466 \mathrm{~mm} \mathrm{Hg}$ & $\Delta \mathrm{q}=0.931 \mathrm{~mm} \mathrm{Hg}$ \\
\hline$\times \quad \mathrm{q}=1.397 \mathrm{~mm} \mathrm{Hg}$ & * $\mathrm{q}=1.863 \mathrm{~mm} \mathrm{Hg}$ & - - Linear $(\mathrm{q}=1.863 \mathrm{~mm} \mathrm{Hg})$ \\
\hline $\begin{array}{l}- \text { Linear }(\mathrm{q}=1.397 \mathrm{~mm} \mathrm{Hg}) \\
\text { Linear }(\mathrm{q}=0.0 \mathrm{~mm} \mathrm{Hg})\end{array}$ & - - Linear $(\mathrm{q}=0.931 \mathrm{~mm} \mathrm{Hg})$ & - Linear $(\mathrm{q}=0.466 \mathrm{~mm} \mathrm{Hg})$ \\
\hline
\end{tabular}

Figure 5.16: Heat Transfer Coefficient vs. Temperature Difference of a 25.4 Micron Platinum Filament with $30 \mathrm{~cm}$. Length and Theta $=5^{\circ}$ 


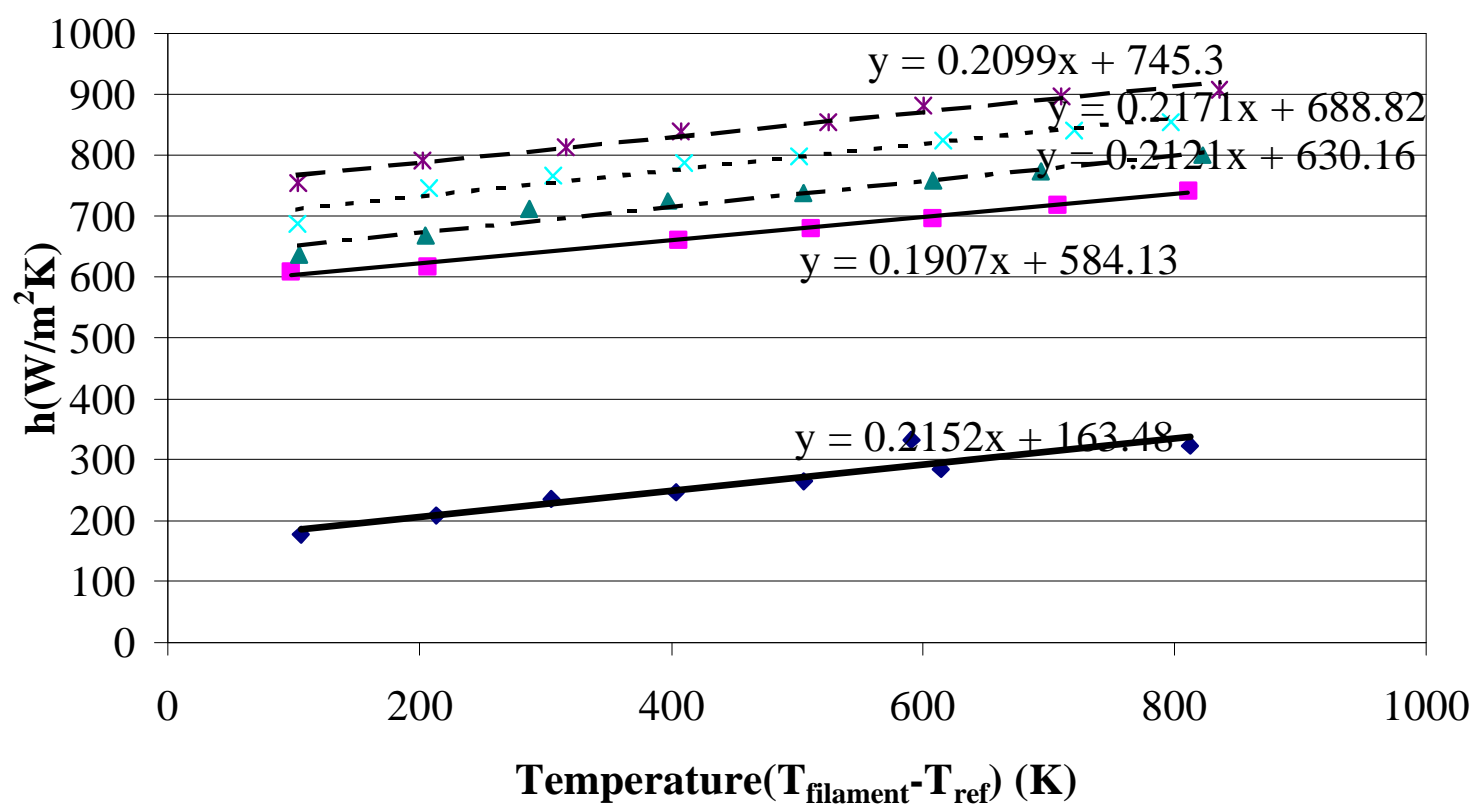

\begin{tabular}{|c|c|c|}
\hline - $\mathrm{q}=0.0 \mathrm{~mm} \mathrm{Hg}$ & $\mathrm{q}=0.466 \mathrm{~mm} \mathrm{Hg}$ & $\Delta \mathrm{q}=0.931 \mathrm{~mm} \mathrm{Hg}$ \\
\hline$\times \quad \mathrm{q}=1.397 \mathrm{~mm} \mathrm{Hg}$ & $* \mathrm{q}=1.863 \mathrm{~mm} \mathrm{Hg}$ & - - Linear $(\mathrm{q}=1.863 \mathrm{~mm} \mathrm{Hg})$ \\
\hline - - Linear $(\mathrm{q}=1.397 \mathrm{~mm} \mathrm{Hg})$ & - - Linear $(\mathrm{q}=0.931 \mathrm{~mm} \mathrm{Hg})$ & - Linear $(\mathrm{q}=0.466 \mathrm{~mm} \mathrm{Hg})$ \\
\hline
\end{tabular}

Figure 5.17: Heat Transfer Coefficient vs. Temperature Difference of a 76 Micron Platinum Filament with $30 \mathrm{~cm}$. Length and Theta $=7^{\circ}$ 


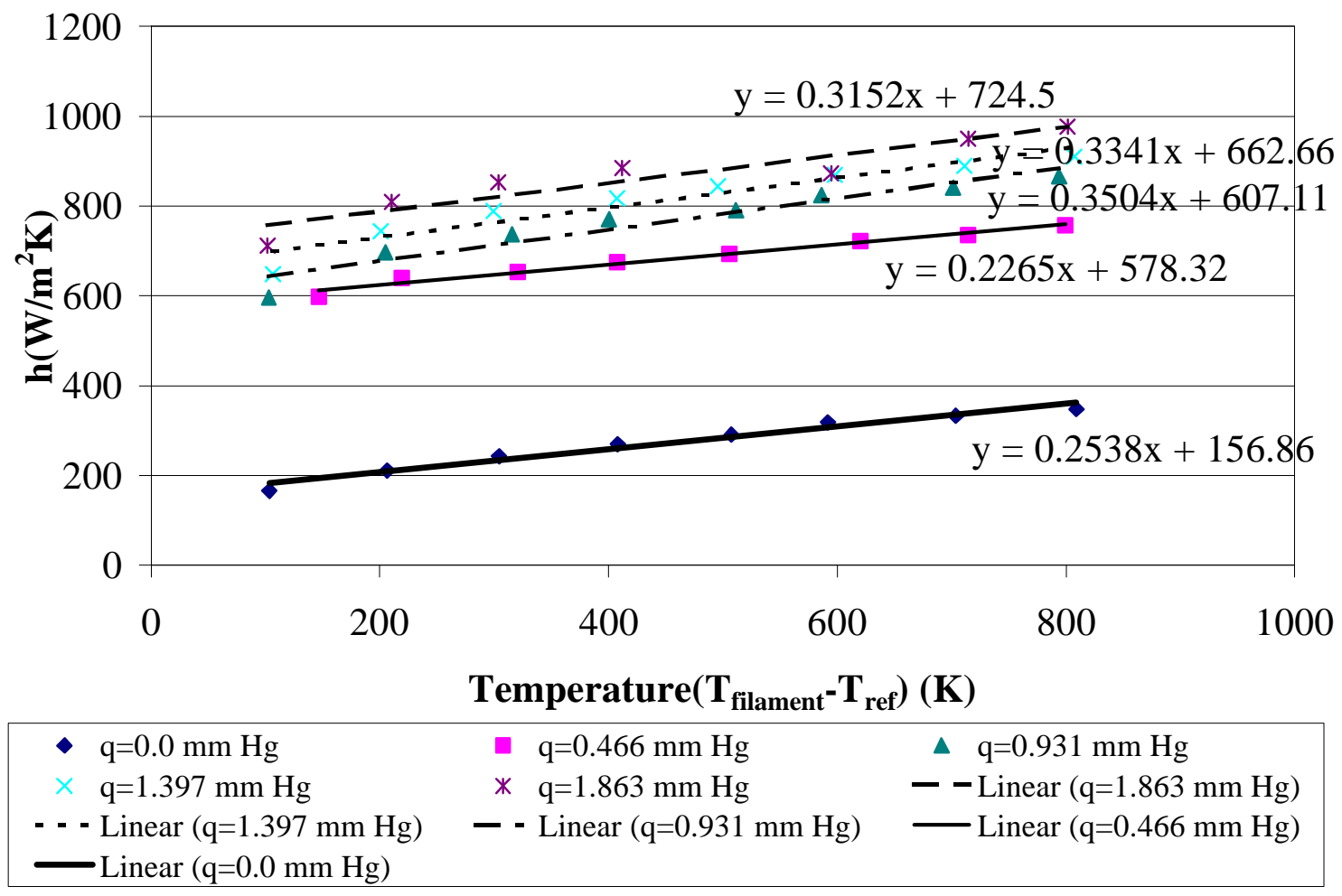

Figure 5.18: Heat Transfer Coefficient vs. Temperature of a 63.5 Micron Platinum Filament with $30 \mathrm{~cm}$. Length and Theta $=7^{\circ}$ 


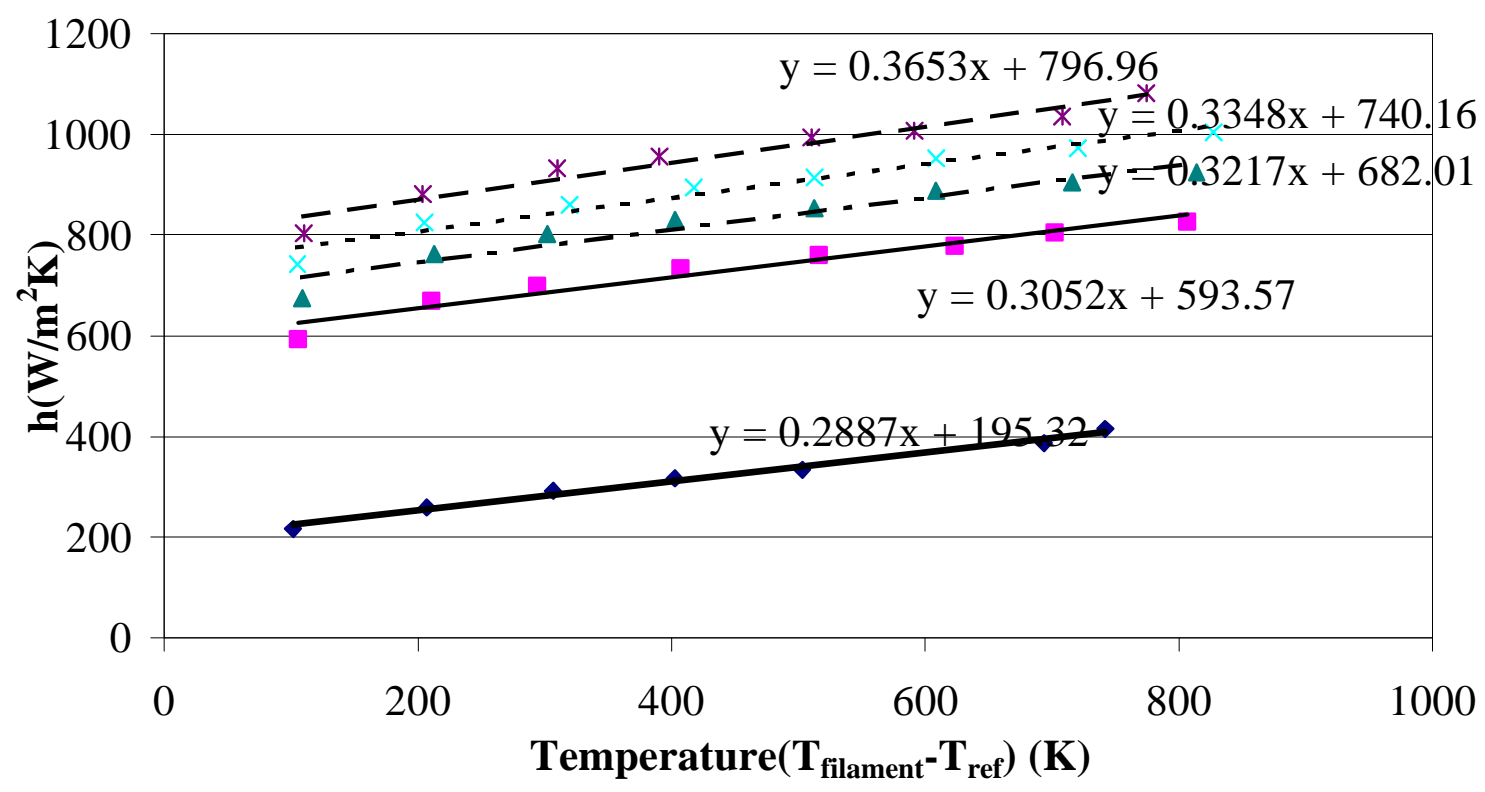

- $\mathrm{q}=0.0 \mathrm{~mm} \mathrm{Hg}$

$\times \mathrm{q}=1.397 \mathrm{~mm} \mathrm{Hg}$

- - Linear (q=1.397 $\mathrm{mm} \mathrm{Hg})$

Linear $(\mathrm{q}=0.0 \mathrm{~mm} \mathrm{Hg})$

\section{- $\mathrm{q}=0.466 \mathrm{~mm} \mathrm{Hg} \quad \Delta \mathrm{q}=0.931 \mathrm{~mm} \mathrm{Hg}$}

* q=q.863 mm Hg - - Linear (q=q.863 $\mathrm{mm} \mathrm{Hg}$ )

- $\operatorname{Linear}(\mathrm{q}=0.931 \mathrm{~mm} \mathrm{Hg}) \quad$ Linear $(\mathrm{q}=0.466 \mathrm{~mm} \mathrm{Hg})$

Figure 5.19: Heat Transfer Coefficient vs. Temperature Difference of a 51 Micron Platinum Filament with $30 \mathrm{~cm}$. Length and Theta $=7^{\circ}$ 


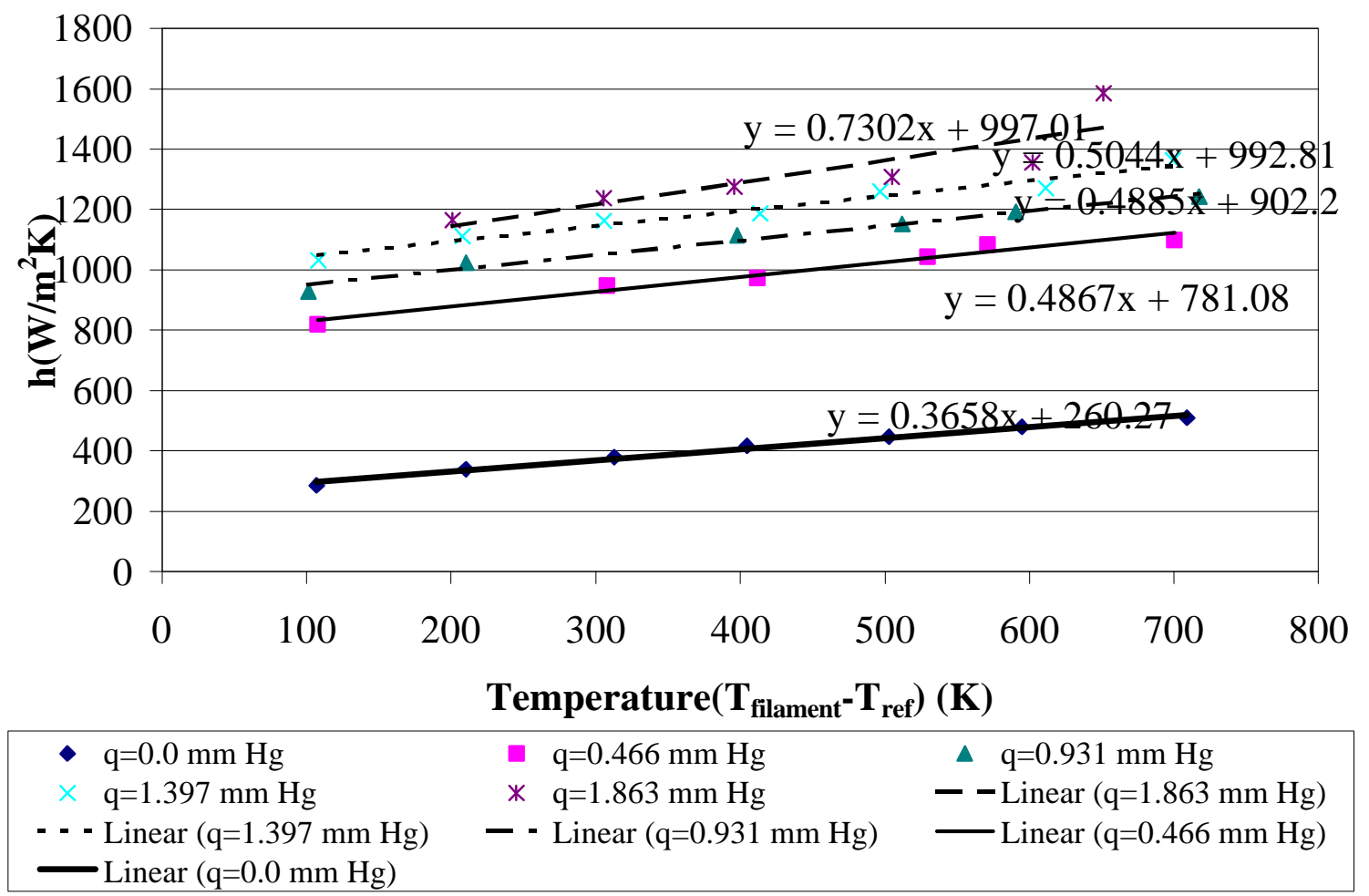

Figure 5.20: Heat Transfer Coefficient vs. Temperature Difference for a 38.5 Micron Platinum Filament with $30 \mathrm{~cm}$. Length and Theta $=7^{\circ}$ 


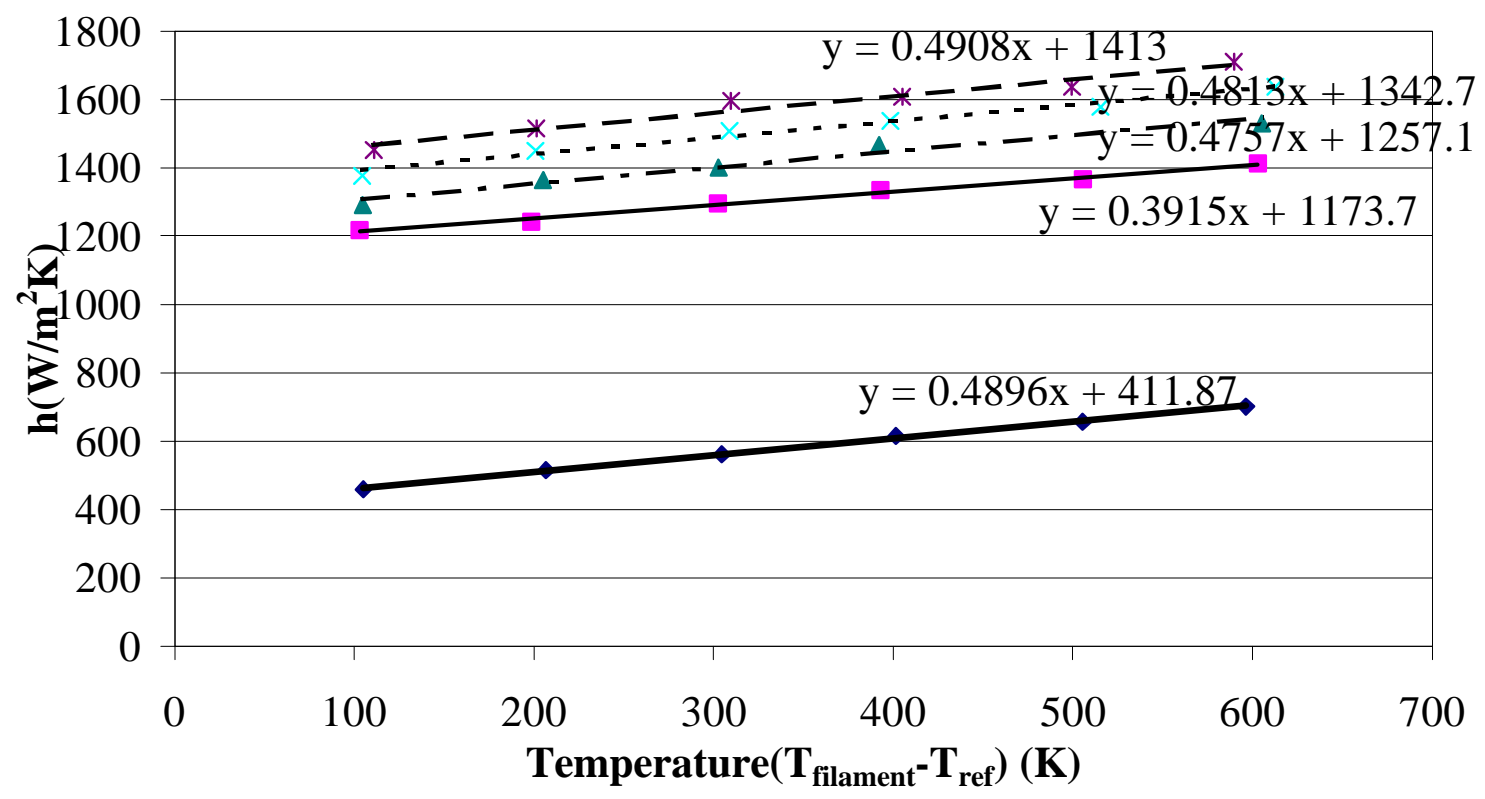

- $\mathrm{q}=0.0 \mathrm{~mm} \mathrm{Hg}$

$\times \quad \mathrm{q}=1.397 \mathrm{~mm} \mathrm{Hg}$

- - Linear $(\mathrm{q}=1.397 \mathrm{~mm} \mathrm{Hg})$

Linear $(\mathrm{q}=0.0 \mathrm{~mm} \mathrm{Hg})$
$\Delta \mathrm{q}=0.931 \mathrm{~mm} \mathrm{Hg}$

- - Linear (q=1.863 $\mathrm{mm} \mathrm{Hg}$ )

* $\mathrm{q}=1.863 \mathrm{~mm} \mathrm{Hg}$

- - Linear $(\mathrm{q}=0.931 \mathrm{~mm} \mathrm{Hg})$

- Linear $(\mathrm{q}=0.466 \mathrm{~mm} \mathrm{Hg})$

Figure 5.21: Heat Transfer Coefficient vs. Temperature Difference of a 25.4 Micron Platinum filament with $30 \mathrm{~cm}$. Length and Theta $=7^{\circ}$ 


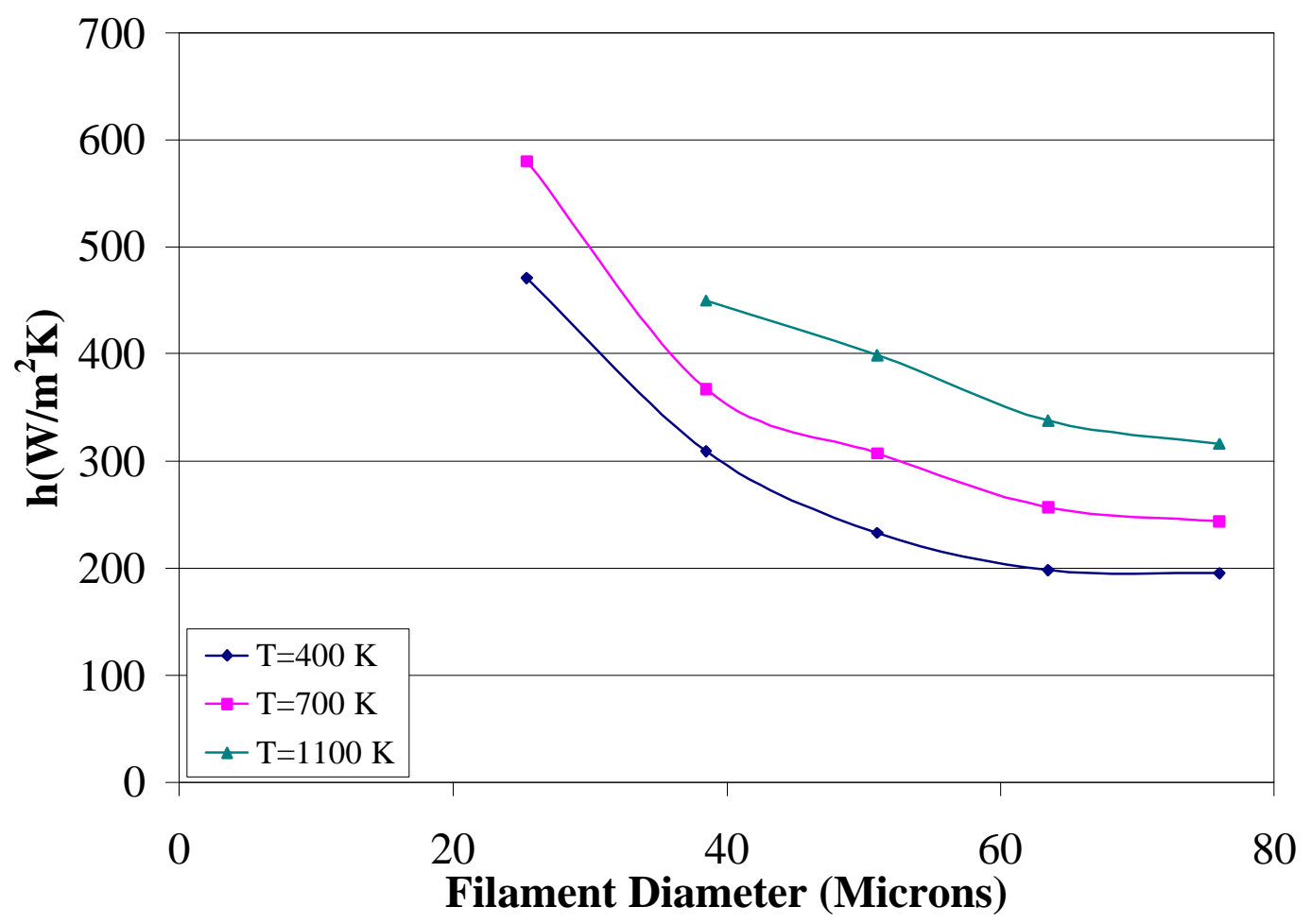

Figure 5.22: Heat Transfer Coefficients vs. Filament Diameter at Various Constant Temperatures for a $30 \mathrm{~cm}$.. Platinum Filament with Dynamic Pressure q=0.0 $\mathrm{mm} \mathrm{Hg}$ and Theta $=0^{\circ}$ 


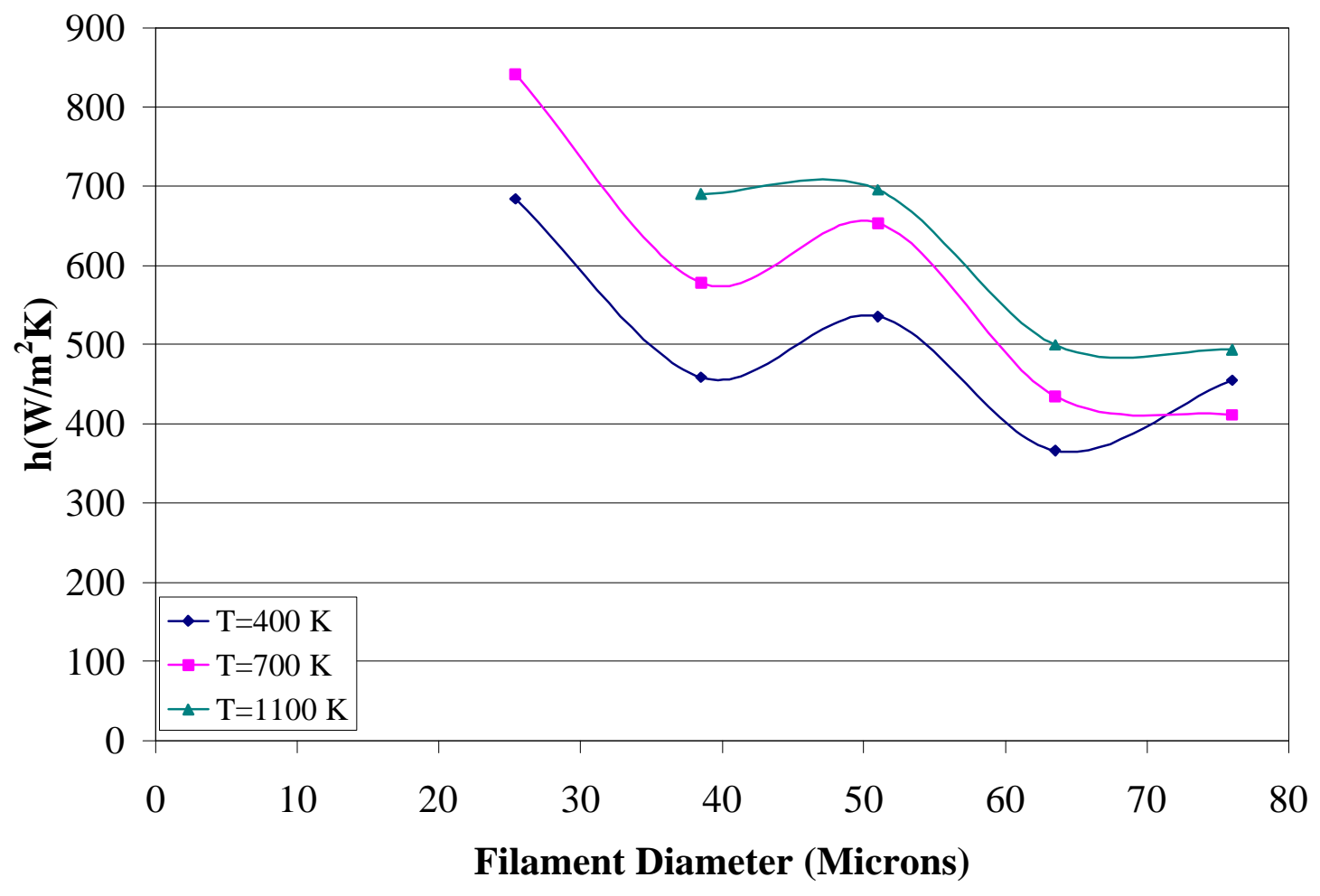

Figure 5.23: Heat Transfer Coefficients vs. Filament Diameter at Various Constant Temperatures for a $30 \mathrm{~cm}$.. Platinum filament with Dynamic Pressure q=0.466 mm Hg and Theta $=0^{\circ}$ 


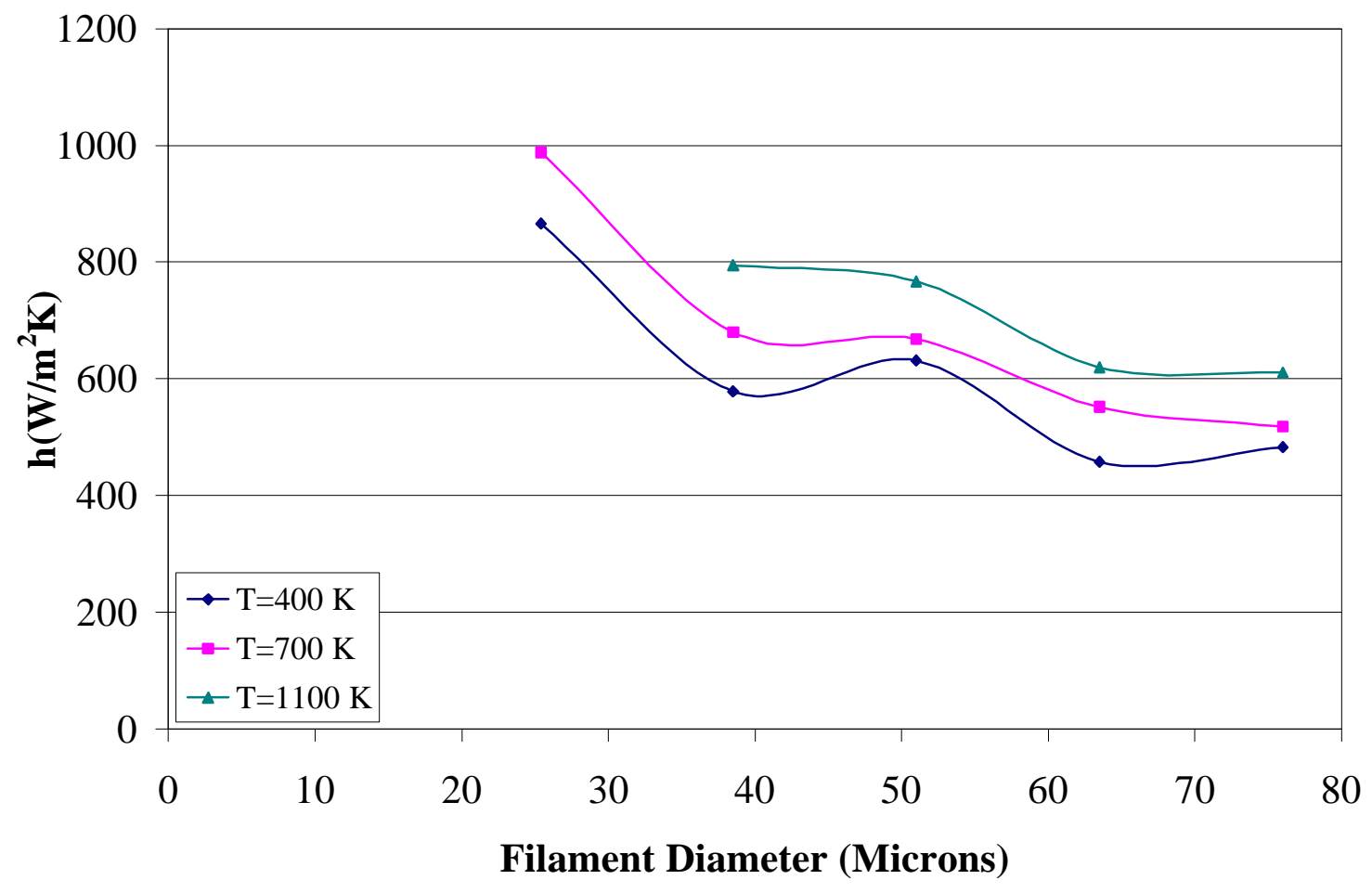

Figure 5.24: Heat Transfer Coefficient vs. Filament Diameter at Various constant Temperatures for a $30 \mathrm{~cm}$.. Platinum filament with Dynamic Pressure $\mathrm{q}=0.931 \mathrm{~mm} \mathrm{Hg}$ and Theta $=0^{\circ}$ 


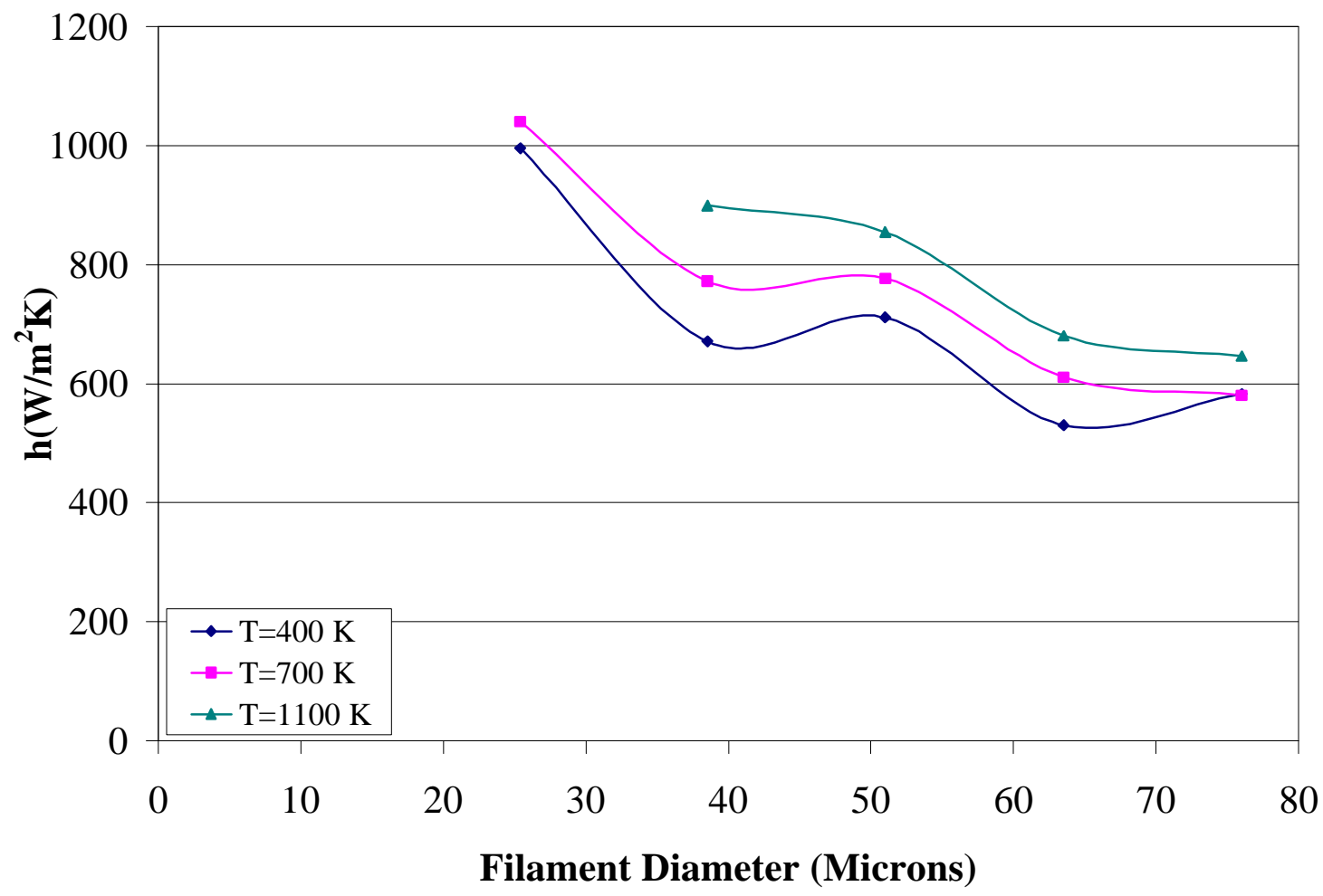

Figure 5.25: Heat Transfer Coefficients vs. Filament Diameter at Various Constant Temperatures for a $30 \mathrm{~cm}$.. Platinum Filament with Dynamic Pressure $\mathrm{q}=1.397 \mathrm{~mm} \mathrm{Hg}$ and Theta $=0^{\circ}$ 


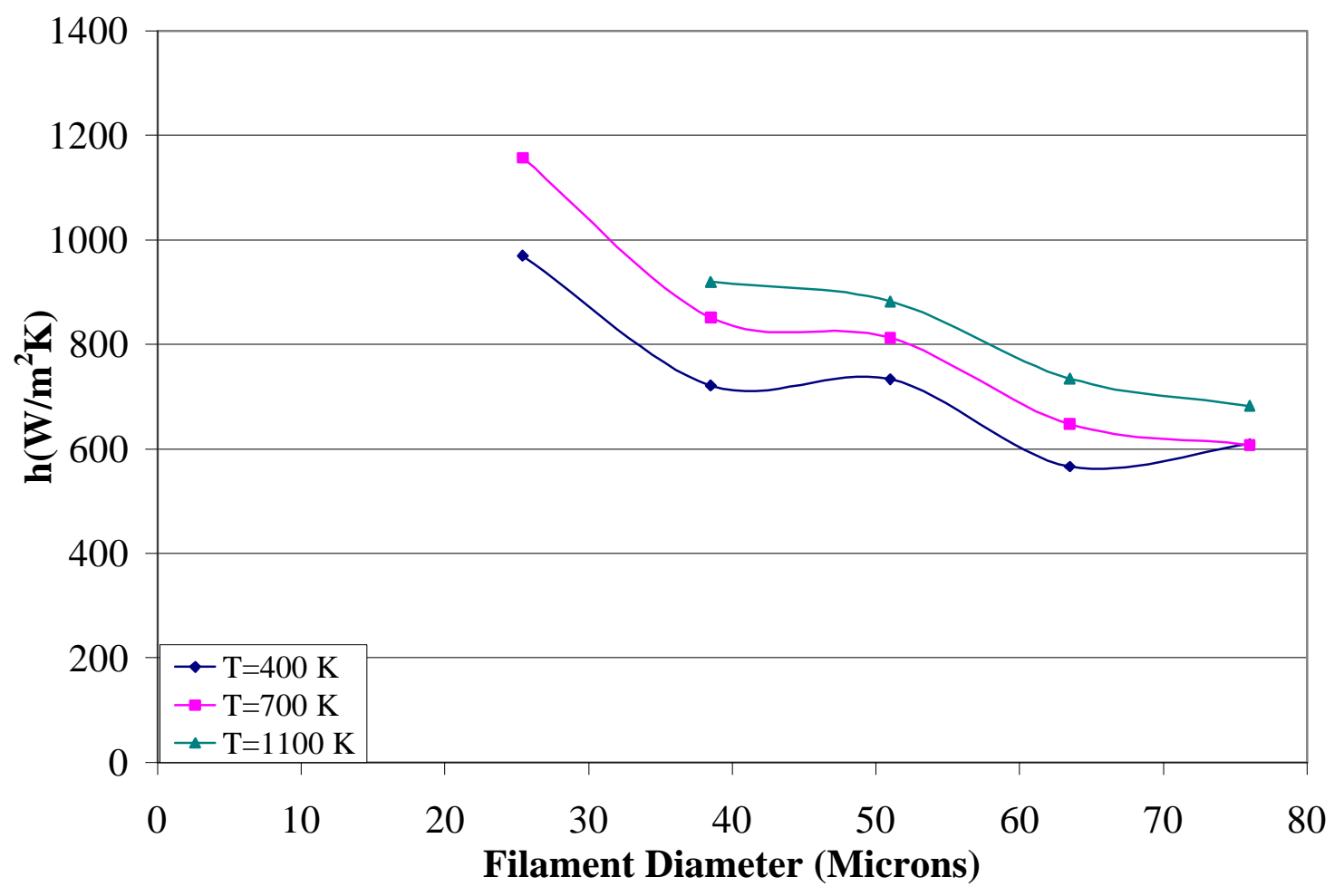

Figure 5.26: Heat Transfer Coefficients vs. Filament Diameter at Various Constant Temperatures for a $30 \mathrm{~cm}$.. Platinum Filament with Dynamic Pressure q=1.863 mm Hg and Theta $=0^{\circ}$ 


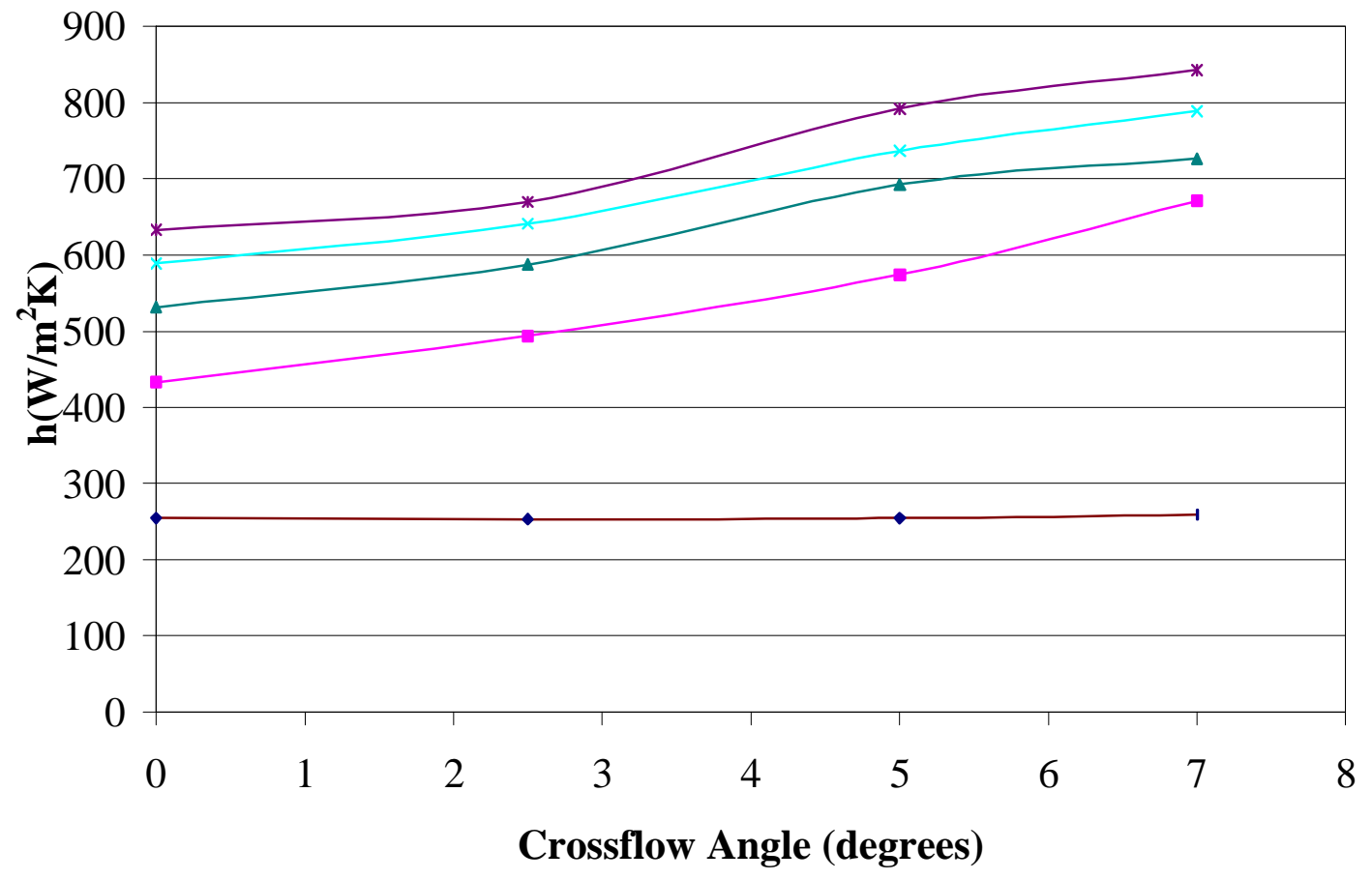

$\mathrm{q}=0.0 \mathrm{~mm} \mathrm{Hg} \rightarrow \mathrm{q}=0.466 \mathrm{~mm} \mathrm{Hg} \rightarrow \mathrm{q}=0.931 \mathrm{~mm} \mathrm{Hg} \rightarrow \mathrm{q}=1.397 \mathrm{~mm} \mathrm{Hg} \rightarrow \mathrm{q}=1.863 \mathrm{~mm} \mathrm{Hg}$

Figure 5.27: Heat Transfer Coefficient vs. Crossflow Angle for a 76 Micron Platinum Filament with $30 \mathrm{~cm}$. Length and $\mathrm{T}=1100 \mathrm{~K}$ 


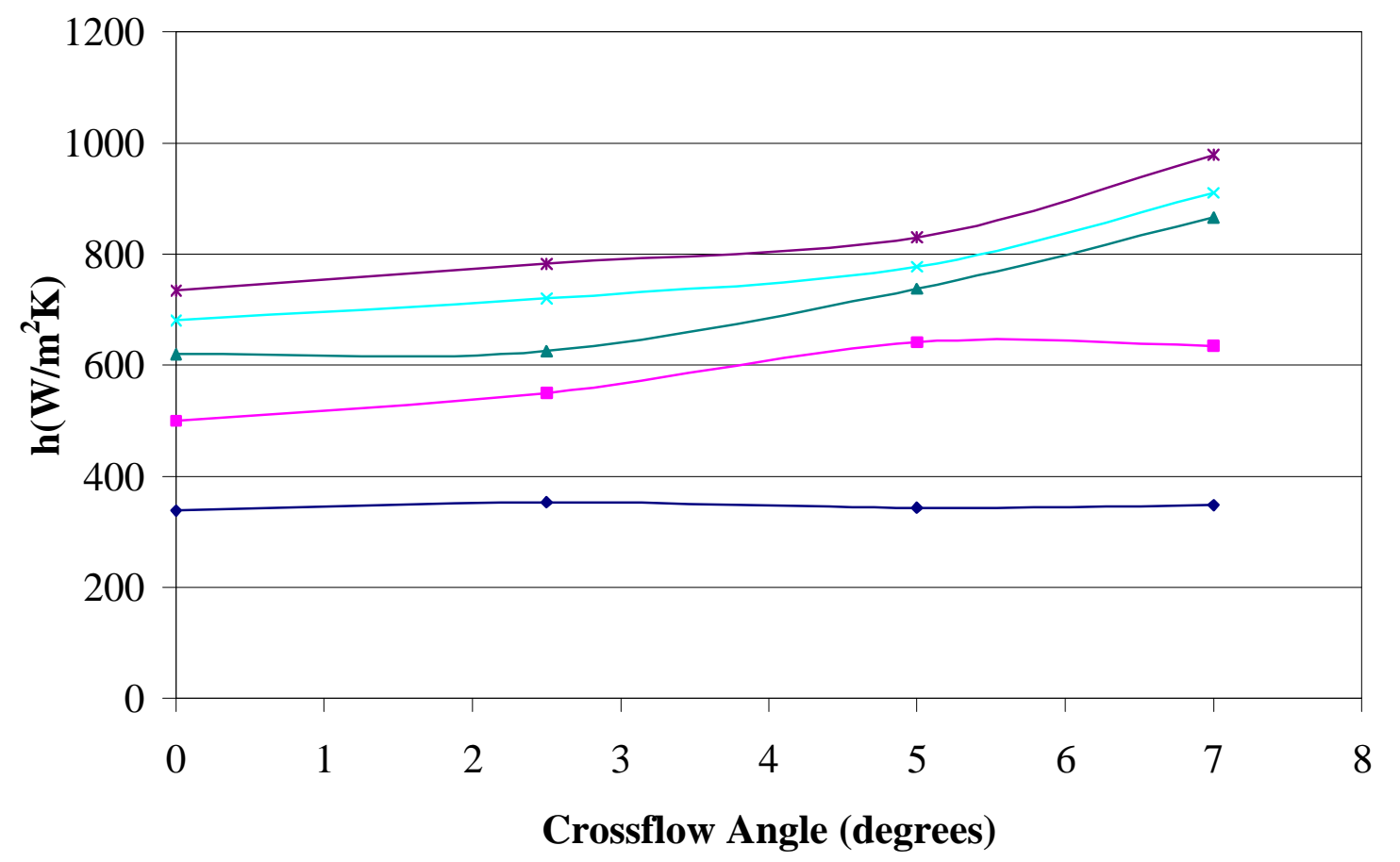

$\bullet \mathrm{q}=0.0 \mathrm{~mm} \mathrm{Hg} \rightarrow \mathrm{q}=0.466 \mathrm{~mm} \mathrm{Hg} \rightarrow \mathrm{q}=0.931 \mathrm{~mm} \mathrm{Hg} \rightarrow \mathrm{q}=1.397 \mathrm{~mm} \mathrm{Hg} * \mathrm{q}=1.863 \mathrm{~mm} \mathrm{Hg}$

Figure 5.28: Heat Transfer Coefficient vs. Crossflow Angle for a 63.5 Micron Platinum Filament with $30 \mathrm{~cm}$. Length and $\mathrm{T}=1100 \mathrm{~K}$ 


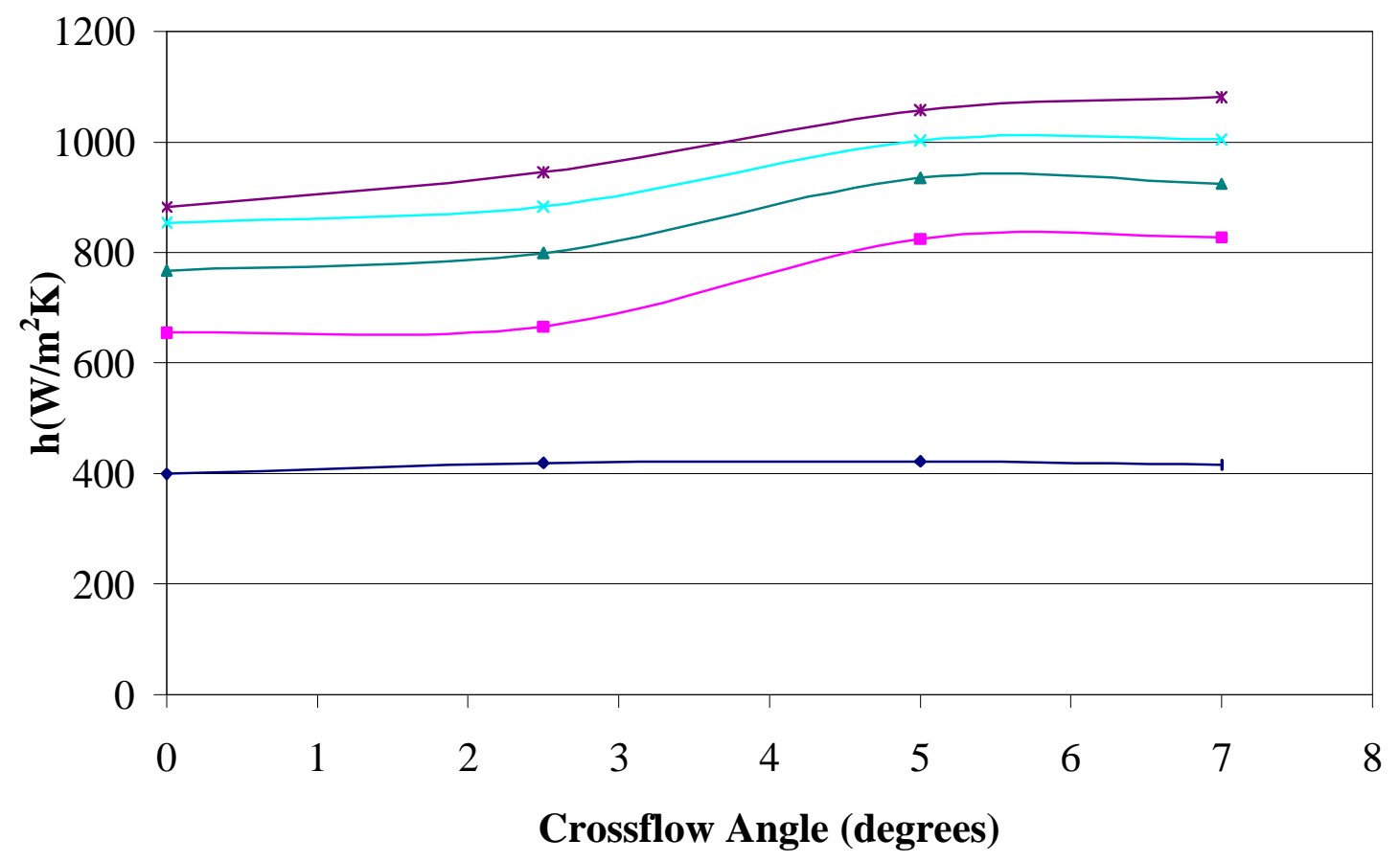

$\mathrm{q}=0.0 \mathrm{~mm} \mathrm{Hg} \rightarrow \mathrm{q}=0.466 \mathrm{~mm} \mathrm{Hg} \rightarrow \mathrm{q}=0.931 \mathrm{~mm} \mathrm{Hg} * \mathrm{q}=1.397 \mathrm{~mm} \mathrm{Hg} \rightarrow \mathrm{q}=1.863 \mathrm{~mm} \mathrm{Hg}$

Figure 5.29: Heat Transfer Coefficient vs. Crossflow Angle For a 51 Micron Platinum Filament with $30 \mathrm{~cm}$. Length and $\mathrm{T}=1000 \mathrm{~K}$ 


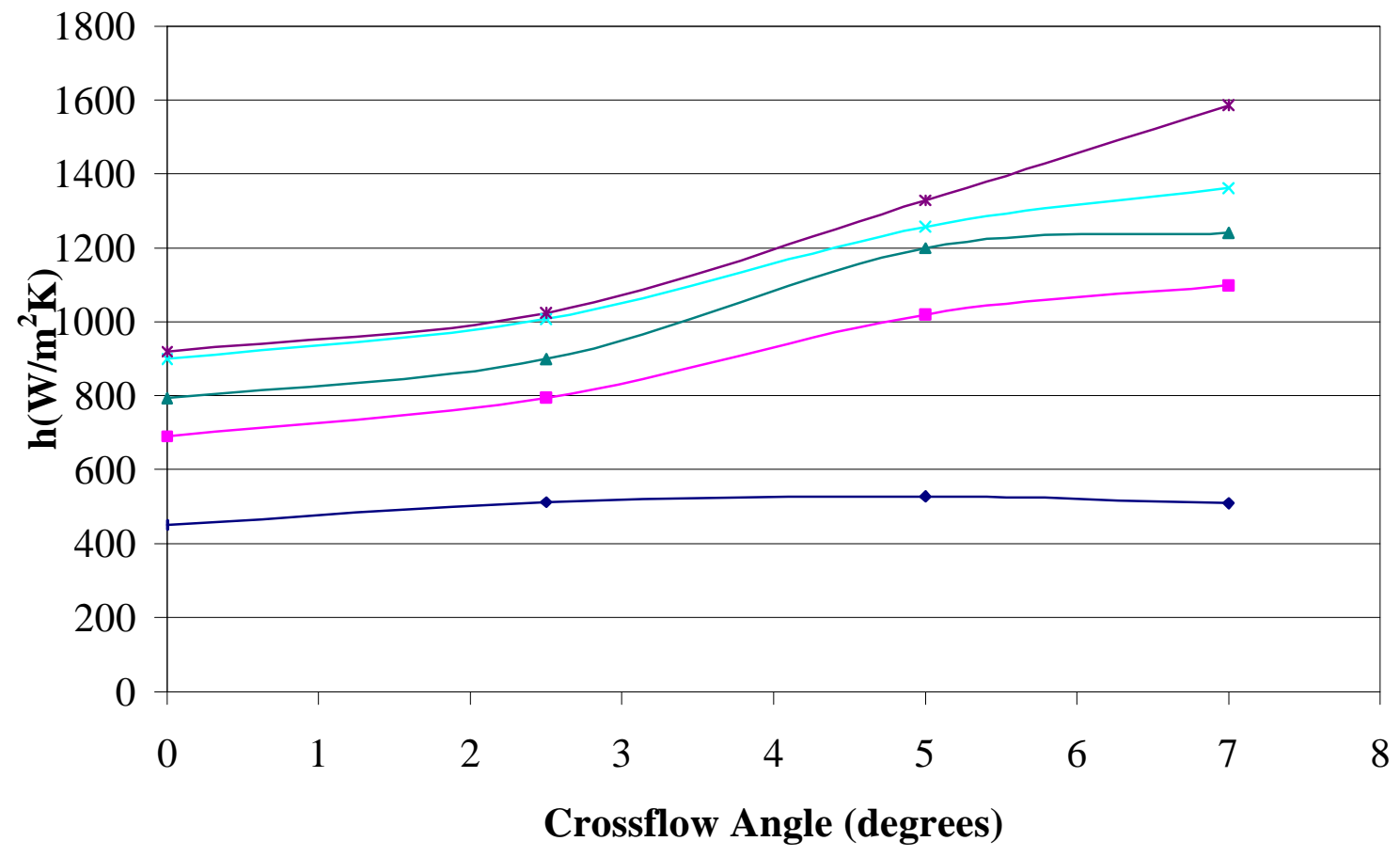

$\mathrm{q}=0.0 \mathrm{~mm} \mathrm{Hg} \rightarrow \mathrm{q}=0.466 \mathrm{~mm} \mathrm{Hg} \leftarrow \mathrm{q}=0.931 \mathrm{~mm} \mathrm{Hg} * \mathrm{q}=1.397 \mathrm{~mm} \mathrm{Hg} * \mathrm{q}=1.863 \mathrm{~mm} \mathrm{Hg}$

Figure 5.30: Heat Transfer Coefficient vs. Crossflow Angle for a 38.5 Micron Platinum Filament with $30 \mathrm{~cm}$. Length and $\mathrm{T}=900 \mathrm{~K}$ 


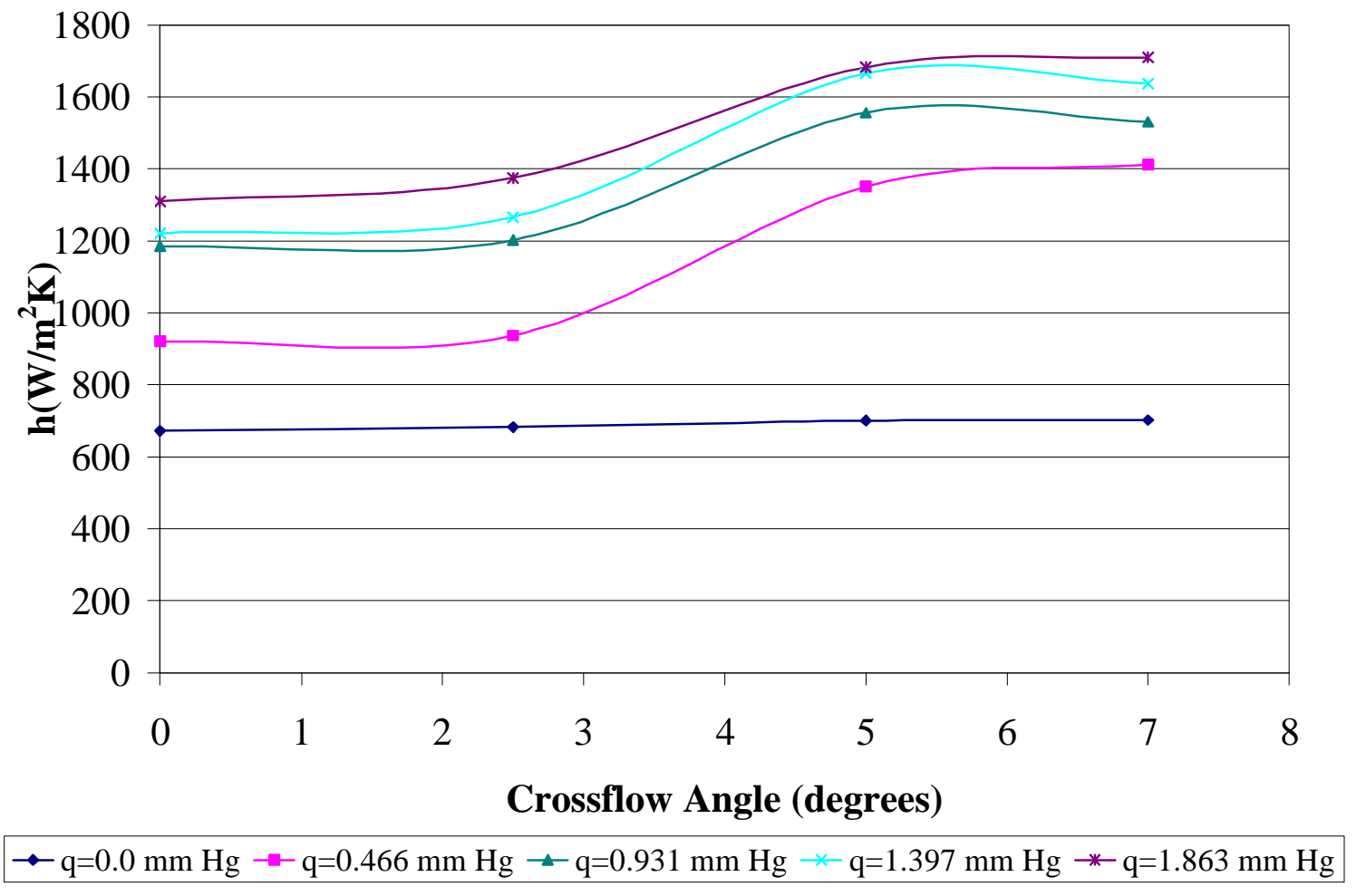

Figure 5.31: Heat Transfer Coefficient vs. Crossflow Angle for a 38.5 Micron platinum Filament with a $30 \mathrm{~cm}$. Length and $\mathrm{T}=900 \mathrm{~K}$ 


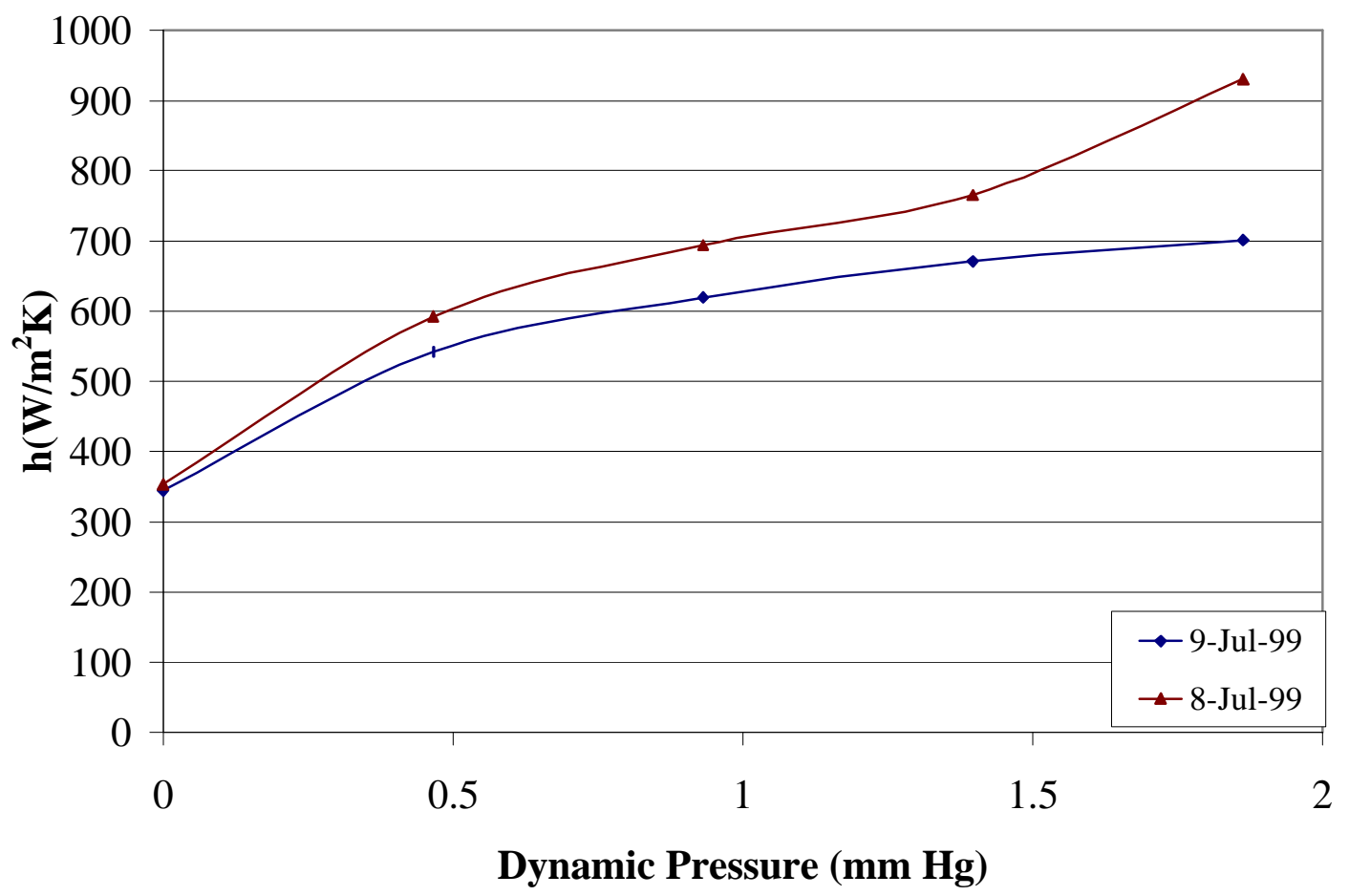

Figure 5.32: Heat Transfer coefficient vs. Dynamic Pressure for a 63.5 Micron Platinum Filament with $30 \mathrm{~cm}$. Length and Theta $=2.5^{\circ}$ 


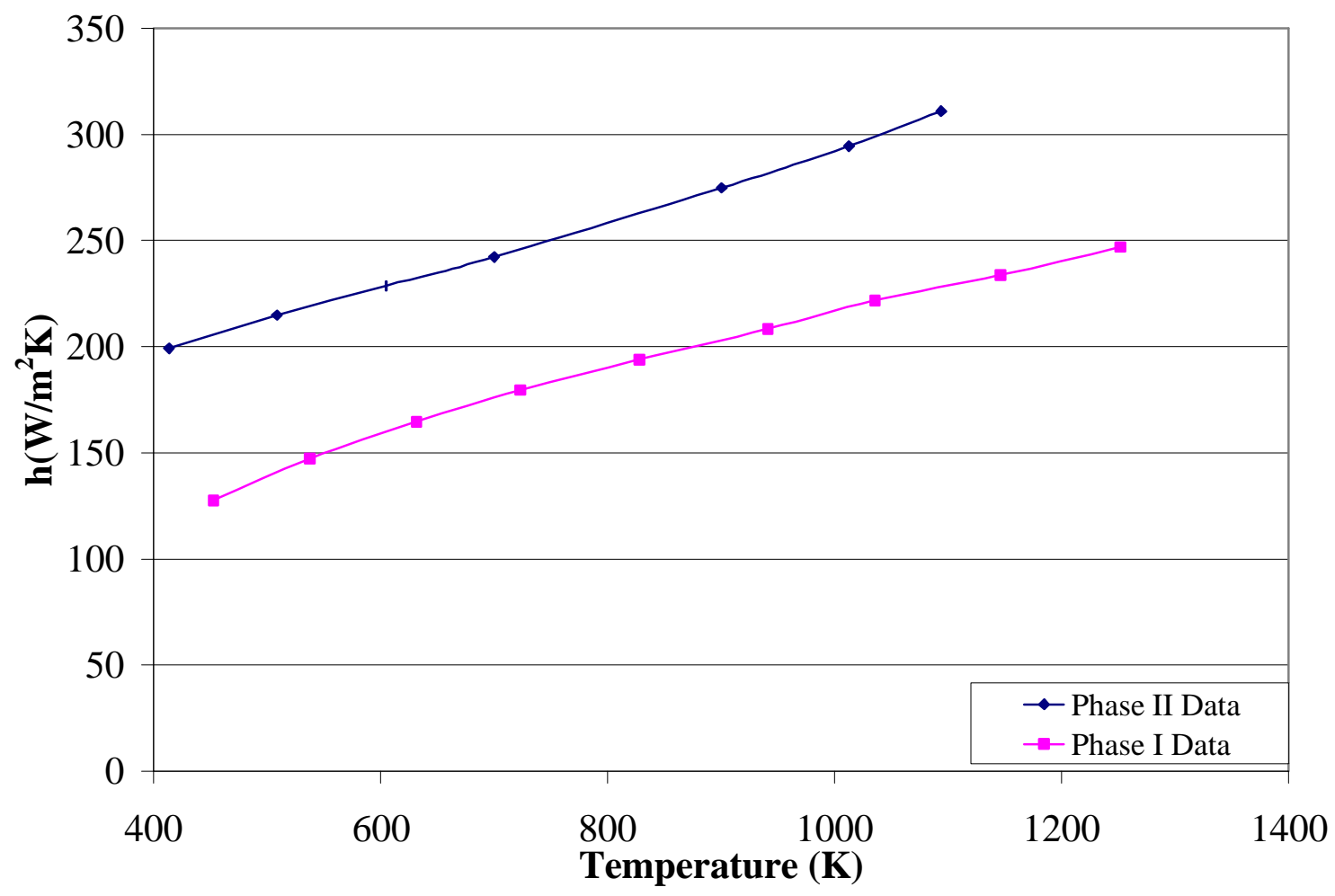

Figure 5.33: Comparison of Phase I and Phase II Heat Transfer Coefficients vs. Temperature for a 76 Micron Platinum Filament with $30 \mathrm{~cm}$. Length and Dynamic Pressure $\mathrm{q}=0.0 \mathrm{~mm} \mathrm{Hg}$ and Theta $=0^{\circ}$ 


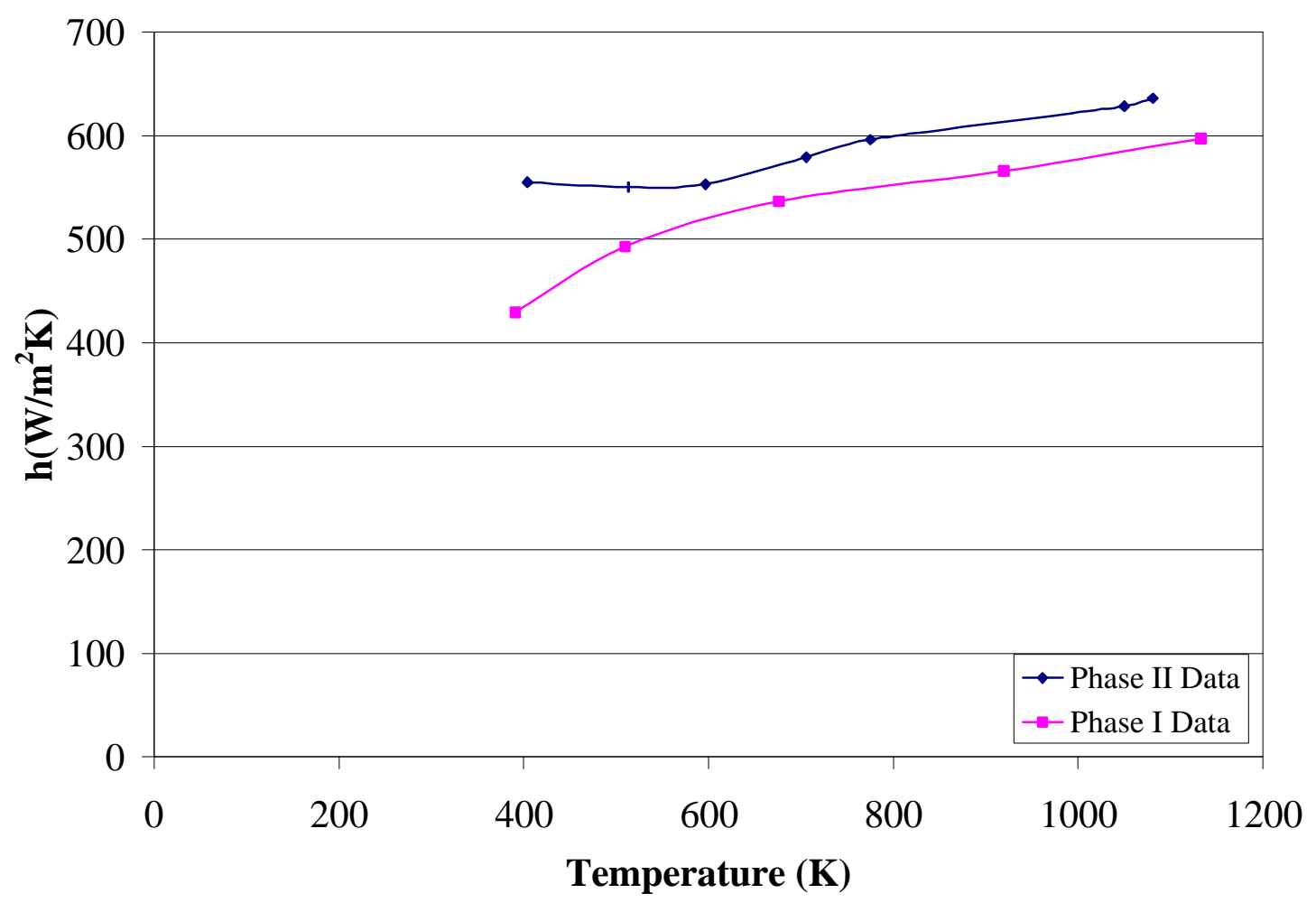

Figure 5.34: Comparison of Phase I and Phase II Heat Transfer Coefficients vs. Temperature for a 76 Micron Platinum Filament with $30 \mathrm{~cm}$. Length and Dynamic Pressure $\mathrm{q}=0.931 \mathrm{~mm} \mathrm{Hg}$ and $\mathrm{Theta}=0^{\circ}$ 


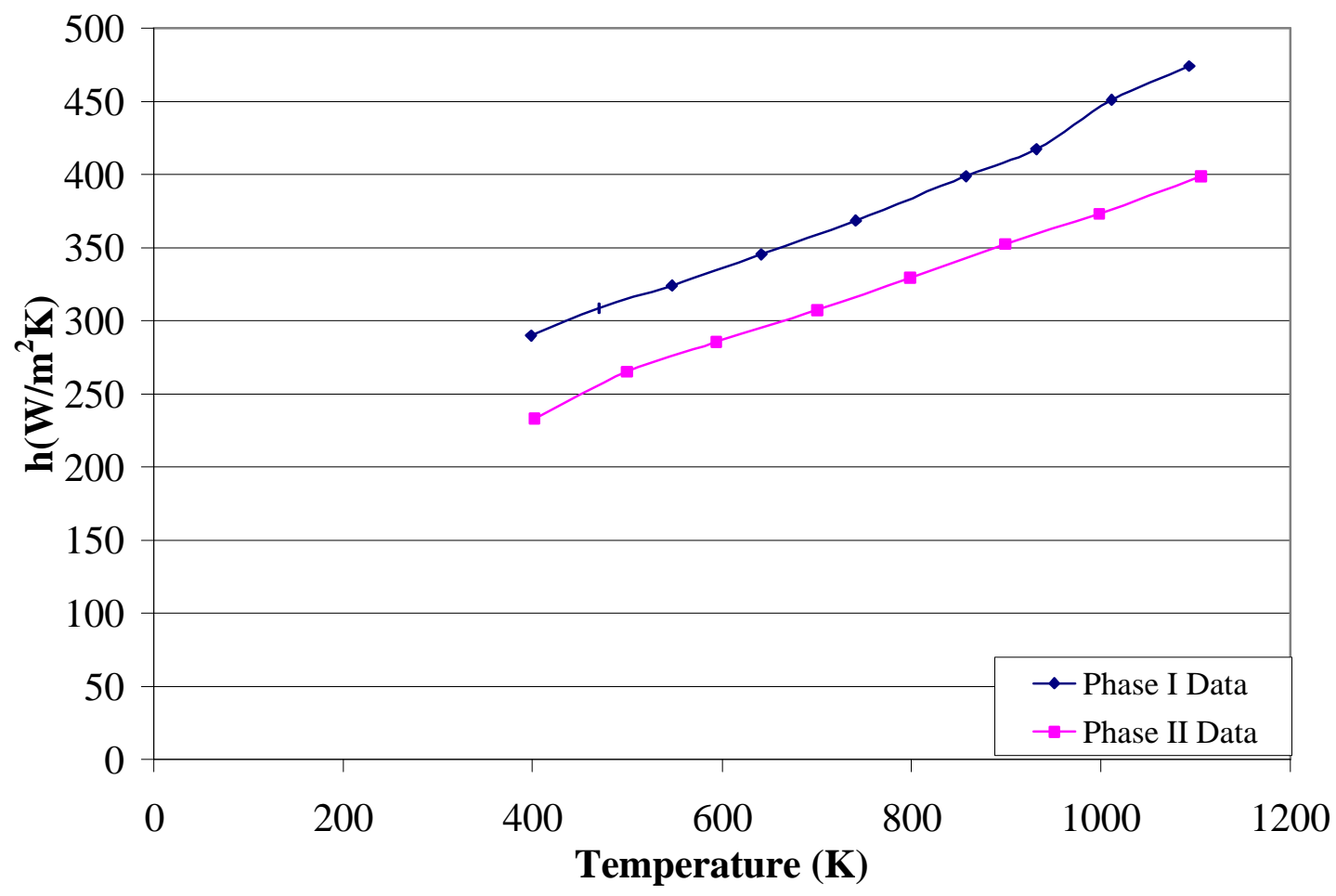

Figure 5.35: Comparison of Phase I and Phase II Heat Transfer Coefficients vs. Temperature for a 51 Micron Platinum Filament with $30 \mathrm{~cm}$. Length and Dynamic Pressure $\mathrm{q}=0.0 \mathrm{~mm} \mathrm{Hg}$ and Theta $=0^{\circ}$ 


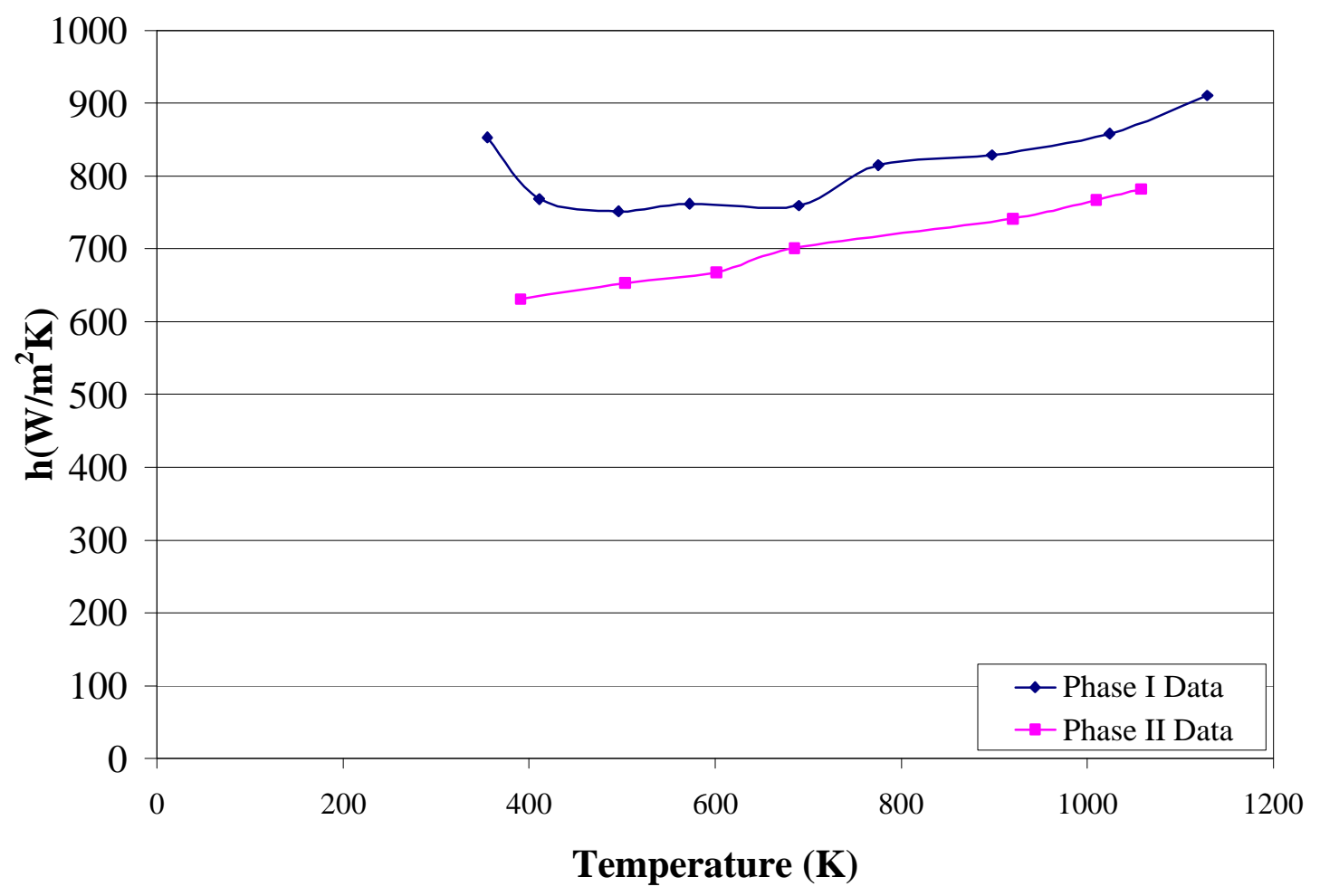

Figure 5.36: Comparison of Phase I and Phase II Heat Transfer Coefficients vs. Temperature for a 51 Micron platinum Filament with $30 \mathrm{~cm}$. Length and Dynamic Pressure $1=0.931 \mathrm{~mm} \mathrm{Hg}$ and Theta $=0^{\circ}$ 


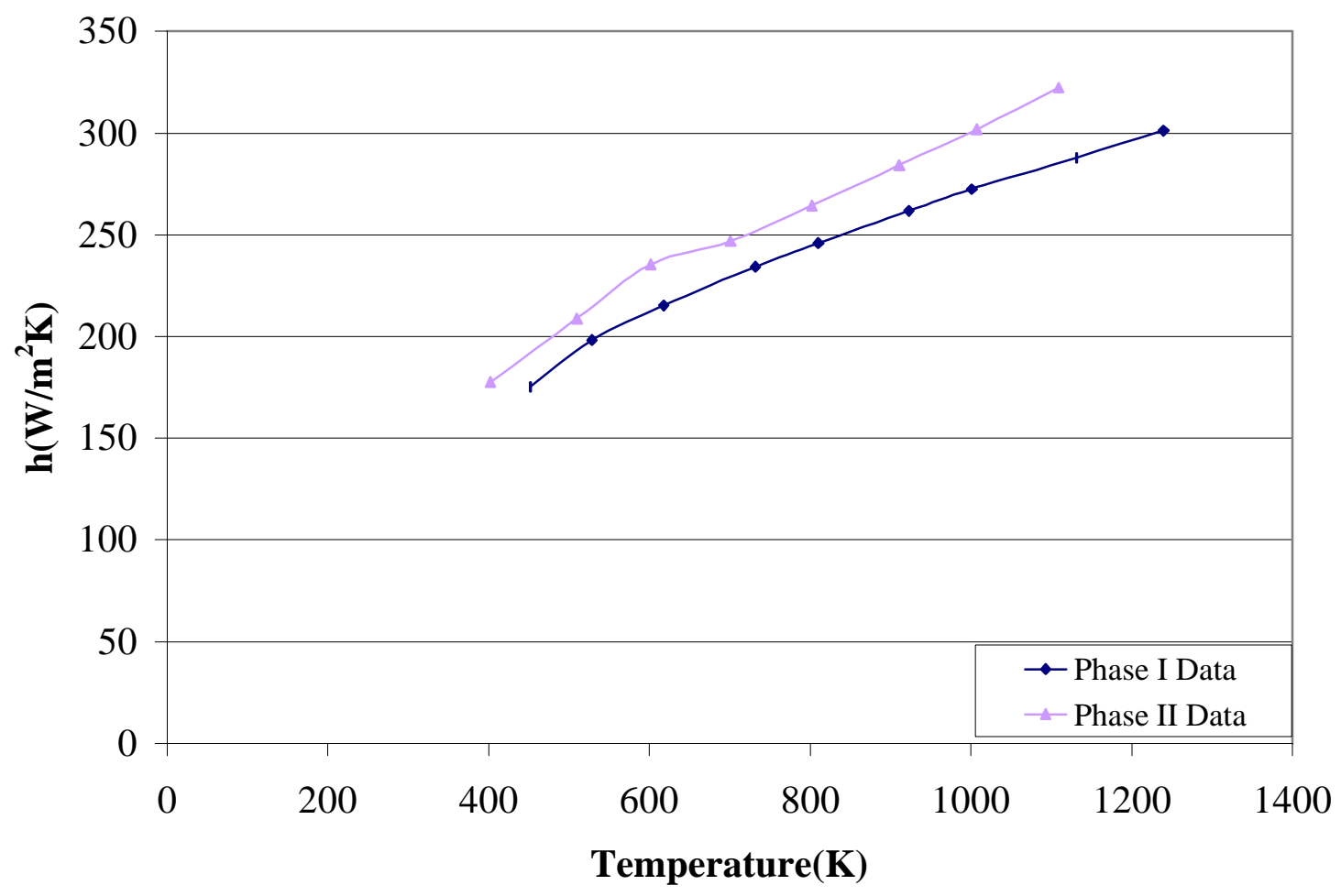

Figure 5.37: Comparison of Phase I and Phase II Heat Transfer Coefficients vs. Temperature for a 76 Micron Platinum Filament with $30 \mathrm{~cm}$. Length and Dynamic Pressure $\mathrm{q}=0.0 \mathrm{~mm} \mathrm{Hg}$ at $\mathrm{Theta}=7^{\circ}$ 


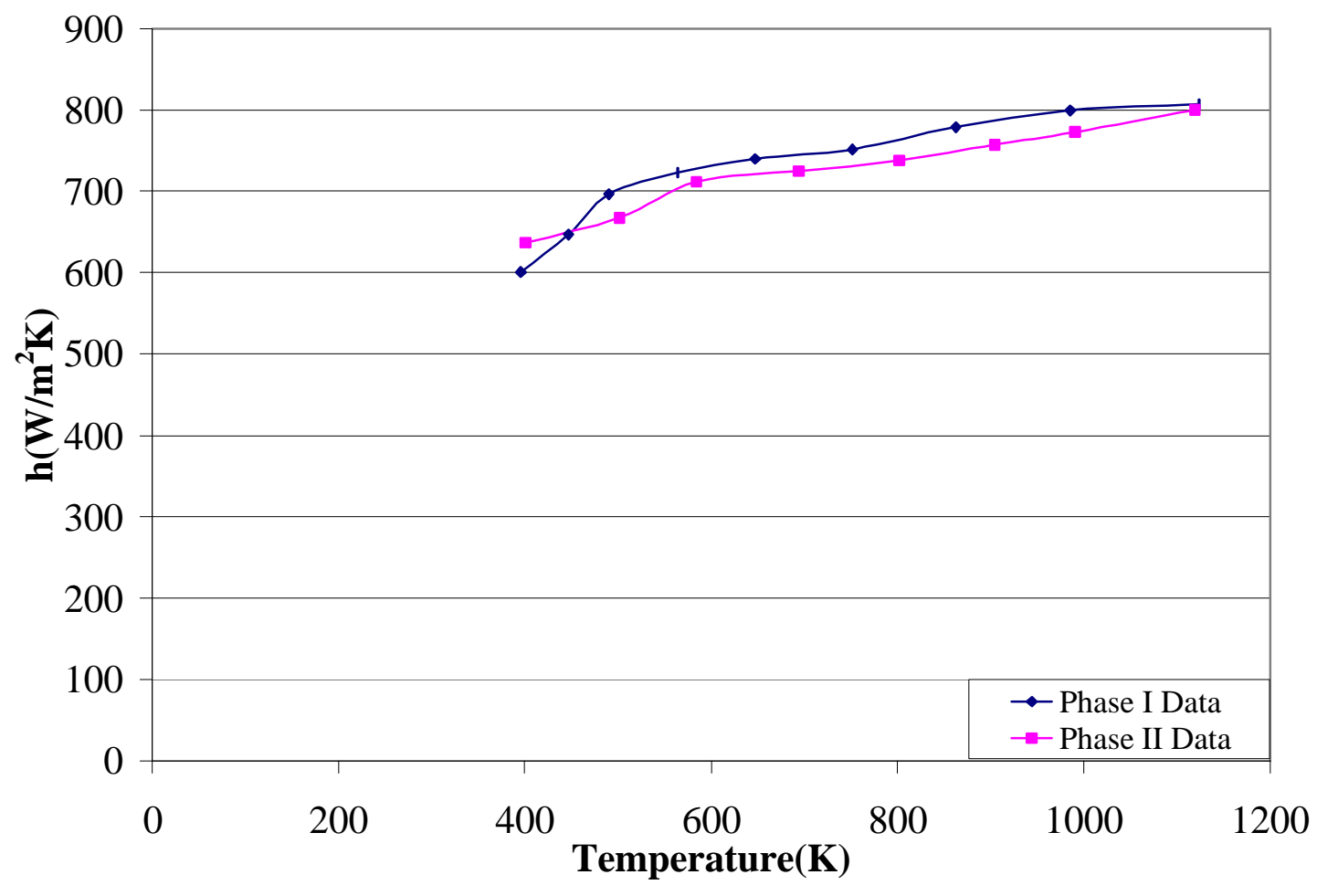

Figure 5.38: Comparison of Phase I and Phase II Heat Transfer Coefficients for a 76 Micron Platinum Filament with $30 \mathrm{~cm}$. Length nd Dynamic Pressure q=0.931 mm Hg and Theta $=7^{\circ}$ 


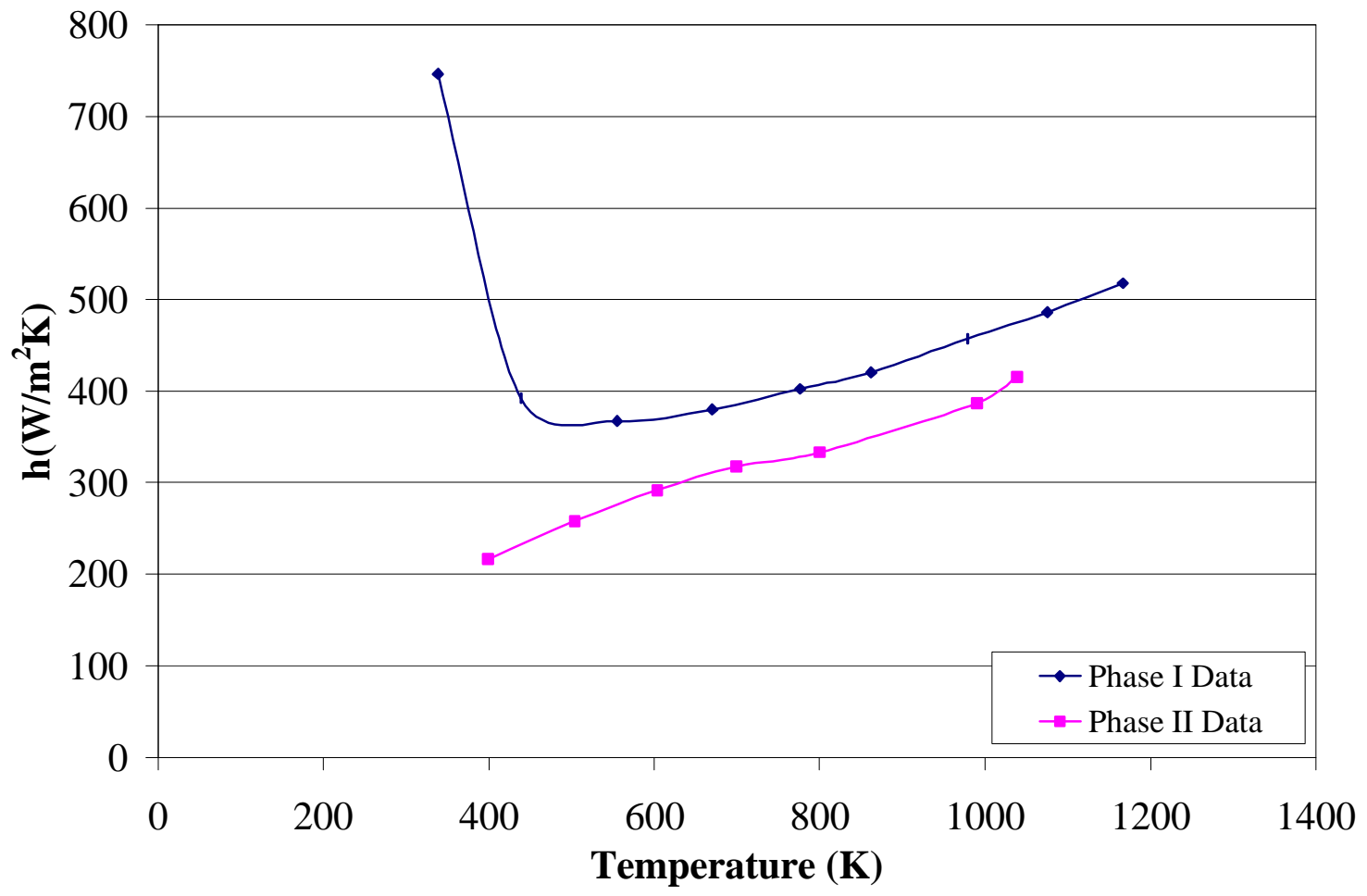

Figure 5.39: Comparison of Phase I and Phase II Heat Transfer Coefficients vs. Temperature for a 51 Micron Platinum Filament with $30 \mathrm{~cm}$. Length and Dynamic Pressure $\mathrm{q}=0.0 \mathrm{~mm} \mathrm{Hg}$ and Theta $=7^{\circ}$ 


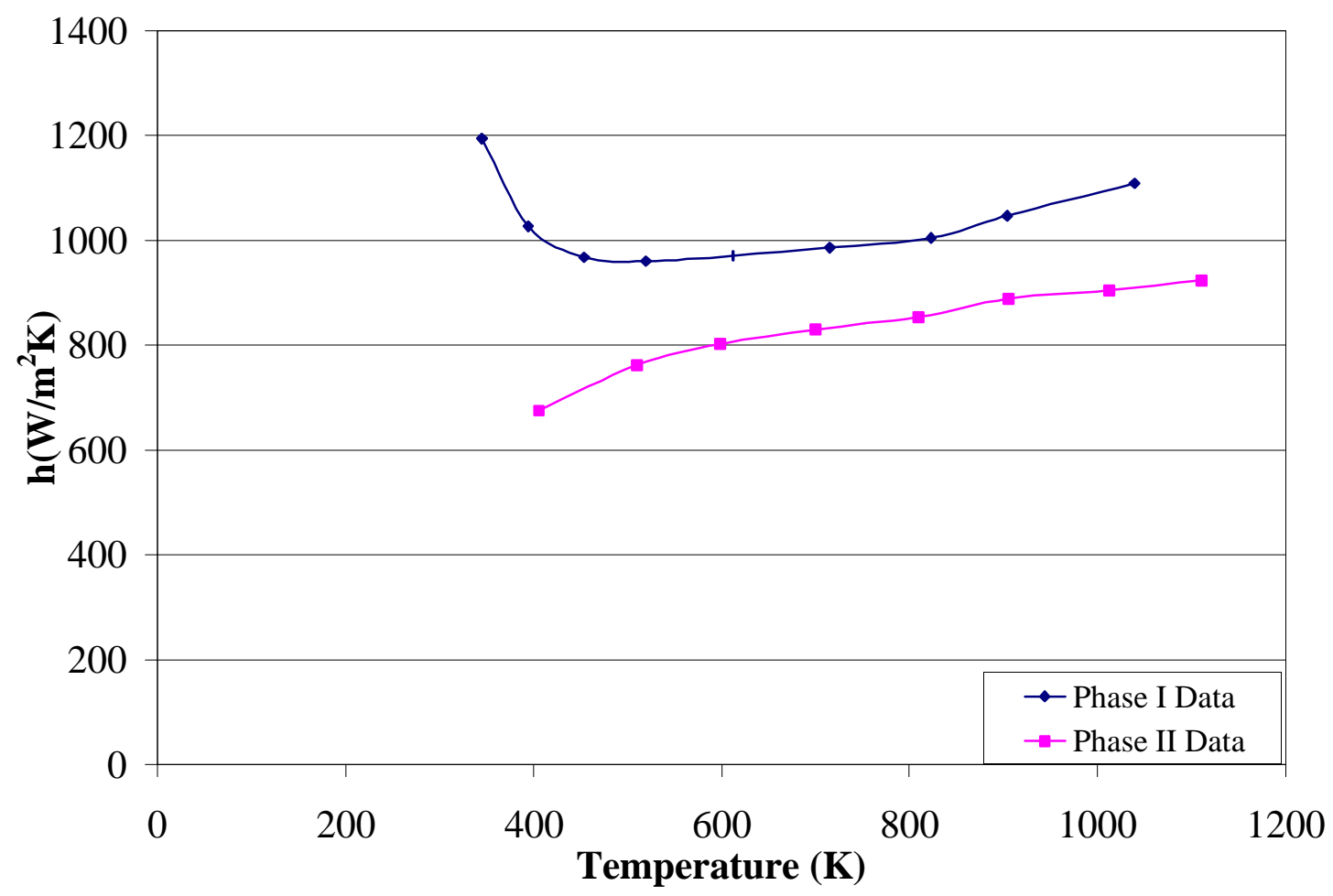

Figure 5.40: Comparison of Phase I and Phase II Heat Transfer Coefficients vs. Temperature for a 51 Micron Platinum Filament with $30 \mathrm{~cm}$. Length and dynamic Pressure $\mathrm{q}=0.931 \mathrm{~mm} \mathrm{Hg}$ and Theta $=7^{\circ}$ 


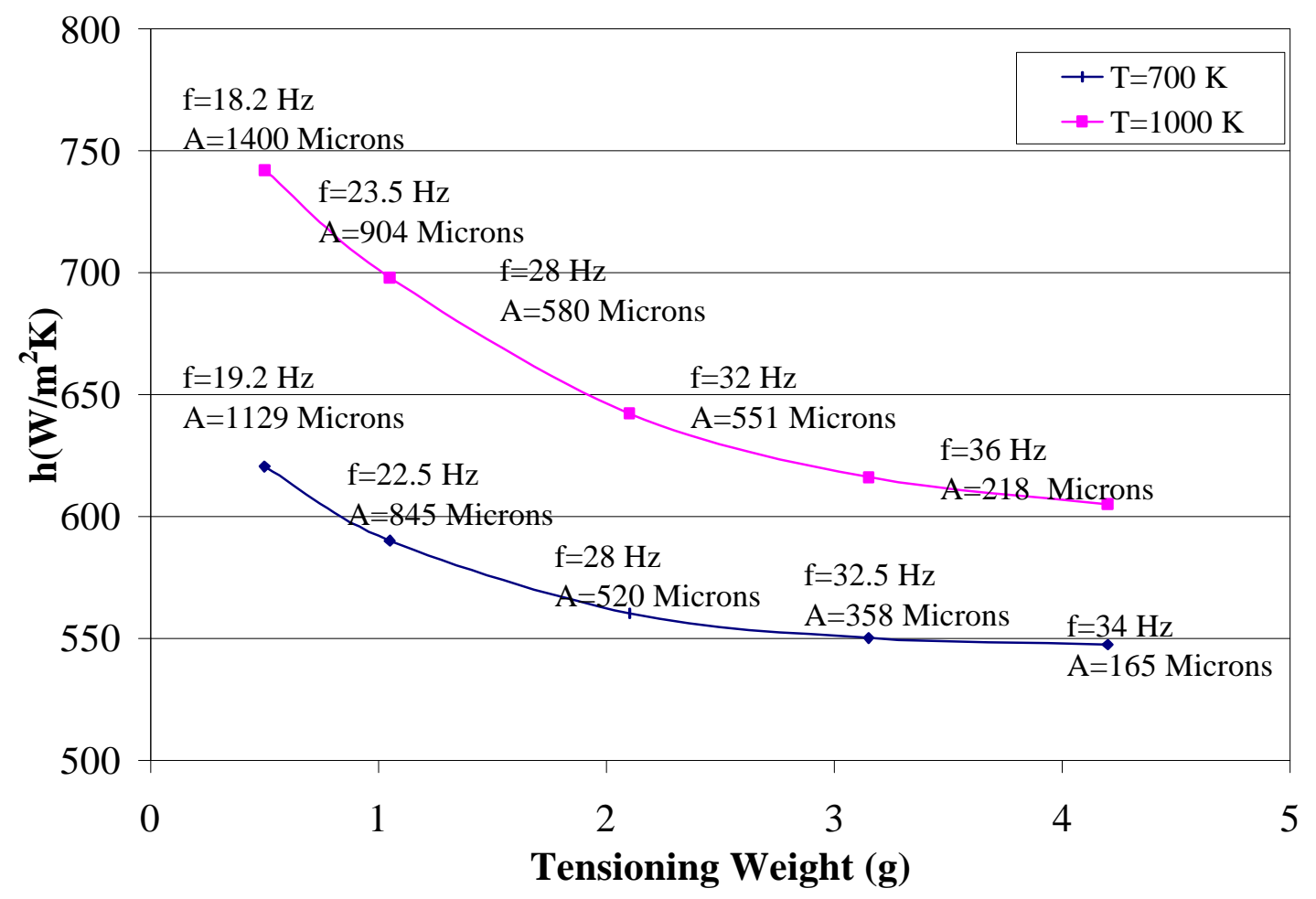

Figure 5.41: Heat Transfer Coefficient vs. Tensioning Weight with Frequency and Amplitude of Vibrations Listed for a Each Point for a 76 Micron Platinum Filament with $30 \mathrm{~cm}$. Length, Dynamic Pressure q=1.397 $\mathrm{mm} \mathrm{Hg}$ and Theta $=0^{\circ}$ 


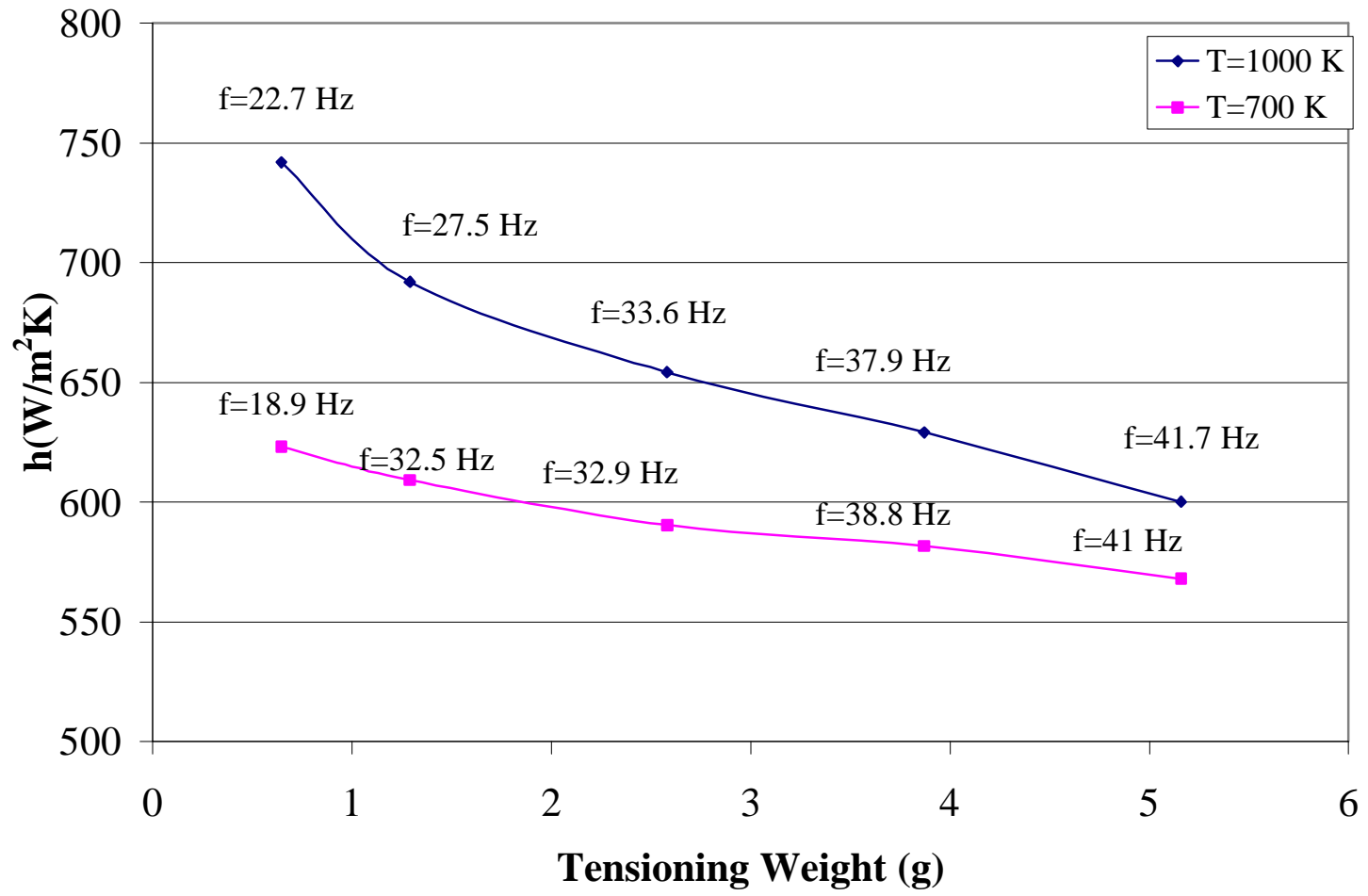

Figure 5.42: Heat Transfer Coefficient vs. Tensioning Weight with Frequency of Vibrations Listed for a Each Point for a 76 Micron Platinum Filament with $30 \mathrm{~cm}$. Length, Dynamic Pressure $\mathrm{q}=1.397 \mathrm{~mm} \mathrm{Hg}$ and Theta $=0^{\circ}$ 


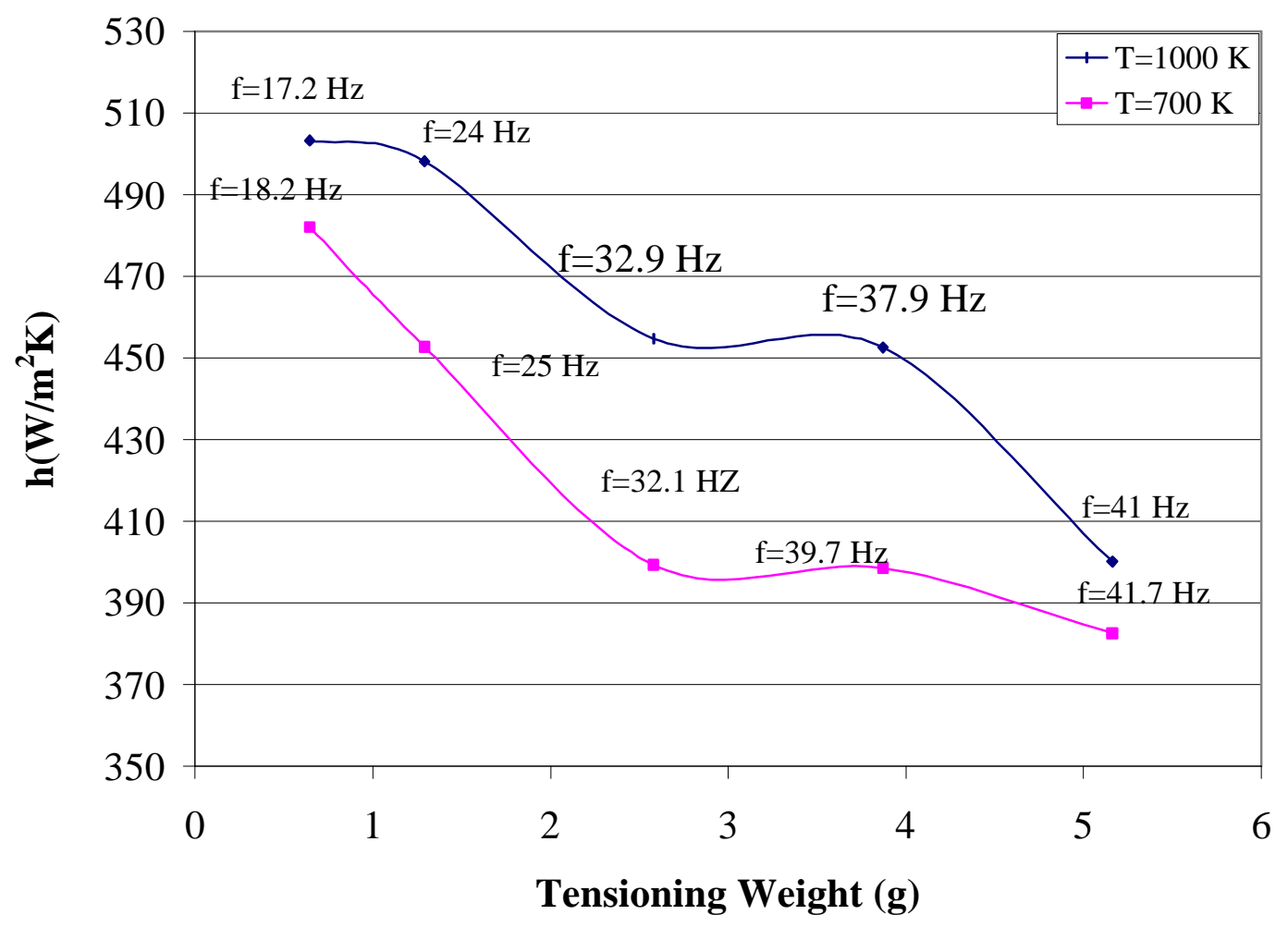

Figure 5.43: Heat Transfer Coefficient vs. Tensioning Weight with Frequency of Vibrations Listed for a Each Point for a 76 Micron Platinum filament with $30 \mathrm{~cm}$. Length, Dynamic Pressure q $=0.466 \mathrm{~mm} \mathrm{Hg}$ and Theta $=0^{\circ}$ 


\section{Chapter 6}

\subsection{Empirical Equation for Heat Transfer Coefficient}

Based on the behavior of experimental data collected throughout the project, it was possible to develop an empirical equation capable of predicting the heat transfer coefficient based on various operating parameters. From an earlier study by Morris, Loth and Bond [1] it was determined that distance from the leading point of the filament was insignificant to the overall heat transfer coefficient. Experimental data indicated that the influencing factors of heat transfer coefficient were the filament diameter, temperature difference between the filament and the freestream, filament temperature, flow velocity and crossflow angle. The empirical equation for the heat transfer coefficient was assumed to take the form:

$$
\mathrm{h}=\mathrm{A}+\mathrm{B}
$$

where $\mathrm{h}$ is the heat transfer coefficient in $\mathrm{W} / \mathrm{m}^{2} \mathrm{~K}$, and $\mathrm{A}$ and $\mathrm{B}$ are the two components of the empirical equation for heat transfer coefficient. Component $\mathrm{A}$ is the component representing heat transfer coefficient at parallel flow as a function of filament diameter, filament temperature and flow velocity or the heat transfer coefficient at zero degree crossflow angle. Component $\mathrm{B}$ is a modification to the heat transfer coefficient to account for crossflow angle.

\subsection{Component A of Empirical Equation for Heat Transfer Coefficient}

Observation of the heat transfer coefficient vs. temperature graphs (Figures 5.1, $5.2,5.3,5.4,5.5)$ reveals a strong tendency in all of the curves shown on these graphs 
toward linearity. Assuming that the relationship between heat transfer coefficient and temperature is linear yields an A component in Equation 6.1 that follows the form

$$
A=S\left(T-T_{\infty}\right)+I
$$

where $\mathrm{A}$ is a component of the heat transfer coefficient (Equation 6.1) in W/m $\mathrm{m}^{2} \mathrm{~K}, \mathrm{~S}$ is the slope of the linear relationship of heat transfer coefficient and temperature, $\mathrm{T}$ is temperature of the filament in Kelvin, $\mathrm{T}_{\infty}$ is the freestream temperature in Kelvin and $\mathrm{I}$ is the intercept of the linear relationship of heat transfer coefficient and temperature difference. In this equation, both $\mathrm{S}$ and I components may be functions of various operational parameters. A linear least squares fit was performed on all of the data series contained in the heat transfer coefficient versus temperature graphs. The trendline and resulting linear equations can be observed on the heat transfer coefficient vs. temperature graphs plotted in Chapter 5 (Figures 5.1 through 5.20).

It was determined that the zero velocity data should not be included in the empirical equation due to the uncertainty that occurred in these data. Zero velocity refers to the absence of forced flow, but does not consider the occurrence of natural convective flow. This natural flow is difficult to detect or measure and may result in abnormalities of data trends. Additionally, the zero velocity case is not a practical configuration experienced in the filament forming industry therefore including these data in the curvefit would not be beneficial for use in this area.

After a linear fit was produced for all of the heat transfer versus temperature graphs, the resulting equations were examined. Because the slopes of these trendlines, referred to as slope ${ }^{\text {ht }}$ due to their origins in the heat transfer vs. temperature graphs to avoid confusion with other slopes being discussed, were not constant and appeared to be 
a function of velocity and filament diameter, they were plotted vs. flow velocity (Figure 6.1), and this relationship was observed to be linear. A linear least squares fit was performed on these data. The resulting trendlines and equations can be observed on Figure 6.1. With the exception of 25.4-micron filament data, the slopes of the resulting trendlines are nearly constant with velocity. Because of this, the midpoint of these data, determined to be at approximately $15 \mathrm{~m} / \mathrm{s}$, was chosen as the appropriate slope ${ }^{\text {ht }}$ value. These midpoint data were then plotted versus filament diameter (Figure 6.2). This relationship was observed to be linear but not constant, and a linear least squares fit was performed on this data. The resulting trendline and equation can be observed in Figure 6.2. Because slope ${ }^{\text {ht }}$ is a strong function of filament diameter, the linear equation representing the resulting trendline was determined to be the $\mathrm{S}$ value in the A component of the linear equation for heat transfer coefficient (Equation 6.1). Therefore, equation 6.2 becomes:

$$
\mathrm{A}=(-0.01180 * \mathrm{~d}+0.9057) *\left(\mathrm{~T}-\mathrm{T}_{\infty}\right)+\mathrm{I}
$$

where $\mathrm{A}$ is the a component of the heat transfer coefficient (Equation 6.1 ) in $\mathrm{W} / \mathrm{m}^{2} \mathrm{~K}, \mathrm{~d}$ is filament diameter in microns, $\mathrm{T}$ is filament temperature in Kelvin, $\mathrm{T}_{\infty}$ is the freestream temperature in Kelvin and I is the intercept yet to be determined.

Determination of the intercept (I) involves much the same procedure involved in determining the slope (S) and based on the following procedure was assumed to take the form

$$
\mathrm{I}=\mathrm{S}_{\mathrm{I}} \mathrm{V}+\mathrm{C}(\mathrm{d})
$$

where $\mathrm{I}$ is the intercept to be included in Equation $6.3, \mathrm{~S}_{\mathrm{I}}$ is the slope of the intercept trendlines and $\mathrm{C}(\mathrm{d})$ is some function of filament diameter. 
The intercepts were determined from the linear trendline equations from the heat transfer coefficient vs. temperature graphs (Figures 5.1 through 5.5). These intercepts were plotted versus flow velocity (Figure 6.3). These relationships were observed to be linear. A linear least squares fit was performed on these data. These trendlines and equations are shown on Figure 6.3. Observing the trendlines on Figure 6.3, it is apparent that the slopes of the trendlines are very similar. An average slope representative of the slopes of all the trendlines depicted on Figure 6.3 was determined to be 23.006. Inserting this in Equation 6.4 yields

$$
\mathrm{I}=23.01 * \mathrm{~V}+\mathrm{C}(\mathrm{d})
$$

The midpoint on these data series was also determined to be at approximately 15 $\mathrm{m} / \mathrm{s}$. The value of the intercepts at this midpoint, henceforth referred to as $\mathrm{I}_{\mathrm{M}}$, was determined and plotted versus filament diameter (Figure 6.4). Using $\mathrm{I}_{\mathrm{M}}$ as $\mathrm{I}$ and $15 \mathrm{~m} / \mathrm{s}$ as $\mathrm{V}, \mathrm{C}(\mathrm{d})$ can be determined.

$$
\mathbf{C}(\mathbf{d})=\mathbf{I}_{M}-(\mathbf{2 3 . 0 1}) *(\mathbf{1 5})
$$

From the linear fit equation illustrated in Figure 6.4 and from Equation $6.6 \mathrm{C}(\mathrm{d})$ can be determined.

$$
C(d)=-6.612 * d+573.5
$$

This leads to the following equation for I:

$$
\mathrm{I}=23.01 * \mathrm{~V}-6.612 * \mathrm{~d}+573.5
$$

Based on Equations 6.3 and 6.8 the component $\mathrm{A}$ of the overall heat transfer coefficient equation becomes

$$
\mathrm{A}=(-0.01180 * \mathrm{~d}+0.9057) *\left(\mathrm{~T}-\mathrm{T}_{\infty}\right)+(23.01 * \mathrm{~V}-6.612 * \mathrm{~d}+573.5)
$$


where $\mathrm{d}$ is filament diameter in microns, $\mathrm{T}$ is temperature in Kelvin and $\mathrm{V}$ is velocity in $\mathrm{m} / \mathrm{s}$. Substituting experimental points into the equation verifies the curve-fit for zero crossflow angle (Figures 6.5 through 6.8).

\subsection{Component B of Empirical Equation for Heat Transfer Coefficient.}

The first step in determining the modification to the empirical equation for heat transfer coefficient to account for angle is to observe the heat transfer coefficient vs. angle graphs (Figures 5.26 through 5.30). These graphs lead to the assumption that the relationship between heat transfer coefficient and angle is a strong function of velocity.

The zero velocity data was subtracted from the rest of the data yielding a $\Delta \mathrm{h}$, change in heat transfer coefficient from the zero angle case. This delta heat transfer coefficient was plotted versus velocity at the different angles at any constant temperature (Figures 6.9 through 6.13). This relationship was observed to be approximately linear and a linear least squares fit was performed. The resulting trendlines and equations can be observed for varying filament diameters in Figures 6.9 through 6.13. The slopes of these graphs were plotted versus angle (Figure 6.14). Because a reliable equation had already been developed for a no crossflow (zero angle) case, a change in slope was plotted by subtracting the no crossflow angle heat transfer data from the rest of the data (Figure 6.15). The relationship between the change in slope of the $\Delta \mathrm{h}$ versus velocity graphs and the crossflow angle did not appear to be linear.

The modification to the empirical equation for heat transfer coefficient to correct for different crossflow angles had to fulfill several requirements. The modification had to 
drop out of the equation at a crossflow angle of zero. A sine function would fulfill this requirement and also be a physically expected relationship. The next step to obtain a realistic curve fit for the heat transfer coefficient versus angle was to examine each individual curve from Figure 6.15 and to try to obtain the best possible fit for the entire graph. The functions that most closely followed the experimental curves appeared to be a quadratic equation and a sine squared function. Each of these were plotted with the curve to determine the best fit (Figures 6.16 through 6.20). The sine squared function appeared to be as good a fit in some cases and slightly better in others. So the modification was assumed to take the form

$$
\mathrm{B}=\mathrm{V} *\left(\mathrm{~K} * \sin ^{2}(\theta)\right)
$$

where $\mathrm{B}$ is the crossflow component of the heat transfer coefficient component from Equation $6.1, \mathrm{~V}$ is the velocity in $\mathrm{m} / \mathrm{s}, \mathrm{K}$ is the coefficient of the sine-squared term and $\theta$ is the crossflow angle in degrees. The coefficient of the sine-squared term was not a constant. Because it varied with filament diameter Equation 6.10 was rewritten as

$$
\mathrm{B}=\mathrm{V} *\left(\mathrm{~K}(\mathrm{~d}) * \sin ^{2}(\theta)\right)
$$

where $\mathrm{d}$ is the filament diameter in microns. $\mathrm{K}(\mathrm{d})$ was then plotted versus wire diameter (Figure 6.21). The resulting curve was fitted with both a linear and a quadratic function, which can be observed on Figure 6.21. The quadratic function was selected as the most appropriate fit. Equation 6.10 therefore became

$$
B=V *\left(\left(0.8452 d^{2}-111.3 d+4631\right) * \sin ^{2}(\theta)\right)
$$

Adding components $\mathrm{A}$ and $\mathrm{B}$ yields the following empirical equation for heat transfer coefficient 


$$
\begin{gathered}
\mathrm{h}\left(\mathrm{W} / \mathrm{m}^{2} \mathrm{~K}\right)=(-0.01180 * \mathrm{~d}+0.9057) *\left(\mathrm{~T}-\mathrm{T}_{\infty}\right)+(23.01 * \mathrm{~V}-6.612 * \mathrm{~d}+573.5)+ \\
\mathrm{V} *\left(\left(0.8452 \mathrm{~d}^{2}-111.3 \mathrm{~d}+4631\right) * \sin ^{2}(\theta)\right)
\end{gathered}
$$

where $\mathrm{d}$ is filament diameter in microns, $\mathrm{T}$ is filament temperature in Kelvin, $\mathrm{T}_{\infty}$ freestream temperature in Kelvin, $\mathrm{V}$ is flow velocity in $\mathrm{m} / \mathrm{s}$ and $\theta$ is crossflow angle in degrees. The empirical equation can be verified by plotting experimental points and the empirical equation on the same graph (Figure 6.22 through 6.36). Figures 6.22 through 6.27 illustrate the empirical equation results and experimental heat transfer coefficient versus velocity, and Figures 6.28 through 6.36 show the experimental and modeled heat transfer coefficients versus temperature difference between the filament and the freestream. While not precisely fitting the experimental data, the empirical equation is accurate within an acceptable error range.

\subsection{Error Analysis of Empirical Equation}

Due to the inherent uncertainties associated with some of the operating parameters involved in this project, some error is to be expected. For example the crossflow angle setting is only accurate to approximately $12^{\circ}$. As shown in Chapter 5 , repeated data can differ up to $15 \%$. Therefore, even if the empirical model was a perfect fit of the experimental data, an actual error of nearly $15 \%$ could be expected. To determine the accuracy of the empirical model in reproducing the experimental data, an error analysis on these data was performed.

In order to determine the error in the empirical equation, 170 experimental data points were selected, one point for each of the different velocities at each different filament diameter for three temperatures: a maximum $(1100 \mathrm{~K})$, a minimum $(400 \mathrm{~K})$, and 
a midpoint $(600 \mathrm{~K})$, and at three different crossflow angles, zero, $2.5^{\circ}$, and $7^{\circ}$. Errors were computed between each experimental point and the point resulting from the same parameters input into the empirical equation. A summary of the errors and standard deviations is given in Table 6.1. The average percent error for this study was $11.5 \%$, with a standard deviation of approximately $87 \mathrm{~W} / \mathrm{m}^{2} \mathrm{~K}$. Based on the error present in the experimental data (discussion to follow), it is believed that these numbers are well within acceptable limits.

Table 6.1: Summary of Error Analysis of Empirical Equation

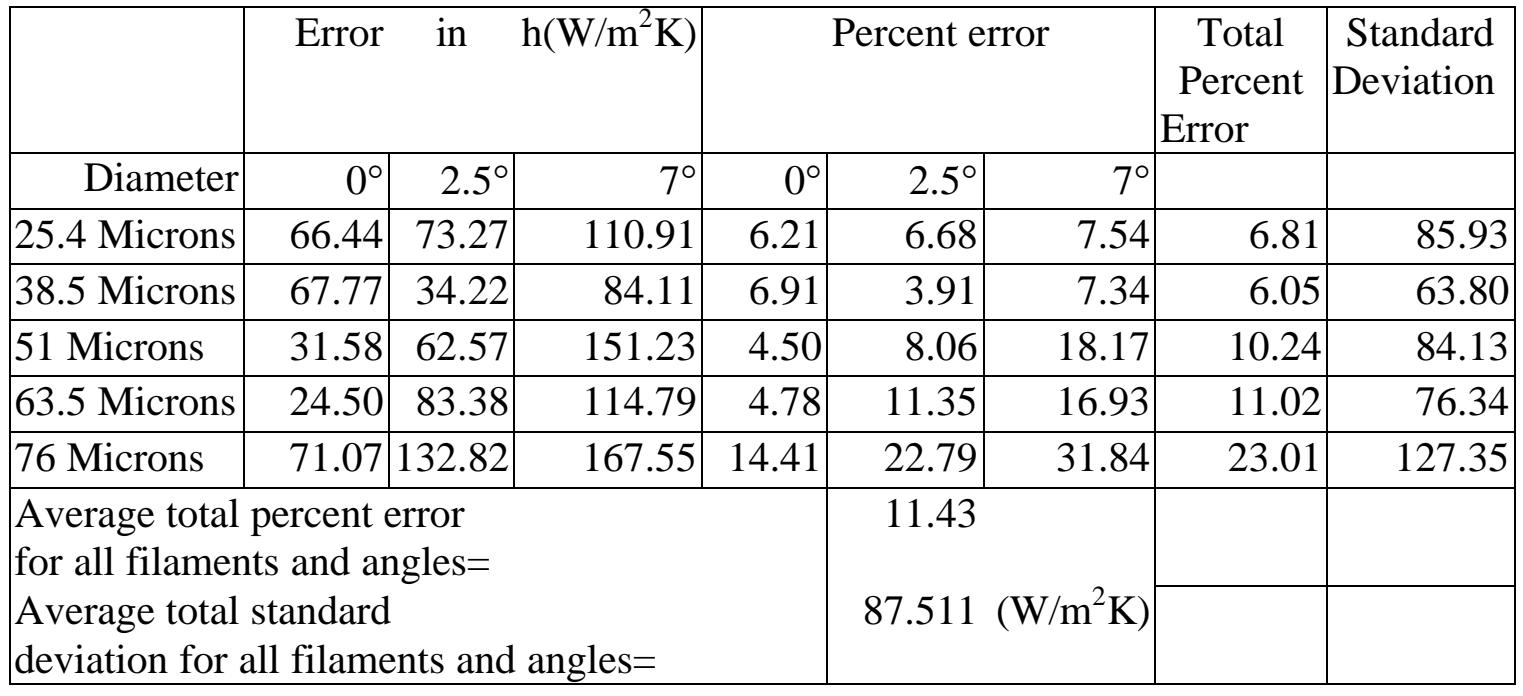

\subsection{Error Analysis of the Experimental Data}

A formal error analysis yields the approximate uncertainty in the measurements.

This uncertainty can be determined from the error in each of the dependent variables in the empirical equation, from the following equation:

$$
\mathrm{W}=\left[\left((\partial \mathrm{h} / \partial \mathrm{T}) * \mathrm{w}_{\mathrm{T}}\right)^{2}+\left((\partial \mathrm{h} / \partial \mathrm{d}) * \mathrm{w}_{\mathrm{d}}\right)^{2}+\left((\partial \mathrm{h} / \partial \mathrm{V})^{*} \mathrm{w}_{\mathrm{V}}\right)^{2}+\left((\partial \mathrm{h} / \partial \theta)^{*} \mathrm{w}_{\theta}\right)^{2}\right]^{1 / 2}
$$


where $\mathrm{W}$ is the overall uncertainty, $\partial \mathrm{h} / \partial \mathrm{T}$ is the partial derivative of the empirical equation for heat transfer coefficient with respect to filament temperature, $\mathrm{w}_{\mathrm{T}}$ is the uncertainty in temperature measurement, $\partial \mathrm{h} / \partial \mathrm{d}$ is the partial derivative of the empirical equation for heat transfer coefficient with respect to the filament diameter, $\mathrm{w}_{\mathrm{d}}$ is the uncertainty in the filament diameter measurement, $\partial \mathrm{h} / \partial \mathrm{V}$ is the partial derivative of the empirical equation for heat transfer coefficient with respect to freestream velocity, $\mathrm{w}_{\mathrm{V}}$ is the uncertainty in the velocity measurement, $\partial \mathrm{h} / \partial \theta$ is the partial derivative of the empirical equation for heat transfer coefficient with respect to crossflow angle, $\mathrm{w}_{\theta}$ is the uncertainty in the crossflow angle measurement. The uncertainty in the temperature measurement is assumed to be $50 \mathrm{~K}$ because this was the highest departure from the target temperature during measurements. The uncertainty in the diameter measurements is assumed to be 1.25 microns from the highest accuracy of the filament measurements. The crossflow angle can only be measured to approximately one degree. The velocity error can be calculated using the same technique shown in Equation 6.11. Incorporating the error in the dynamic pressure reading of 0.02 inches of water, and the error in the density of water, $0.04 \mathrm{~kg} / \mathrm{m}^{3}$, and taking the partial derivatives of the velocity equation with respect to both dynamic pressure and density, the velocity uncertainty is found to be $0.528 \mathrm{~m} / \mathrm{s}$. From these uncertainties, the maximum uncertainty can be found to be $15.3 \%$ (Appendix G). 


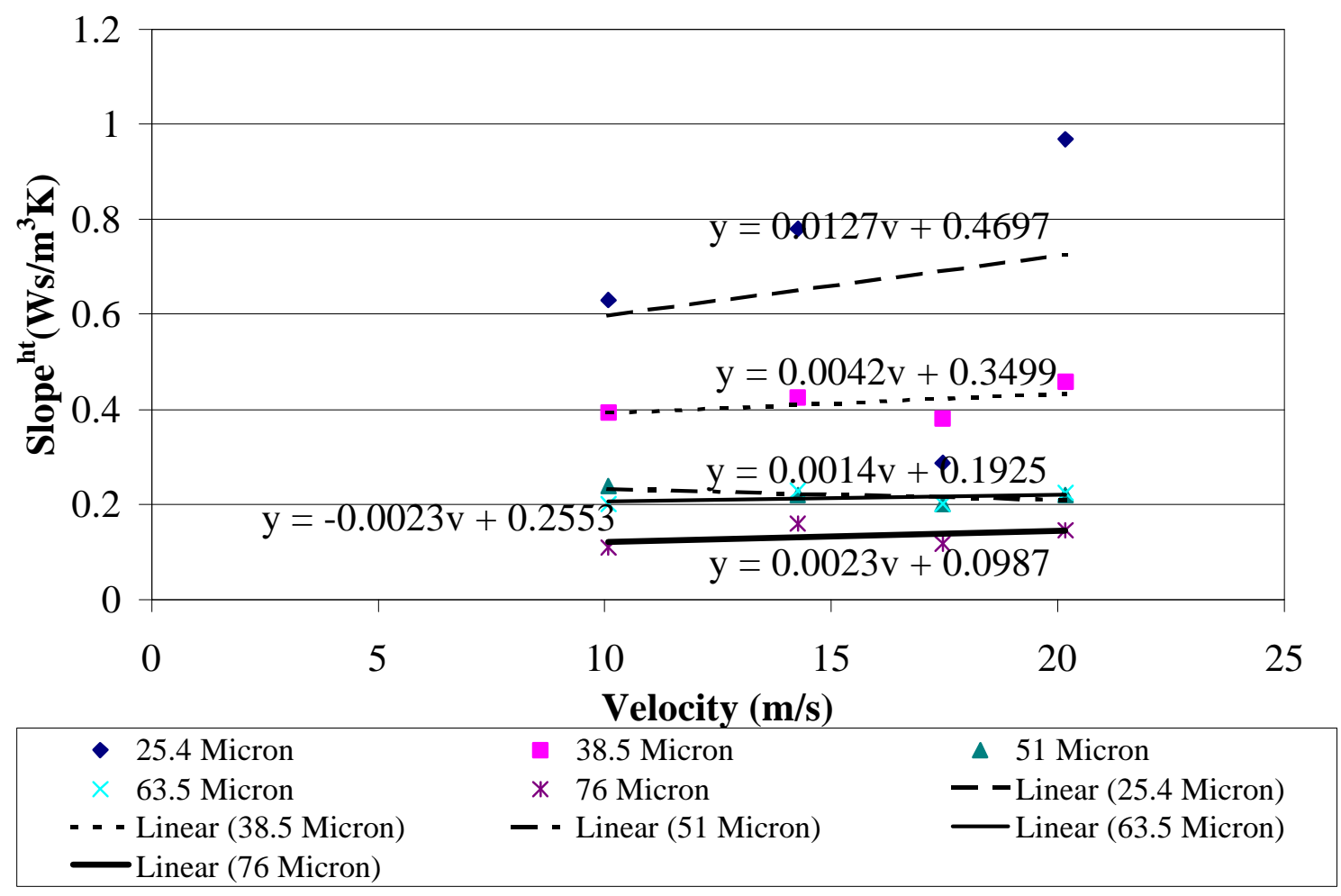

Figure 6.1: Effect of Velocity on Slope ${ }^{\text {ht }}$ of Heat Transfer Coefficient vs. Temperature Graphs for Theta $=0^{\circ}$ 


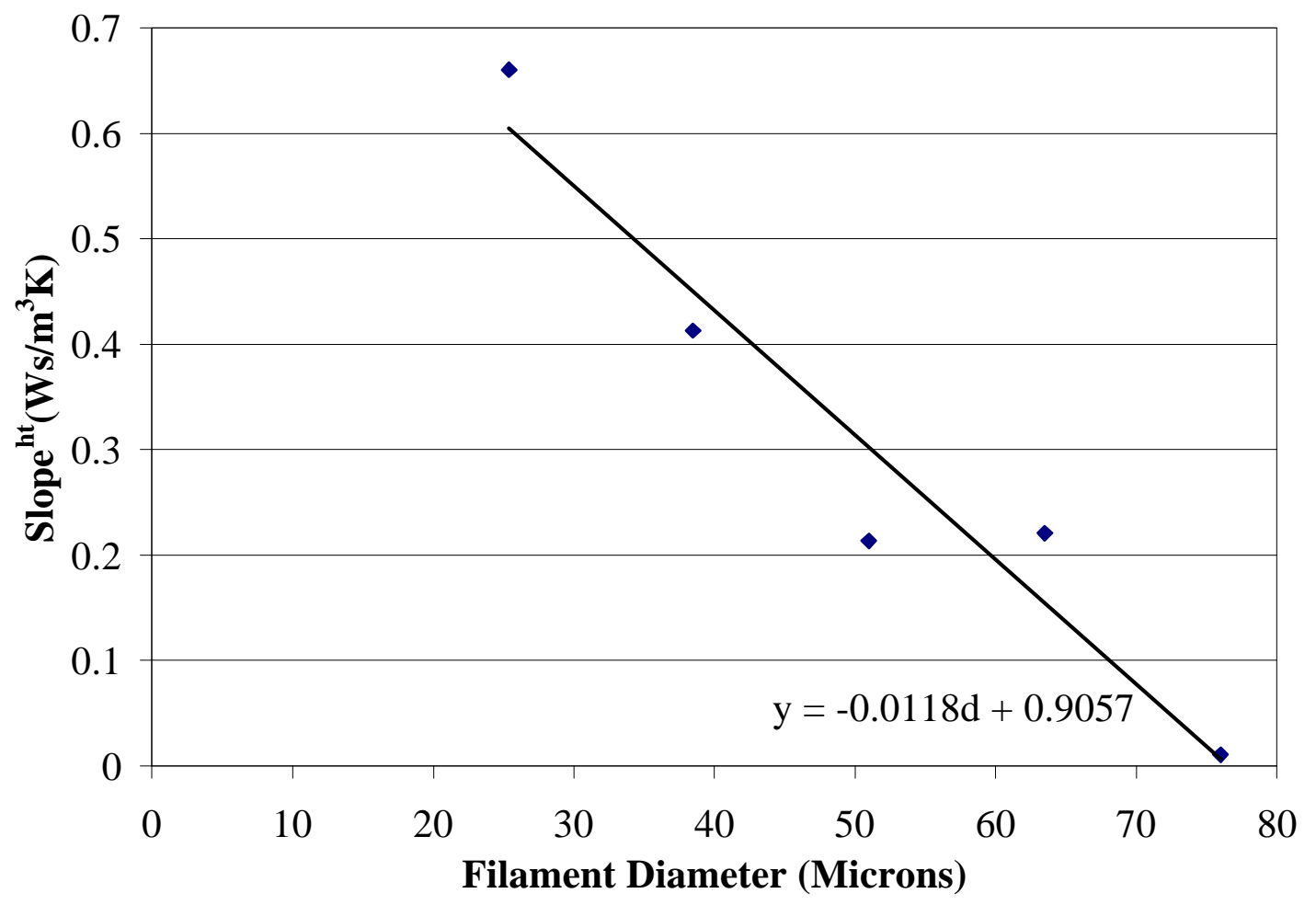

Figure 6.2: Midpoint of Slope ${ }^{\text {ht }}$ vs. Filament Diameter at Theta $=0^{\circ}$ 


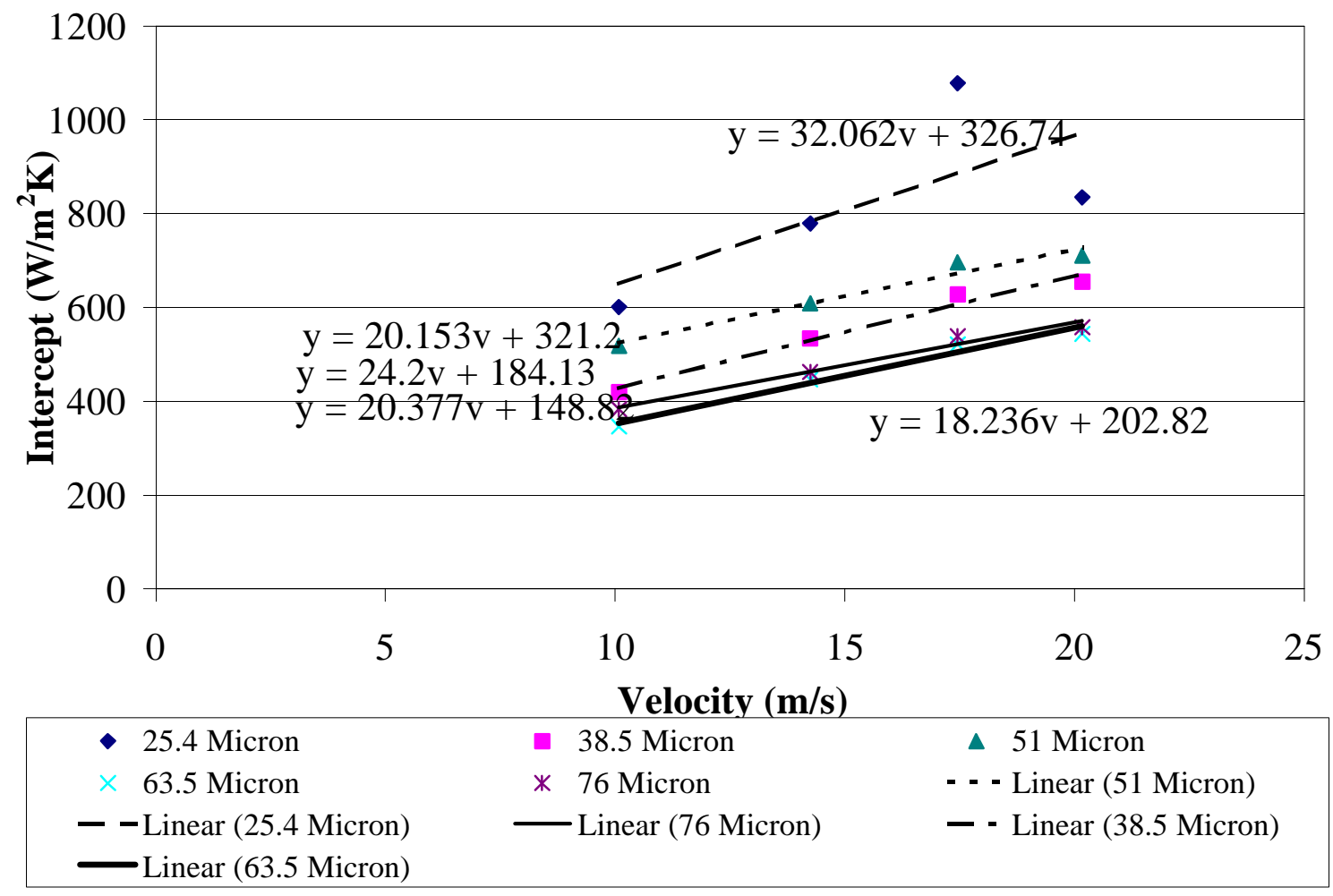

Figure 6.3: Effect of velocity on the Intercepts of the Heat Transfer Coefficient vs. Temperature Graphs at Theta $=0^{\circ}$ 


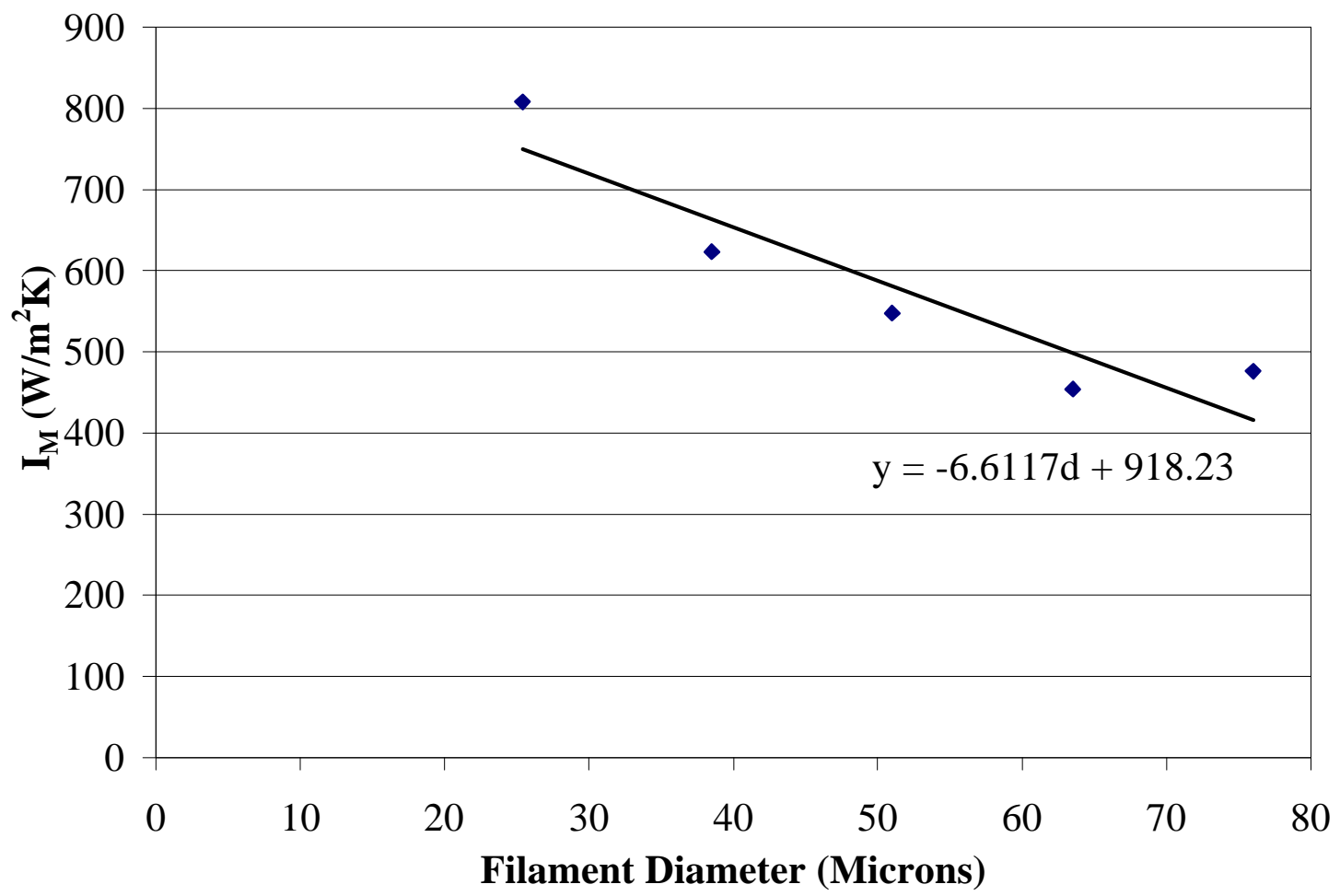

Figure 6.4: Effect of Filament Diameter on $I_{M}$ for the Intercept of Heat Transfer Coefficient vs. Temperature Graphs for Theta $=0^{\circ}$ 


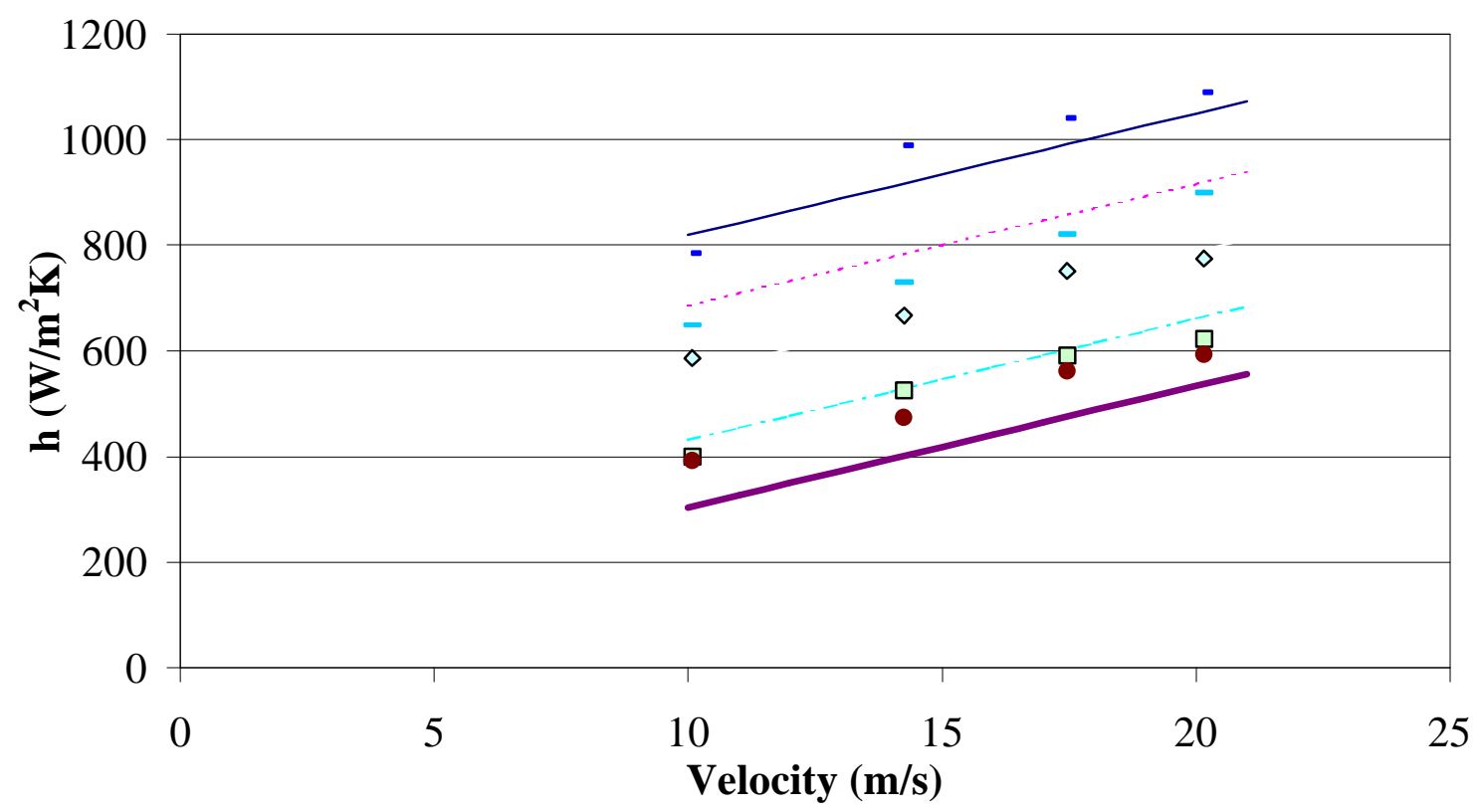

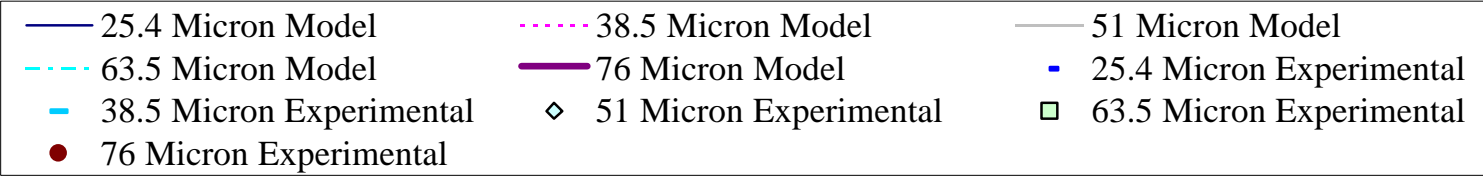

Figure 6.5: Comparison of Experimental and Model Heat Transfer Coefficients vs. Velocity at $600 \mathrm{~K}$ and Theta $=0^{\circ}$ 


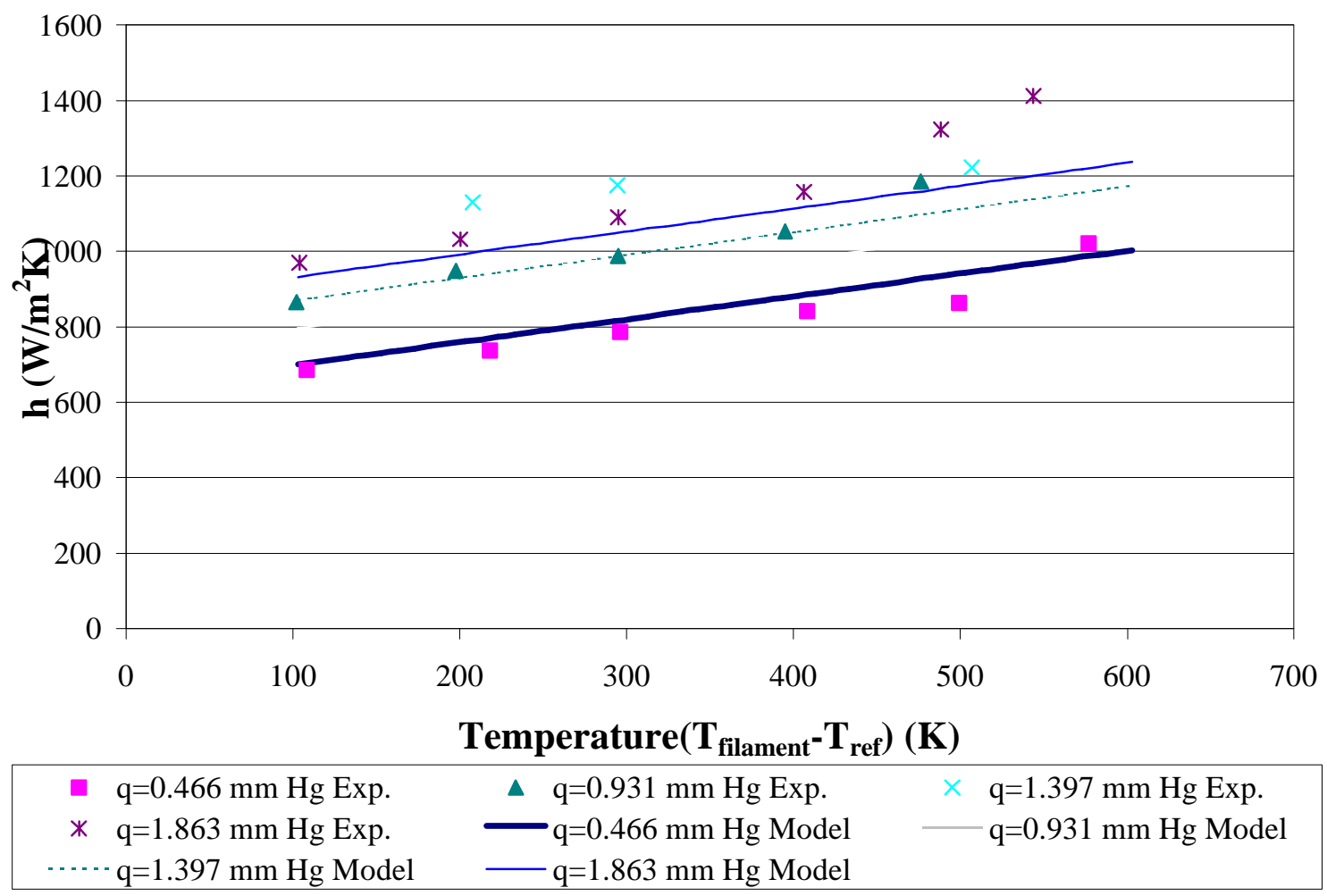

Figure 6.6: Experimental and Model Heat Transfer Coefficient vs. Temperature Difference of a 25.4 Micron Platinum Filament with a $30 \mathrm{~cm}$. Length and Theta $=0^{\circ}$ 


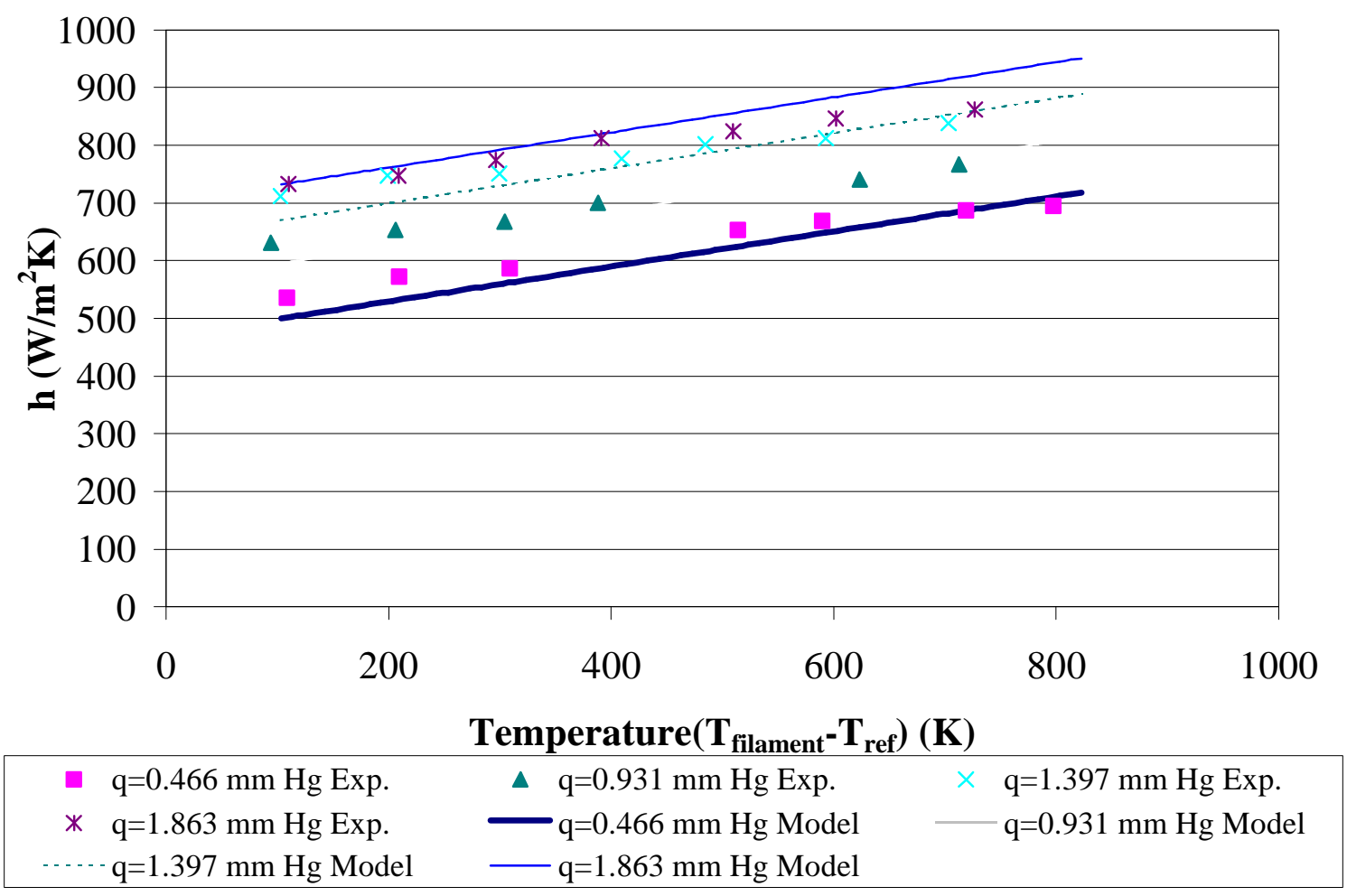

Figure 6.7: Experimental and Model heat Transfer coefficients vs. Temperature difference of a 51 Micron Platinum Filament with $30 \mathrm{~cm}$. Length and Theta $=0^{\circ}$ 


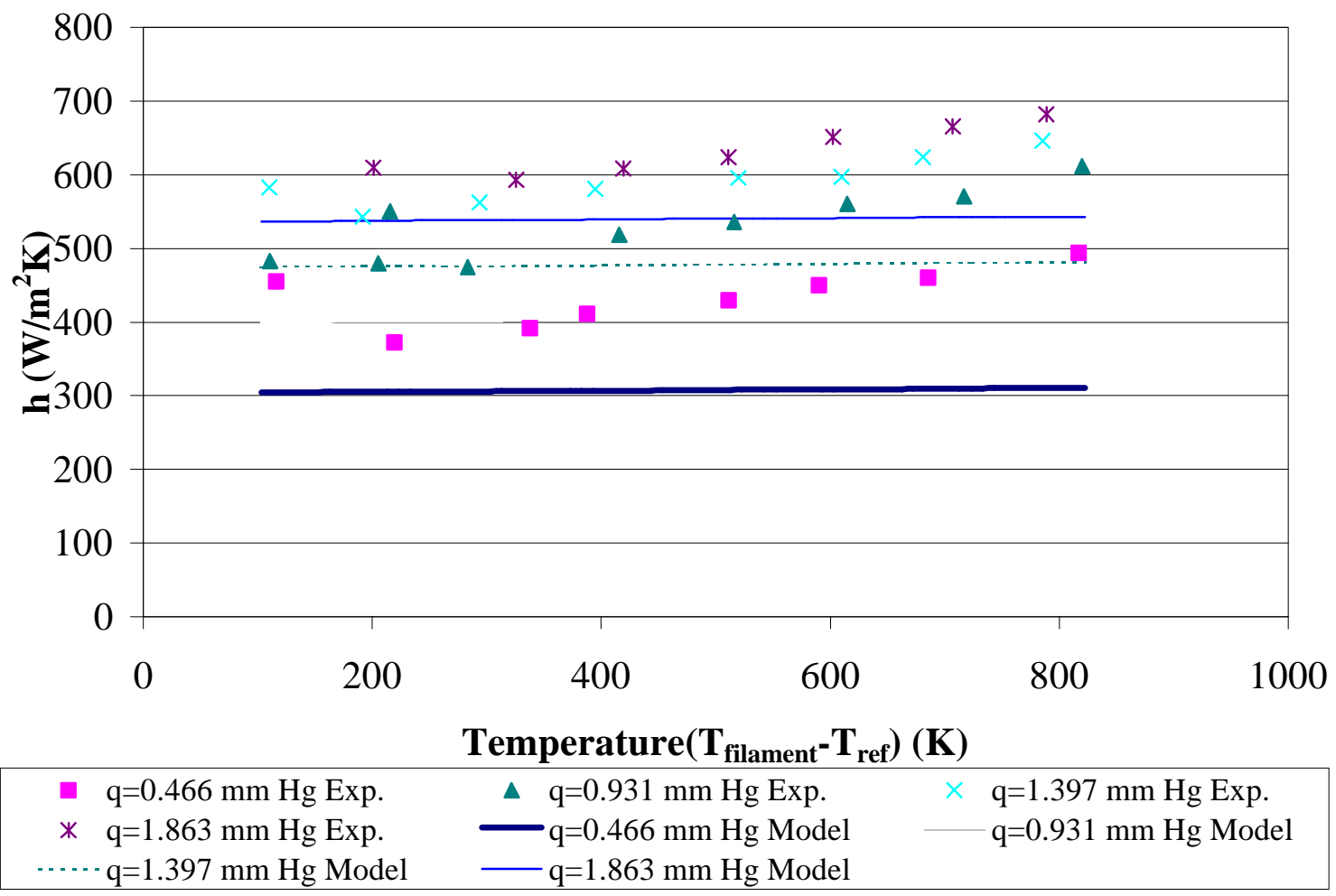

Figure 6.8: Experimental and Model Heat Transfer Coefficient vs. Temperature Difference of a 76 Micron Platinum Filament with $30 \mathrm{~cm}$. Length and Theta $=0^{\circ}$ 


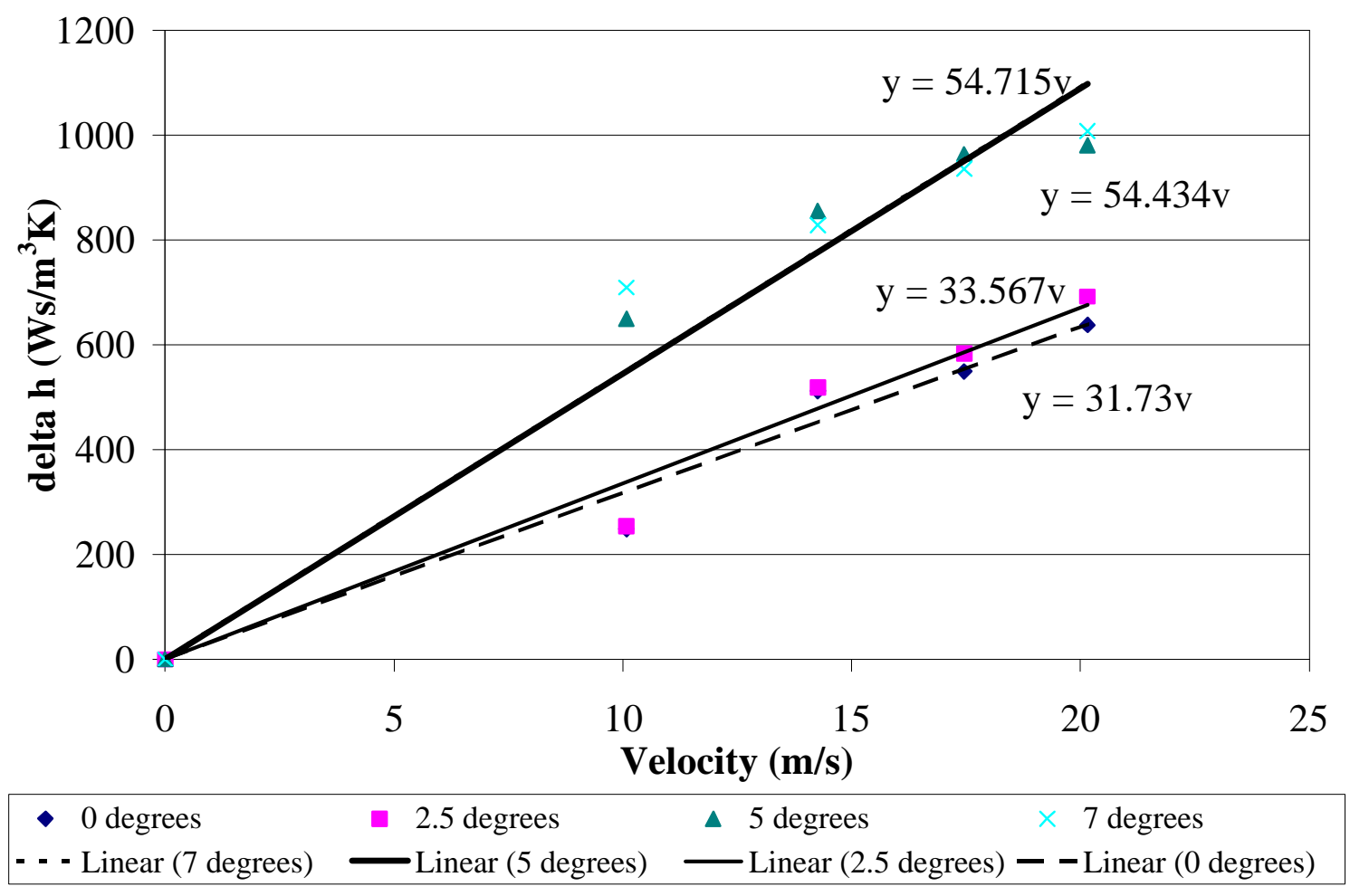

Figure 6.9: Increase in Heat Transfer Coefficient due to Velocity for a 25.4 Micron Platinum Filament with $30 \mathrm{~cm}$. Length and $\mathrm{T}=900 \mathrm{~K}$ 


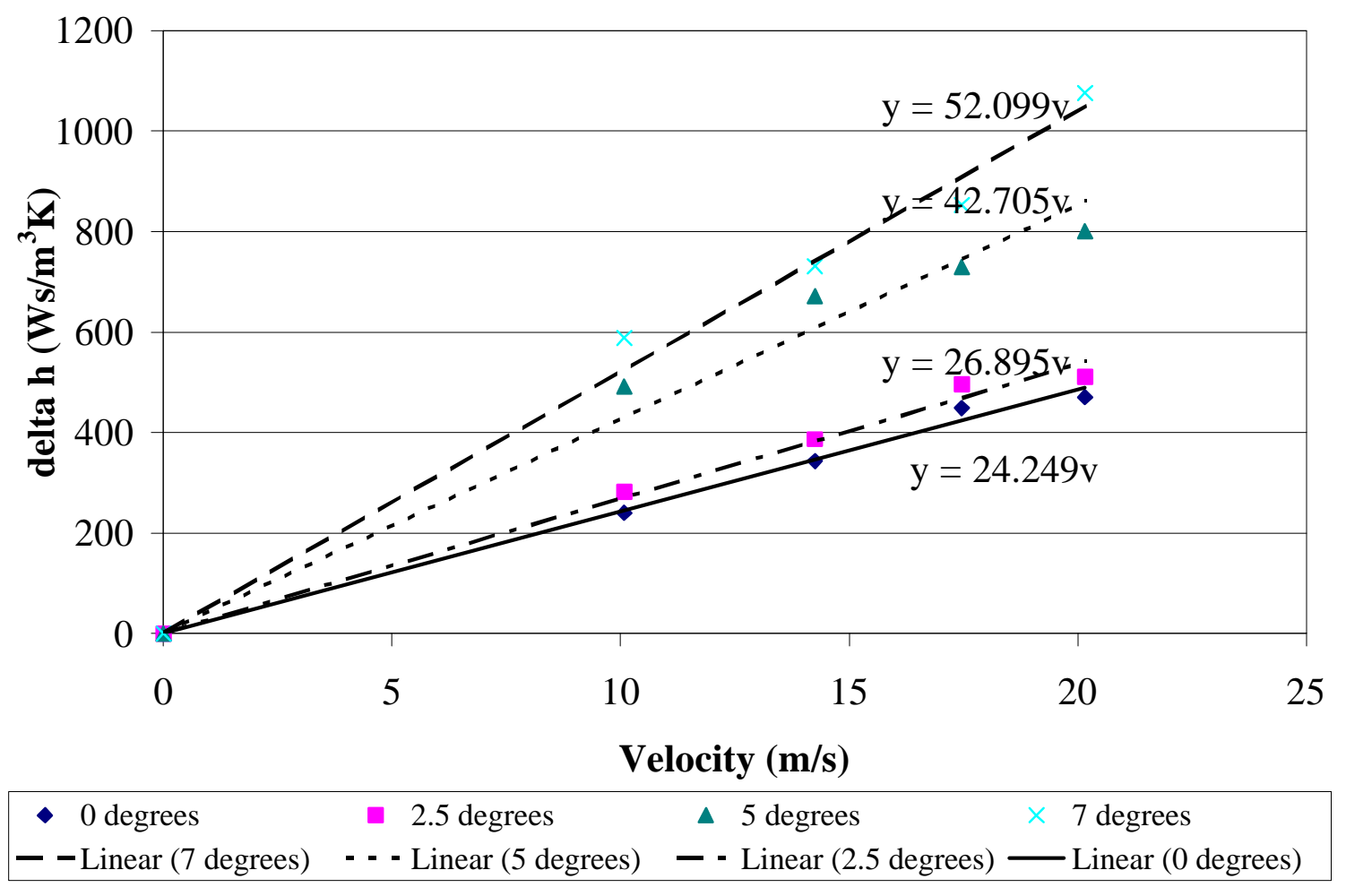

Figure 6.10: Increase in Heat Transfer Coefficient due to Velocity for a 38.5 Micron Platinum Filament with $30 \mathrm{~cm}$. Length and $\mathrm{T}=1000 \mathrm{~K}$ 


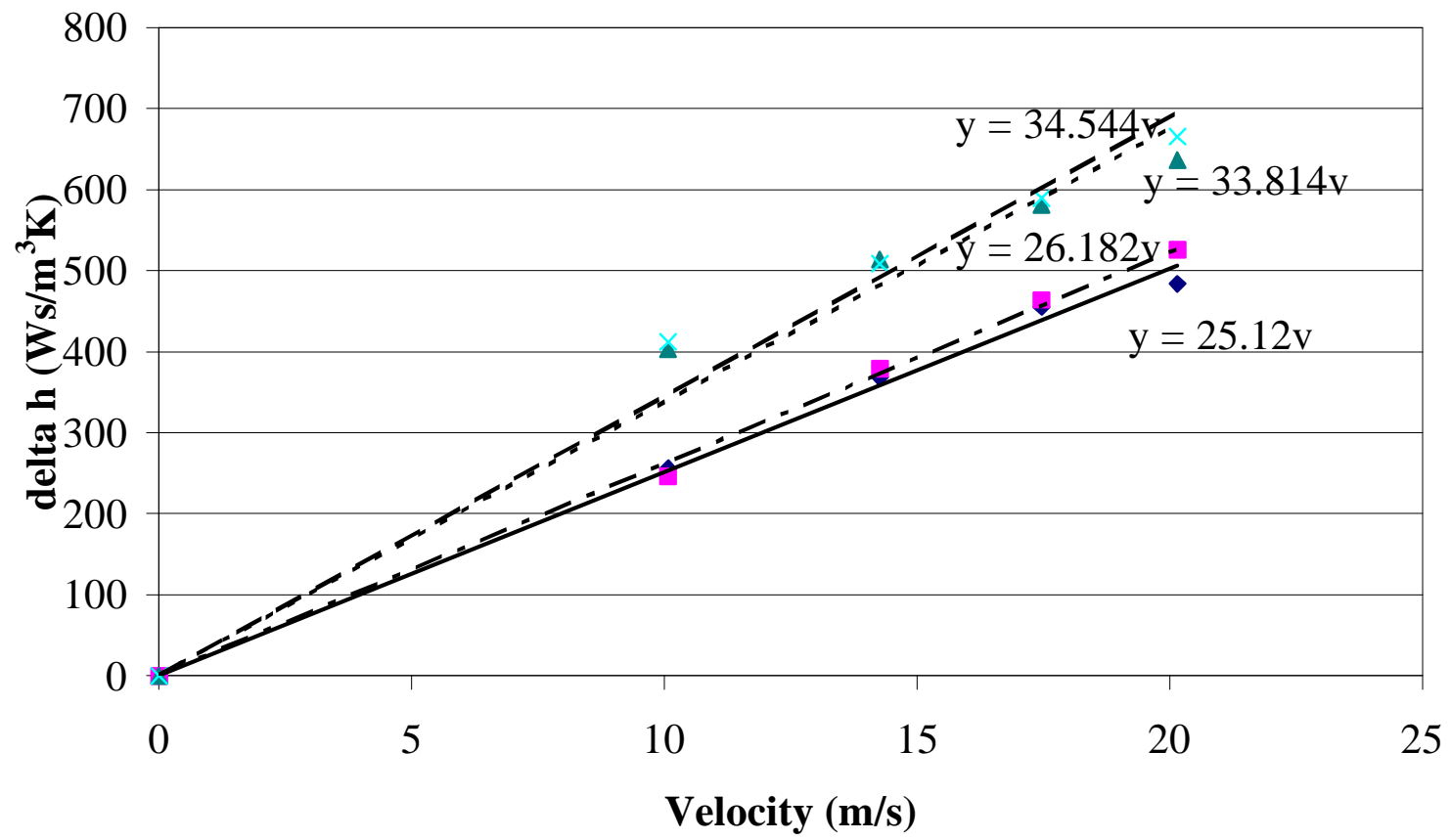

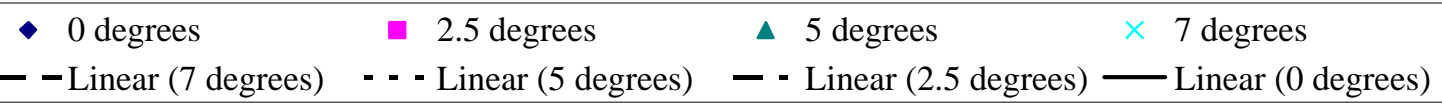

Figure 6.11: Increase in Heat Transfer Coefficient due to Velocity for a 51 Micron Platinum Filament with $30 \mathrm{~cm}$. Length and T=1100 K 


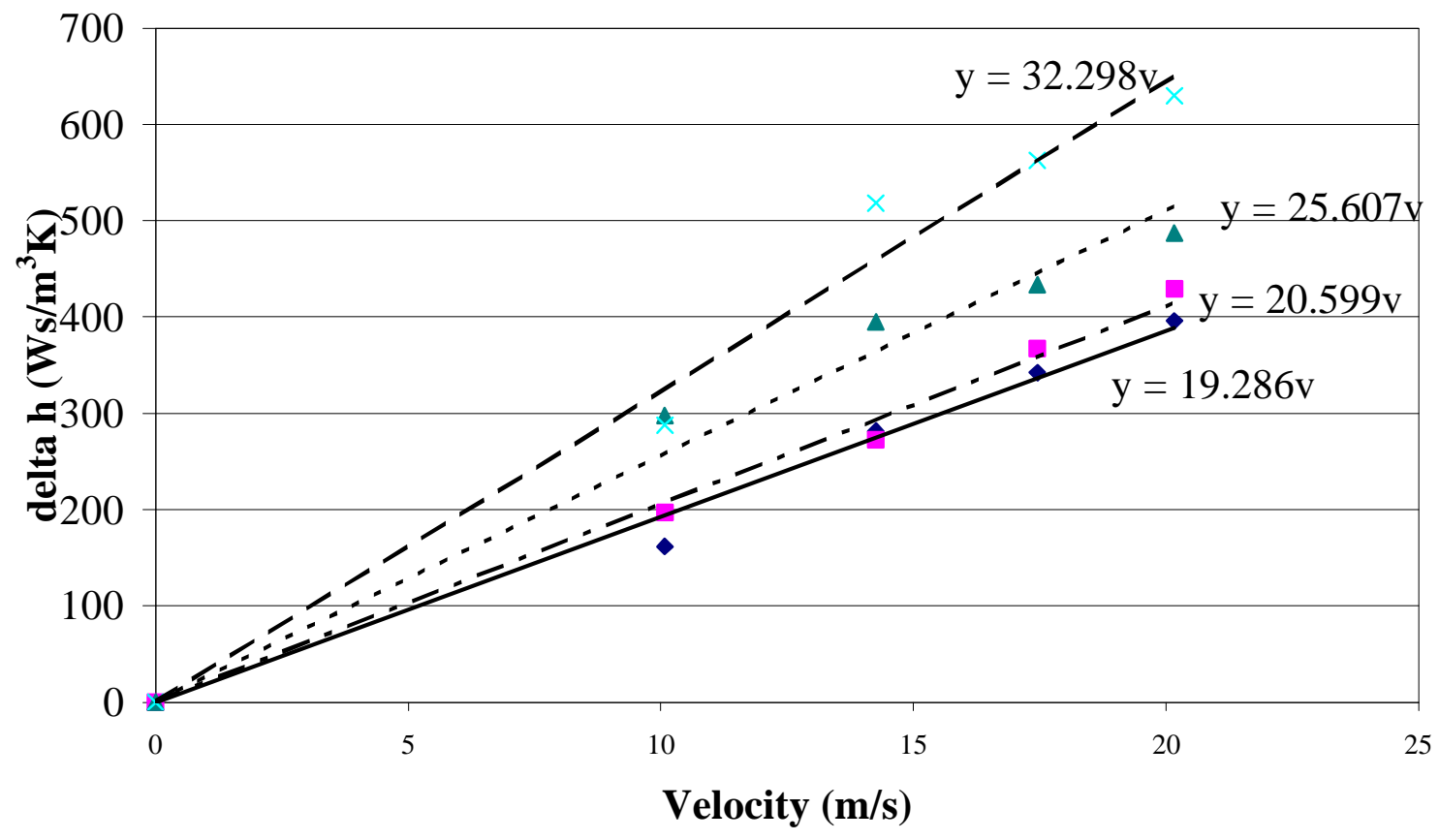

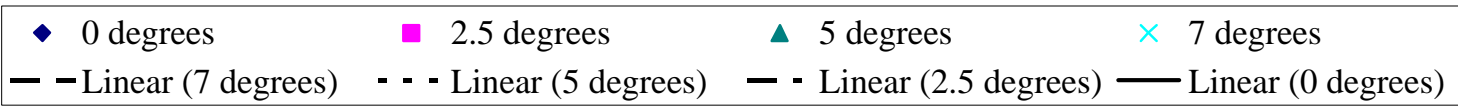

Figure 6.12: Increase in Heat Transfer Coefficient due to Velocity for a 63.5 Micron Platinum Filament with $30 \mathrm{~cm}$. Length and $\mathrm{T}=1100 \mathrm{~K}$ 


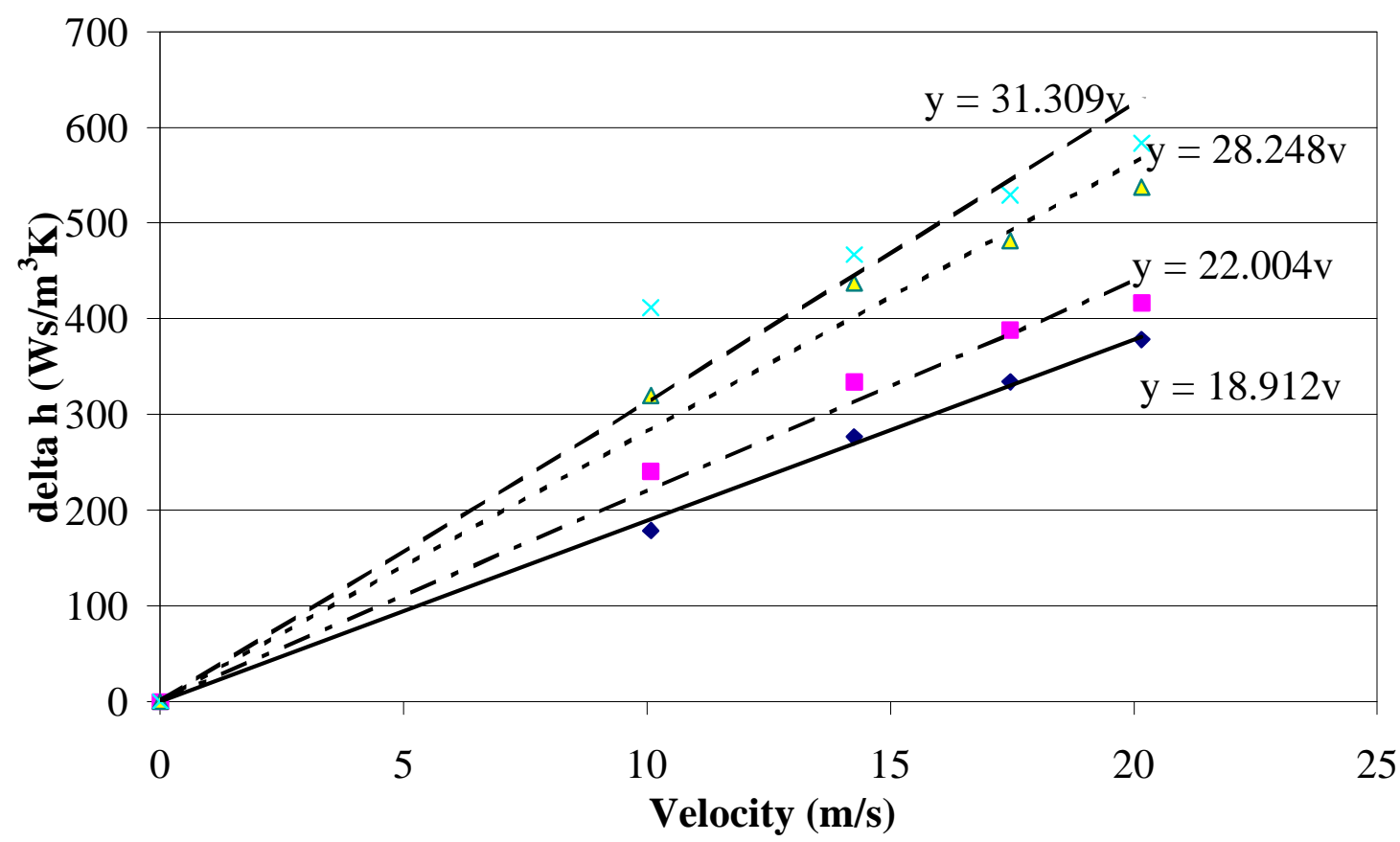

\begin{tabular}{|c|c|c|c|}
\hline - 0 degrees & - 2.5 degrees & $\Delta 5$ degrees & $\times 7$ degrees \\
\hline - - Linear (7 degrees) & - - Linear (5 degrees) & - - Linear (2.5 degrees) & - Linear (0 degrees) \\
\hline
\end{tabular}

Figure 6.13: Increase in Heat Transfer Coefficient due to Velocity for a 76 Micron Platinum Filament with $30 \mathrm{~cm}$. Length and $\mathrm{T}=1100 \mathrm{~K}$ 


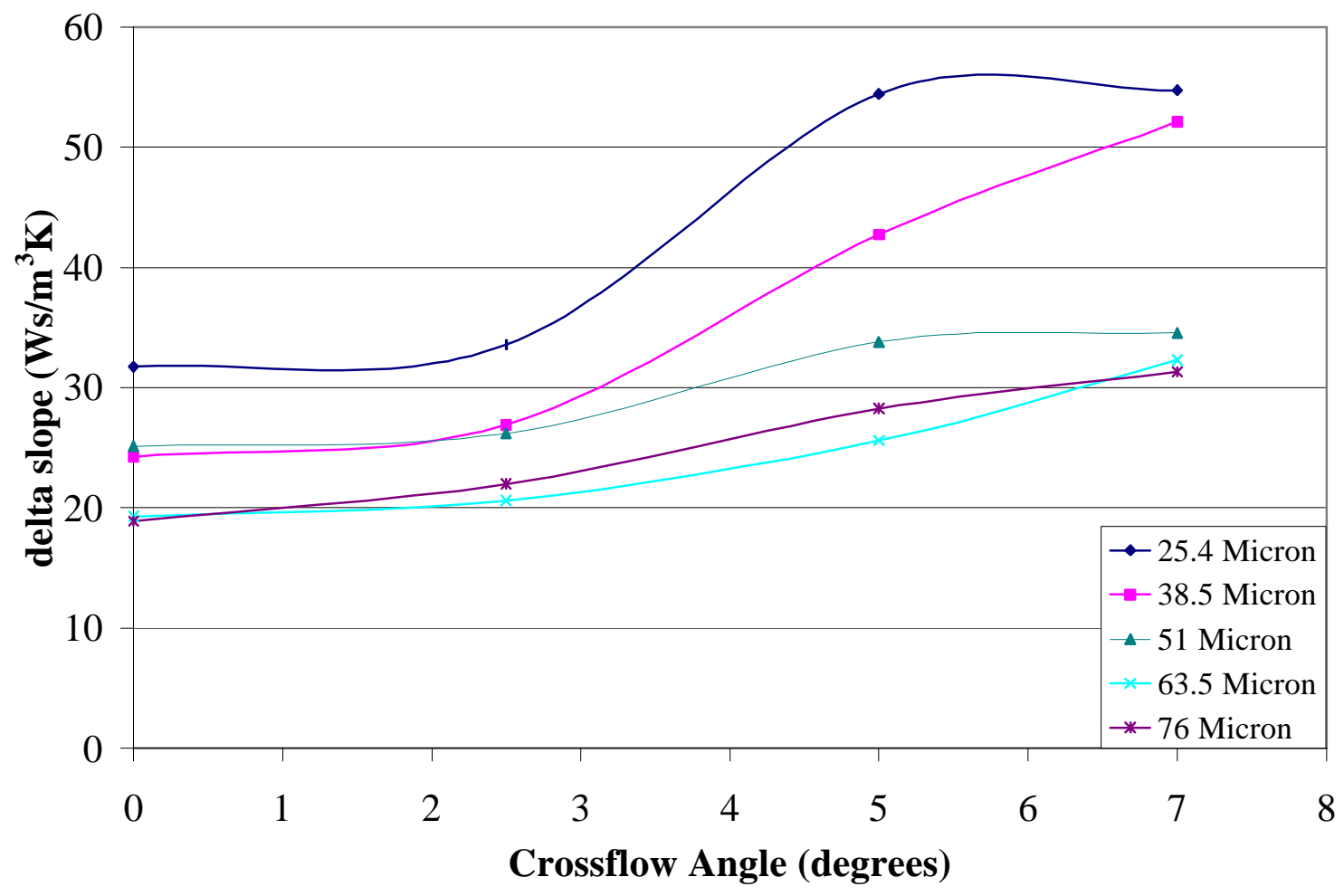

Figure 6.14: Effect of Crossflow Angle on the Change of Slope of delta h vs. Velocity Graphs 


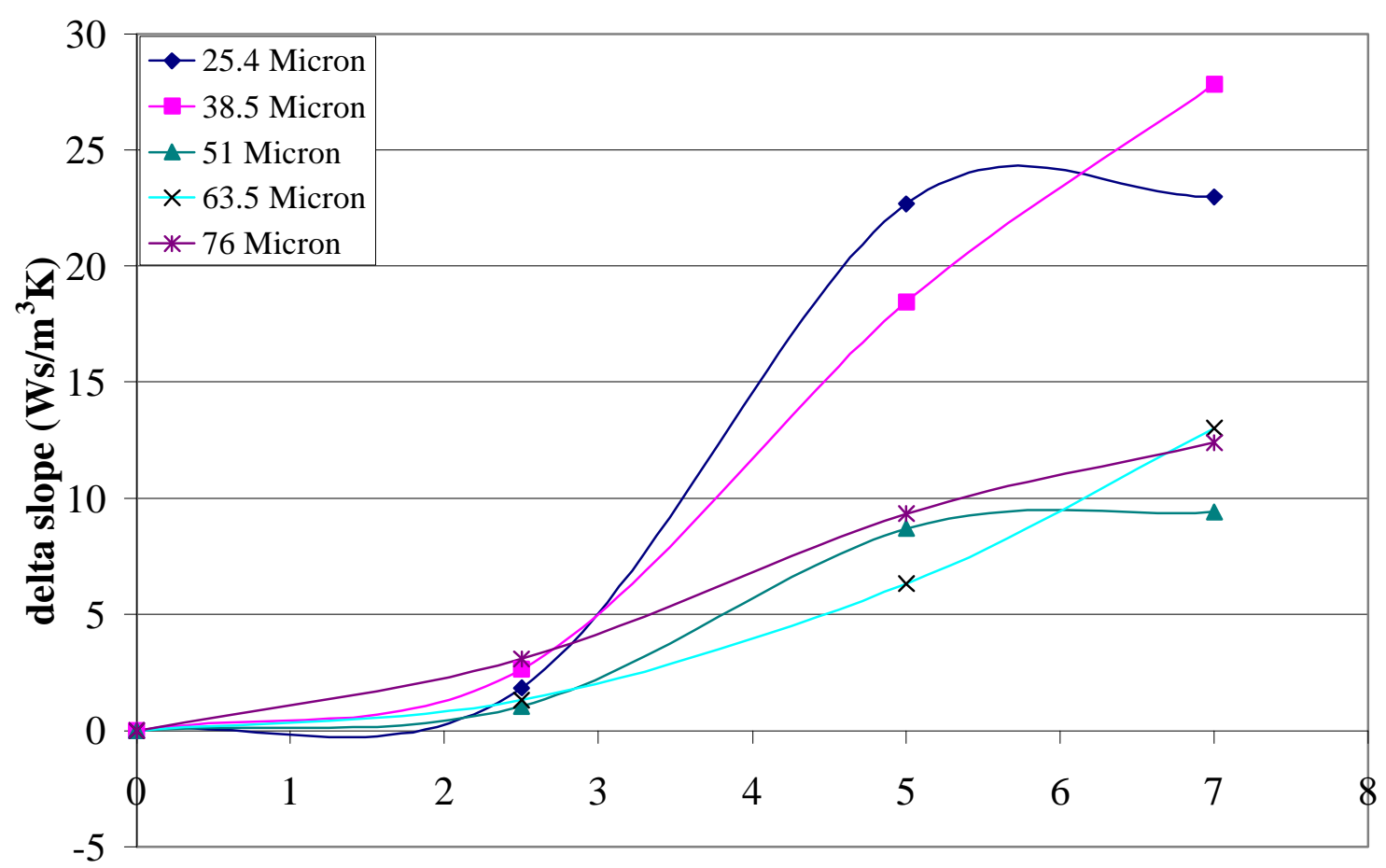

Crossflow Angle (degrees)

Figure 6.15: Change in Slope of delta h vs. Velocity Graphs vs. Crossflow Angle 


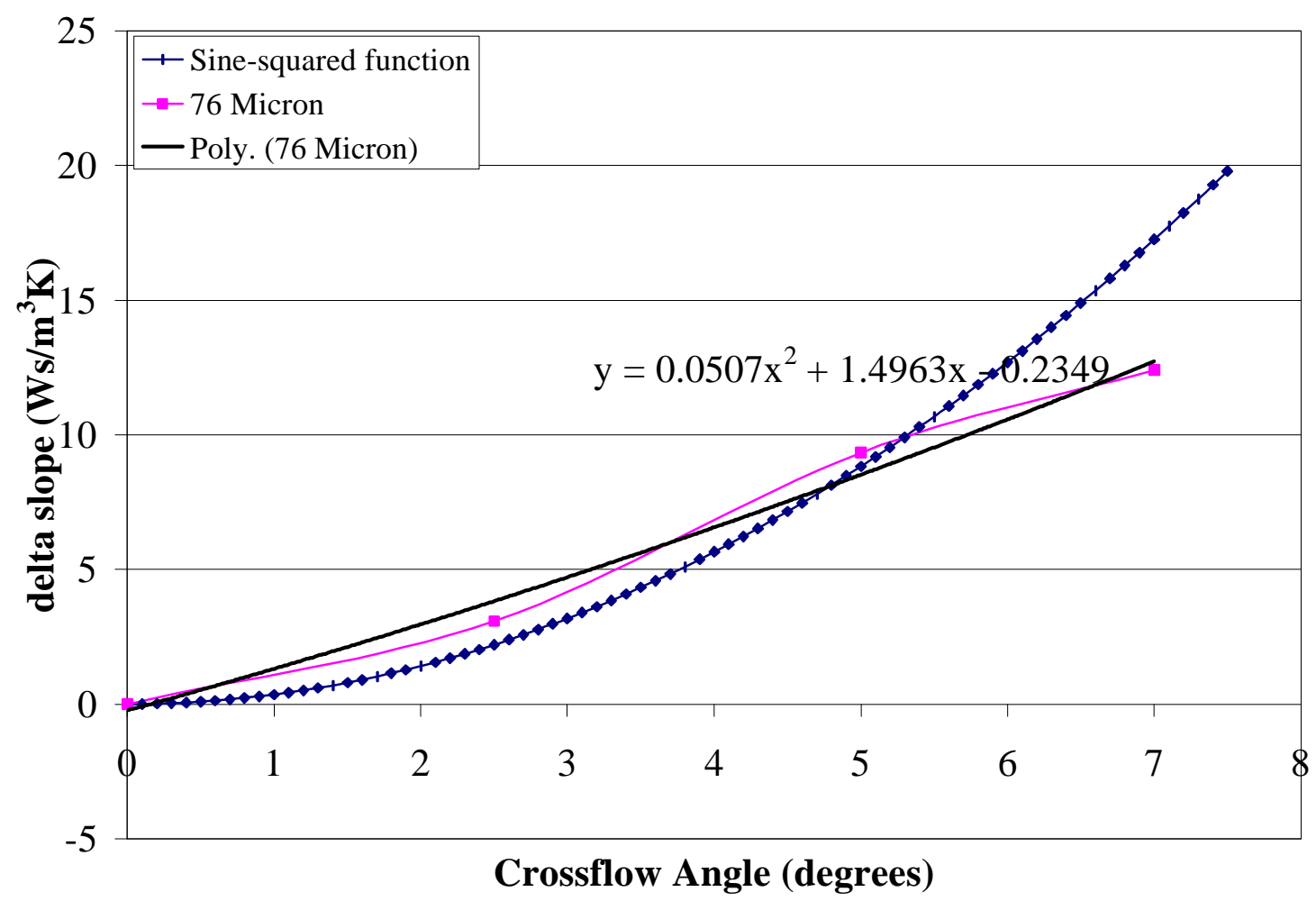

Figure 6.16: Comparison of Sine-Squared and Quadratic Curve-Fitting Functions of Change in Slope of delta h vs. Velocity Graphs vs. Crossflow Angle for a 76 Micron Platinum Filament with $30 \mathrm{~cm}$. Length and $\mathrm{T}=1100 \mathrm{~K}$ 


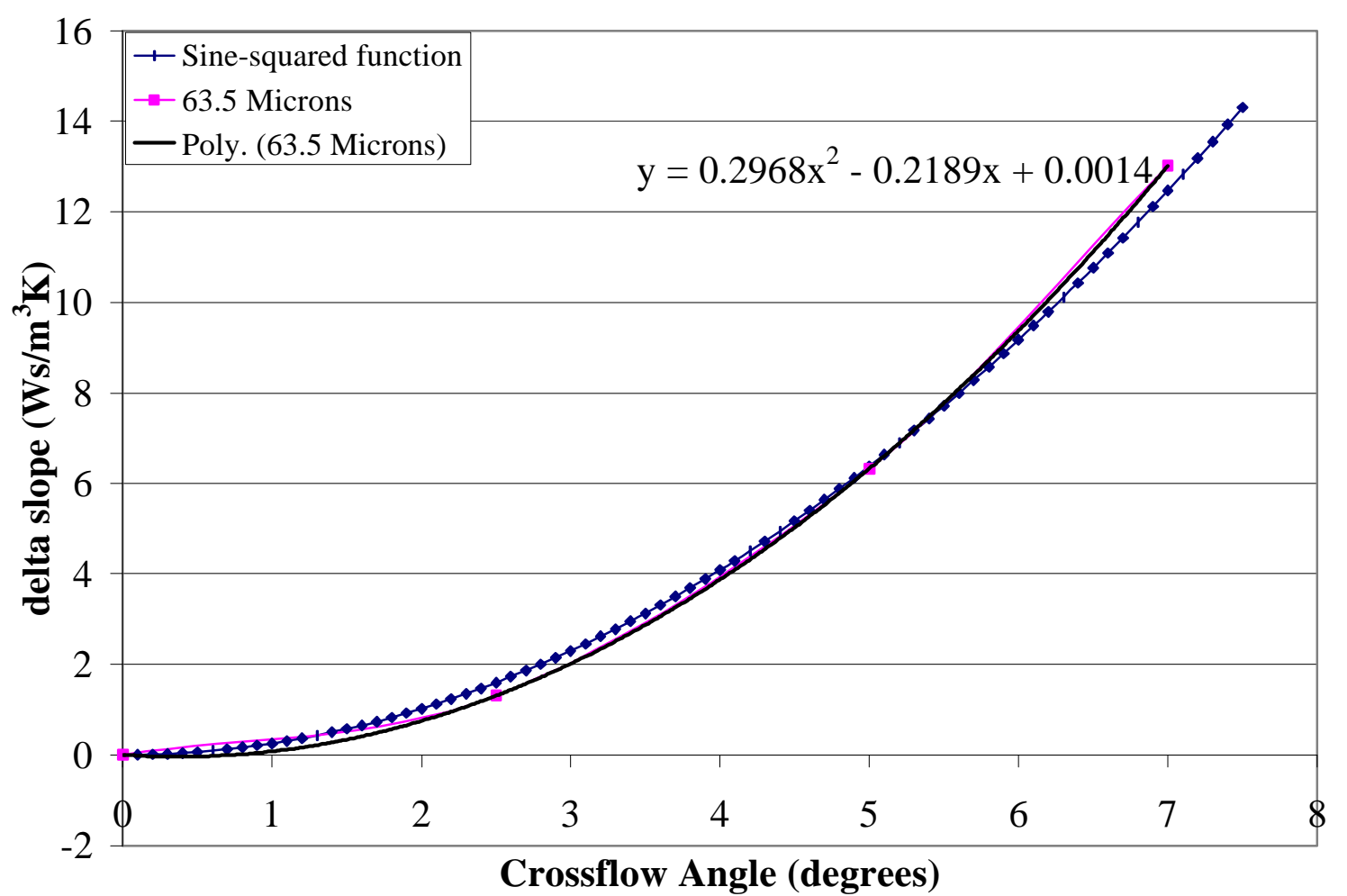

Figure 6.17: Comparison of Sine-Squared and Quadratic Curve-Fitting Functions of Change in Slope of delta h vs. Velocity Graphs vs. Crossflow Angle for a 63.5 Micron Platinum Filament with $30 \mathrm{~cm}$. Length and $\mathrm{T}=1100 \mathrm{~K}$ 


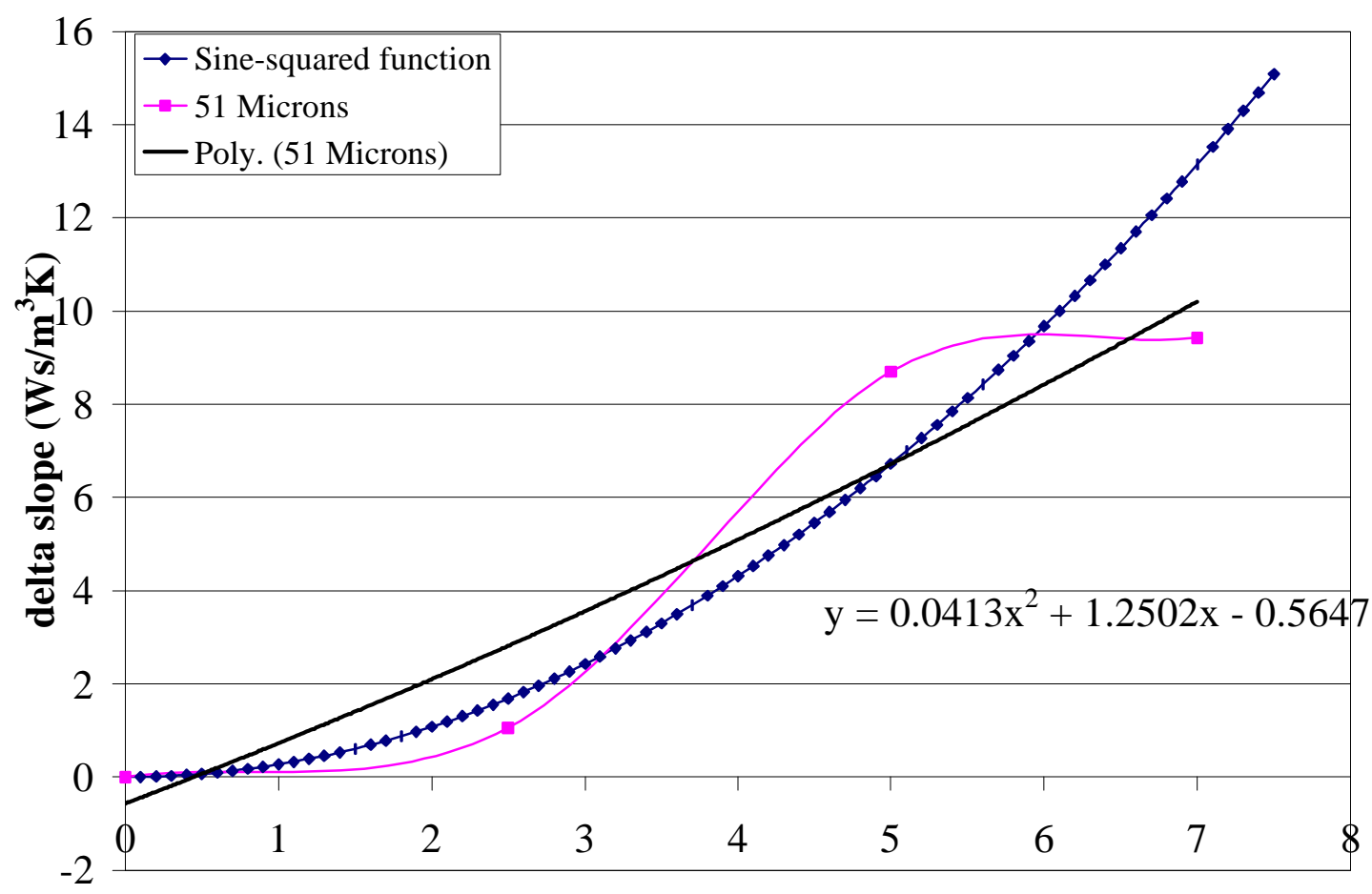

Crossflow Angle (degrees)

Figure 6.18: Comparison of Sine-Squared and Quadratic Curve-Fitting Functions of Change in Slope of delta h vs. Velocity Graphs vs. Crossflow Angle for a 51 Micron Platinum Filament with $30 \mathrm{~cm}$. Length and T=1000 K 


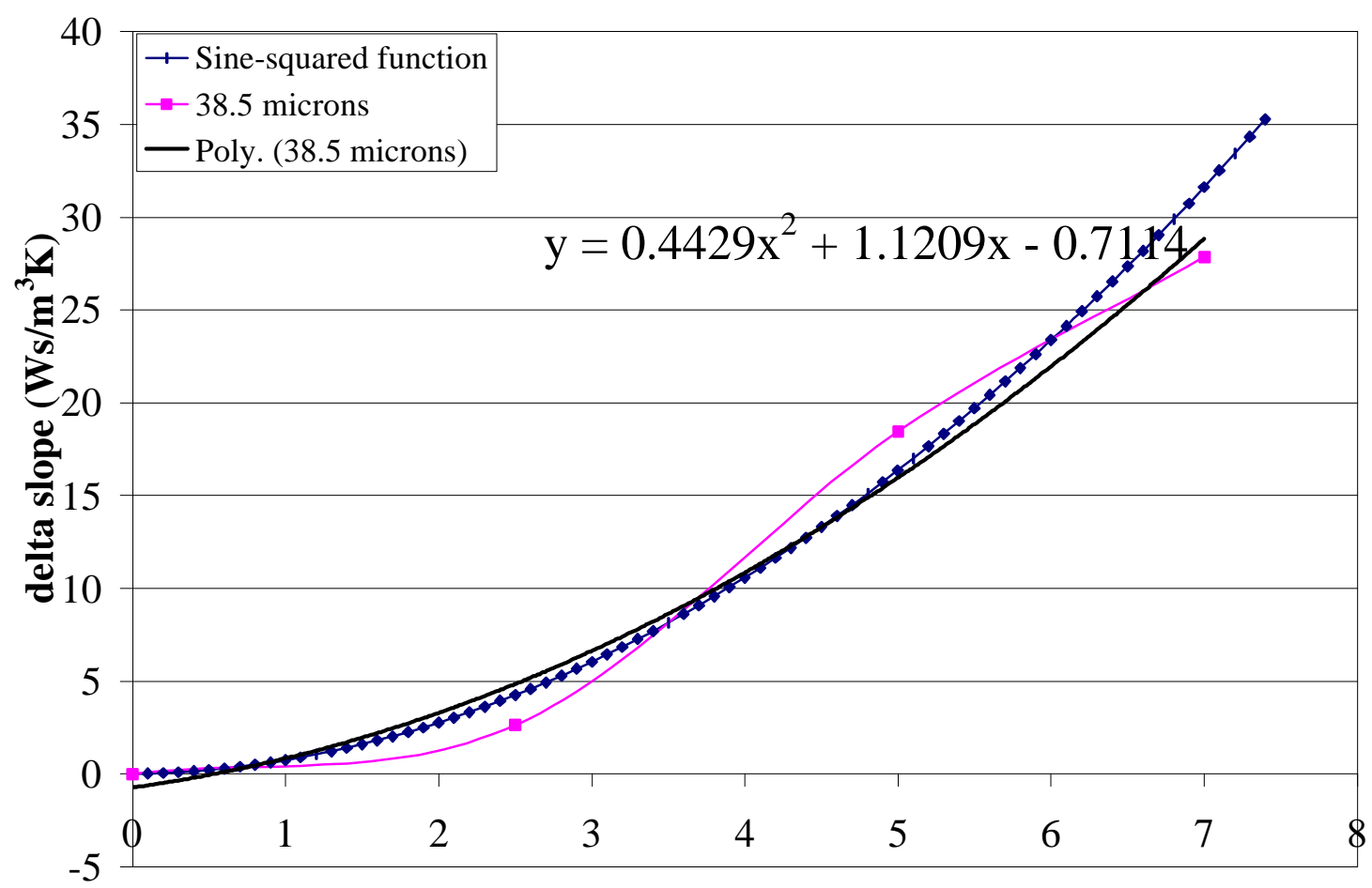

Crossflow Angle (degrees)

Figure 6.19: Comparison of Sine-Squared and Quadratic Curve-Fitting Functions of Change in Slope of delta h vs. Velocity Graphs vs. Crossflow Angle for a 38.5 Micron Platinum Filament with $30 \mathrm{~cm}$. Length and $\mathrm{T}=900 \mathrm{~K}$ 


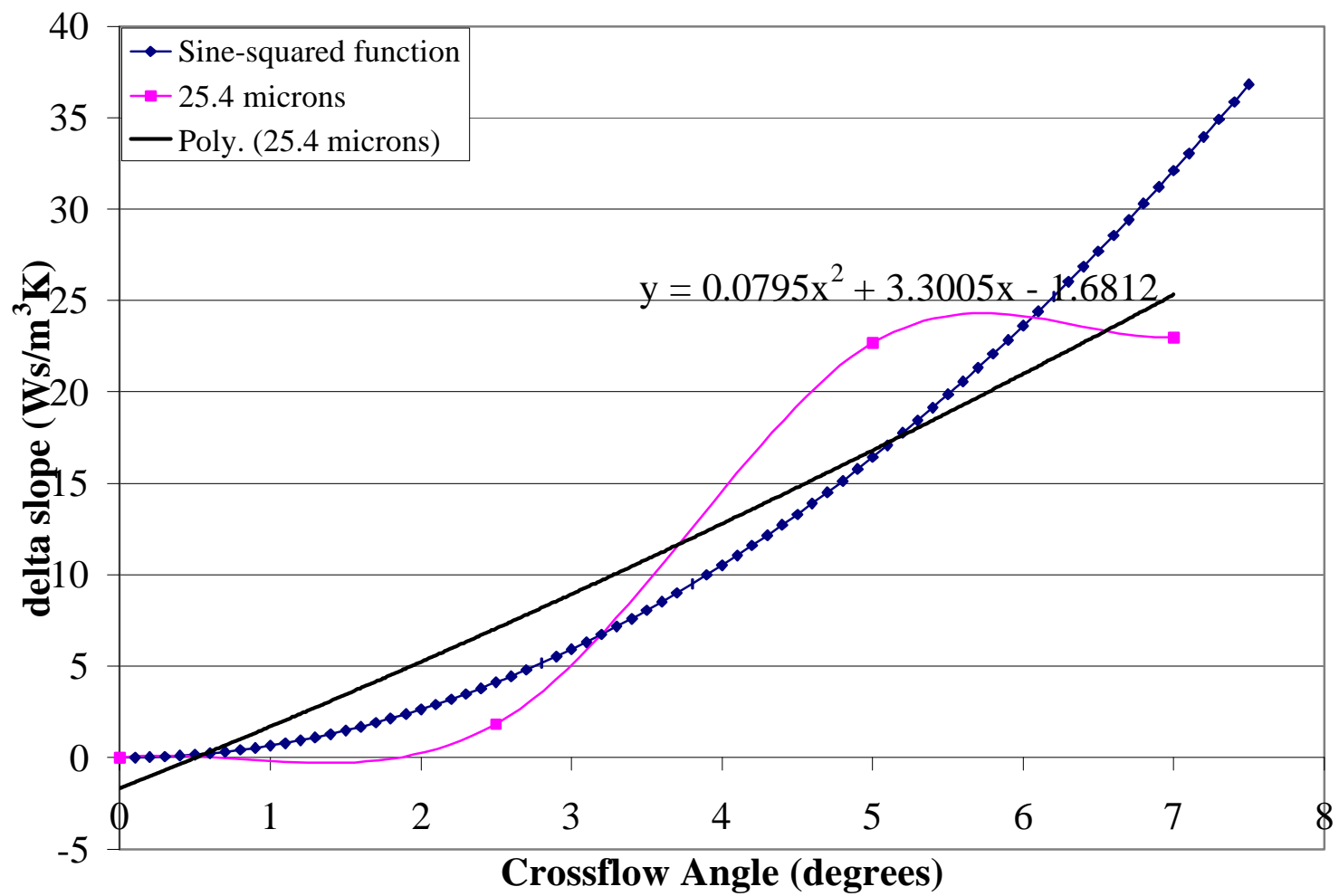

Figure 6.20: Comparison of Sine-Squared and Quadratic Curve-Fitting Functions of Change in Slope of delta h vs. Velocity Graphs vs. Crossflow Angle for a 24.5 Micron Platinum Filament with $30 \mathrm{~cm}$. Length and $\mathrm{T}=900 \mathrm{~K}$ 


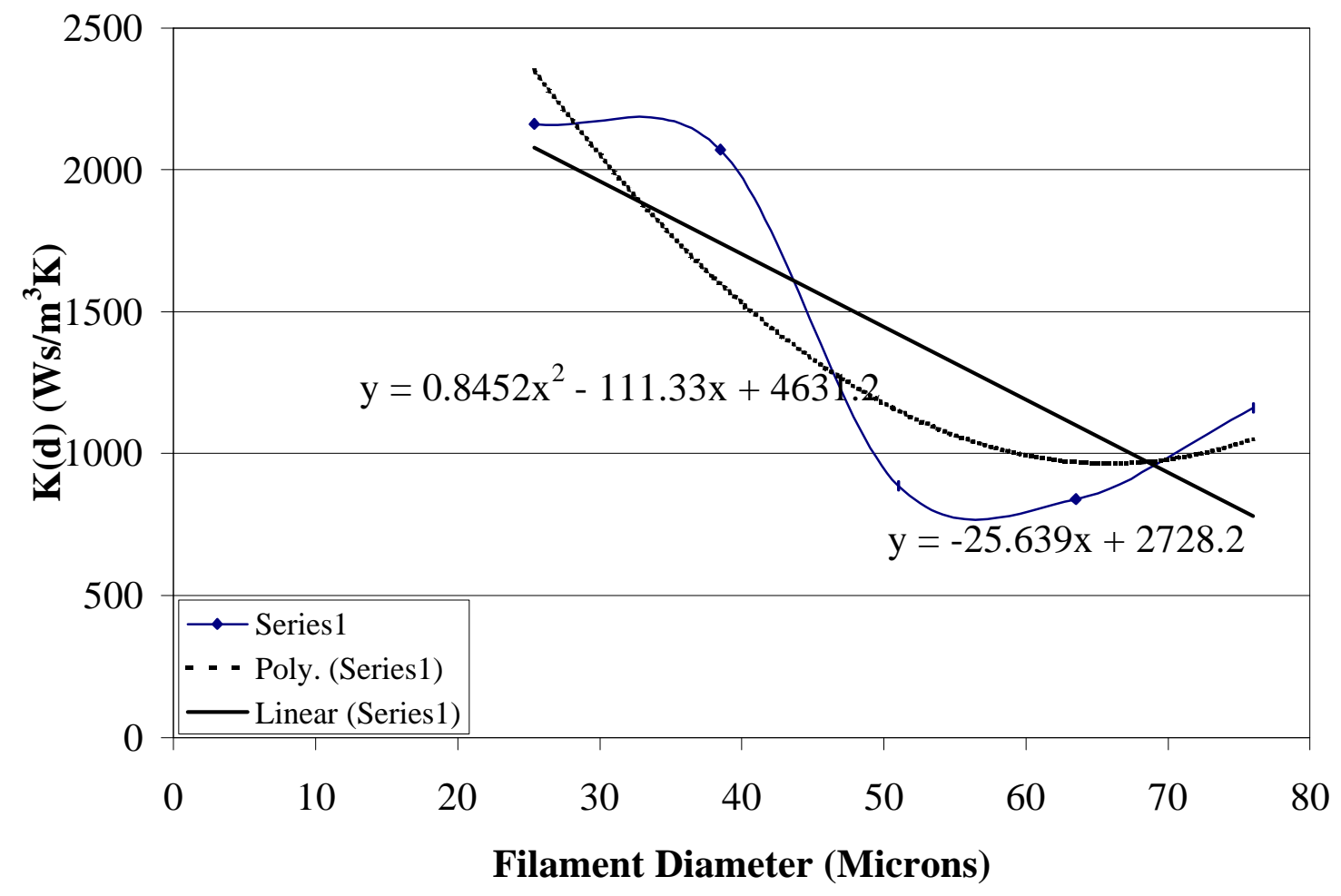

Figure 6.21: Slope Coefficient K(d) vs. Filament Diameter 


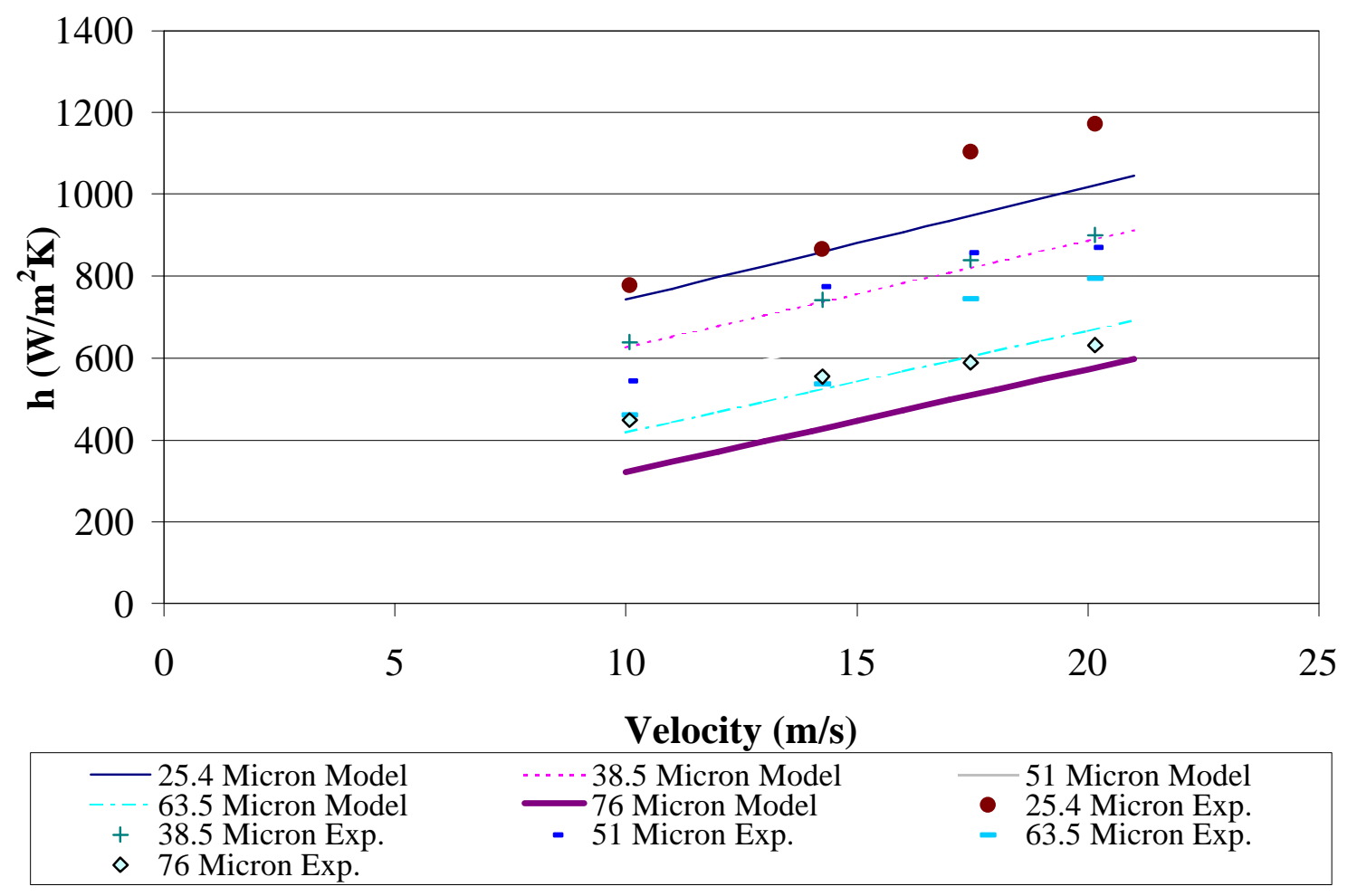

Figure 6.22: Comparison of Experimental and Model Heat Transfer Coefficients for a Platinum Filament with $30 \mathrm{~cm}$. Length at $400 \mathrm{~K}$ and Theta $=2.5^{\circ}$ 


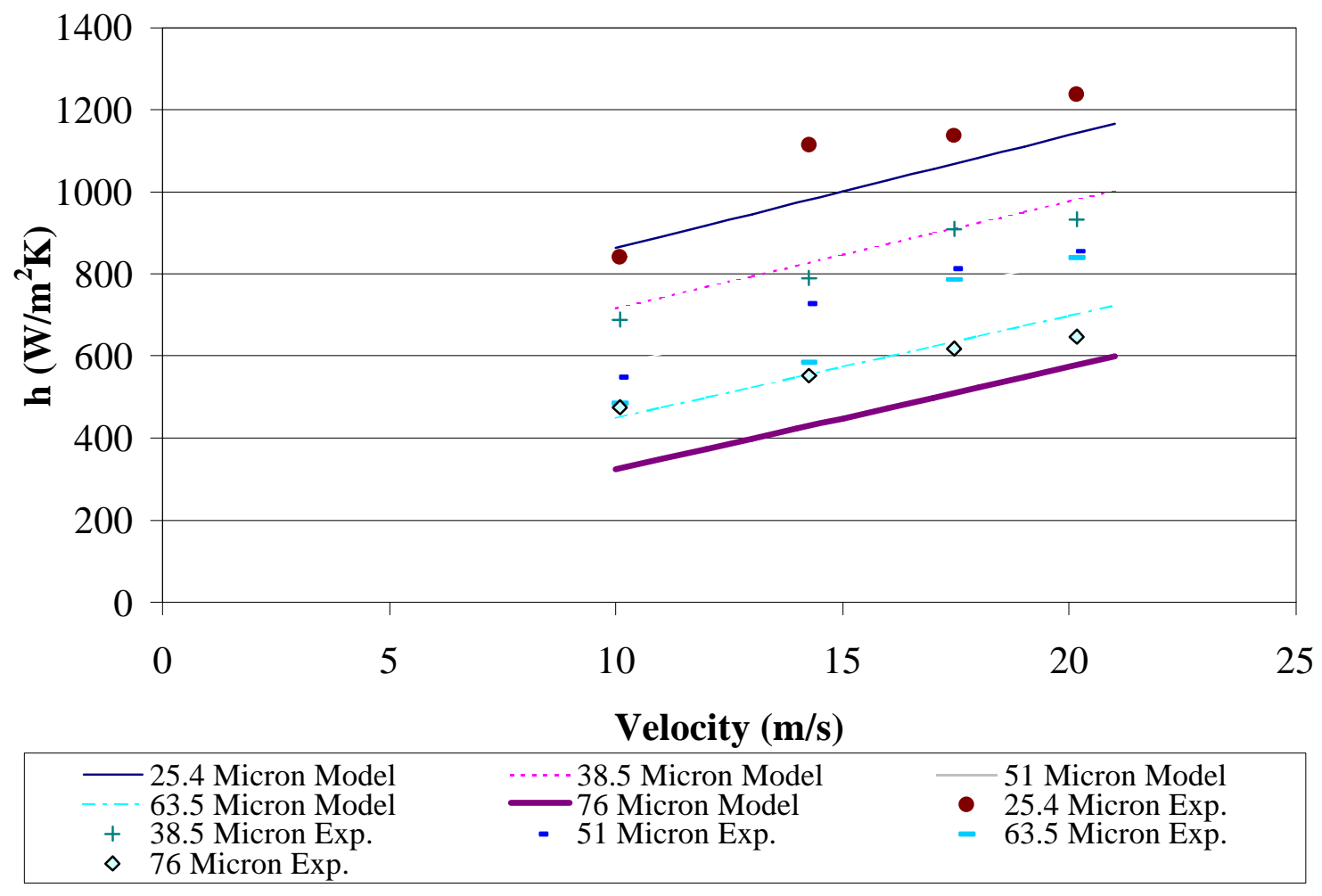

Figure 6.23: Comparison of Experimental and Model Heat Transfer Coefficients for a Platinum Filament with $30 \mathrm{~cm}$. Length at $600 \mathrm{~K}$ and Theta $=2.5^{\circ}$ 


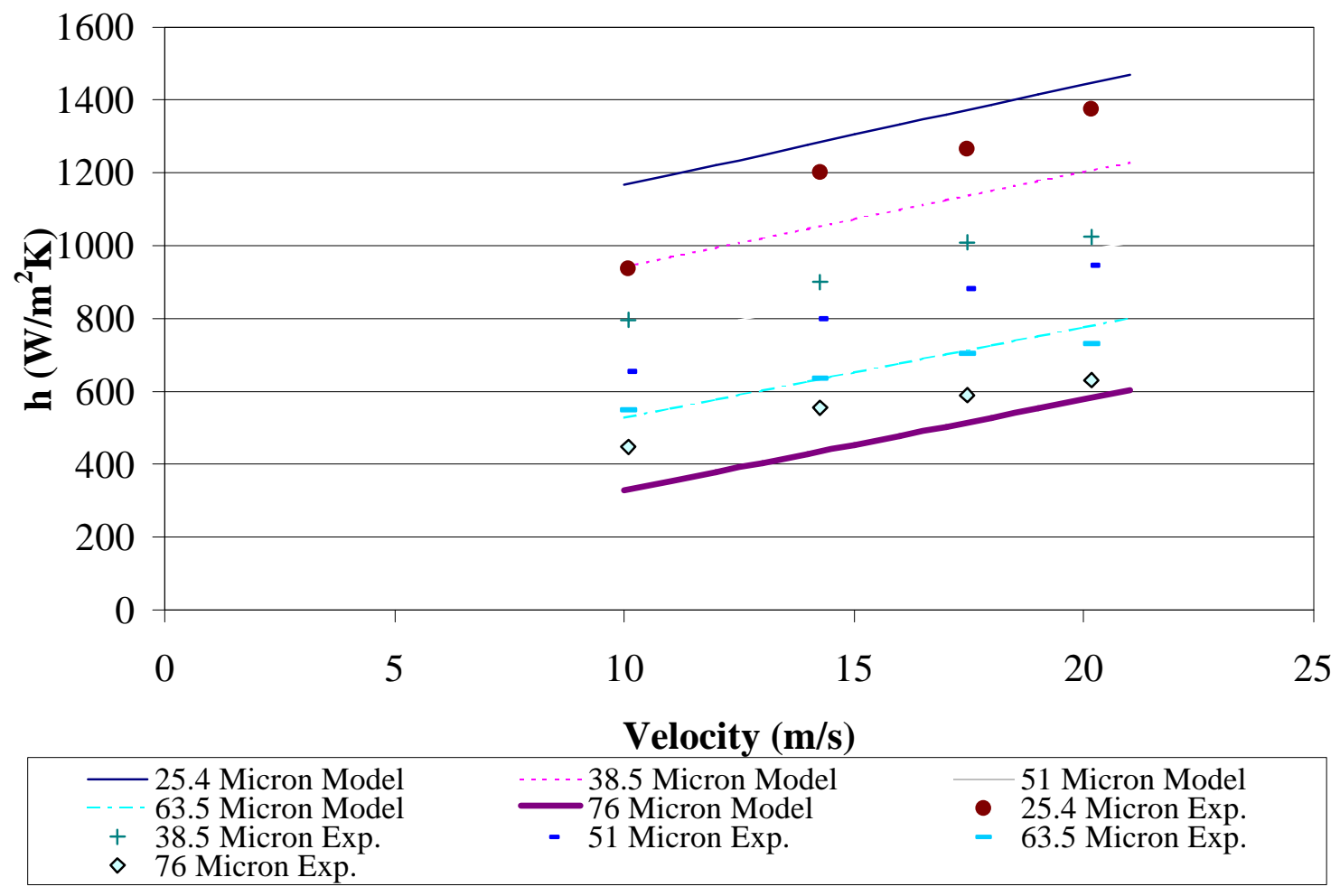

Figure 6.24: Comparison of Experimental and Model Heat Transfer Coefficients for a Platinum Filament with $30 \mathrm{~cm}$. Length at $1100 \mathrm{~K}$ and Theta $=2.5^{\circ}$ 


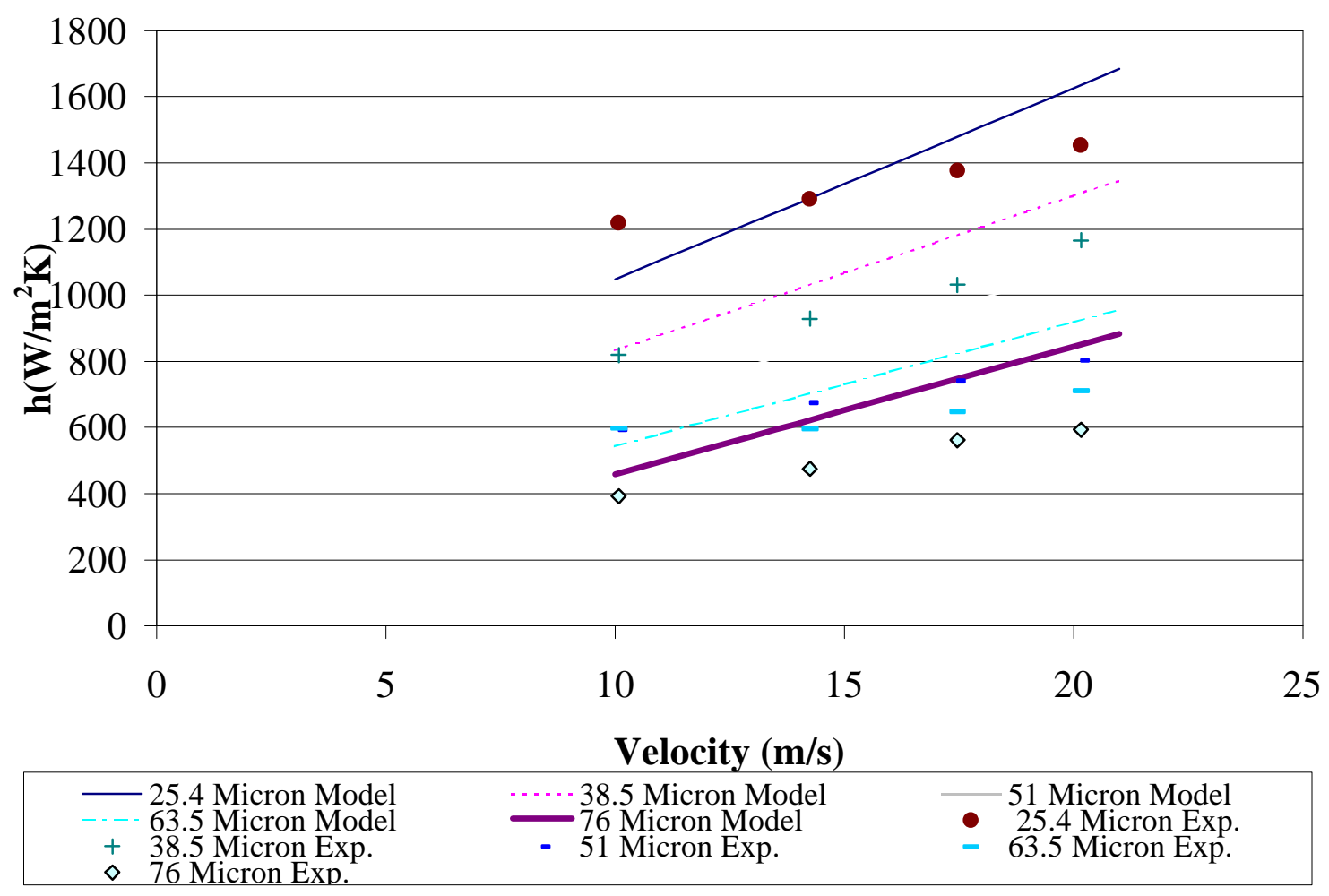

Figure 6.25: Comparison of Experimental and Model Heat Transfer Coefficients for a Platinum Filament with $30 \mathrm{~cm}$. Length at $400 \mathrm{~K}$ and Theta $=7^{\circ}$ 


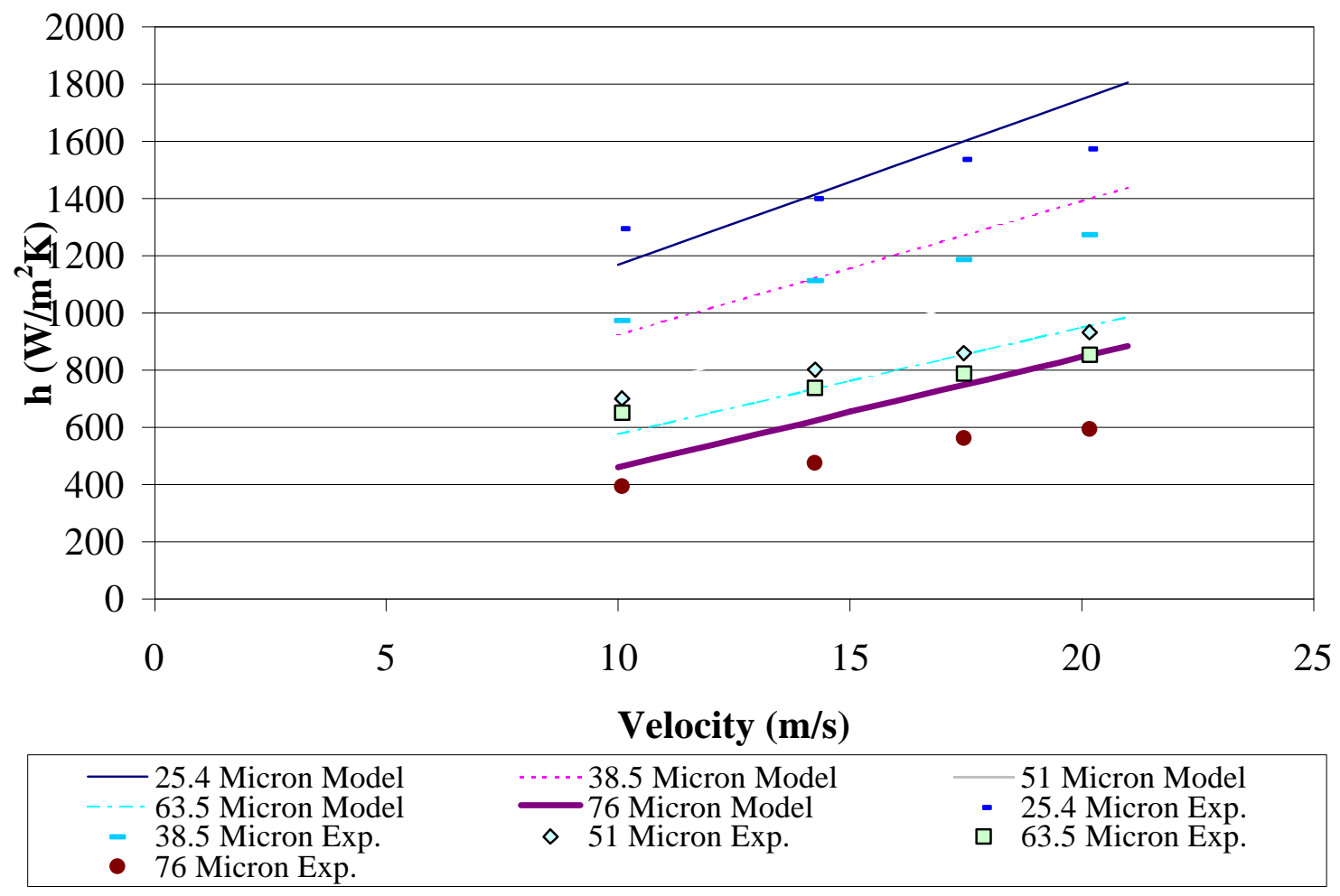

Figure 6.26: Comparison of Experimental and Model Heat Transfer Coefficients for a Platinum Filament with $30 \mathrm{~cm}$. Length at $600 \mathrm{~K}$ and Theta $=7^{\circ}$ 


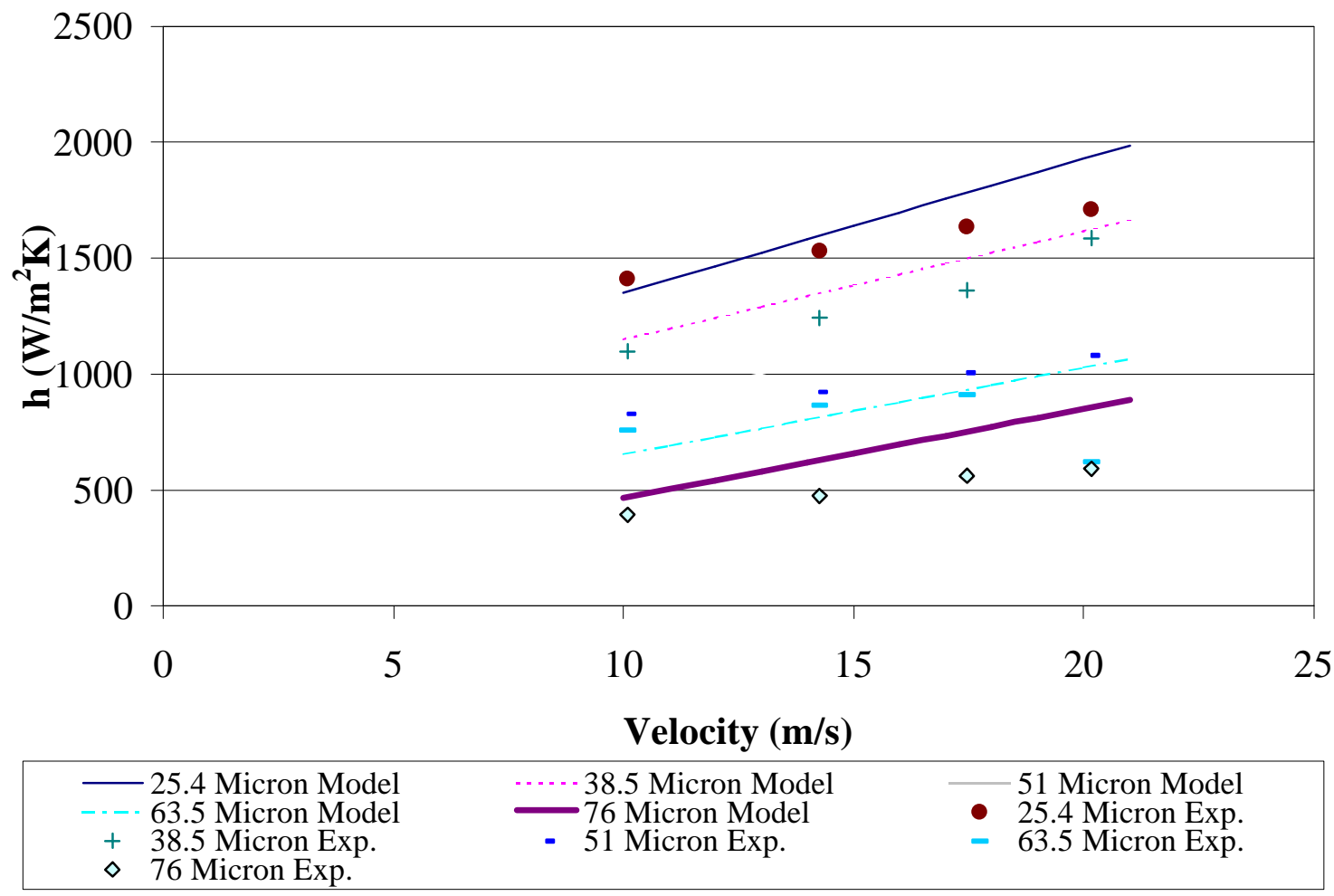

Figure 6.27: Comparison of Experimental and Model Heat Transfer Coefficients for a Platinum Filament with $30 \mathrm{~cm}$. Length at $1100 \mathrm{~K}$ and Theta $=7^{\circ}$ 


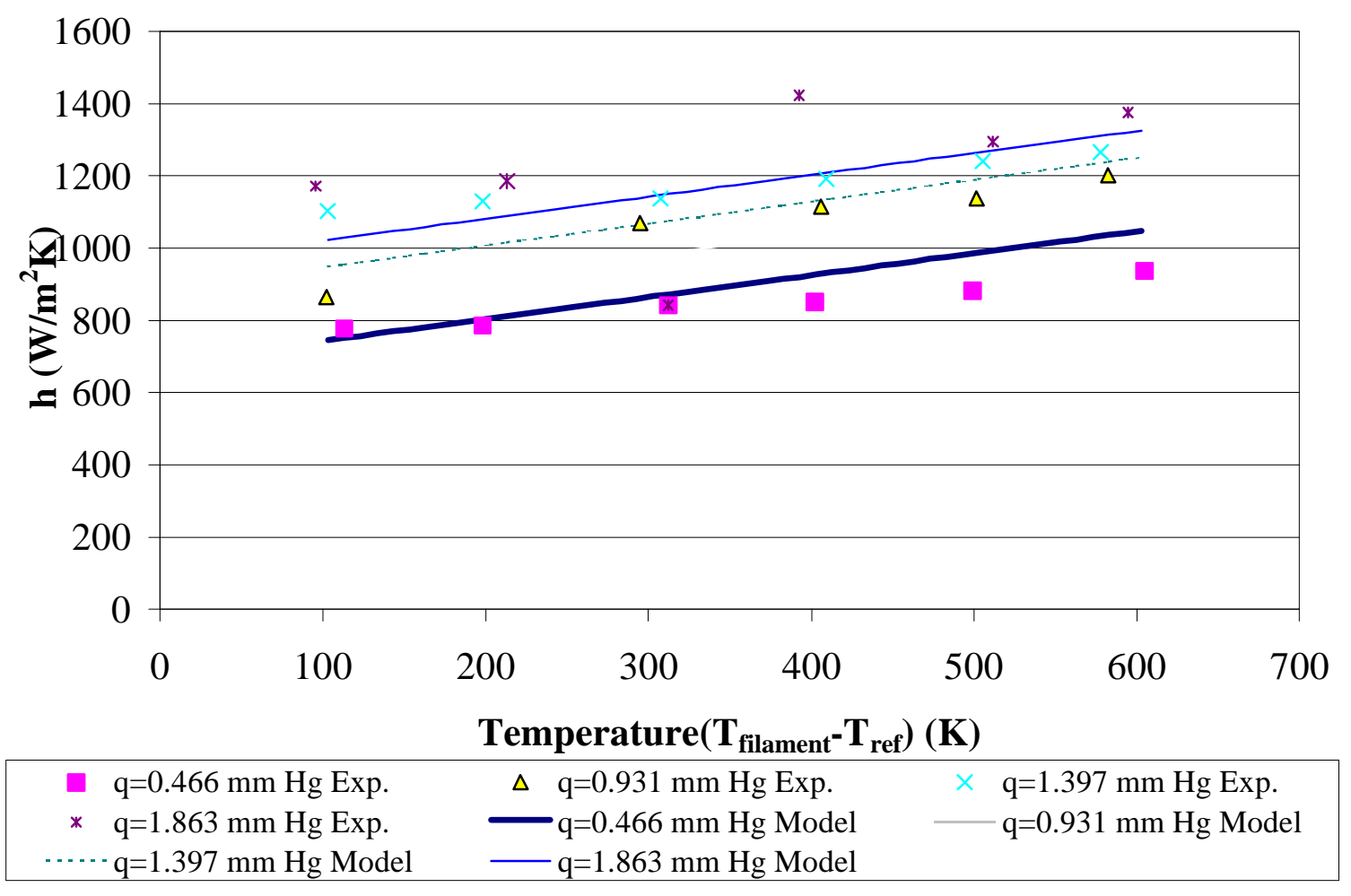

Figure 6.28: Experimental and Model Heat Transfer Coefficients vs. Temperature Difference of a 25.4 Micron Platinum Filament with $30 \mathrm{~cm}$. Length and Theta $=2.5^{\circ}$ 


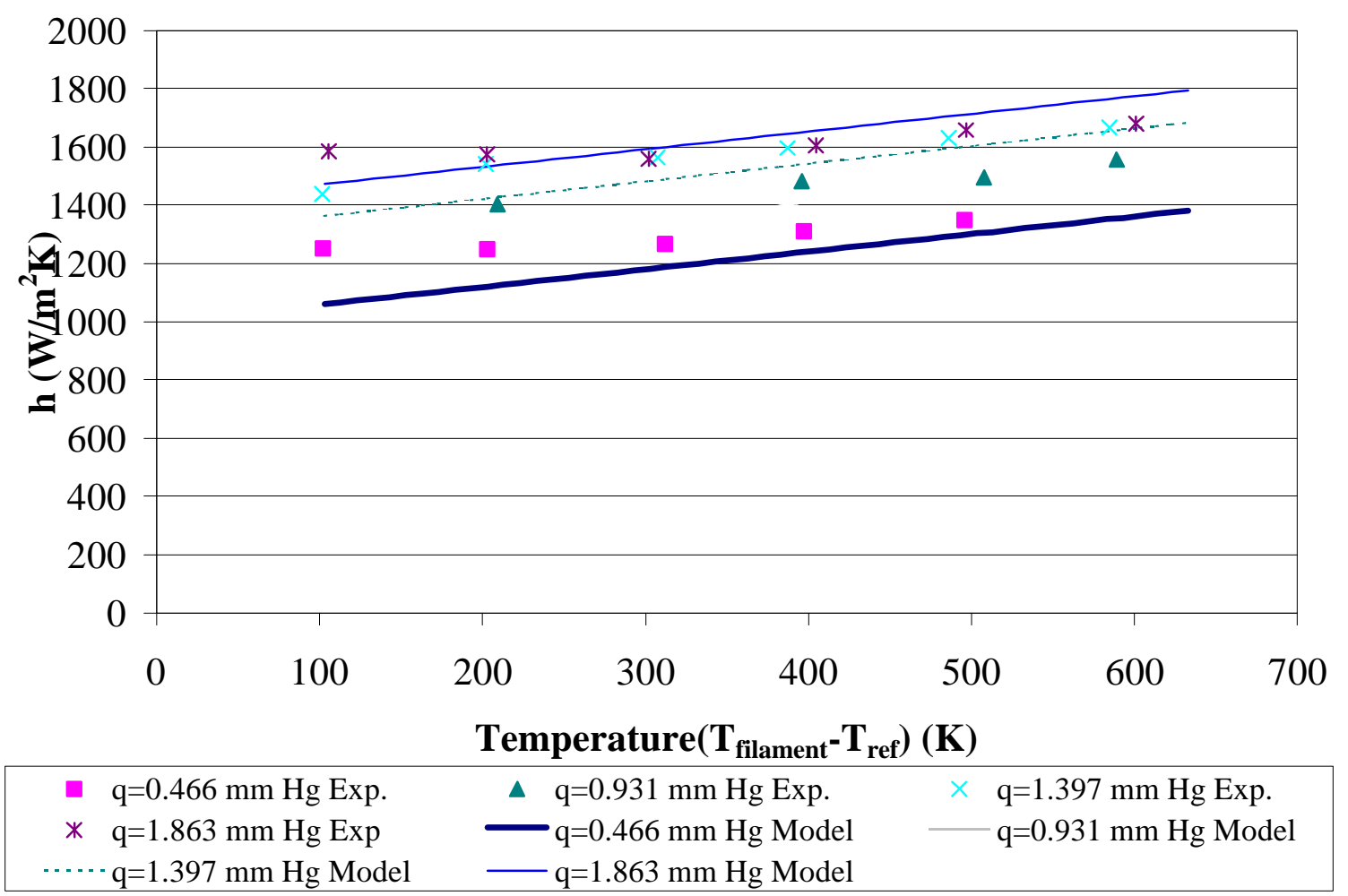

Figure 6.29: Experimental and Model Heat Transfer Coefficients vs. Temperature Difference of a 25.4 Micron Platinum Filament with $30 \mathrm{~cm}$. Length and Theta $=5^{\circ}$ 


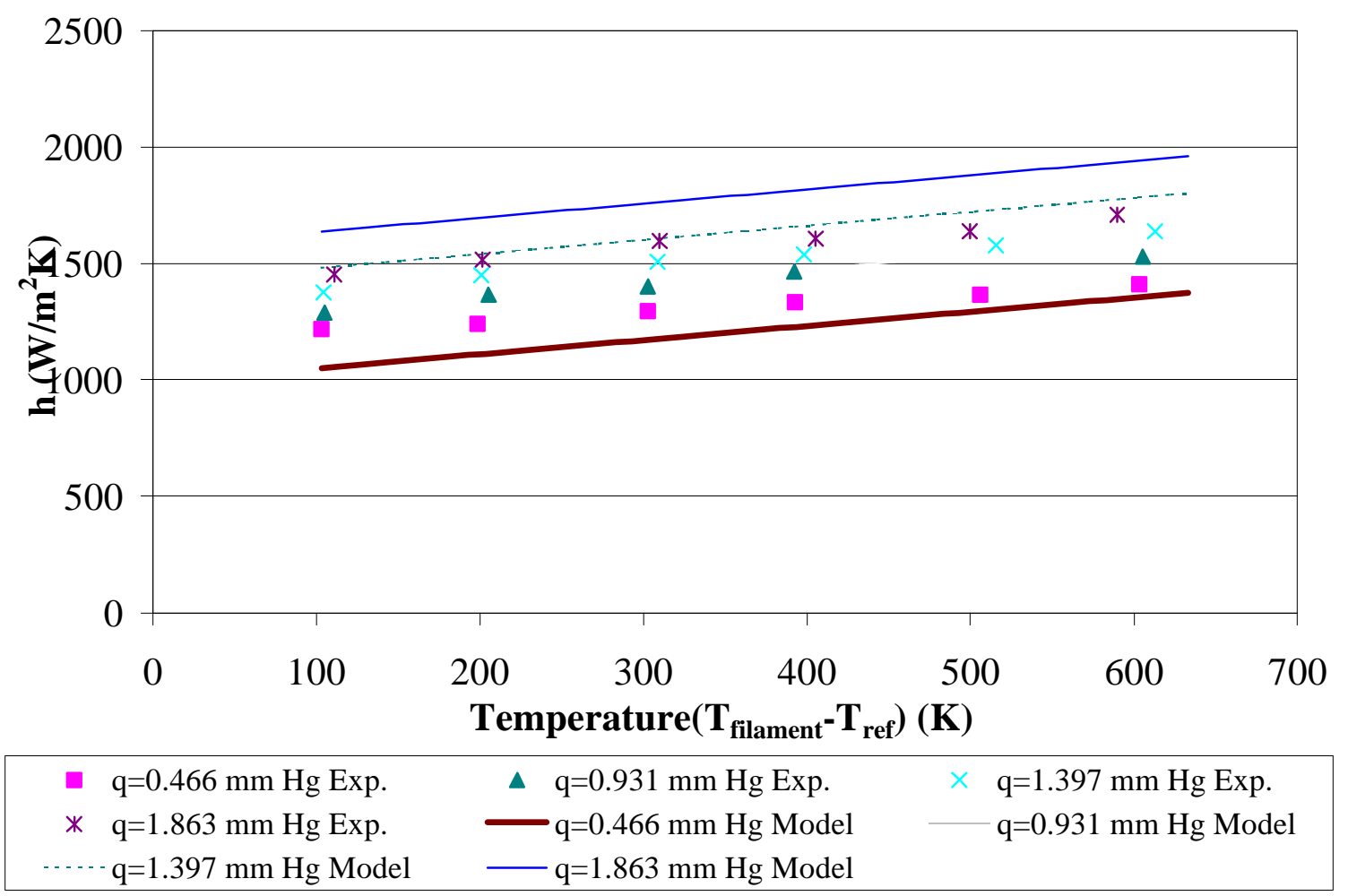

Figure 6.30: Experimental and Model Heat Transfer Coefficients vs. Temperature Difference of a 25.4 Micron Platinum Filament with $30 \mathrm{~cm}$. Length and Theta $=7^{\circ}$ 


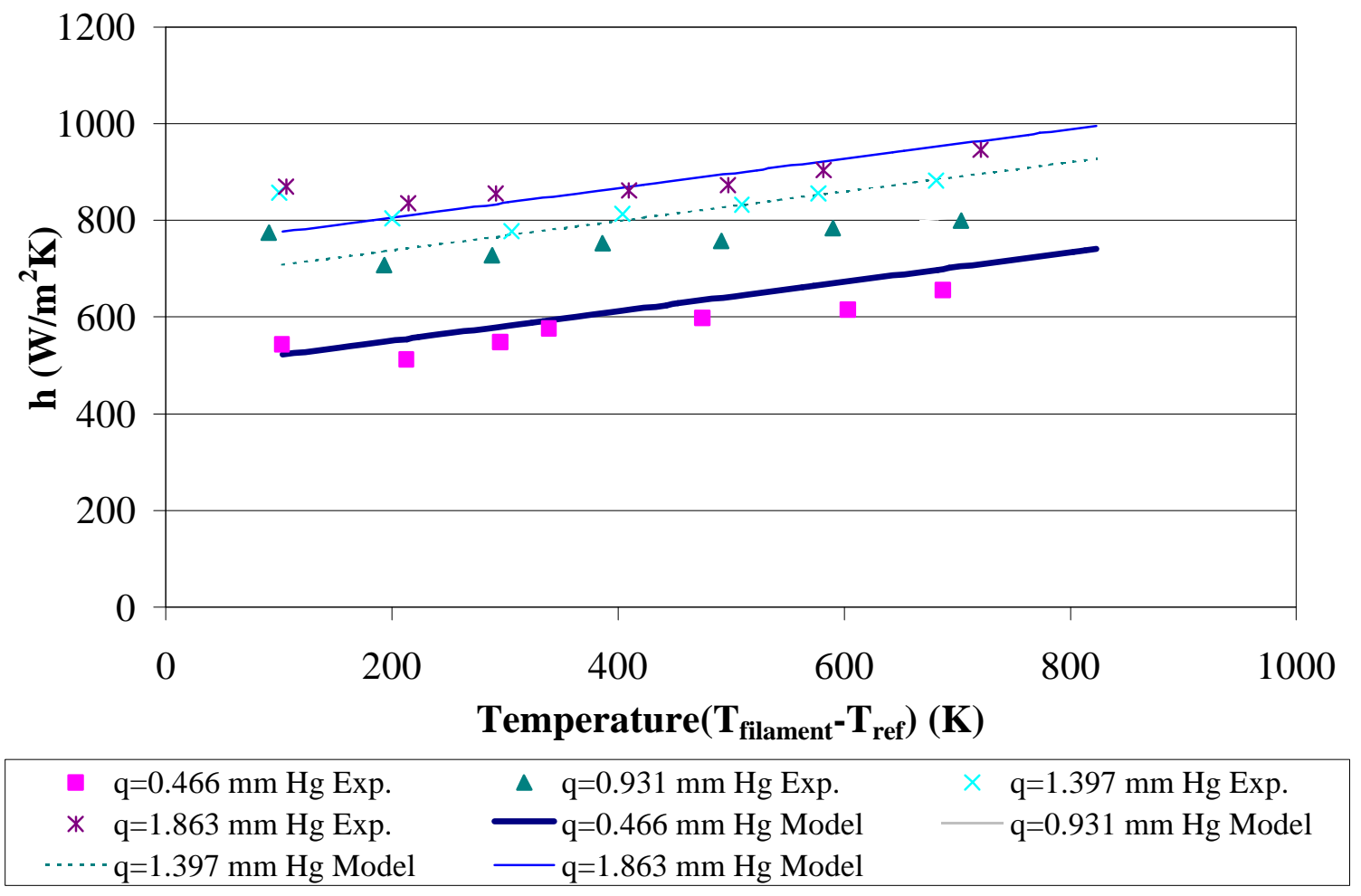

Figure 6.31: Experimental and Model Heat Transfer Coefficients vs. Temperature Difference of a 51 Micron Platinum Filament with $30 \mathrm{~cm}$. Length and Theta $=2.5^{\circ}$ 


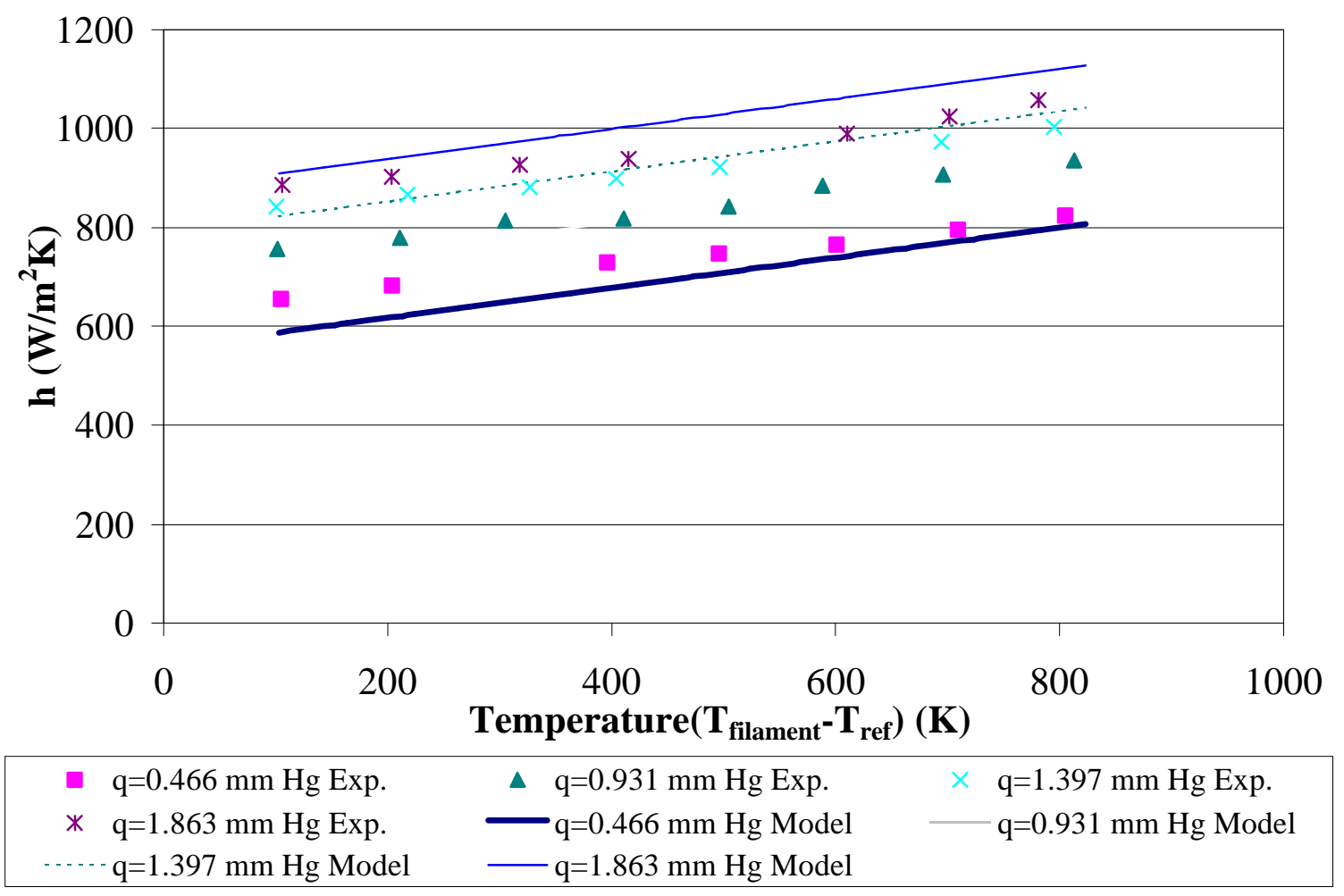

Figure 6.32: Experimental and Model Heat Transfer Coefficients vs. Temperature Difference of a 51 Micron Platinum Filament with $30 \mathrm{~cm}$. Length and Theta $=5^{\circ}$ 


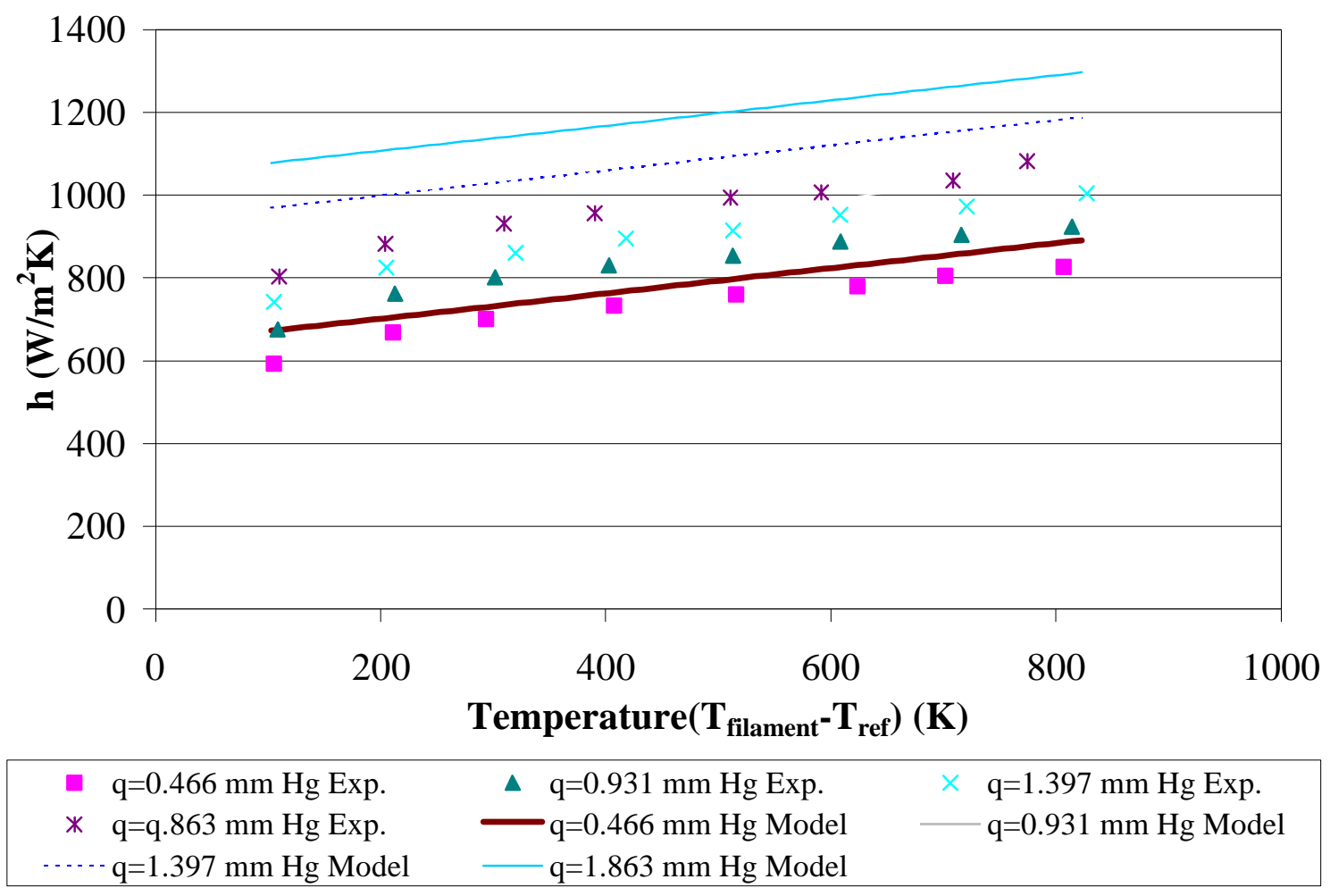

Figure 6.33: Experimental and Model Heat Transfer Coefficients vs. Temperature Difference of a 51 Micron Platinum Filament with $30 \mathrm{~cm}$. Length and Theta $=7^{\circ}$ 


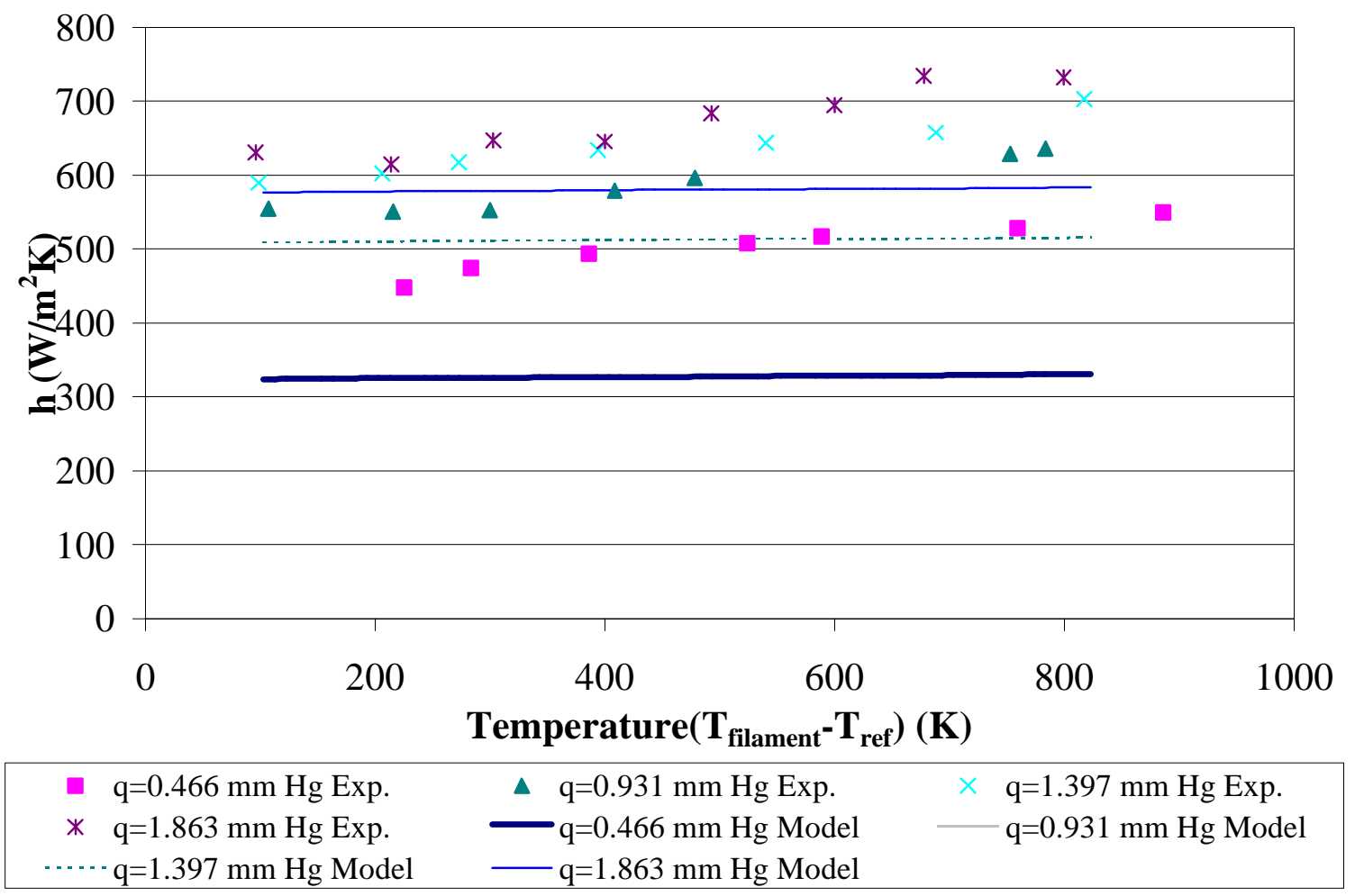

Figure 6.34: Experimental and Model Heat Transfer Coefficients vs. Temperature Difference of a 76 Micron Platinum Filament with $30 \mathrm{~cm}$. Length and Theta $=2.5^{\circ}$ 


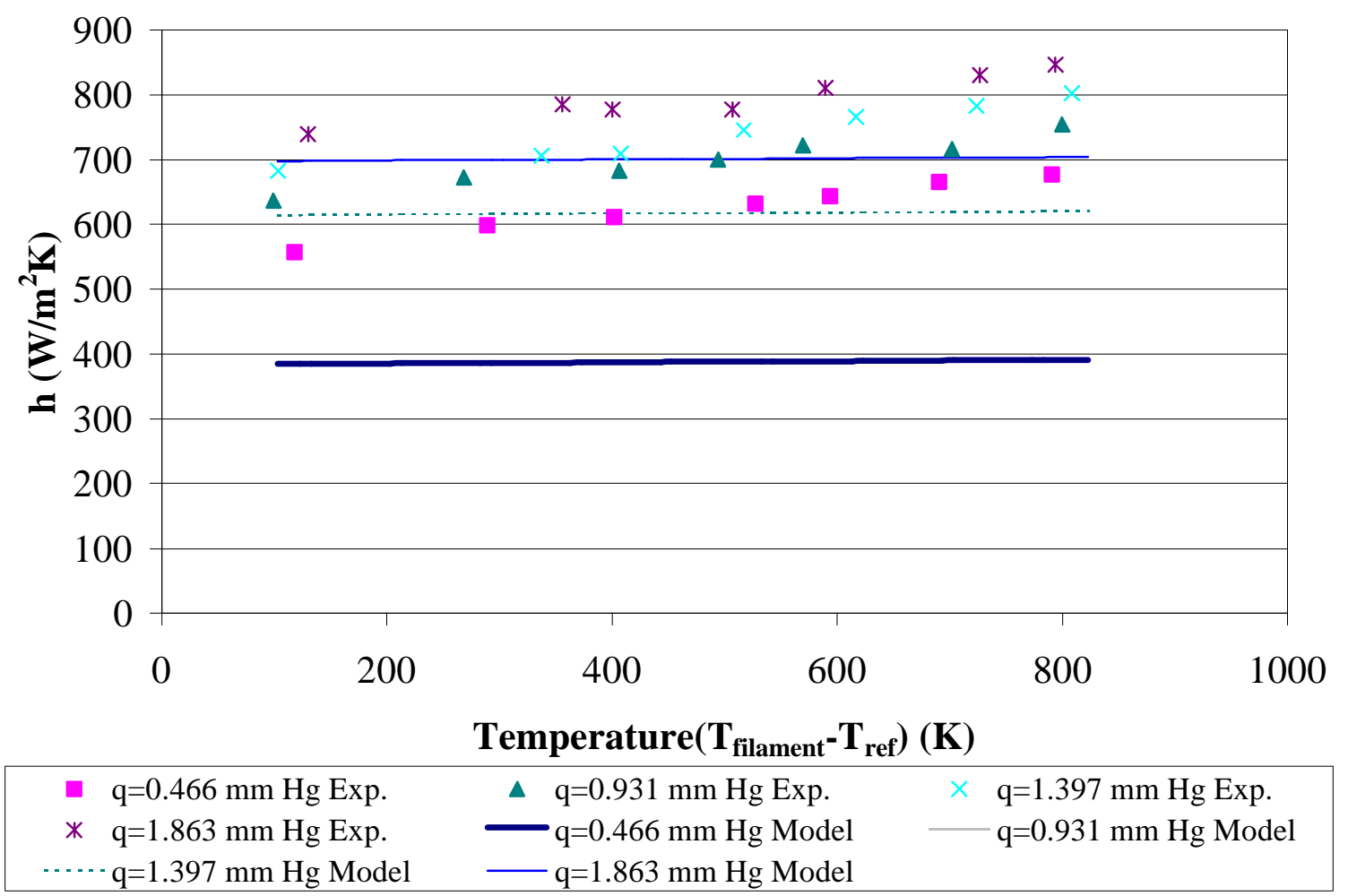

Figure 6.35: Experimental and Model Heat Transfer Coefficients vs. Temperature Difference of a 76 Micron Platinum Filament with $30 \mathrm{~cm}$. Length and Theta $=5^{\circ}$ 


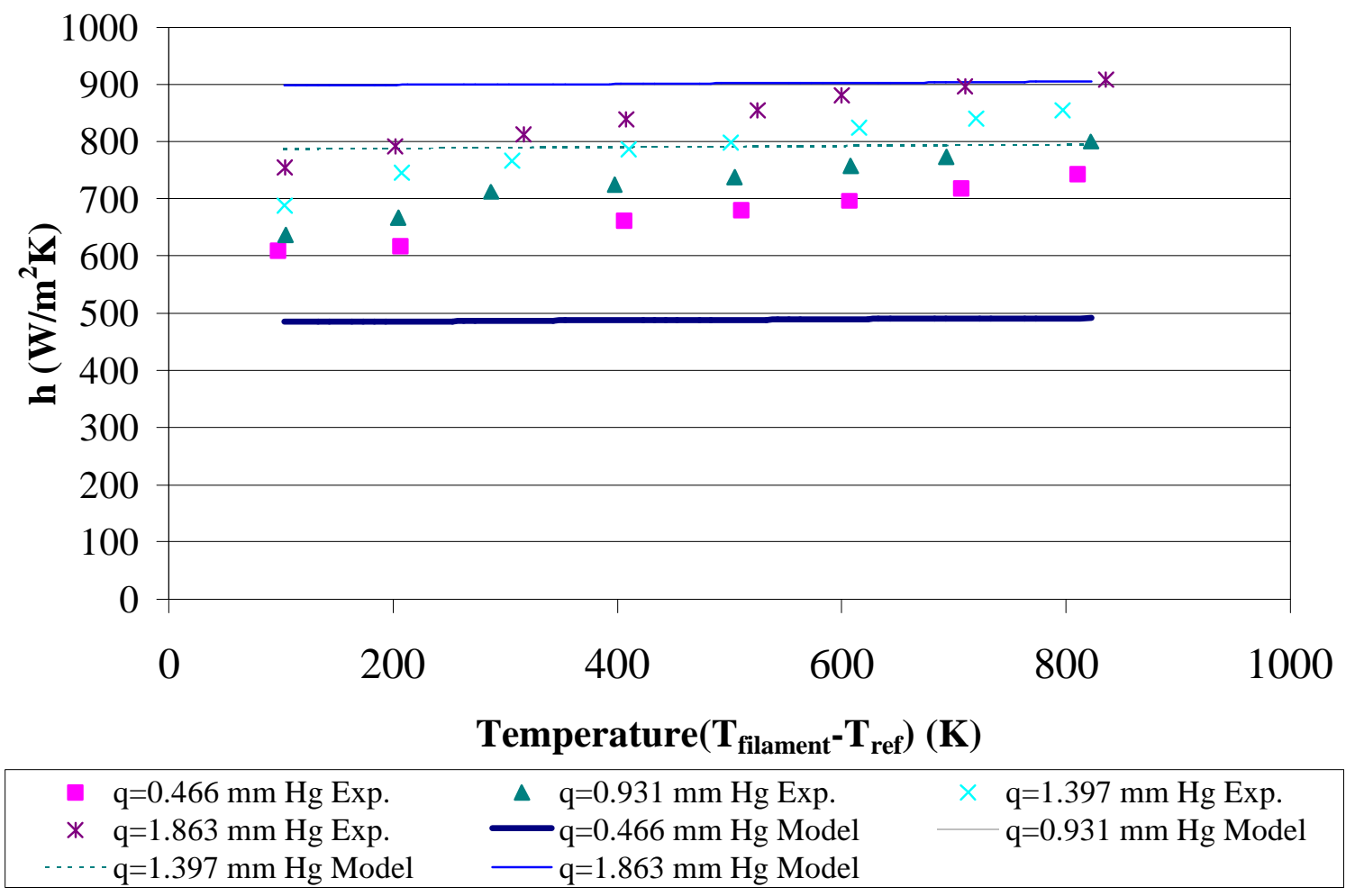

Figure 6.36: Experimental and Model Heat Transfer Coefficients vs. Temperature Difference of a 76 Micron Platinum Filament with $30 \mathrm{~cm}$. Length and Theta $=7^{\circ}$ 


\section{Chapter 7: Conclusions}

The purpose of this study was to characterize the heat transfer from an electrically heated thin filament as a function of various operating parameters such a filament diameter, flow velocity, filament temperature and crossflow angle. Experimental data were taken and plotted to determine these relationships. The plots were then examined with respect to each of the operating parameters under consideration. The results of this study have lead to the following conclusions:

1. Data taken in the current research illustrates similar trends to those taken in a previous similar study by Morris, Loth and Bond [1].

2. Heat transfer coefficient varies linearly with filament temperature for each different flow velocity, filament diameter and crossflow angle tested.

3. Heat transfer coefficient is not inversely proportional to filament diameter as previously assumed. Heat transfer coefficient decreases with increasing filament diameter in a second order relationship.

4. Forced convection heat transfer coefficients increase significantly with increasing crossflow angle. The relationship was found to be a sine-squared of second order relationship.

5. Heat transfer is influenced by filament vibration. Heat transfer coefficient increases with decreasing tensioning weight. Frequency of vibration tends to increase with tensioning weight, whereas amplitude of vibration increases with decreasing tensioning weight.

6. An empirical model for heat transfer coefficient was developed that relates the convective heat transfer coefficient to filament velocity, crossflow angle, 
temperature and filament diameter. When plotted with experimental data the empirical model is accurate to an average of $11 \%$. Errors in the model can be attributed to errors inherent in the data acquisition process and variables in operating conditions and operating parameters. The empirical model took the form:

$\mathrm{h}\left(\mathrm{W} / \mathrm{m}^{2} \mathrm{~K}\right)=(-0.01180 * \mathrm{~d}+0.957) *\left(\mathrm{~T}-\mathrm{T}_{\infty}\right)+(23.01 * \mathrm{~V}-6.612 * \mathrm{~d}+573.5)+\mathrm{V} *\left(\left(0.8452 * \mathrm{~d}^{2}-\right.\right.$

$$
\left.111.3 * d+4631) *\left(\sin ^{2} \theta\right)\right)
$$

where $\mathrm{d}$ is filament diameter in microns, $\mathrm{T}-\mathrm{T}_{\infty}$ is difference between filament temperature in Kelvin and freestream temperature in Kelvin, $\mathrm{V}$ is freestream velocity in $\mathrm{m} / \mathrm{s}$ and $\theta$ is crossflow angle in degrees. 


\section{Chapter 8: Recommendations}

Examination of the heat transfer associated with a thin filament has produced a great deal of information regarding the nature of heat transfer from the filament in relation to several of the operating parameters. Completion of the examination revealed several obvious recommendations for improvement of future testing. These include the experimental setup and procedure to improve the characterization of heat transfer coefficient from a forming filament. It is recommended that:

1. A larger array of testing conditions could be studied to further improve accuracy of the empirical model. More filament diameters, wider temperature ranges, a larger number of flow velocities and more crossflow angles would probably reduce the error in the empirical model.

2. A larger diameter test section could be used to allow for larger crossflow angles to be obtained.

3. Vibrational analysis revealed more than one mode of vibration. An extremely low turbulence wind tunnel should be used to help reduce this.

4. More in-depth analysis of vibration would be valuable. Investigations into vibrations of several different wire sizes at different crossflow angles should be performed.

5. Adjustments to the empirical model could be made using an expanded database of vibrational data. 
6. A study could be performed to determine the cause of the no-repeatability of the data. This may be useful to reduce the $15 \%$ error in repeatability problem. 


\section{References}

1. Morris, G.J., Loth, J.L, and Bond, R.E., Cooling Rate of a Filament, Final Contract Report, Dec. 1997.

2. Maebius, R.E., Effects of Heat Transfer on Melt Spinning, Journal of Applied Polymer Science, Vol. 30, Jan 1985, pp.1639-1652.

3. Kase, S., and Matsuo, T., Studies on Melt Spinning. I. Fundamental Equations on the Dynamics of Melt Spinning, Journal of Polymer Science, Vol. 3, Part A, 1965, pp. 2541-2554.

4. Lueptow, R.M., Turbulent Boundary Layer on a Cylinder in Axial Flow, AIAA Journal, Vol. 28, No. 10, October 1990, pp. 1705-1707.

5. Sakiadis, B.C., Boundary-Layer Behavior on Continuous Solid Surfaces: I. Boundary-Layer Equations for Two-Dimensional and Axisymmetric Flow, A.I.Ch.E Journal, Vol. 7, March 1961, pp. 26-28.

6. Karnis, J., and Pechoc, V., The Thermal Laminar Boundary Layer on a Continuous Cylinder, Int. Journal of Heat and Mass Transfer, Vol. 21, April 1977, pp.41-47.

7. Bourne, D.E. and Davies, D.R., Heat Transfer Through the Laminar Boundary Layer on a Circular Cylinder In Axial Incompressible Flow, Quarterly Journal of Applied Mechanics and Applied Mathematics, Vol. XI, Pt. 1, 1958, pp. 52-66.

8. Bourne, D.E, Davies, D.R., and Wardle, S., A Further Note on the Calculation of Heat Transfer Through The Axisymmetrical Laminar boundary Layer on A Circular Cylinder, Quarterly Journal of Applied Mechanics and Applied Mathematics, Vol. XII, Pt. 2, 1959, pp.257-260.

9. Eshghy, S. and Hornbeck, R., Flow and Heat Transfer in the Axisymmetric Boundary Layer over a Circular Cylinder, Int. Journal of Heat and Mass Transfer, Vol. 10, 1957, pp. 1757-1766.

10. Bourne, D.E, and Elliston, D.G., Heat Transfer Through the Axially Symmetric Boundary Layer on a Moving Circular Fibre, Int. Journal of Heat and Mass Transfer, Vol. 13, 1970, pp. 583-593.

11. Beese E. and Gersten, K, Skin Friction and Heat Transfer on a Circular Cylinder Moving in a Fluid at Rest, Journal of Applied Mathematics and Physics, Vol. 30, 1979, pp.117-127. 
12. Bourne, D.E., and Dixon, H., The Cooling of Fibres in the Formation Process, Int, Journal of Heat and Mass Transfer, Vol. 24, 1971, pp. 1323-1332.

13. Papamichael, $\mathrm{H}$ and Miaoulis, I.N., The Cooling of Optical Fibres During the Drawing Process, Glass Technology, Vol. 33, No. 4, August 1992, pp. 136-140

14. Papamichael, $\mathrm{H}$ and Miaoulis, I.N., Axial Heat Conduction Effects in the Cooling of Optical Fibres, Glass Technology, Vol. 32, No. 3, June 1991, pp. 102-108.

15. Eswara, A.T. and Nath, G., Unsteady Forced Convection Laminar Boundary Layer Flow Over a Moving Longitudinal Cylinder, Acta Mechanica 93, 1992, pp. 13-28.

16. Ha, M.Y., Jung, M.J., and Kim, Y.S., Numerical Study on Transient Heat Transfer and Fluid Flow of Natural Convection in an Enclosure with a Heat-Generating Conducting Body, Numerical Heat Transfer, Part A, Vol. 35, 1999, pp. 415-433.

17. Ball, S.J., Ashforth-Frost, S., Jambunathan, K, and Whitney, C.F., Appraisal of a HotWire Temperature Compensation Technique for Velocity Measurements in NonIsothermal Flows, Int. Journal of Heat and Mass Transfer, Vol. 42, 1999, pp.30973102.

18. Dyos, G.T and Farrell, T., Electrical Resistivity Handbook, Short Run Press, 1992.

19. Weast, R.C., Handbook of Chemistry and Physics, Chemical Rubber Company, 1972. 


\section{Appendix A: \\ Results of Hot-Film Anemometry}




\section{Appendix A}

Table A.1: Hot Film anemometry Readings

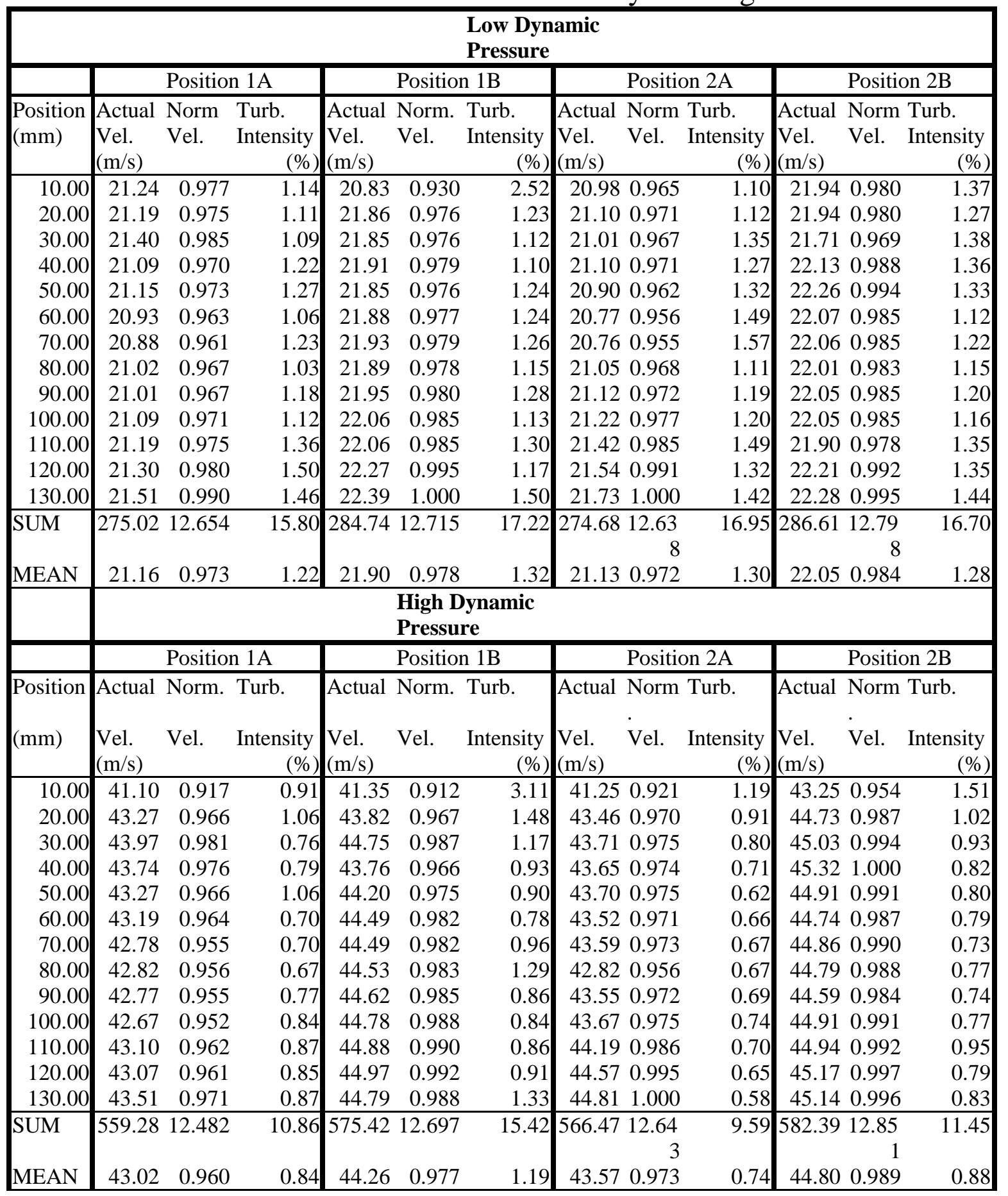




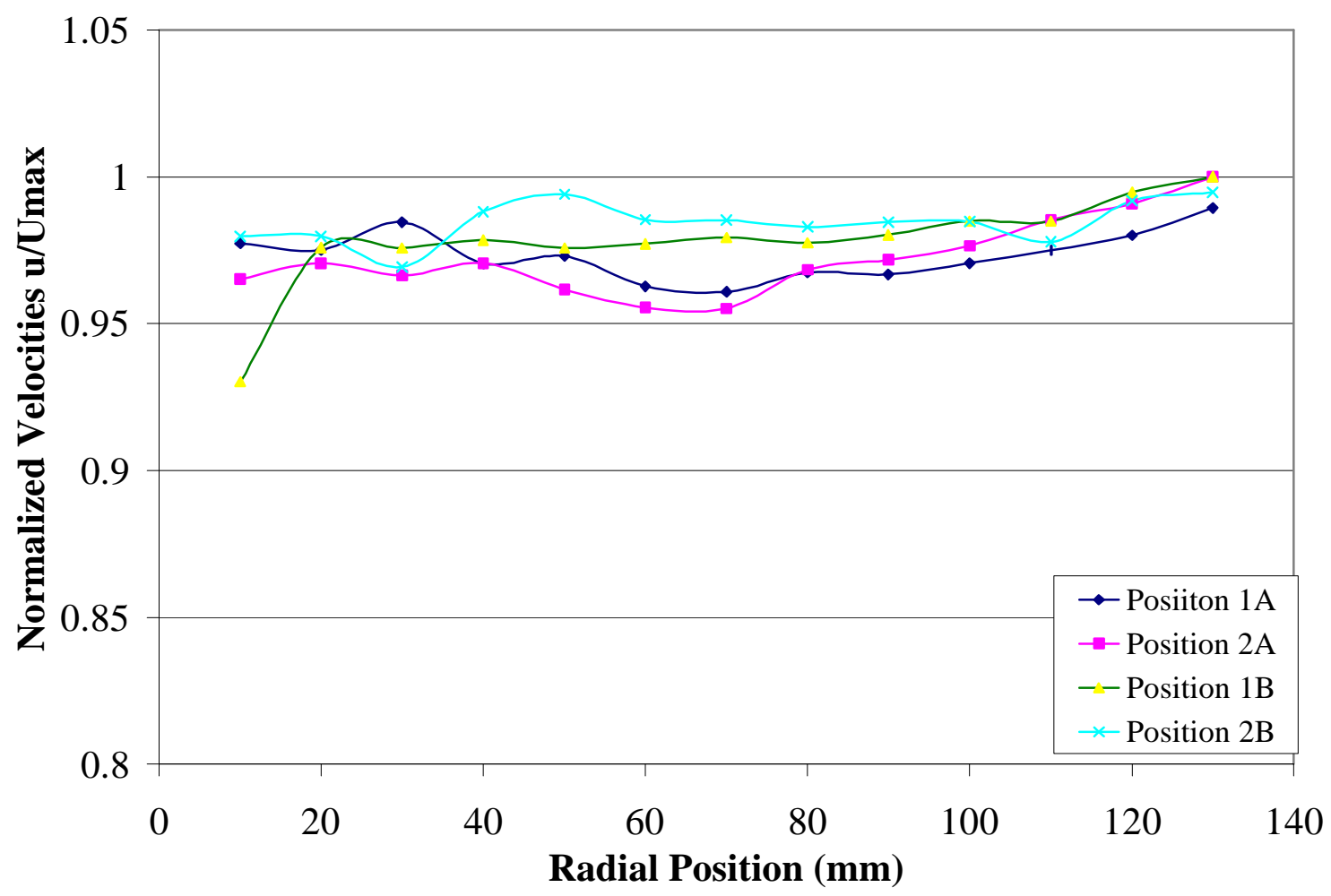

Figure A.1: Normalized Velocity Profiles at Low Dynamic Pressure q=2.32 $\mathrm{mm} \mathrm{Hg}$ $\left(\mathrm{U}_{\max }=322.39 \mathrm{~m} / \mathrm{s}\right)$ 


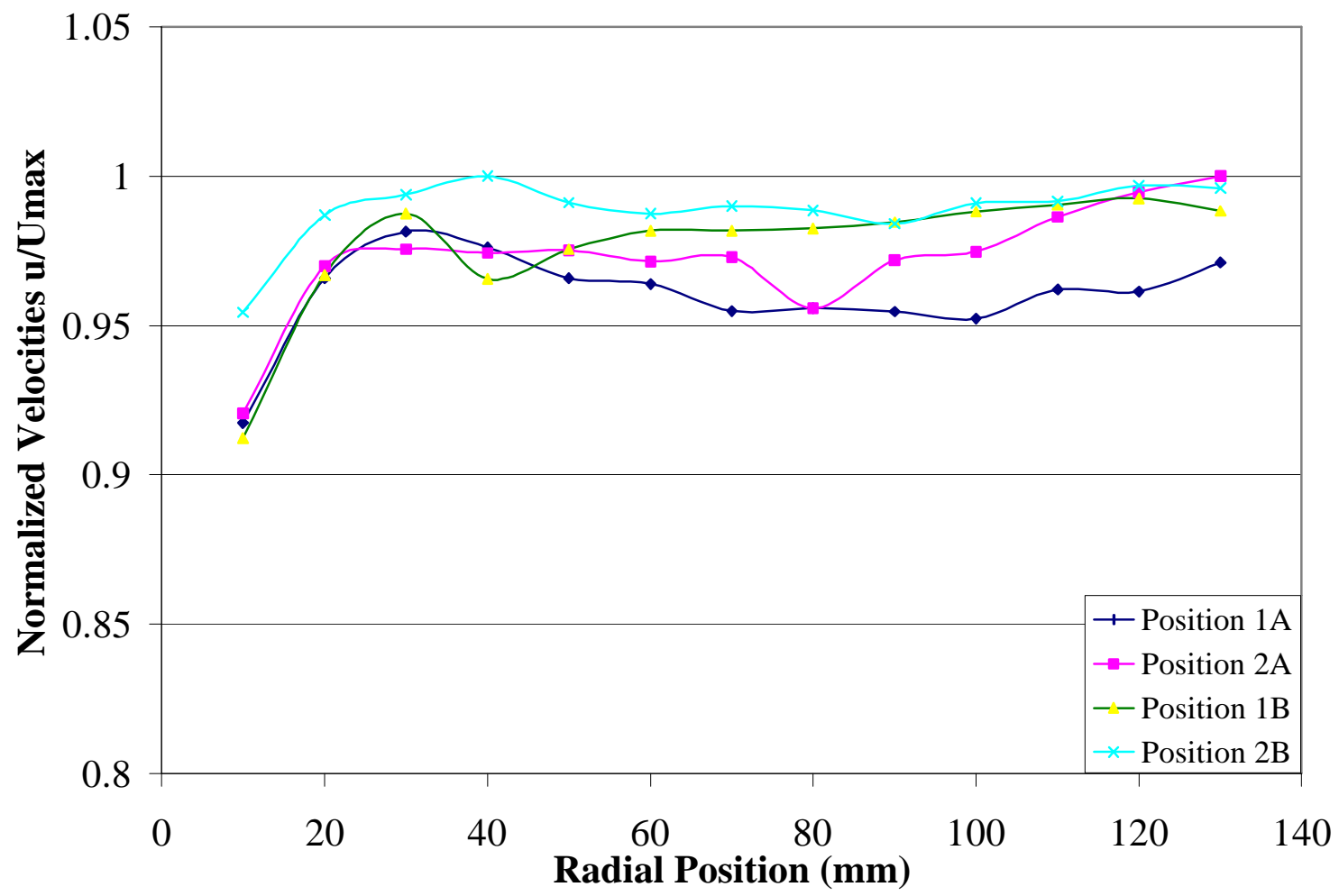

Figure A.2: Normalized Velocity Profiles at High Dynamic Pressure q=9.31 mm $\mathrm{Hg}$ $\left(\mathrm{U}_{\max }=45.32 \mathrm{~m} / \mathrm{s}\right)$ 


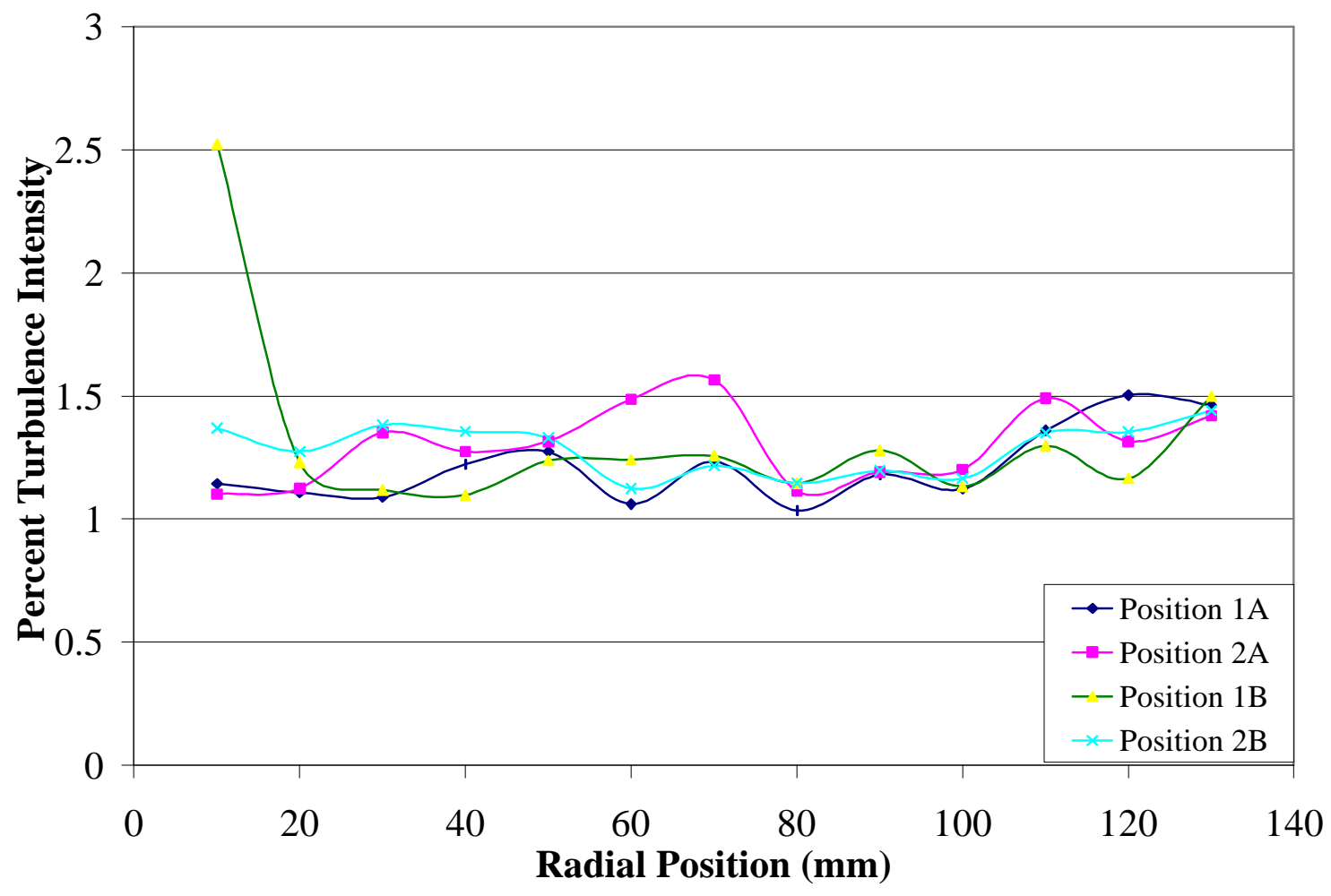

Figure A.3: Percent Turbulence Intensity at Low Dynamic Pressure q=2.32 mm Hg 


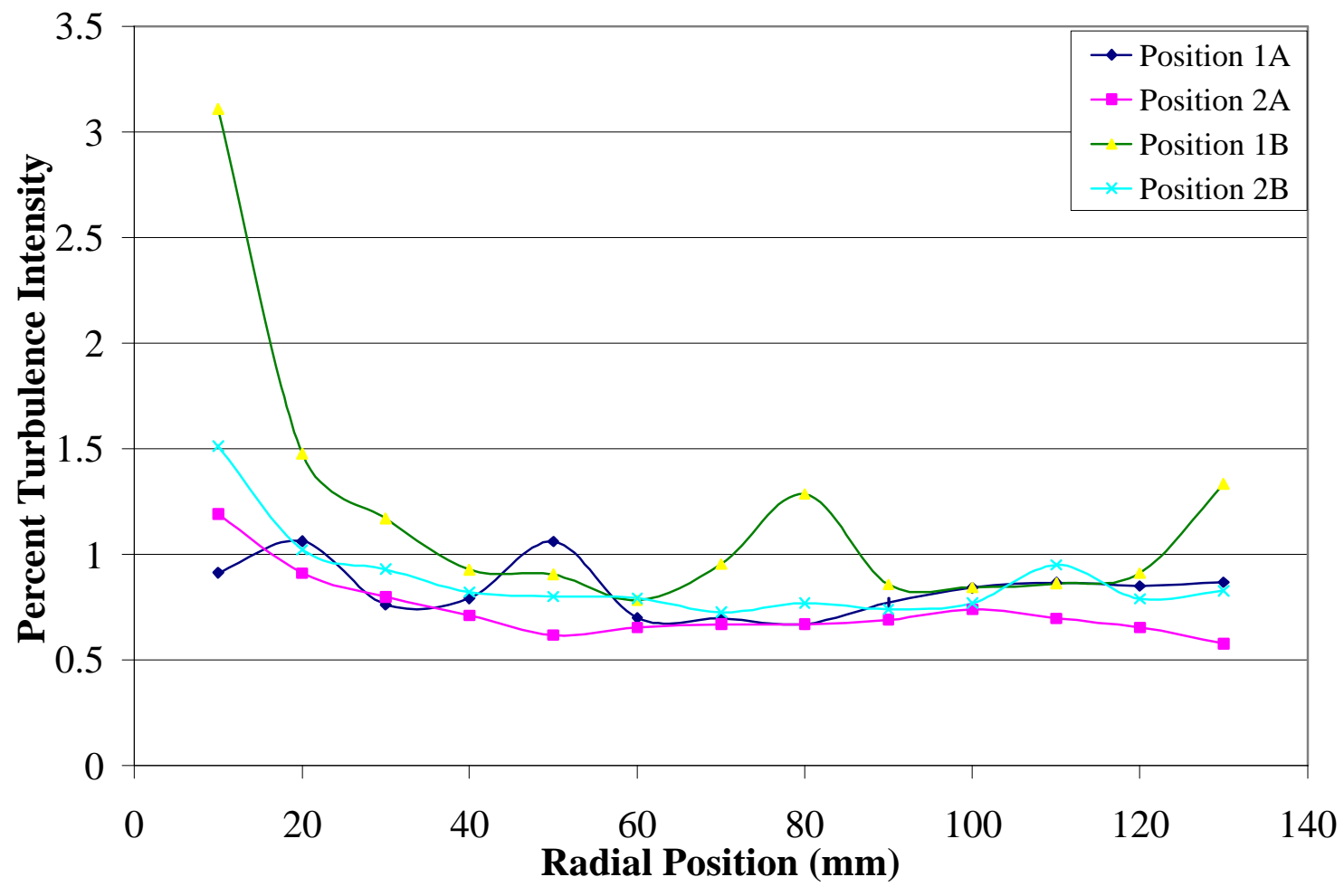

Figure A.4: Percent Turbulence Intensity at High Dynamic Pressure q=9.31 mm Hg 


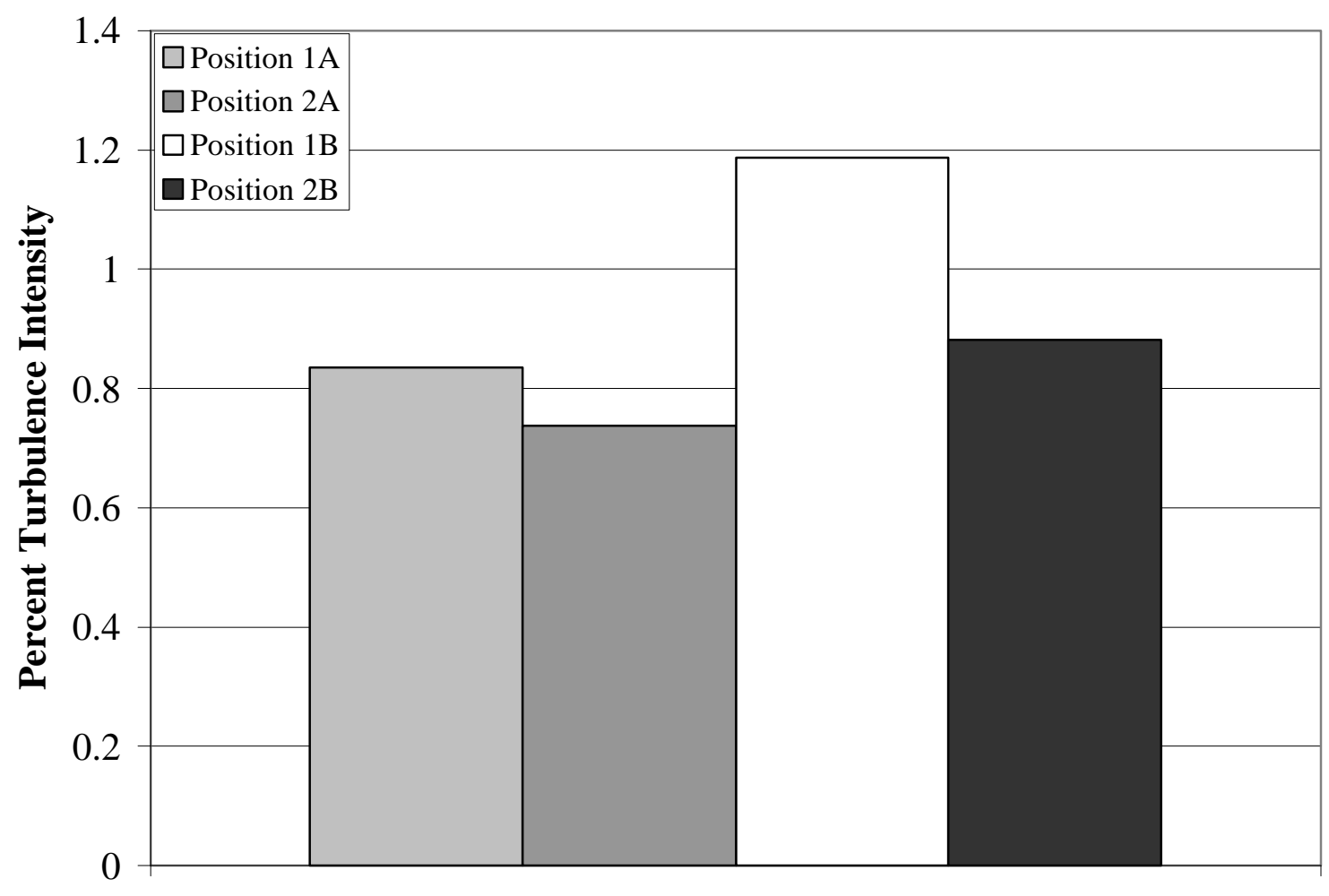

Figure A.5: Mean Values for Percent Turbulence Intensity at High Dynamic Pressure 


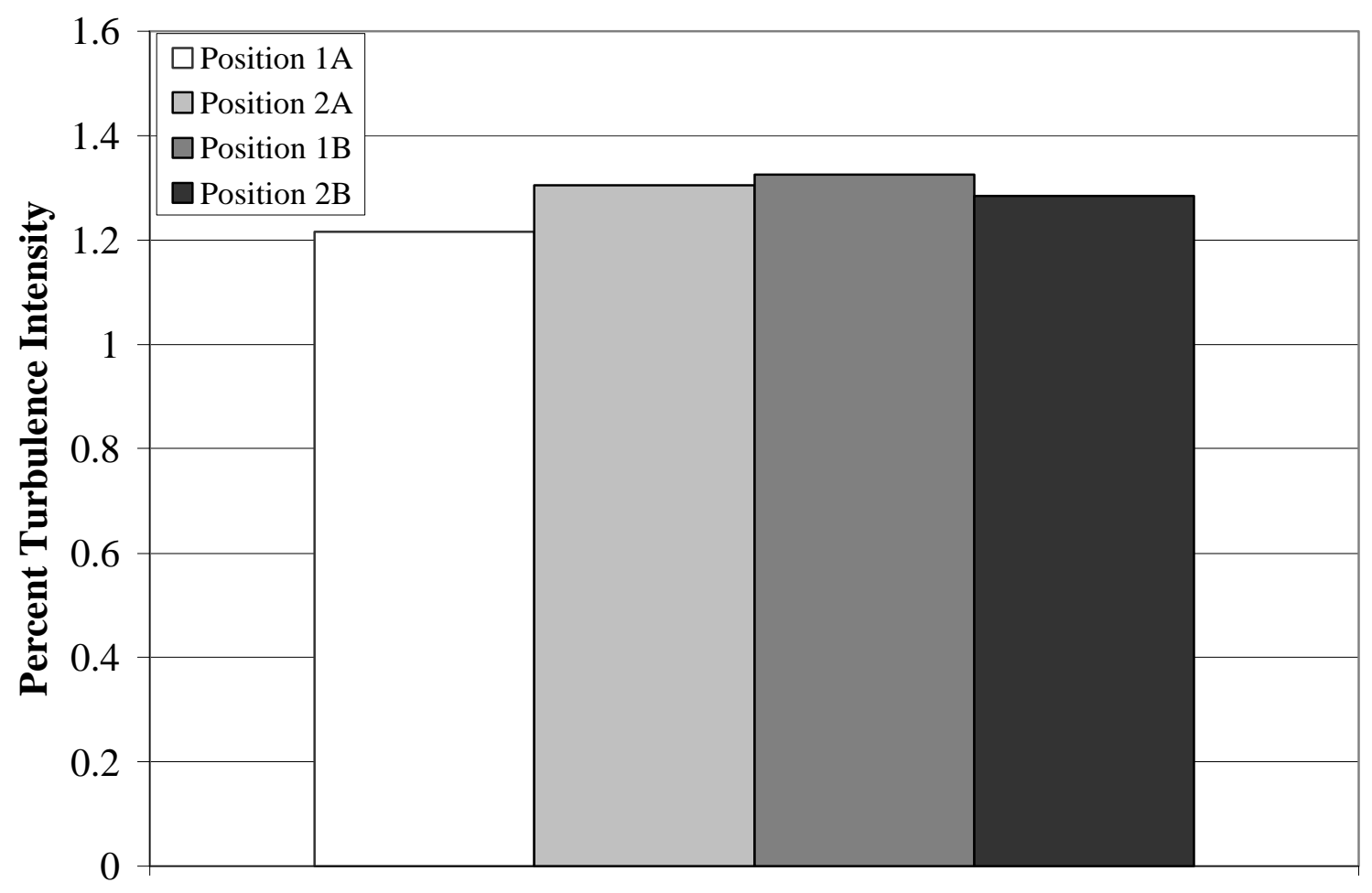

Figure A.6: Mean Values for Percent Turbulence Intensity at Low Dynamic Pressure 


\section{Appendix B:}

Data Acquisition Program 
Appendix B

'
'
'
'
Written
by
Robert E Bond
and
Amy J. Cragg

DEFINT I

DEFDBL V

DECLARE SUB INITIALIZE CDECL (SEG IERSTAT\%)

DECLARE SUB AIN815 CDECL (BYVAL ILCHAN\%, BYVAL IBOARD\%, BYVAL IPCHAN\%, BYVAL IGAIN\%, SEG IERSTAT\%)

DECLARE FUNCTION AIN\% CDECL (BYVAL ILCHAN\%, SEG IERSTAT\%)

DECLARE SUB DELAY CDECL (BYVAL MIN\%, BYVAL SEC\%, BYVAL HUND\%)

'-----Wire Information-----'

Dia $=.0025$

WireL $=30$

WireA $=(3.14159 / 4) *(\operatorname{Dia} * 2.54 / 100) \wedge 2$

'-----Resistor Values-----'

CURRRES = 5 '---Current

VD1 $=21905 \quad$ '---Voltage Divider

VD2 $=2960$ '---Measured Voltage Divider

samp $=5000$

$\operatorname{GAIN}(0)=1$

$\operatorname{GAIN}(1)=1$

DIM IVAL0 (samp + 1)

DIM IVAL1(samp + 1)

Initialize RTI Board and Set Channels 


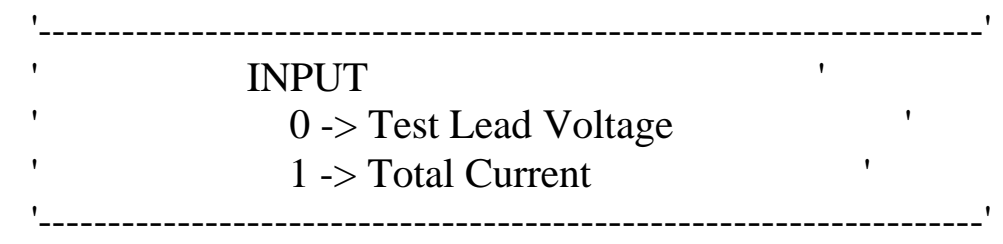

\section{CLS}

\section{CALL INITIALIZE(IERSTAT)}

IF IERSTAT <> 0 THEN PRINT "ERROR DURING INITIALIZE "; IERSTAT: END $\mathrm{IBOARD}=1$
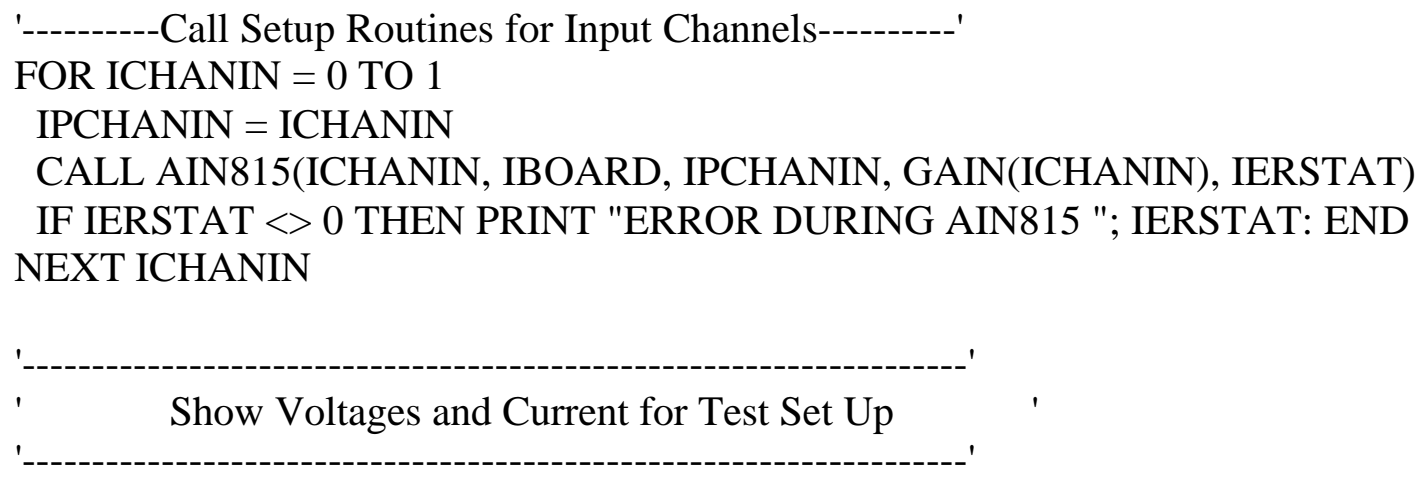

\section{CLS}

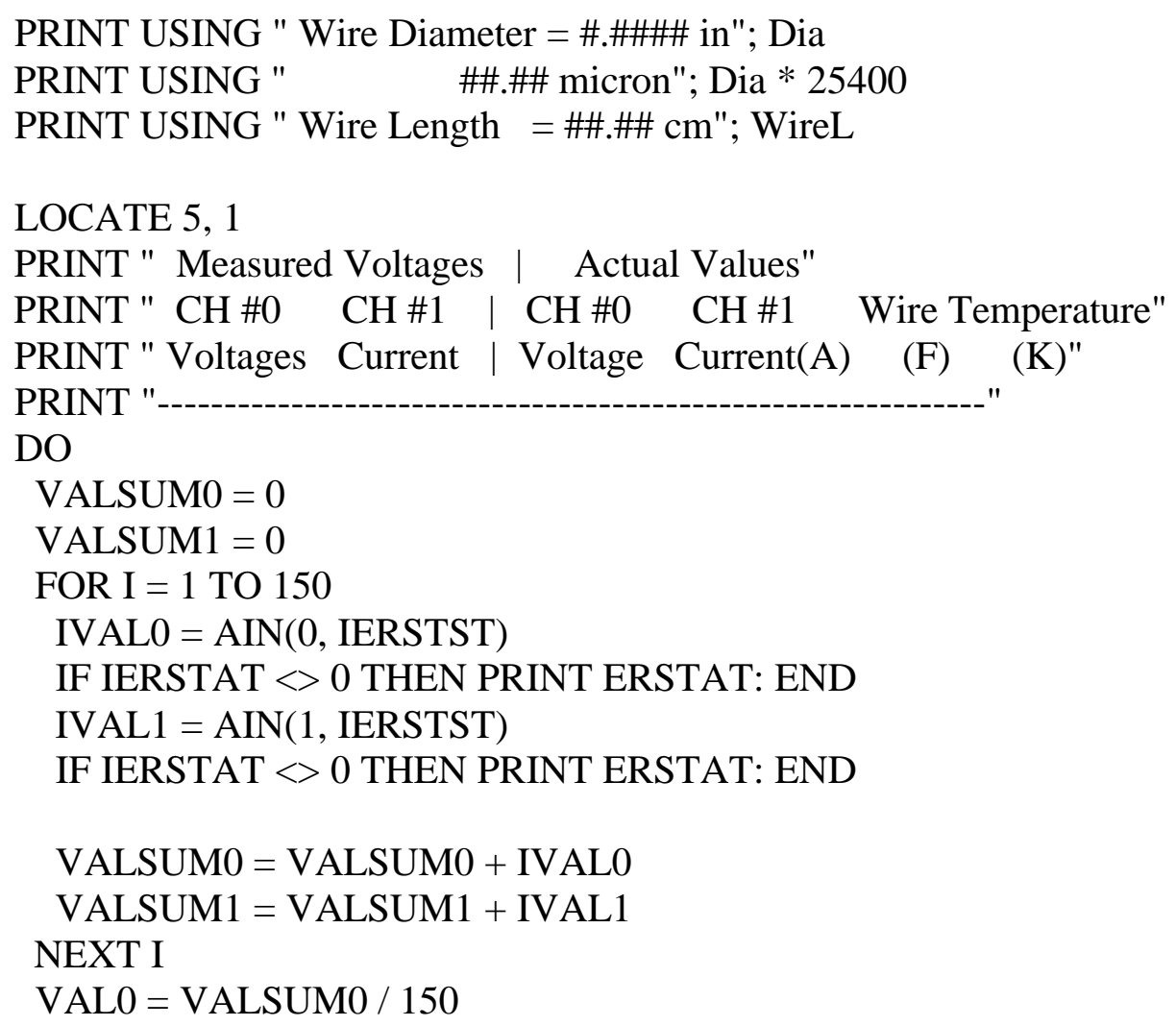


$\mathrm{VAL} 1=\mathrm{VALSUM} 1 / 150$

'-----Change Counts to Volts, Current and Temperature-----'

Volts $0=$ VAL0 $* 10$ ! / 4095!

Volts $1=$ VAL1 $* 10 ! / 4095$ !

WireV $=$ Volts $0 *(\mathrm{VD} 1+\mathrm{VD} 2) / \mathrm{VD} 2$

WireC $=$ Volts $1 /$ CURRRES

$\mathrm{Rcm}=\mathrm{WireV} /($ WireL $*$ WireC $)$

Rho8 $=$ WireA $*$ Rcm $* 100 * 100000000$

WireTK $=40.25+22.1161 * \operatorname{Rho} 8+.148058 * \operatorname{Rho} 8 \wedge 2$

WireTF $=$ WireTK $* 9 / 5-460$

LOCATE 9, 1

PRINT USING " \#\#.\#\#\# \#\#.\#\#\# \#\#\#.\#\#\# \#.\#\#\# \#\#\#\# \#\#\#\#"; Volts0; Volts1; WireV; WireC; WireTF; WireTK

LOOP WHILE INKEY\$ = "'

'---------------------------------------------------------------------'

\section{CLS}

PRINT "Taking Data"

$\mathrm{t} 1=$ TIMER

FOR I = 1 TO samp

FOR ID = 1 TO 8: NEXT ID

$\operatorname{IVAL} 0(\mathrm{I})=\operatorname{AIN}(0$, IERSTST $)$

IF IERSTAT <> 0 THEN PRINT "ERROR DURING AIN \#0 "; IERSTAT: END

$\operatorname{IVAL} 1(\mathrm{I})=$ AIN $(1$, IERSTAT $)$

IF IERSTAT <> 0 THEN PRINT "ERROR DURING AIN \#1 "; IERSTAT: END

NEXT I

$\mathrm{t} 2=$ TIMER

CLS

PRINT "Data Collected"

Freq $=$ samp $/(\mathrm{t} 2-\mathrm{t} 1)$

PRINT : PRINT : PRINT

PRINT USING " ET=\#\#\#\#\#\# No. of Points=\#\#\#\# Frequency=\#\#\#\# +/-\#\#\# Hz"; t2 -

t1; samp; Freq; Freq * $(1 / 15) /(\mathrm{t} 2-\mathrm{t} 1)$

PRINT : PRINT : PRINT

PRINT " Would you like to write a data file $<\mathrm{y} / \mathrm{n}>$ ?"

DO

ans\$ = INKEY\$

LOOP UNTIL ans\$ = "y" OR ans\$ = "Y" OR ans\$ = "n" OR ans\$ = "N" 
IF ans\$ = "n" OR ans\$= "N" THEN GOTO 10

Input Test Conditions

PRINT

PRINT " Please input the following test conditions:"

PRINT

INPUT " Dynamic Pressure in-H2O "; q

PRINT USING " Atmospheric Pressure in-Hg <\#\#.\#\#> "; Patm; : INPUT ans

IF ans $=0$ THEN Patm $=$ Patm ELSE Patm $=$ ans

PRINT USING " Atmospheric Temperature F <\#\#.\#> "; Tatm; : INPUT ans

IF ans $=0$ THEN Tatm $=$ Tatm ELSE Tatm $=$ ans

PRINT : PRINT : PRINT

' '----------------------------------------------------------------------'

INPUT "Please enter file name (Ex. b:Idata1.dat)"; FILE\$

OPEN FILE\$ FOR OUTPUT AS \#1

PRINT \#1, " Dia Length VD1 VD2 Ires q Patm Tatm Time $f$ ferr"

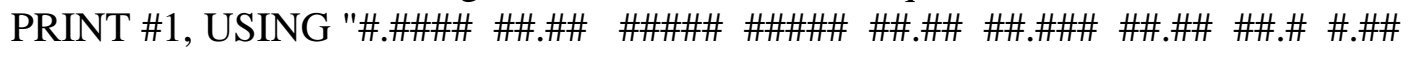

\#\#\#\# \#\#\#"; Dia; WireL; VD1; VD2; CURRRES; q; Patm; Tatm; t2 - t1; Freq; Freq * (1 /

$15) /(\mathrm{t} 2-\mathrm{t} 1)$

PRINT \#1,

PRINT \#1, "CH0(V), CH1(V), Time"

FOR I = 1 TO samp

'-----Change Counts to Volts, Current and Temperature-----'

Volts0 = IVAL0(I) * 10! / 4095!

Volts1 = IVAL1(I) $* 10$ ! / 4095!

WireV $=$ Volts $0 *(\mathrm{VD} 1+\mathrm{VD} 2) / \mathrm{VD} 2$

WireC $=$ Volts $1 /$ CURRRES

$\mathrm{Rcm}=$ WireV / (WireL $*$ WireC)

Rho8 $=$ WireA $*$ Rcm * $100 * 100000000$

WireTK $=40.25+22.1161 * \operatorname{Rho} 8+.148058 * \mathrm{Rho}^{\wedge} 2$

WireTF $=$ WireTK $* 9 / 5-460$

Time $=$ I $/$ Freq

PRINT \#1, USING "\#\#.\#\#, \#\#.\#\#\#, \#.\#\#\#\#"; Volts0; Volts1; Time

NEXT I

CLOSE \# 1

PRINT : PRINT : PRINT

PRINT "Would you like to run the program again $<y / n\rangle$ ?" 
DO

ans\$ = INKEY\$

LOOP UNTIL ans\$ = "y" OR ans\$ = "Y" OR ans\$ = "n" OR ans\$ = "N"

IF ans\$ = "y" OR ans\$ = "Y" THEN GOTO 10

END 


\section{Appendix C:}

\section{BASIC Program to Produce Statistical Information from a Raw Data File}




\section{Appendix C}

'STAT.BAS 1-1-1999

'This program will perform a statistical analysis on a raw data file, 'producing averages and standard deviations for the information contained ' in the original data file and writing the information to a new data 'file of the user's choice.

'This program was written by Amy J. Cragg

\section{DEFINT I \\ DEFINT C \\ CLS \\ samp $=5000$ \\ DIM volts0(samp + 1) \\ DIM time $($ samp + 1) \\ DIM volts1 $($ samp +1$)$ \\ DIM wireV $(\operatorname{samp}+1)$ \\ DIM wireC $(\operatorname{samp}+1)$ \\ DIM wireTK $($ samp + 1) \\ DIM wireTF(samp + 1) \\ DIM rho8(samp + 1) \\ $\operatorname{DIM} \operatorname{rcm}(\operatorname{samp}+1)$ \\ DIM power(samp + 1) \\ DIM h(samp + 1) \\ DIM qrad(samp + 1)}

40 INPUT "Please enter raw data file name to be read from."; file\$

OPEN file\$ FOR INPUT AS \#1

INPUT "Please enter name of new destination data file.", try\$

OPEN try\$ FOR OUTPUT AS \#2

50

$$
\begin{aligned}
& \operatorname{sum} 0=0 \\
& \text { sum1 }=0 \\
& \operatorname{sum} 20=0 \\
& \operatorname{sum} 21=0 \\
& \text { sumwireV }=0 \\
& \text { sumwireC }=0 \\
& \text { sumwireTK }=0
\end{aligned}
$$




$$
\begin{aligned}
& \text { sumwireTF }=0 \\
& \mathrm{f}=0 \\
& \mathrm{~g}=0 \\
& \mathrm{lh}=0 \\
& \mathrm{k}=0 \\
& \text { sumh }=0 \\
& \text { sumpower }=0 \\
& \text { sumqrad }=0 \\
& \text { sumqconv }=0 \\
& \text { sumW }=0 \\
& \text { sume }=0
\end{aligned}
$$

' Read extra line of data at top of data file.

\section{INPUT \#1, junk1\$}

' Read perameters into program

INPUT \#1, dia, L, r2, r3, r1, q, Patm, Tatm, T, freq, errorfreq

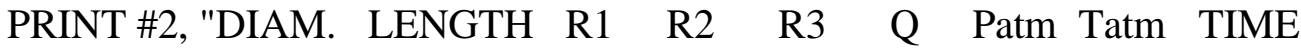

\section{FREQ ERROR"}

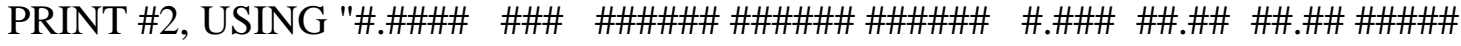

\#\#\#\#\# \#\#\#\#\#"; dia; L; r1; r2; r3; q; Patm; Tatm; T; freq; errorfreq

INPUT \#1, junk\$

area $=(3.14159 / 4) *(\operatorname{dia} * 2.54 / 100) \wedge 2$

' Read actual raw data file into arrays.

INPUT \#1, junk, junk, junk

FOR I = 1 TO samp

INPUT \#1, volts0(I), volts1(I), time(I)

$$
\begin{aligned}
& \text { sum } 0=\operatorname{sum} 0+\operatorname{volts} 0(\text { I }) \\
& \text { sum } 1=\operatorname{sum} 1+\operatorname{volts} 1(\text { I })
\end{aligned}
$$

NEXT I

ave $0=\operatorname{sum} 0 /$ samp
ave $1=\operatorname{sum} 1 /$ samp

\section{CLOSE \#1}

FOR I = 1 TO samp

$$
\begin{aligned}
& \operatorname{sum} 20=(\operatorname{volts} 0(\mathrm{I})-\operatorname{ave} 0)^{\wedge} 2+\operatorname{sum} 20 \\
& \operatorname{sum} 21=(\operatorname{volts} 1(\mathrm{I})-\operatorname{ave} 1)^{\wedge} 2+\operatorname{sum} 21
\end{aligned}
$$

NEXT I

'Compute the standard deviation.

standev0 $=\operatorname{SQR}(\operatorname{sum} 20 /(\operatorname{samp}-1))$

standev1 $=\mathrm{SQR}(\operatorname{sum} 21 /(\operatorname{samp}-1))$

FOR I = 1 TO samp

$$
\text { wireV }(\mathrm{I})=\operatorname{volts} 0(\mathrm{I}) *(\mathrm{r} 2+\mathrm{r} 3) / \mathrm{r} 3
$$




$$
\begin{aligned}
& \text { wireC }(\mathrm{I})=\operatorname{volts} 1(\mathrm{I}) / \mathrm{r} 1 \\
& \operatorname{rcm}(\mathrm{I})=\operatorname{wireV}(\mathrm{I}) /(\mathrm{L} * \operatorname{wireC}(\mathrm{I})) \\
& \operatorname{rho}(\mathrm{I})=\operatorname{area} * \operatorname{rcm}(\mathrm{I}) * 100 * 100000000 \\
& \text { wireTK }(\mathrm{I})=40.25+22.1161 * \operatorname{rho} 8(\mathrm{I})+.148058 * \operatorname{rho} 8(\mathrm{I}) \wedge 2 \\
& \text { sumwireV }=\operatorname{sumwireV}+\operatorname{wireV}(\mathrm{I}) \\
& \text { sumwireC = sumwireC + wireC }(\mathrm{I}) \\
& \text { power }(\mathrm{I})=\operatorname{wireV}(\mathrm{I}) * \operatorname{wireC}(\mathrm{I}) \\
& \text { sumwireTK = sumwireTK + wireTK(I) } \\
& \text { sumpower = sumpower + power(I) }
\end{aligned}
$$

100 NEXT I

avewireV = sumwireV / samp

avewireC $=$ sumwireC / samp

avewireTK = sumwireTK / samp

avepower $=$ sumpower $/ \mathrm{samp}$

$$
\begin{aligned}
\text { FOR I }= & 1 \text { TO samp } \\
& \text { wireV }(\mathrm{I})=\operatorname{volts} 0(\mathrm{I}) *(\mathrm{r} 2+\mathrm{r} 3) / \mathrm{r} 3 \\
& \text { wireC }(\mathrm{I})=\operatorname{volts} 1(\mathrm{I}) / \mathrm{r} 1 \\
& \operatorname{rcm}(\mathrm{I})=\operatorname{wireV}(\mathrm{I}) /(\mathrm{L} * \text { wireC }(\mathrm{I})) \\
& \operatorname{rho} 8(\mathrm{I})=\operatorname{area} * \operatorname{rcm}(\mathrm{I}) * 100 * 100000000 \\
& \text { wireTK }(\mathrm{I})=40.25+22.1161 * \operatorname{rho} 8(\mathrm{I})+.148058 * \operatorname{rho} 8(\mathrm{I}) \wedge 2 \\
& \mathrm{f}=(\text { wireV }(\mathrm{I})-\operatorname{avewireV})^{\wedge} 2+\mathrm{f} \\
& \mathrm{g}=(\text { wireC }(\mathrm{I})-\operatorname{avewireC})^{\wedge} 2+\mathrm{g} \\
& \mathrm{lh}=(\text { wireTK}(\mathrm{I})-\text { avewireTK })^{\wedge} 2+\mathrm{lh} \\
& \mathrm{k}=(\mathrm{h}(\mathrm{I})-\operatorname{aveh})^{\wedge} 2+\mathrm{k}
\end{aligned}
$$

\section{NEXT I}

devwireV $=\mathrm{SQR}(\mathrm{f} /(\mathrm{samp}-1))$

devwireC $=\operatorname{SQR}(\mathrm{g} /(\mathrm{samp}-1))$

devwireTK = SQR $($ lh / (samp - 1))

$\operatorname{devh}=\mathrm{SQR}(\mathrm{k} /(\mathrm{samp}-1))$

PRINT \#2, "The average value of the measured voltages in channel $1=\quad$ "; ave0

PRINT \#2, "The average value of the measured voltages in channel 2= "; ave1

PRINT \#2, "The average value of the actual voltage in channel $1=\quad$ "; avewireV

PRINT \#2, "The average value of the actual current in channel 2= $\quad$ "; avewireC; ""

PRINT \#2, "The average value of the temperature in Kelvin=

PRINT \#2, "The average value of the power=

"; avewireTK

PRINT \#2, "The average value of the emmisivity=

PRINT \#2, "The average value of $Q$ radiation=

PRINT \#2, "The average value of $Q$ convection=
"; avepower
"; avee
"; aveqrad

"; aveqconv

PRINT \#2, "The standard deviation of the measured voltages in channel 1="; standev0

PRINT \#2, "The standard deviation of the measured voltages in channel 2="; standev1

PRINT \#2, "The standard deviation of the actual voltages in channel 1= "; devwireV

PRINT \#2, "The standard deviation of the actual currents in channel 2= "; devwireC

PRINT \#2, "The standard deviation of the temperature in $\mathrm{K}=\quad$ "; devwireTK 
INPUT "Do you wish to run the program again?", ans\$

IF ans\$ = "yes" THEN

CLOSE \#2

GOTO 40

ELSE

CLOSE \#2

END

END IF

END 


\section{Appendix D:}

\section{BASIC Program to Produce Time-Related Data from a Raw Data}

File 
Appendix D

'TIME.BAS 12-16-1998

'This program will perform an analysis on a raw data file, 'producing related information from the raw data contained 'in the original file and writing the information to a new data file of 'the user's choice.

'This program was written by Amy J. Cragg

\section{DEFINT I \\ DEFINT C \\ CLS \\ samp $=5000$ \\ DIM volts0(samp + 1) \\ DIM time $($ samp + 1) \\ DIM volts1 (samp + 1) \\ DIM wireV $(\operatorname{samp}+1)$ \\ DIM wireC $(\operatorname{samp}+1)$ \\ DIM wireTK $($ samp + 1) \\ DIM wireTF $(\operatorname{samp}+1)$ \\ DIM rho8(samp + 1) \\ DIM rcm $(\operatorname{samp}+1)$ \\ DIM power(samp + 1)}

40 INPUT "Please enter raw data file name to be read from."; file\$ OPEN file\$ FOR INPUT AS \#1

INPUT "Please enter name of new destination data file.", try\$ OPEN try\$ FOR OUTPUT AS \#2

50

$$
\begin{aligned}
& \operatorname{sum} 0=0 \\
& \operatorname{sum} 1=0 \\
& \operatorname{sum} 20=0 \\
& \operatorname{sum} 21=0 \\
& \text { sumwireV }=0 \\
& \text { sumwireC }=0 \\
& \text { sumwireTK }=0 \\
& \text { sumwireTF }=0
\end{aligned}
$$


' Read extra line of data at top of data file.

INPUT \#1, junk1\$

' Read perameters into program

INPUT \#1, dia, L, r2, r3, r1, q, Patm, Tatm, T, freq, errorfreq

PRINT \#2, "DIAM. LENGTH R1 R2 R3 Q Patm Tatm TIME

FREQ ERROR"

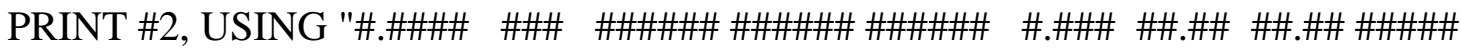

\#\#\#\# \#\#\#\#\#"; dia; L; r1; r2; r3; q; Patm; Tatm; T; freq; errorfreq

INPUT \#1, junk\$

area $=(3.14159 / 4) *(\operatorname{dia} * 2.54 / 100) \wedge 2$

' Read actual raw data file into arrays

FOR I = 1 TO samp

INPUT \#1, volts0(I), volts1(I), time(I)

\section{NEXT I}

CLOSE \#1

FOR I = 1 TO samp

wire $\mathrm{V}(\mathrm{I})=\operatorname{volts} 0(\mathrm{I}) *(\mathrm{r} 2+\mathrm{r} 3) / \mathrm{r} 3$

wireC $(\mathrm{I})=\operatorname{volts} 1(\mathrm{I}) / \mathrm{r} 1$

$\operatorname{rcm}(\mathrm{I})=$ wireV $(\mathrm{I}) /(\mathrm{L} *$ wireC $(\mathrm{I}))$

$\operatorname{rho} 8(\mathrm{I})=\operatorname{area} * \operatorname{rcm}(\mathrm{I}) * 100 * 100000000$

wireTK $(\mathrm{I})=40.25+22.1161 * \operatorname{rho} 8(\mathrm{I})+.148058 * \operatorname{rho} 8(\mathrm{I}) \wedge 2$

$\operatorname{power}(\mathrm{I})=\operatorname{wireV}(\mathrm{I}) *$ wireC $(\mathrm{I})$

100 NEXT I

'Print statistical information to a data file.

PRINT \#2, " Actual Values"

PRINT \#2, "Time CH\#0 CH\#1 Wire Temp. Power"

PRINT \#2, "(S) Voltage Current (K) (W)"

FOR I = 1 TO samp

PRINT \#2, USING "\#.\#\#\#\# \#\#.\#\#\# \#.\#\#\# \#\#\#\#\# \#\#\#.\#\#\#"; time(I);

wireV(I); wireC(I); wireTK(I); power(I)

NEXT I

INPUT "Do you wish to run the program again?(y/n)", ans\$

IF ans\$ = "y" THEN

GOTO 40

CLOSE \#2

ELSE

CLOSE \#2

END IF

END 


\section{Appendix E:}

Verification of Frequency and Amplitude Measured Using the LDA System 


\section{Appendix E}

Laser Doppler anemometry is not typically used to determine vibrational characteristics of objects like a thin filament. It was therefore deemed desirous to determine the accuracy of the frequency and amplitude of the vibrating filament that was being detected by the LDA system. A method of accurately calculating the frequency and amplitude of the vibrating filament needed to be devised.

A 228 micron steel wire was suspended with a known weight attached to the bottom. The laser Doppler anemometry system was focussed on the suspended filament and frequency and velocity readings were taken. These readings would later be compared to theoretical frequency and measured amplitude of the vibrating wire.

Theoretical frequency is not difficult to calculate. The first step is to determine the tensioning force on the wire. Using

$$
\mathrm{F}=\mathrm{m}^{*} \mathrm{~g}
$$

where $\mathrm{F}$ is the tensioning force in Newtons, $\mathrm{m}$ is the mass of the tensioning weight in grams and $\mathrm{g}$ is the acceleration of gravity $\left(9.81 \mathrm{~m} / \mathrm{s}^{2}\right)$. Speed of the vibrating wire can be calculated using

$$
v=\sqrt{\frac{F}{\mu}}
$$

where $v$ is the wave speed, $F$ is the tensioning force in Newtons and $\mu$ is the mass per unit length of the wire. The frequency can then be calculated using

$$
\mathrm{f}=\lambda / v
$$

where $\mathrm{f}$ is the frequency in $\mathrm{Hz}, \lambda$ is the wavelength in meters and $v$ is the velocity in $\mathrm{m} / \mathrm{s}$. Table E.1 illustrates the theoretical and laser Doppler anemometry determined frequency 
for three different tensioning weights, $510 \mathrm{~g}, 102.8 \mathrm{~g}$ and $69.15 \mathrm{~g}$ for a 228 micron steel wire. The error in the number is small as can be seen in Figure E.1. Figure E.1 shows the LDA frequency vs. the theoretical frequency. As can be seen on the Figure the points are very close to a theoretical $45^{\circ}$ line that would exist is if the LDA and theoretical were a perfect match.

Table E.1 Theoretical and LDA Measured Frequency for a 228 Micron vibrating Steel Wire

\begin{tabular}{|c|c|c|c|}
\hline $\begin{array}{l}\text { Tensioning weight } \\
(\mathrm{g})\end{array}$ & $\begin{array}{c}\text { Theoretical } \\
\text { Frequency }(\mathrm{Hz})\end{array}$ & $\begin{array}{l}\text { Sample } \\
\text { Number }\end{array}$ & $\begin{array}{c}\text { LDA Frequency } \\
(\mathrm{Hz})\end{array}$ \\
\hline \multirow{4}{*}{69.15} & \multirow{4}{*}{37.28} & 1 & 37.62 \\
\hline & & 2 & 37.63 \\
\hline & & 3 & 37.24 \\
\hline & & 4 & 37.43 \\
\hline \multirow{4}{*}{102.8} & \multirow{4}{*}{45} & 1 & 44.13 \\
\hline & & 2 & 45.53 \\
\hline & & 3 & 46.16 \\
\hline & & 4 & 45.91 \\
\hline \multirow{4}{*}{510} & \multirow{4}{*}{105} & 1 & 102.1 \\
\hline & & 2 & 104.3 \\
\hline & & 3 & 102.9 \\
\hline & & 4 & 101.9 \\
\hline
\end{tabular}




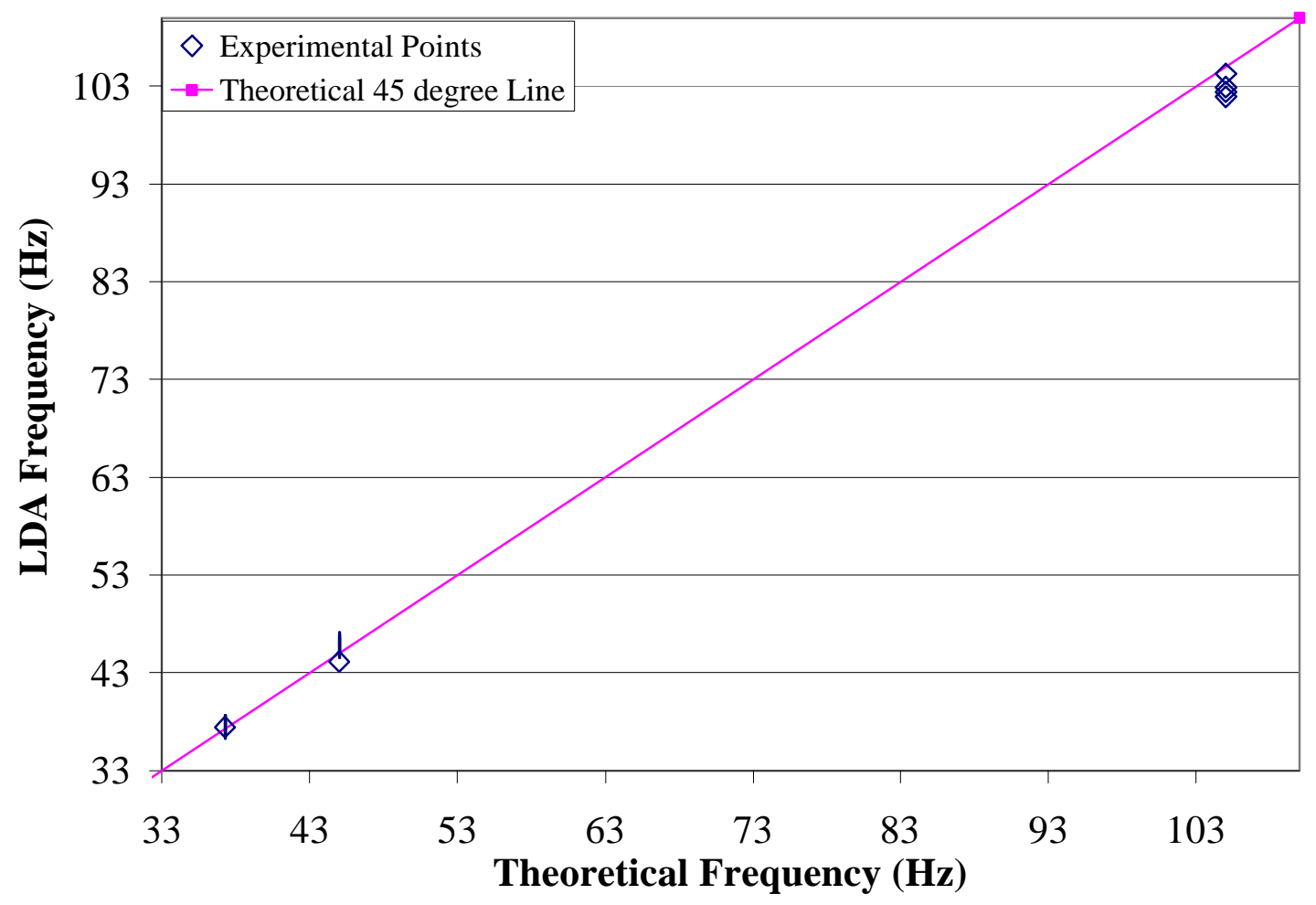

Figure E.1: Error in LDA Measured Frequency vs. Theoretical Frequency 
Calculation of amplitude of vibrating wire involved determining the fringe spacing of the LDA system using

$$
\Delta x=\lambda / 2 \sin (\theta / 2)
$$

where $\Delta \mathrm{x}$ is the fringe spacing, $\lambda$ is the wavelength of the laser and $\theta$ is the angle of the beams. The maximum velocity of the wire $\left(\mathrm{V}_{\max }\right)$ can be determined from the fringe spacing of the LDA system and the period . The amplitude can be determined from assuming sine wave behavior.

$$
\mathrm{V}=\mathrm{a} \sin \mathrm{bt}
$$

where $\mathrm{V}$ is velocity, $\mathrm{a}$ is $\mathrm{V}_{\max }, \mathrm{b}$ is $2 \pi / \Delta \mathrm{t}$ and

$$
\mathrm{V}=\mathrm{dx} / \mathrm{dt}
$$

so by integrating the equation for $\mathrm{V}$, the amplitude can be obtained.

$$
\begin{gathered}
\int d x=V_{\max } \int \sin \left(\frac{2 \pi}{\Delta t} t\right) d t \\
x=V_{\text {max }} *\left[-\frac{\Delta t}{2 \pi} * \cos \left(\frac{2 \pi}{\Delta t} t\right)\right.
\end{gathered}
$$

where $\mathrm{x}$ is amplitude $\mathrm{V}_{\max }$ is the maximum wire speed obtained and $\Delta \mathrm{t}$ is the period measured by the LDA system.

To verify the accuracy of the LDA system in measuring the amplitude, the vibrating wire was projected onto a screen where its amplitude could be directly measured. The size of the projected wire was also measured and the approximate magnification factor determined. The measured and LDA calculated amplitudes for a 228 micron steel wire with the same three tensioning weights are listed in Table E.2. The error in the amplitude measurements is illustrated in Figure E.2, where LDA measured amplitude is plotted against actual amplitude. 
Table E.2: Actual and LDA Measured Amplitudes of a 228 Micron Vibrating Steel Wire

\begin{tabular}{|c|c|c|}
\hline Trial number & Actual Amplitude & LDA Measured Amplitude \\
\hline 1 & 0.011144 & 0.014386 \\
\hline 2 & 0.010987 & 0.011569 \\
\hline 3 & 0.010825 & 0.011097 \\
\hline 4 & 0.009389 & 0.007435 \\
\hline 5 & 0.009875 & 0.005936 \\
\hline 6 & 0.015575 & 0.014386 \\
\hline 7 & 0.009815 & 0.005151 \\
\hline 8 & 0.00294 & 0.002123 \\
\hline 9 & 0.015904 & 0.01499 \\
\hline 10 & 0.026881 & 0.026861 \\
\hline 11 & 0.016166 & 0.015191 \\
\hline 12 & 0.013315 & 0.014588 \\
\hline
\end{tabular}




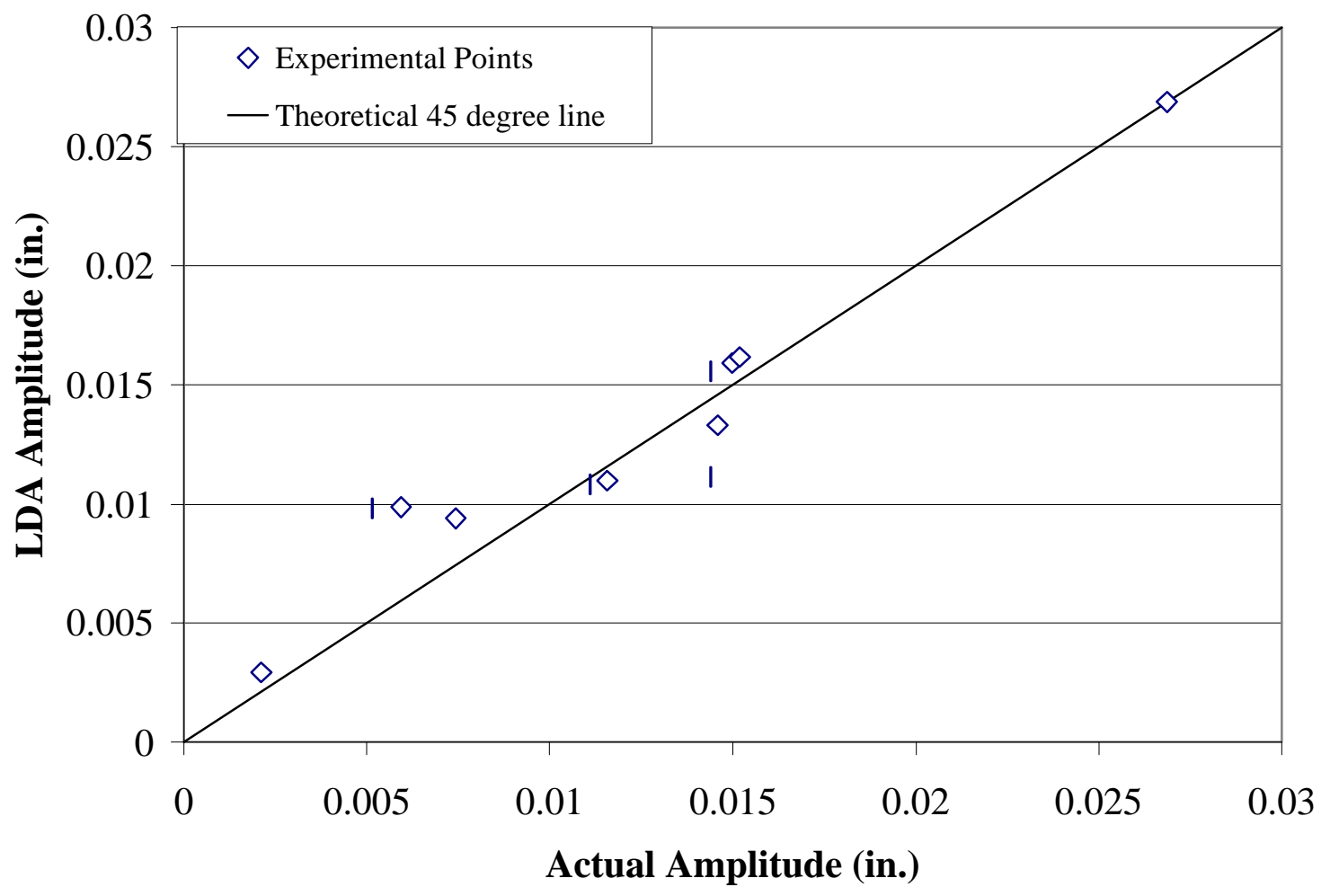

Figure E.2: Error in LDA Measured Amplitude vs. Actual Amplitude 


\section{Appendix F:}

Sample Heat Transfer Data Spreadsheet 


\section{Appendix F}

Table F.1: Sample Heat Transfer Data Spreadsheet

\begin{tabular}{|c|c|c|c|c|c|c|c|c|}
\hline $\begin{array}{l}\text { A3m } \\
\text { surf }=\end{array}$ & $1.98656 \mathrm{E}-06$ & $\begin{array}{l}\text { sigma10^ } \\
8\end{array}$ & \multicolumn{6}{|c|}{$5.669 \mid \begin{array}{l}\text { platinum emissivity } \\
\mathrm{e}=0.0235^{*}(\mathrm{~T} / 1000)^{\wedge} 2+.1538 *(\mathrm{~T} / 1000)-.0072\end{array}$} \\
\hline \multicolumn{6}{|c|}{ T platinum $=40.25+22.1161 *$ rho $^{*} 10^{\wedge}-8+.148058^{*}\left(\mathrm{rho}^{*} 10^{\wedge}-8\right)^{\wedge} 2$} & \multicolumn{2}{|c|}{ A3m sect*Rcm } & \\
\hline & & $\begin{array}{l}\mathrm{m}^{\wedge} 2 \\
* 10^{\wedge} 8\end{array}$ & & & & & & \\
\hline & & & & & & & & \\
\hline & Measured & Measured & Voltage & Current & Temp. & Power & Volts per & Power per \\
\hline & Value Ch1 & Value Ch2 & Ch1 & Ch2 & & & unit length & unit length \\
\hline Q in. H20 & $\mathrm{v} 0$ & v1 & Volts & Amps & Kelvin & Watts & $\mathrm{V} / \mathrm{cm}$ & $\mathrm{P} / \mathrm{cm}$ \\
\hline 0.000 & 0.717 & 1.463 & 4.095 & 0.299 & 399.163 & 1.199 & 0.136 & 0.041 \\
\hline 0.000 & 1.193 & 1.945 & 6.814 & 0.389 & 499.916 & 2.650 & 0.227 & 0.088 \\
\hline 0.000 & 1.691 & 2.294 & 9.658 & 0.459 & 604.937 & 4.430 & 0.322 & 0.148 \\
\hline 0.000 & 2.143 & 2.542 & 12.235 & 0.508 & 697.655 & 6.220 & 0.408 & 0.207 \\
\hline 0.000 & 2.667 & 2.789 & 15.227 & 0.558 & 800.554 & 8.494 & 0.508 & 0.283 \\
\hline 0.000 & 3.269 & 3.030 & 18.664 & 0.606 & 915.644 & 11.312 & 0.622 & 0.377 \\
\hline 0.000 & 3.744 & 3.204 & 21.377 & 0.641 & 1002.739 & 13.698 & 0.713 & 0.457 \\
\hline 0.000 & 4.331 & 3.416 & 24.726 & 0.683 & 1101.321 & 16.894 & 0.824 & 0.563 \\
\hline & & & & & & & & \\
\hline 0.250 & 0.973 & 1.996 & 5.553 & 0.399 & 397.090 & 2.216 & 0.185 & 0.074 \\
\hline 0.250 & 1.598 & 2.586 & 9.126 & 0.517 & 503.705 & 4.719 & 0.304 & 0.157 \\
\hline 0.250 & 2.163 & 2.956 & 12.347 & 0.591 & 600.215 & 7.298 & 0.412 & 0.243 \\
\hline 0.250 & 2.716 & 3.277 & 15.506 & 0.655 & 685.407 & 10.160 & 0.517 & 0.339 \\
\hline 0.250 & 3.360 & 3.521 & 19.187 & 0.704 & 799.381 & 13.508 & 0.640 & 0.450 \\
\hline 0.250 & 3.982 & 3.782 & 22.739 & 0.756 & 891.846 & 17.195 & 0.758 & 0.573 \\
\hline 0.250 & 4.571 & 3.937 & 26.097 & 0.788 & 995.738 & 20.547 & 0.870 & 0.685 \\
\hline 0.250 & 5.241 & 4.129 & 29.924 & 0.826 & 1103.417 & 24.707 & 0.997 & 0.824 \\
\hline & & & & & & & & \\
\hline 0.500 & 1.180 & 2.338 & 6.736 & 0.468 & 411.005 & 3.149 & 0.225 & 0.105 \\
\hline 0.500 & 2.426 & 3.355 & 13.854 & 0.671 & 592.782 & 9.295 & 0.462 & 0.310 \\
\hline 0.500 & 2.635 & 3.219 & 15.047 & 0.692 & 626.495 & 10.406 & 0.502 & 0.347 \\
\hline 0.500 & 3.459 & 3.748 & 18.378 & 0.750 & 712.382 & 13.771 & 0.613 & 0.459 \\
\hline 0.500 & 3.756 & 3.953 & 21.444 & 0.791 & 795.168 & 16.953 & 0.715 & 0.565 \\
\hline 0.500 & 4.717 & 4.253 & 26.933 & 0.851 & 945.692 & 22.902 & 0.898 & 0.764 \\
\hline 0.500 & 4.857 & 4.329 & 27.730 & 0.866 & 958.020 & 24.003 & 0.924 & 0.800 \\
\hline 0.500 & 5.585 & 4.538 & 31.889 & 0.908 & 1064.696 & 28.941 & 1.063 & 0.965 \\
\hline & & & & & & & & \\
\hline & & & & & & & & \\
\hline 0.750 & 1.206 & 2.444 & 6.888 & 0.489 & 402.083 & 3.366 & 0.230 & 0.112 \\
\hline 0.750 & 1.922 & 3.144 & 10.977 & 0.629 & 498.263 & 6.901 & 0.366 & 0.230 \\
\hline 0.750 & 2.685 & 3.616 & 15.332 & 0.723 & 609.694 & 11.087 & 0.511 & 0.370 \\
\hline 0.750 & 3.265 & 3.898 & 18.644 & 0.780 & 693.220 & 14.534 & 0.621 & 0.485 \\
\hline 0.750 & 3.974 & 4.151 & 22.693 & 0.830 & 802.044 & 18.839 & 0.756 & 0.628 \\
\hline 0.750 & 4.658 & 4.389 & 26.596 & 0.878 & 899.682 & 23.342 & 0.887 & 0.778 \\
\hline
\end{tabular}




\begin{tabular}{|r|r|r|r|r|r|r|r|r|}
\hline 0.750 & 5.253 & 4.558 & 29.992 & 0.912 & 987.518 & 27.338 & 1.000 & 0.911 \\
\hline 0.750 & 5.854 & 4.755 & 33.423 & 0.951 & 1065.409 & 31.780 & 1.114 & 1.060 \\
\hline & & & & & & & & \\
\hline & & & & & & & & \\
\hline 1.000 & 1.310 & 2.597 & 7.480 & 0.519 & 410.772 & 3.885 & 0.249 & 0.130 \\
\hline 1.000 & 1.930 & 3.176 & 11.018 & 0.635 & 495.005 & 6.997 & 0.367 & 0.233 \\
\hline 1.000 & 2.770 & 3.718 & 15.816 & 0.744 & 611.636 & 11.759 & 0.527 & 0.392 \\
\hline 1.000 & 3.444 & 4.043 & 19.666 & 0.809 & 705.995 & 15.901 & 0.656 & 0.530 \\
\hline 1.000 & 4.037 & 4.243 & 23.050 & 0.849 & 796.587 & 19.556 & 0.768 & 0.652 \\
\hline 1.000 & 4.835 & 4.482 & 27.605 & 0.896 & 916.127 & 24.741 & 0.920 & 0.825 \\
\hline 1.000 & 5.350 & 4.685 & 30.545 & 0.937 & 977.244 & 28.615 & 1.018 & 0.954 \\
\hline 1.000 & 6.198 & 4.959 & 35.390 & 0.992 & 1084.172 & 35.091 & 1.180 & 1.170 \\
\hline & & & & & & & & \\
\hline
\end{tabular}

\begin{tabular}{|c|c|c|c|c|c|c|c|c|}
\hline & $\begin{array}{l}\text { Tmelt in } \\
\mathrm{K}\end{array}$ & 2028 & & & & & & \\
\hline & Tref in $\mathrm{K}$ & 295 & & & & & & \\
\hline & & & & & & & & \\
\hline emissivity & Radiation & \begin{tabular}{|l|} 
Convectio \\
$\mathrm{n}$
\end{tabular} & \begin{tabular}{|l} 
Heat \\
Trans \\
\end{tabular} & Stand. Dev & $\begin{array}{l}\text { Stand. } \\
\text { Dev. }\end{array}$ & Stand Dev. & $\begin{array}{l}\text { Stand. } \\
\text { Dev }\end{array}$ & $\begin{array}{l}\text { Stand. } \\
\text { Dev }\end{array}$ \\
\hline & heat trans. & heat trans. & coefficient & Ch 1 & Ch 2 & Ch 1 & Ch 2 & \\
\hline $\mathrm{e}$ & qrad & qconv & h & meas. & meas. & Volts & Amps & Temp. \\
\hline 0.050 & 0.000 & 0.041 & 197.804 & 0.004 & $\begin{array}{l}0.007 \\
\end{array}$ & 0.023 & 0.001 & 1.538 \\
\hline 0.064 & 0.000 & 0.088 & 216.736 & 0.005 & $\begin{array}{l}0.008 \\
\end{array}$ & 0.031 & 0.002 & 1.415 \\
\hline 0.077 & 0.001 & 0.147 & 238.576 & 0.007 & 0.008 & 0.037 & 0.002 & 1.312 \\
\hline 0.089 & 0.002 & 0.205 & 256.769 & 0.008 & 0.008 & 0.044 & 0.002 & 1.524 \\
\hline 0.101 & 0.005 & 0.279 & 277.709 & 0.013 & 0.009 & 0.074 & 0.002 & 2.414 \\
\hline 0.114 & 0.009 & 0.368 & 298.913 & 0.021 & 0.011 & 0.120 & 0.002 & 4.144 \\
\hline 0.123 & 0.014 & 0.443 & 315.135 & 0.024 & 0.012 & 0.134 & 0.002 & 4.067 \\
\hline 0.134 & 0.022 & 0.541 & 338.074 & 0.033 & 0.015 & 0.190 & 0.003 & 5.855 \\
\hline & & & & & & & & \\
\hline 0.050 & 0.000 & 0.074 & 366.156 & 0.012 & 0.021 & 0.071 & 0.004 & 7842 \\
\hline 0.064 & 0.000 & 0.157 & 379.720 & 0.026 & \begin{tabular}{l|}
0.035 \\
\end{tabular} & 0.149 & 0.007 & 14.258 \\
\hline 0.077 & 0.001 & 0.242 & 400.427 & 0.033 & 0.048 & 0.187 & 0.010 & 18.939 \\
\hline 0.087 & 0.002 & 0.337 & 434.801 & 0.043 & 0.048 & 0.245 & 0.010 & 21.471 \\
\hline 0.101 & 0.005 & 0.446 & 445.536 & 0.055 & |0.050 & 0.313 & 0.010 & 25.739 \\
\hline 0.111 & 0.008 & 0.565 & 477.440 & 0.061 & 0.058 & 0.348 & 0.012 & 29.676 \\
\hline 0.123 & 0.013 & 0.672 & 482.893 & 0.068 & 0.058 & 0.389 & 0.012 & 32.192 \\
\hline 0.134 & 0.022 & 0.801 & 499.434 & 0.059 & 0.049 & 0.336 & 0.010 & 28.237 \\
\hline & & & & & & & & \\
\hline \begin{tabular}{l|}
0.052 \\
\end{tabular} & 0.000 & 0.105 & 457.596 & 0.016 & \begin{tabular}{l|}
0.027 \\
\end{tabular} & 0.092 & 0.005 & 9.263 \\
\hline 0.076 & 0.001 & 0.309 & 523.303 & 0.029 & 0.038 & 0.165 & 0.008 & 13.562 \\
\hline 0.080 & 0.001 & 0.346 & 525.902 & 0.040 & 0.052 & 0.228 & 0.010 & 19.260 \\
\hline 0.090 & 0.003 & 0.457 & 551.561 & 0.055 & 0.059 & 0.313 & 0.012 & 24.655 \\
\hline 0.100 & 0.004 & 0.561 & 565.119 & 0.052 & 0.054 & 0.296 & 0.011 & 23.084 \\
\hline 0.117 & 0.010 & 0.753 & 583.217 & 0.072 & 0.073 & 0.414 & 0.015 & 33.762 \\
\hline 0.119 & 0.011 & 0.789 & 599.746 & 0.078 & 0.076 & 0.447 & 0.015 & 35.567 \\
\hline 0.130 & 0.019 & 0.946 & 619.323 & 0.070 & 0.064 & 0.401 & 0.013 & 31.550 \\
\hline
\end{tabular}




\begin{tabular}{|r|r|r|r|r|r|r|r|r|}
\hline & & & & & & & & \\
\hline & & & & & & & & \\
\hline 0.051 & 0.000 & 0.112 & 530.322 & 0.012 & 0.021 & 0.068 & 0.004 & 6.224 \\
\hline 0.064 & 0.000 & 0.230 & 570.690 & 0.023 & 0.037 & 0.134 & 0.007 & 11.228 \\
\hline 0.078 & 0.001 & 0.369 & 590.720 & 0.042 & 0.060 & 0.238 & 0.012 & 19.886 \\
\hline 0.088 & 0.002 & 0.482 & 610.717 & 0.044 & 0.054 & 0.249 & 0.011 & 19.354 \\
\hline 0.101 & 0.005 & 0.623 & 619.761 & 0.054 & 0.062 & 0.307 & 0.012 & 24.024 \\
\hline 0.112 & 0.008 & 0.770 & 641.781 & 0.073 & 0.074 & 0.414 & 0.015 & 31.678 \\
\hline 0.122 & 0.013 & 0.899 & 653.760 & 0.077 & 0.073 & 0.439 & 0.015 & 33.124 \\
\hline 0.130 & 0.019 & 1.041 & 680.641 & 0.081 & 0.086 & 0.461 & 0.017 & 37.701 \\
\hline & & & & & & & & \\
\hline & & & & & & & & \\
\hline 0.052 & 0.000 & 0.129 & 565.823 & 0.014 & 0.024 & 0.080 & 0.005 & 6.691 \\
\hline 0.063 & 0.000 & 0.233 & 588.062 & 0.022 & 0.031 & 0.125 & 0.006 & 9.308 \\
\hline 0.078 & 0.001 & 0.391 & 622.699 & 0.031 & 0.044 & 0.180 & 0.009 & 14.025 \\
\hline 0.090 & 0.002 & 0.528 & 647.368 & 0.053 & 0.059 & 0.300 & 0.012 & 21.870 \\
\hline 0.100 & 0.004 & 0.648 & 650.691 & 0.055 & 0.058 & 0.314 & 0.012 & 22.590 \\
\hline 0.114 & 0.009 & 0.816 & 661.943 & 0.069 & 0.059 & 0.395 & 0.012 & 27.279 \\
\hline 0.121 & 0.012 & 0.942 & 695.516 & 0.074 & 0.072 & 0.425 & 0.014 & 31.622 \\
\hline 0.132 & 0.020 & 1.149 & 733.834 & 0.081 & 0.076 & 0.463 & 0.015 & 34.237 \\
\hline & & & & & & & & \\
\hline
\end{tabular}




\section{Appendix G:}

Error Analysis 
Table G.1: Uncertainty in Heat Transfer Coefficient

\begin{tabular}{|c|c|c|c|c|c|c|c|}
\hline & & & & & Diameters & (microns) & \\
\hline Angle & Temperature & Velocity & 25.4 & 38.5 & 51 & 63.5 & 76 \\
\hline (degrees) & (Kelvin) & $(\mathrm{m} / \mathrm{s})$ & & & \multicolumn{2}{|c|}{ Uncertainty $\left(\mathrm{W} / \mathrm{m}^{2} \mathrm{~K}\right)$} & \\
\hline 0 & 400 & 10.08 & 34.08 & 27.44 & 21.78 & 17.45 & 15.60 \\
\hline 0 & 400 & 14.25 & 34.08 & 27.44 & 21.78 & 17.45 & 15.60 \\
\hline 0 & 400 & 17.46 & 34.08 & 27.44 & 21.78 & 17.45 & 15.60 \\
\hline 0 & 400 & 20.16 & 34.08 & 27.44 & 21.78 & 17.45 & 15.60 \\
\hline 0 & 600 & 10.08 & 35.04 & 28.62 & 23.25 & 19.26 & 17.60 \\
\hline 0 & 600 & 14.25 & 35.04 & 28.62 & 23.25 & 19.26 & 17.60 \\
\hline 0 & 600 & 17.46 & 35.04 & 28.62 & 23.25 & 19.26 & 17.60 \\
\hline 0 & 600 & 20.16 & 35.04 & 28.62 & 23.25 & 19.26 & 17.60 \\
\hline 0 & 1100 & 10.08 & 38.34 & 32.58 & 27.98 & 24.76 & 23.50 \\
\hline 0 & 1100 & 14.25 & 38.34 & 32.58 & 27.98 & 24.76 & 23.50 \\
\hline 0 & 1100 & 17.46 & 38.34 & 32.58 & 27.98 & 24.76 & 23.50 \\
\hline 0 & 1100 & 20.16 & 38.34 & 32.58 & 27.98 & 24.76 & 23.50 \\
\hline 2.5 & 400 & 10.08 & 49.48 & 39.29 & 32.15 & 27.58 & 26.09 \\
\hline 2.5 & 400 & 14.25 & 57.33 & 43.97 & 35.16 & 30.04 & 29.07 \\
\hline 2.5 & 400 & 17.46 & 64.21 & 48.18 & 37.92 & 32.31 & 31.78 \\
\hline 2.5 & 400 & 20.16 & 70.42 & 52.05 & 40.49 & 34.43 & 34.27 \\
\hline 2.5 & 600 & 10.08 & 50.21 & 40.18 & 33.20 & 28.76 & 27.31 \\
\hline 2.5 & 600 & 14.25 & 57.98 & 44.78 & 36.14 & 31.13 & 30.16 \\
\hline 2.5 & 600 & 17.46 & 64.81 & 48.94 & 38.84 & 33.33 & 32.76 \\
\hline 2.5 & 600 & 20.16 & 70.97 & 52.77 & 41.36 & 35.39 & 35.19 \\
\hline 2.5 & 1100 & 10.08 & 52.72 & 43.21 & 36.74 & 32.72 & 31.37 \\
\hline 2.5 & 1100 & 14.25 & 60.22 & 47.57 & 39.45 & 34.82 & 33.85 \\
\hline 2.5 & 1100 & 17.46 & 66.85 & 51.53 & 41.96 & 36.81 & 36.18 \\
\hline 2.5 & 1100 & 20.16 & 72.87 & 55.20 & 44.32 & 38.69 & 38.37 \\
\hline 7 & 400 & 10.08 & 113.07 & 78.33 & 55.38 & 43.48 & 45.66 \\
\hline 7 & 400 & 14.25 & 151.72 & 104.37 & 74.32 & 59.97 & 63.79 \\
\hline 7 & 400 & 17.46 & 182.29 & 125.04 & 89.28 & 72.80 & 77.84 \\
\hline 7 & 400 & 20.16 & 208.39 & 142.71 & 102.05 & 83.69 & 89.73 \\
\hline 7 & 600 & 10.08 & 113.70 & 79.08 & 56.22 & 44.28 & 46.18 \\
\hline 7 & 600 & 14.25 & 152.29 & 105.03 & 75.03 & 60.57 & 64.10 \\
\hline 7 & 600 & 17.46 & 182.83 & 125.65 & 89.92 & 73.31 & 78.06 \\
\hline 7 & 600 & 20.16 & 208.91 & 143.30 & 102.65 & 84.14 & 89.89 \\
\hline 7 & 1100 & 10.08 & 115.58 & 81.38 & 58.93 & 47.06 & 48.25 \\
\hline 7 & 1100 & 14.25 & 153.95 & 107.03 & 77.26 & 62.66 & 65.45 \\
\hline 7 & 1100 & 17.46 & 184.38 & 127.48 & 91.91 & 75.07 & 79.08 \\
\hline 7 & 1100 & 20.16 & 210.39 & 145.03 & 104.49 & 85.70 & 90.71 \\
\hline
\end{tabular}


Table G.2: Percent Uncertainty

\begin{tabular}{|c|c|c|c|c|c|c|c|}
\hline & & & & & Diameters & (microns) & \\
\hline Angle & Temperature & Velocity & 25.4 & 38.5 & 51 & 63.5 & 76 \\
\hline (degrees) & (Kelvin) & $(\mathrm{m} / \mathrm{s})$ & & & \multicolumn{2}{|c|}{ Percent Uncertainty } & \\
\hline 0 & 400 & 10.08 & 4.96 & 4.16 & 4.06 & 4.59 & 4.40 \\
\hline 0 & 400 & 14.25 & 3.94 & 4.04 & 3.45 & 3.81 & 4.08 \\
\hline 0 & 400 & 17.46 & 3.78 & 3.56 & 3.06 & 3.29 & 3.23 \\
\hline 0 & 400 & 20.16 & 3.51 & 3.34 & 2.97 & 3.09 & 3.06 \\
\hline 0 & 600 & 10.08 & 4.46 & 4.40 & 3.97 & 4.81 & 4.49 \\
\hline 0 & 600 & 14.25 & 3.55 & 3.92 & 3.48 & 3.66 & 3.71 \\
\hline 0 & 600 & 17.46 & 3.37 & 3.49 & 3.10 & 3.26 & 3.13 \\
\hline 0 & 600 & 20.16 & 3.21 & 3.18 & 3.00 & 3.09 & 2.97 \\
\hline 0 & 1100 & 10.08 & 4.16 & 3.39 & 4.27 & 4.96 & 5.43 \\
\hline 0 & 1100 & 14.25 & 3.24 & 2.95 & 3.65 & 4.00 & 4.42 \\
\hline 0 & 1100 & 17.46 & 2.90 & 2.66 & 3.28 & 3.64 & 3.99 \\
\hline 0 & 1100 & 20.16 & 2.80 & 2.59 & 3.17 & 3.37 & 3.71 \\
\hline 2.5 & 400 & 10.08 & 6.36 & 6.15 & 5.91 & 5.98 & 5.83 \\
\hline 2.5 & 400 & 14.25 & 6.62 & 5.93 & 4.54 & 5.59 & 5.24 \\
\hline 2.5 & 400 & 17.46 & 5.82 & 5.74 & 4.43 & 4.33 & 5.39 \\
\hline 2.5 & 400 & 20.16 & 6.01 & 5.78 & 4.66 & 4.33 & 5.43 \\
\hline 2.5 & 600 & 10.08 & 5.97 & 5.83 & 6.05 & 5.93 & 5.75 \\
\hline 2.5 & 600 & 14.25 & 5.21 & 5.66 & 4.96 & 5.32 & 5.45 \\
\hline 2.5 & 600 & 17.46 & 5.70 & 5.38 & 4.78 & 4.24 & 5.31 \\
\hline 2.5 & 600 & 20.16 & 5.74 & 5.65 & 4.84 & 4.21 & 5.43 \\
\hline 2.5 & 1100 & 10.08 & 5.62 & 5.44 & 5.60 & 5.53 & 5.71 \\
\hline 2.5 & 1100 & 14.25 & 5.01 & 5.29 & 4.94 & 5.02 & 5.32 \\
\hline 2.5 & 1100 & 17.46 & 5.28 & 5.11 & 4.75 & 4.81 & 5.14 \\
\hline 2.5 & 1100 & 20.16 & 5.30 & 5.39 & 4.69 & 4.16 & 5.24 \\
\hline 7 & 400 & 10.08 & 9.28 & 9.57 & 9.34 & 7.27 & 11.65 \\
\hline 7 & 400 & 14.25 & 11.77 & 11.23 & 11.01 & 10.05 & 13.44 \\
\hline 7 & 400 & 17.46 & 13.25 & 12.12 & 12.04 & 11.22 & 13.85 \\
\hline 7 & 400 & 20.16 & 14.35 & 12.24 & 12.71 & 11.77 & 15.13 \\
\hline 7 & 600 & 10.08 & 8.78 & 8.12 & 8.03 & 6.79 & 11.78 \\
\hline 7 & 600 & 14.25 & 10.87 & 9.43 & 9.35 & 8.21 & 13.51 \\
\hline 7 & 600 & 17.46 & 11.89 & 10.60 & 10.45 & 9.30 & 13.89 \\
\hline 7 & 600 & 20.16 & 13.27 & 11.24 & 11.02 & 9.86 & 15.16 \\
\hline 7 & 1100 & 10.08 & 8.19 & 7.41 & 7.12 & 6.21 & 12.31 \\
\hline 7 & 1100 & 14.25 & 10.06 & 8.62 & 8.36 & 7.24 & 13.80 \\
\hline 7 & 1100 & 17.46 & 11.26 & 9.36 & 9.15 & 8.24 & 14.07 \\
\hline 7 & 1100 & 20.16 & 12.31 & 9.15 & 9.66 & 13.76 & 15.30 \\
\hline
\end{tabular}

